Tactical Wheeled Vehicle Survivability: Results of Experiments to Quantify Aboveground Impulse

John Q. Ehrgott, Jr.

March 2010

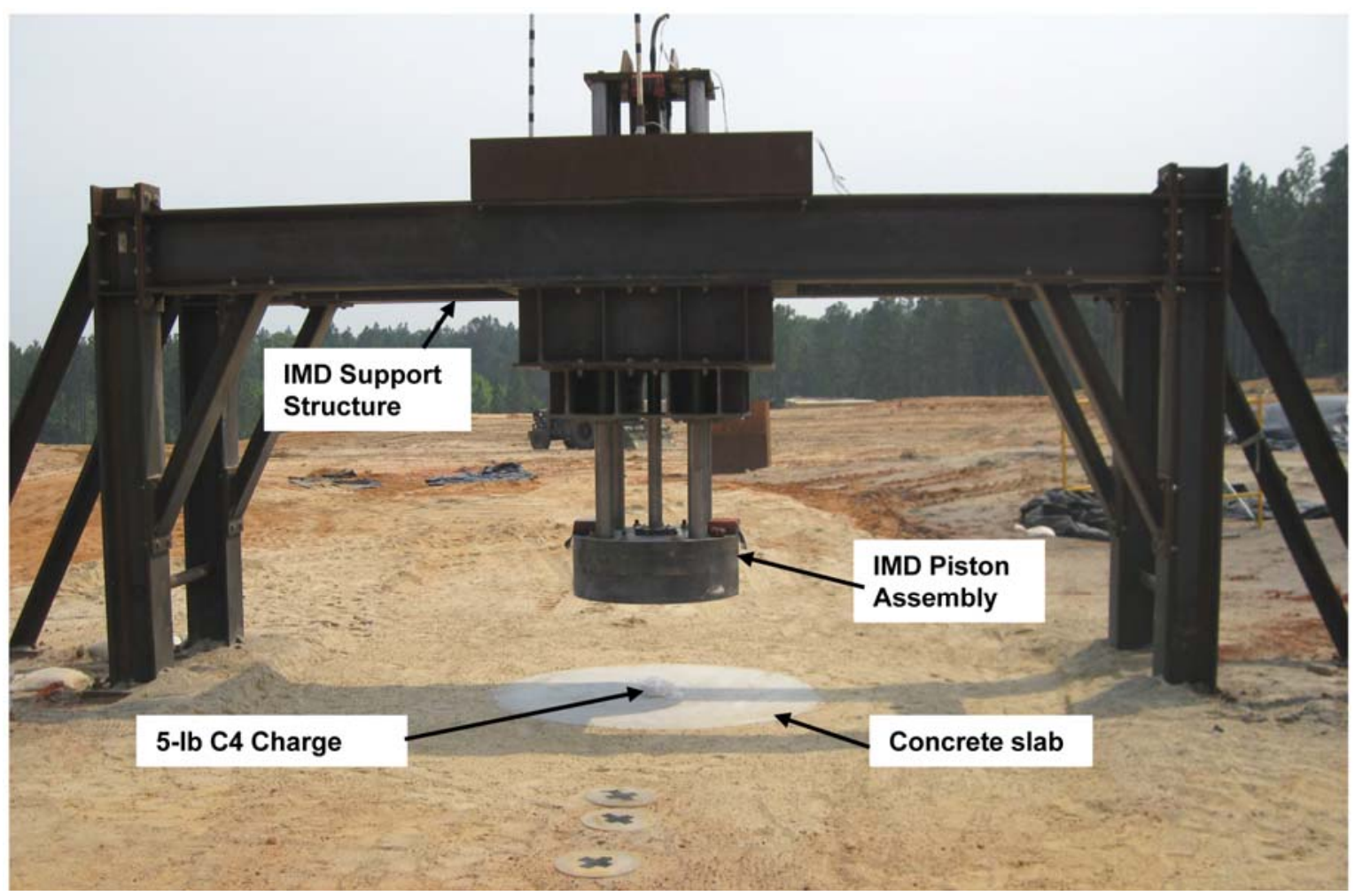




\section{Tactical Wheeled Vehicle Survivability: Results of Experiments to Quantify Aboveground Impulse}

John Q. Ehrgott, Jr.

Geotechnical and Structures Laboratory

U.S. Army Engineer Research and Development Center

3909 Halls Ferry Road

Vicksburg, MS 39180-6199

Final report

Approved for public release; distribution is unlimited.

Prepared for U.S. Army Tank Automotive Research, Development and Engineering Center Warren, MI 48397-5000

and Headquarters, U.S. Army Corps of Engineers

Washington, DC 20314-1000

Under Army Technology Objective AT40, Work Package "Tactical Wheeled Vehicle Survivability" 


\begin{abstract}
The U.S. Army Engineer Research and Development Center conducted a series of carefully controlled field experiments to quantify the aboveground environments created by the detonation of surface and nearsurface bare-charge explosives in or on three very different soil backfills. The experiments provided blast pressure, soil stress, and impulse data for each soil type. To measure the aboveground impulse produced by the combined airblast and soil debris, an impulse measurement device was designed, fabricated, and calibrated for use in the field experiments. Results of these experiments are documented, along with initial conclusions regarding the complex loadings that would be applied to an aboveground structure.
\end{abstract}

DISCLAIMER: The contents of this report are not to be used for advertising, publication, or promotional purposes. Citation of trade names does not constitute an official endorsement or approval of the use of such commercial products. All product names and trademarks cited are the property of their respective owners. The findings of this report are not to be construed as an official Department of the Army position unless so designated by other authorized documents. 


\section{Contents}

Figures and Tables..............................................................................................................................

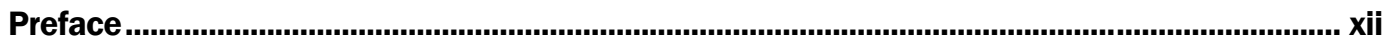

Conversion Factors, Non-SI to SI Units of Measurement............................................................. xiii

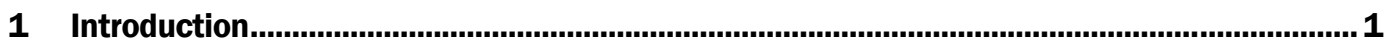

Background ...................................................................................................... 1

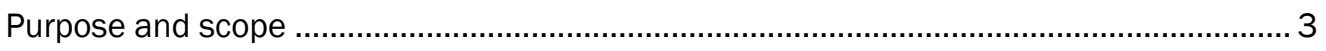

2 Design and Fabrication of an Impulse Measurement Device .............................................. 4

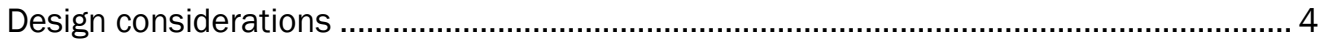

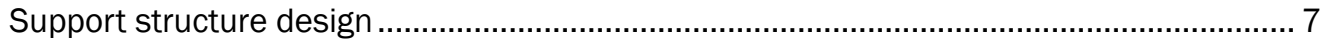

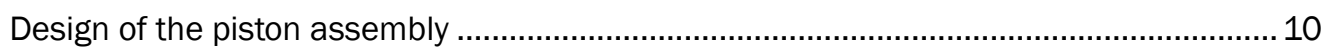

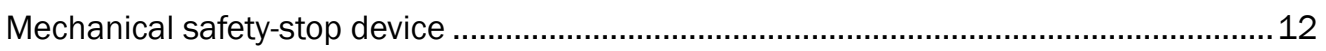

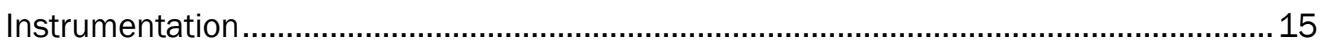

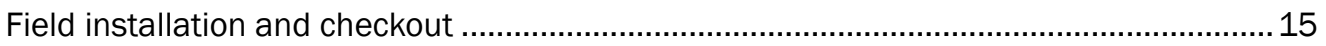

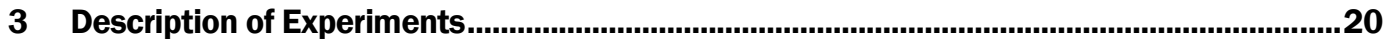

Experimental parameters ........................................................................................ 20

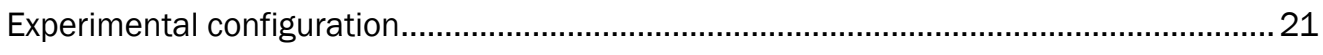

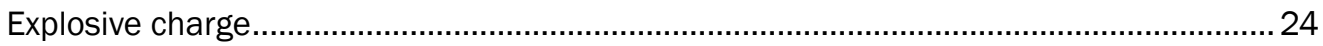

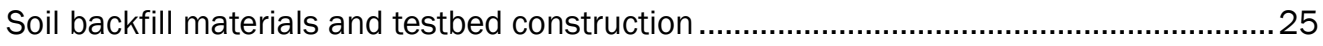

Charge placement and arming................................................................................ 29

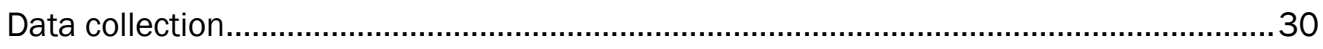

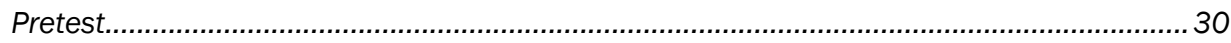

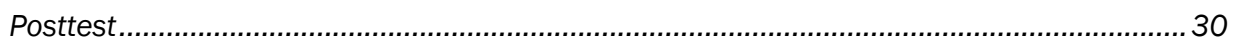

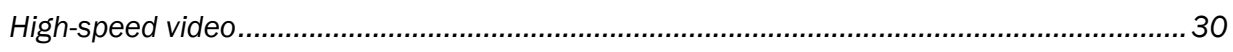

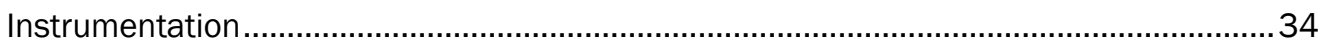

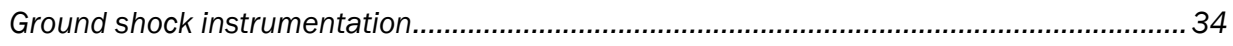

Blast pressure instrumentation............................................................................. 40

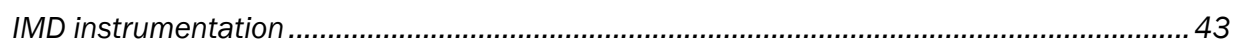

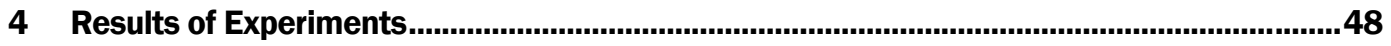

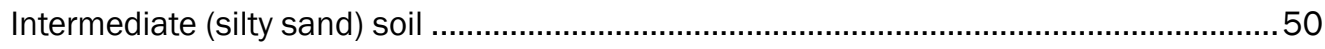

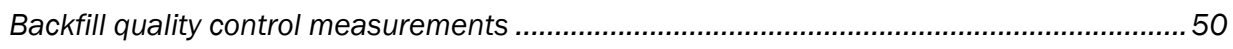

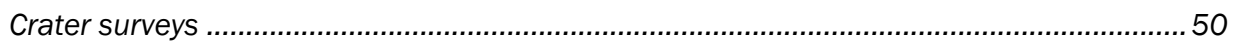

Ground shock stress and particle velocity..................................................................56

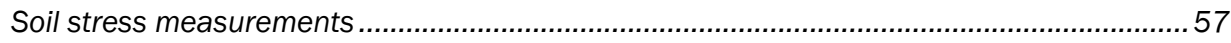

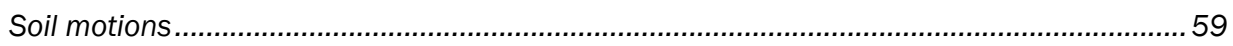

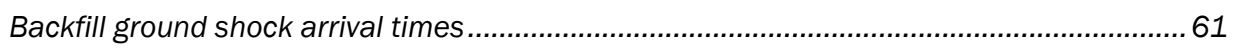

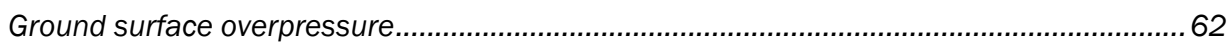

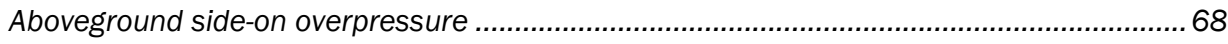




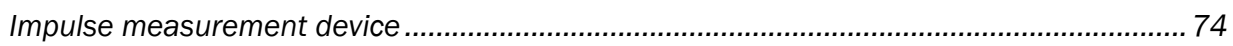

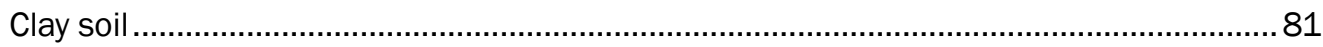

Backfill quality control measurements ........................................................................... 81

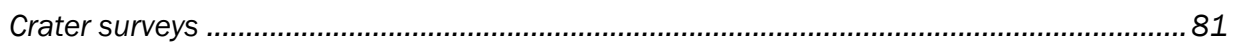

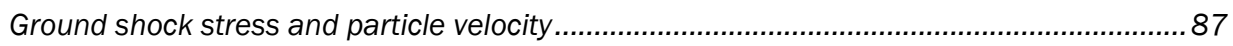

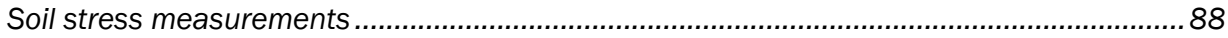

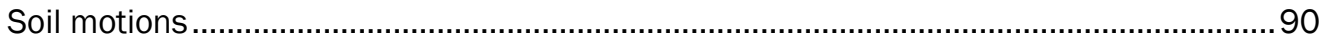

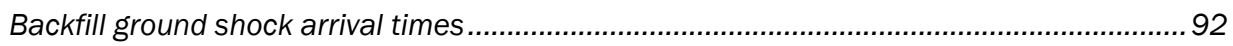

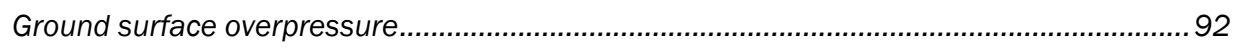

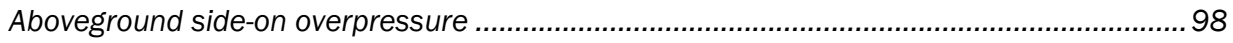

Impulse measurement device ................................................................................ 105

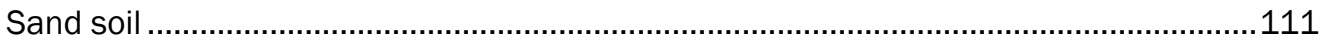

Backfill quality control measurements ......................................................................111

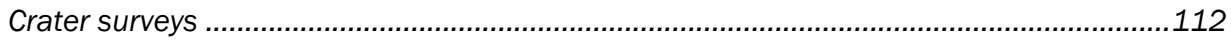

Ground shock stress and particle velocity .................................................................112

Soil stress measurements ........................................................................................118

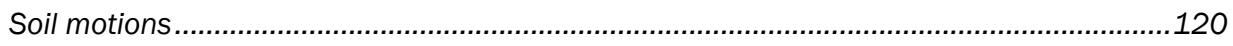

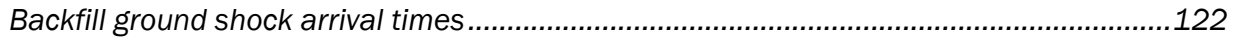

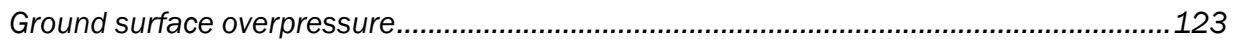

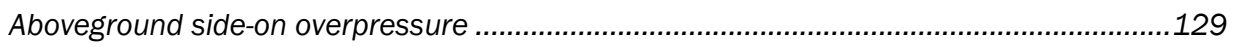

Impulse measurement device ..................................................................................... 136

5 Comparisons of Experimental Data ..................................................................................... 143

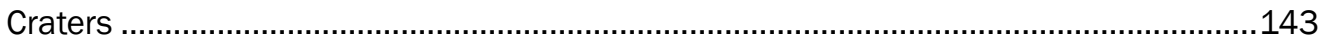

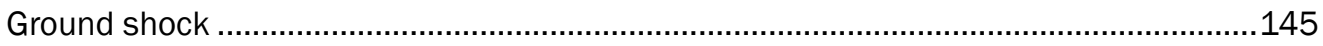

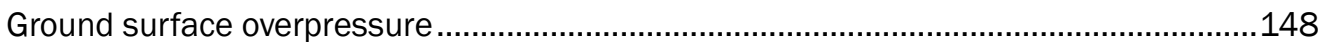

Aboveground side-on overpressure ...................................................................... 152

Total impulse from the IMD .................................................................................. 156

6 Summary and Conclusions................................................................................................157

References.......................................................................................................................................... 160

Report Documentation Page 


\section{Figures and Tables}

\section{Figures}

Figure 2.1. Three-dimensional view of the IMD............................................................................. 6

Figure 2.2. Cross section of a typical test layout.................................................................................. 7

Figure 2.3. Section view of support structure with impulse device and gage mounts....................... 8

Figure 2.4. Section view of the impulse measurement device and photographs of

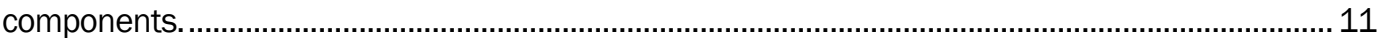

Figure 2.5. Section view of bottom plates and gage mounts. …................................................... 12

Figure 2.6. The mechanical safety-stop device............................................................................ 13

Figure 2.7. Components of the mechanical safety-stop device........................................................ 13

Figure 2.8. Mechanical safety-stop device installed on the IMD..................................................... 13

Figure 2.9. Instrumentation layout for the IMD experiments.......................................................... 16

Figure 2.10. Pretest photograph of IMD experimental test layout.................................................... 17

Figure 2.11. Measured and calculated displacements and velocities of the IMD piston

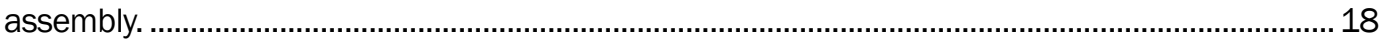

Figure 2.12. Measured velocity and displacement time-histories of the support structure............ 19

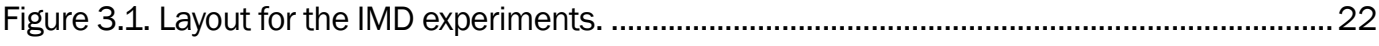

Figure 3.2. Layout for the side-on overpressure gages and the experiment layout.......................... 23

Figure 3.3. The 5-lb C4 charge mold........................................................................................... 24

Figure 3.4. Grain-size distributions and Atterberg limits for backfill soils........................................ 26

Figure 3.5. Summary of QC specifications and test results for silty sand testbed. ...........................2 26

Figure 3.6. Summary of QC specifications and test results for clay testbed................................... 27

Figure 3.7. Summary of QC specifications and test results for dry sand testbed.............................2 28

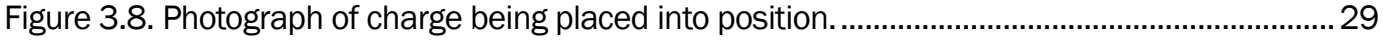

Figure 3.9. Experimental layout showing high-speed camera locations.......................................... 31

Figure 3.10. Phantom V7.3 high-speed digital camera. ……......................................................... 32

Figure 3.11. Screen view from Phantom camera control software.................................................33

Figure 3.12. Backfill instrumentation layout for buried charge using the IMD. ................................ 37

Figure 3.13. Backfill instrumentation layout for buried charge using side-on pressure

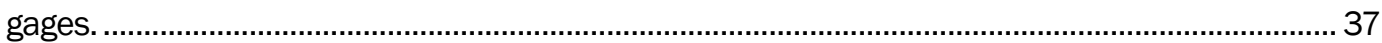

Figure 3.14. Accelerometers mounted in aluminum "hi-fi" canisters. ............................................38

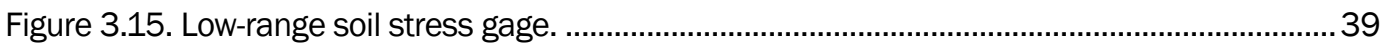

Figure 3.16. Side-On overpressure gage photograph and detail...................................................... 41

Figure 3.17. Photograph of side-on overpressure gages located above a testbed. .......................... 42

Figure 3.18. Ground surface overpressure gage mount details and photograph. ........................... 42

Figure 3.19. Photograph of ground surface overpressure gages...................................................... 43

Figure 3.20. Instrumentation layout for IMD experiments............................................................... 44 
Figure 3.21. Photograph of a cable extension position transducer "yo-yo" gage. ............................ 44

Figure 3.22. Photographs of the IMD instrumentation. .................................................................. 45

Figure 3.23. Diagram of ERDC/WES-designed shock mount for the accelerometer used

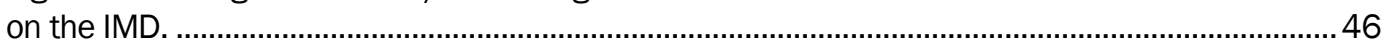

Figure 3.24. Three flush-mounted pressure transducers located

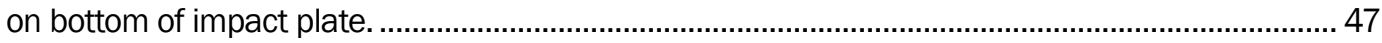

Figure 3.25. Photograph of the three pressure transducers on the IMD impact plate.................... 47

Figure 4.1. Pretest photographs of the IMD testbed. ...................................................................... 48

Figure 4.2. Posttest photograph of the IMD testbed. .................................................................. 49

Figure 4.3. Captured frames from high-speed video of an IMD experiment................................... 49

Figure 4.4. Photograph and cross-section surveys of testbed crater in BM-I-01............................ 51

Figure 4.5. Photograph and cross-section surveys of testbed crater in BM-I-02 .............................52

Figure 4.6. Photograph and cross-section surveys of testbed crater in BM-I-03.............................53

Figure 4.7. Photograph and cross-section surveys of testbed crater in BM-I-04. .............................54

Figure 4.8. Photograph and cross-section surveys of testbed crater in BM-I-05 .............................55

Figure 4.9. Example of changes made to radial stress records to "filter" the records......................57

Figure 4.10. Radial stress time-histories measured in the experiment BM-I-03 backfill..................58

Figure 4.11. Radial stress time-histories measured in the experiment BM-I-05 backfill...................58

Figure 4.12. Peak stress versus range in the experiment BM-I-03 and BM-I-05 backfills.................59

Figure 4.13. Radial particle velocity time-histories measured in the experiment BM-I-03

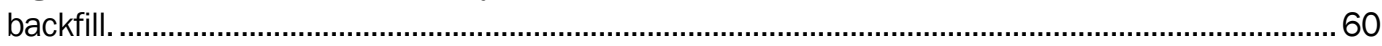

Figure 4.14. Radial particle velocity time-histories measured in experiment the BM-I-05 backfill.

Figure 4.15 Peak particle velocity versus range in the experiment BM-I-03 and BM-I-05 backfills.

Figure 4.16. Initial ground shock times of arrival versus range from the CG of the charge in the experiment BM-I-03 and BM-I-05 backfills.

Figure 4.17. Ground surface overpressure time-histories at ranges of 8,10 , and $14 \mathrm{ft}$ from experiment BM-I-01.

Figure 4.18. Ground surface overpressure time-histories at ranges of 8,10 , and 14 $\mathrm{ft}$ from experiment BM-I-02.

Figure 4.19. Ground surface overpressure time-histories at ranges of 8,10 , and 14 $\mathrm{ft}$ from experiment BM-I-03.

Figure 4.20. Ground surface overpressure time-histories at ranges of 8,10 , and 14 $\mathrm{ft}$ from experiment BM-I-04. 65

Figure 4.21. Ground surface overpressure time-histories at ranges of 8,10 , and $14 \mathrm{ft}$ from experiment BM-I-05.

Figure 4.22. Ground surface overpressure times of arrival versus range for experiments BM-I-01 through BM-I-05. 66

Figure 4.23. Ground surface peak overpressure versus range for experiments BM-I-01 through BM-I-05.

Figure 4.24. Ground surface peak overpressure times of arrival versus range for experiment BM-I-01 through BM-I-05. 
Figure 4.25. Side-on overpressure time-history directly above the charge GZ in experiment BM-I-01.

Figure 4.26. Side-on overpressure time-histories at a horizontal range of 18 in. from GZ experiment BM-I-01

Figure 4.27. Side-on overpressure time-histories at a horizontal range of 36 in. from GZ in experiment BM-I-01.

Figure 4.28. Side-on overpressure time-histories at a horizontal range of 18 in. from GZ in experiment BM-I-02.

Figure 4.29. Side-on overpressure time-histories at a horizontal range of 36 in. from GZ in experiment BM-I-02.

Figure 4.30. Side-on overpressure time-history directly above the charge GZ in experiment BM-I-03.

Figure 4.31. Side-on overpressure time-histories at a horizontal range of 18 in. from GZ in experiment BM-I-03.

Figure 4.32. Side-on overpressure time-histories at a horizontal range of 36 in. from GZ in experiment BM-I-03.

Figure 4.33. Shock times of arrival versus range from side-on overpressure gages in experiments BM-I-01 through BM-I-03.

Figure 4.34. Peak side-on overpressures versus range in experiments BM-I-01 through BM-I-03.

Figure 4.35 Impact-plate pressure time-histories RP2 and RP3 for experiment BM-I-04.

Figure 4.36. Impact-plate pressure time-histories RP2 and RP3 for experiment BM-I-05.

Figure 4.37. Velocity and displacement time-histories from integrated accelerometer SAV1 data in experiment BM-I-04.

Figure 4.38 Velocity and displacement time-histories from integrated accelerometer SAV2 data in experiment BM-I-04.

Figure 4.39. Velocity and displacement time-histories from integrated accelerometer SAV1 data in experiment BM-I-05.

Figure 4.40. Velocity and displacement time-histories from integrated accelerometer SAV2 data in experiment BM-I-05.

Figure 4.41. Photograph and cross-section surveys of testbed crater in BM-C-01

Figure 4.42. Photograph and cross-section surveys of testbed crater in BM-C-02 .........................83

Figure 4.43. Photograph and cross-section surveys of testbed crater in BM-C-03..........................84

Figure 4.44. Photograph and cross-section surveys of testbed crater in BM-C-04........................85

Figure 4.45. Photograph and cross-section surveys of testbed crater in BM-C-05..........................86

Figure 4.46. Radial stress time-histories measured in the experiment BM-C-03 backfill. ..............88

Figure 4.47. Radial stress time-histories measured in the experiment BM-C-05 backfill................89

Figure 4.48 Peak stress versus range in the experiment BM-C-03 and BM-C-05 backfills. ............ 89

Figure 4.49. Radial particle velocity time-histories measured in the experiment BM-C-03 backfill. .

Figure 4.50. Radial particle velocity time-histories measured in the experiment BM-C-05 backfill.

Figure 4.51. Peak particle velocity versus range in the experiment BM-C-03 and BM-C-05 backfill. 
Figure 4.52. Initial ground shock times of arrival versus range from the CG of the charge in the experiments BM-C-03 and BM-C-05 backfills

Figure 4.53. Ground surface overpressure time-histories at ranges

of 8,10 , and $14 \mathrm{ft}$ from experiment BM-C-01.

Figure 4.54. Ground surface overpressure time-histories at ranges

of 8,10 , and $14 \mathrm{ft}$ from experiment BM-C-02.

Figure 4.55. Ground surface overpressure time-histories at ranges

of 8,10 , and $14 \mathrm{ft}$ from experiment BM-C-03.

Figure 4.56. Ground surface overpressure time-histories at ranges

of 8,10 , and $14 \mathrm{ft}$ from experiment BM-C-04.

Figure 4.57. Ground surface overpressure time-histories at ranges

of 8,10 , and $14 \mathrm{ft}$ from experiment BM-C-05.

Figure 4.58. Ground surface overpressure times of arrival versus range for experiments

BM-C-01 through BM-C-05.

Figure 4.59. Ground surface peak overpressure versus range for experiment BM-C-01 through BM-C-05.

Figure 4.60. Ground surface peak overpressure times of arrival versus range for experiments BM-C-01 through BM-C-05.

Figure 4.61. Side-on overpressure time-history directly above the charge GZ in experiment BM-C-01

Figure 4.62. Side-on overpressure time-histories at a horizontal range of $18 \mathrm{in}$. from GZ in experiment BM-C-01.

Figure 4.63. Side-on overpressure time-histories at a horizontal range of 36 in. from GZ in experiment BM-C-01.

Figure 4.64. Side-on overpressure time-history directly above the charge GZ in experiment BM-C-02.

Figure 4.65. Side-on overpressure time-histories at a horizontal range of $18 \mathrm{in}$. from GZ in experiment BM-C-02.

Figure 4.66. Side-on overpressure time-histories at a horizontal range of 36 in. from GZ in experiment BM-C-02.

Figure 4.67. Side-on overpressure time-history directly above the charge GZ in experiment BM-C-03.

Figure 4.68. Side-on overpressure time-histories at a horizontal range of 18 in. from GZ in experiment BM-C-03.

Figure 4.69. Side-on overpressure time-histories at a horizontal range of 36 in. from GZ in experiment BM-C-03.

Figure 4.70. Shock times of arrival versus range from side-on overpressure gages in experiments BM-C-01 through BM-C-03.

Figure 4.71. Peak side-on overpressure versus range in experiment BM-C-01 through BMC-03.

Figure 4.72. Impact-plate pressure time-histories RP2 and RP3 for experiment BM-C-04...........108

Figure 4.73. Impact-plate pressure time-history RP3 for experiment BM-C-05.............................108

Figure 4.74. Velocity and displacement time-histories from integrated accelerometer SAV2 data in experiment BM-C-04.

Figure 4.75. Velocity and displacement time-histories from integrated accelerometer SAV1 data in experiment BM-C-05. 
Figure 4.76. Velocity and displacement time-histories from integrated accelerometer SAV2 data in experiment for BM-C-05.

Figure 4.77. Photograph and cross-section surveys of testbed crater in BM-S-01........................113

Figure 4.78. Photograph and cross-section surveys of testbed crater in BM-S-02 ........................114

Figure 4.79. Photograph and cross-section surveys of testbed crater in BM-S-03........................115

Figure 4.80. Photograph and cross-section surveys of testbed crater in BM-S-04......................116

Figure 4.81. Photograph and cross-section surveys of testbed crater in BM-S-05......................117

Figure 4.82. Radial stress time-histories measured in the experiment BM-S-03 backfill. ............119

Figure 4.83. Radial stress time-histories measured in the experiment BM-S-05 backfill. .............119

Figure 4.84. Peak stress versus range in the experiment BM-S-03 and BM-S-05 backfill............120

Figure 4.85. Radial particle velocity time-histories measured in the experiment BM-S-03 backfill.

Figure 4.86. Radial particle velocity time-histories measured in the experiment BM-S-05 backfill. 121

Figure 4.87. Peak particle velocity versus range in the experiment BM-S-03 and BM-S-05 backfills.

Figure 4.88. Initial ground shock times of arrival versus range from the CG of the charge in the experiment BM-S-03 and BM-S-05 backfills.

Figure 4.89. Ground surface overpressure time-histories at ranges of 8,10 , and $14 \mathrm{ft}$ in experiment BM-S-01.

Figure 4.90. Ground surface overpressure time-histories at ranges of 8, 10, and $14 \mathrm{ft}$ in experiment BM-S-02.

Figure 4.91. Ground surface overpressure time-histories at ranges of 8,10 , and $14 \mathrm{ft}$ in experiment BM-S-03.

Figure 4.92. Ground surface overpressure time-histories at ranges of 8,10 , and $14 \mathrm{ft}$ in experiment BM-S-04.

Figure 4.93. Ground surface overpressure time-histories at ranges of 8,10 , and $14 \mathrm{ft}$ in experiment BM-S-05.

Figure 4.94. Ground surface overpressure times of arrival versus range for experiments BM-S-01 through BM-S-05.

Figure 4.95. Ground surface peak overpressure versus range for experiments BM-S-01 through BM-S-05.

Figure 4.96. Ground surface peak overpressure times of arrival versus range for experiments BM-S-01 through BM-S-05.

Figure 4.97. Side-on overpressure time-history directly above the charge GZ in experiment BM-S-01.

Figure 4.98. Side-on overpressure time-histories at a horizontal range of 18 in. from GZ in experiment BM-S-01.

Figure 4.99. Side-on overpressure time-histories at a horizontal range of 36 in. from GZ in experiment BM-S-01.

Figure 4.100. Side-on overpressure time-history directly above the charge GZ in experiment BM-S-02.

Figure 4.101. Side-on overpressure time-histories at a horizontal range of 18 in. from GZ in experiment BM-S-02...... 
Figure 4.102. Side-on overpressure time-histories at a horizontal range of 36 in. from GZ in experiment BM-S-02

Figure 4.103. Side-on overpressure time-history directly above the charge GZ in experiment BM-S-03.

Figure 4.104. Side-on overpressure time-histories at a horizontal range of 18 in. from GZ in experiment BM-S-03.

Figure 4.105. Side-on overpressure time-histories at a horizontal range of 36 in. from GZ in experiment BM-S-03.

Figure 4.106. Shock time of arrival versus range from side-on over- pressure gages in experiments BM-S-01 through BM-S-03.

Figure 4.107. Peak side-on overpressures versus range in experiments BM-S-01 through BM-S-03.

Figure 4.108. Impact-plate pressure time-histories RP2 and RP3 in experiment BM-S-04.........139

Figure 4.109. Impact-plate pressure time-histories RP2 and RP3 in experiment BM-S-05.........139

Figure 4.110. Velocity and displacement time-histories from integrated accelerometer SAV1 data in experiment BM-S-04

Figure 4.111. Velocity and displacement time-histories from integrated accelerometer SAV2 data in experiment BM-S-04.

Figure 4.112. Velocity and displacement time-histories from integrated accelerometer SAV1 data in experiment BM-S-05

Figure 4.113. Velocity and displacement time-histories from integrated accelerometer SAV2 data in experiment for BM-S-05.

Figure 5.1. Crater profiles from three experiments with the charge placed tangent surface above.

Figure 5.2. Crater profiles from three experiments with the charge placed tangent surface below.

Figure 5.3. Crater profiles from three experiments with the charge buried 4 in.

Figure 5.4. Peak soil stress versus range from the $C G$ of the buried charge.

Figure 5.5. Peak particle velocity versus range from the $C G$ of the buried charge.

Figure 5.6. Initial ground shock times of arrival versus range from the $C G$ of the buried charge.

Figure 5.7. Ground surface overpressure times of arrival for charge placed tangent surface above.

Figure 5.8. Ground surface overpressure times of arrival for charge placed tangent surface below.

Figure 5.9. Ground surface overpressure times of arrival for charge buried $20 \mathrm{in}$.

Figure 5.10. Peak ground surface overpressure for the charge placed tangent surface above.

Figure 5.11. Peak ground surface overpressure for the charge placed tangent surface below.

Figure 5.12. Peak ground surface overpressure for the charge buried 4 in. 151

Figure 5.13. Peak side-on overpressure for the charge placed tangent surface above. 152

Figure 5.14. Peak side-on overpressure for the charge placed tangent surface below. 153

Figure 5.15. Peak side-on overpressure for the charge buried 4 in. 153 
Figure 5.16. Peak side-on overpressure impulse for the charge placed tangent surface above.

Figure 5.17. Peak side-on overpressure impulse for the charge placed tangent surface below.

Figure 5.18. Peak side-on overpressure impulse for the charge buried 4 in. 156

\section{Tables}

Table 2.1. Design characteristics of the safety-stop device components.......................................... 14

Table 3.1. Experimental constants. .............................................................................................. 20

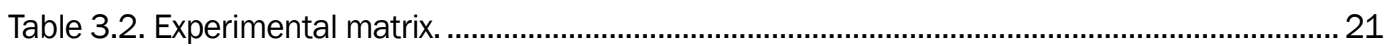

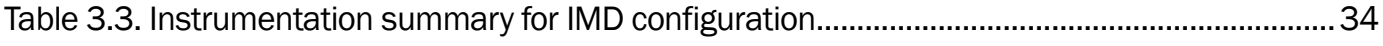

Table 3.4. Instrumentation summary for side-on pressure configuration..........................................36

Table 4.1. Summary of intermediate soil test series. .................................................................. 50

Table 4.2 Ground shock instrumentation summary for intermediate soil experiments. ..................56

Table 4.3 Ground surface overpressure summary for intermediate soil..........................................63

Table 4.4. Side-on overpressure summary for intermediate soil experiments..................................68

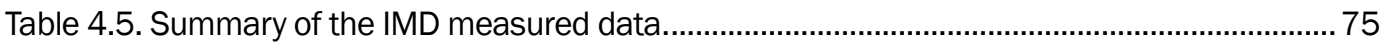

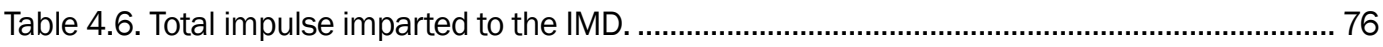

Table 4.7. Summary of clay soil test series............................................................................... 81

Table 4.8. Ground shock instrumentation summary for clay soil experiments................................8 87

Table 4.9. Ground surface overpressure summary for clay soil. ...................................................93

Table 4.10. Side-on overpressure summary for clay soil experiments............................................99

Table 4.11. Summary of the IMD measured data. ………......................................................106

Table 4.12. Total impulse imparted to the IMD. ....................................................................... 107

Table 4.13. Summary of sand soil test series. ..........................................................................112

Table 4.14. Ground shock instrumentation summary for clay soil experiments............................118

Table 4.15. Ground surface overpressure summary for sand soil experiments..............................124

Table 4.16. Side-on overpressure summary for sand soil experiments.........................................129

Table 4.17. Summary of the IMD measured data. .............................................................................. 137

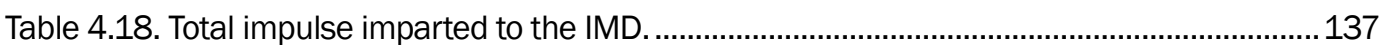

Table 5.1. Peak total impulse imparted to the IMD. .....................................................................156 


\section{Preface}

The U.S. Army Engineer Research and Development Center (ERDC) was tasked by the U.S. Army Tank Automotive Research, Development and Engineering Center (TARDEC) and Headquarters, U.S. Army Corps of Engineers (USACE), to develop techniques to quantify the aboveground environments produced by the detonation of surface and shallow-buried explosives on overlying structures. The research was funded by TARDEC under the Experiments to Measure Aboveground Effects for Buried Bare Charges (Mines) funding document in FY08 and the Soil/Threat Characterization funding document in FY09 and by USACE under the Tactical Wheeled Vehicle Survivability (TWVS) Army Technology ObjectiveDemonstration (ATO-D). Munira Tourner was the TARDEC TWVS ATO-D Manager, Heather Kammer was the TARDEC technical point of contact for this research effort, and Dr. Kent T. Danielson was the ERDC TWVS work package manager. The ERDC research was conducted by staff members in the Impact and Explosion Effects Branch (IEEB), Engineering Systems and Materials Division (ESMD), Geotechnical and Structures Laboratory (GSL).

The Principal Investigator for this research was J ohn Q. Ehrgott, J r., IEEB, who also functioned as the Project Engineer responsible for the design and fabrication of a new impulse measurement device (IMD) used in the field experiments and all experimental efforts conducted under this research effort. Richard G. Rhett, IEEB, designed and oversaw fabrication of a mechanical safety-stop device installed in the IMD. Dr. J on E. Windham, Bevilacqua Research Corporation (BRC), provided advice on selection of backfill soil materials and developed backfill placement specifications. J im W. Hall III, IEEB, was responsible for construction of the backfill test beds. Instrumentation support was provided by J ohnny L. Morrow, Data Acquisition and Instrumentation Branch, ERDC Information Technology Laboratory. This report was prepared by Ehrgott with assistance from Tracey A. Waddell, IEEB, and A. E. J ackson, J r., BRC.

During this investigation, Henry S. McDevitt, J r., was Chief, IEEB; Dr. Larry N. Lynch was Chief, ESMD; Dr. William P. Grogan was Deputy Director, GSL; and Dr. David W. Pittman was Director, GSL.

COL Gary E. J ohnston was Commander and Executive Director of ERDC. Dr. J effery P. Holland was Director. 


\section{Conversion Factors, Non-SI to SI Units of Measurement}

\begin{tabular}{|l|c|l|}
\hline Multiply & By & To Obtain \\
\hline cubic feet & 0.02831685 & cubic meters \\
\hline cubic inches & $1.6387064 \mathrm{E}-05$ & cubic meters \\
\hline degrees (angle) & 0.01745329 & radians \\
\hline feet & 0.3048 & meters \\
\hline inches & 0.0254 & meters \\
\hline mils & 0.0254 & millimeters \\
\hline pounds (force) & 4.448222 & newtons \\
\hline pounds (force) per square inch & 6.894757 & kilopascals \\
\hline pounds (mass) & 0.45359237 & kilograms \\
\hline pounds (mass) per cubic foot & 16.01846 & kilograms per cubic meter \\
\hline pounds (mass) per cubic inch & $2.757990 \mathrm{E}+04$ & kilograms per cubic meter \\
\hline square feet & 0.09290304 & square meters \\
\hline square inches & $6.4516 \mathrm{E}-04$ & square meters \\
\hline
\end{tabular}




\section{Introduction}

\section{Background}

Detonation of an explosive charge, such as a mine or an improvised explosive device (IED) at the ground surface or buried at shallow depth in soil, can produce high airblast pressures and significant dynamic soil debris loads on an overlying structure, such as a vehicle passing over the explosive. The blast loading environment is a function of many factors including the explosive type, configuration, mass, and depth of burial, soil characteristics, and the distance between the ground surface and the target structure.

A buried explosive that detonates and interacts with an aboveground structure typically produces complex responses and interactions. The explosive detonation produces extremely high pressure gases that expand to volumes hundreds of times greater than the initial volume of the explosive charge in order to reach an equilibrium pressure condition. As the detonation gases begin to expand, the confined soil below the explosive charge is severely compressed, even to the point that individual soil grains are pulverized. Meanwhile, the soil overlying the explosive charge, and to a lesser degree the soil in the plane of the charge, is unconfined and accelerates outward, away from the charge center. For those cases in which only a thin layer of soil overlies the explosive, the soil directly above the detonation is projected upward with a velocity approximately equal to that of the expanding shock front. If the chassis of a vehicle is positioned over the detonation point, this high-velocity soil compresses the air between the original ground surface and the chassis to a small fraction of its initial volume. The highly compressed air loads the chassis, followed immediately by the impact of the high-velocity soil, the impact of the expanding detonation gas bubble, and the impact of any detonation residues entrained in the detonation gases. All of these materials intermix and produce extremely complex interfaces and interactions.

Research is needed to better understand the aboveground environment created by the detonation of a shallow-buried explosive. To design adequate protective measures for an aboveground structure, designers must understand the load environment created by these near-surface detonations. Unfortunately, there is no accurate methodology for predicting these 
airblast and soil debris loads to support the designs. Development of the required prediction tools is hampered by lack of well-documented experimental results for these complex loads. Without detailed experimental data, the numerical simulations of these loads cannot be adequately validated for the large deformation, stress, and motion gradients and the resulting interactions with structures.

To address the need for these data, the U.S. Army Engineer Research and Development Center (ERDC) recently designed and deployed an impulse measurement device (IMD) for a series of research experiments. The goal of the research was to quantify the influence of soil properties on the aboveground environment from the detonation of a bare explosive charge resting on the soil surface or from detonation of a shallow-buried explosive charge. To fully quantify the influence of soil parameters, well-controlled experiments were designed to directly measure soil debris and airblast loadings on an aboveground reaction structure due to the detonation of explosives at the surface of, and shallowly buried in, three very different soils. The experiments were performed using specifications and strict quality controls that limited the influence of outside variables and ensured the experiments were repeatable. The experiments provided blast pressure, soil stress, and impulse data from each soil type. These data were analyzed to investigate the influence of the different soil types on the aboveground environment.

Supporting numerical simulations were also conducted and compared with the field experiments. The calculation efforts leveraged an ongoing project to develop and verify a complete Lagrangian mesh-free analysis approach. Mesh-free methods allowed extremely large deformations to be modeled in a Lagrangian sense without the difficulty of highly distorted finite elements corrupting the analysis. Those and future calculations will utilize the EPIC code (J ohnson et al. 2006; Gerlach and J ohnson 2009), which has generalized particle algorithms for use in Lagrangian calculations. An important feature of the EPIC code is the Hybrid-Elastic-Plastic (HEP) library of geomaterial model fits developed at ERDC (Akers et al. 1995; Zimmerman et al. 1987). 


\section{Purpose and scope}

The purpose of this report is to document the results of the experimental program conducted to quantify the influence of soil properties on the aboveground blast environment from the detonation of bare explosive charges located at or near the ground surface. The results of the numerical simulations will be documented in a companion report. Chapter 2 presents the design, analysis, and fabrication of a vertical impulse measurement device that was used in these experiments. Chapter 3 discusses the design, layout, and execution of the field experiments conducted to quantify the influence of three different soil types on aboveground blast environments. Chapter 4 presents the results of these experiments, and Chapter 5 contains comparisons of the experimental data. A summary of the results and conclusions is presented in Chapter 6. 


\section{Design and Fabrication of an Impulse Measurement Device}

\section{Design considerations}

Measurements of the impulse loading produced above an explosive charge can be obtained in a number of ways. Many different measuring devices are used by various research organizations and institutes, but they all use one of two fundamental principles in their designs. The first type uses the pendulum or mass pendulum concept, and the second uses an inertial frame with load cells. Each design principle has its own set of challenges. For the pendulum type of impulse measurement device, a mass moves freely with resistance due only to its own weight and gravity. The devices that use this pendulum concept are oriented either vertically or horizontally. For example, the Vertical Impulse Fixture at the U.S. Army Research Laboratory (ARL) uses this concept with a single vertical floating piston design (Bitting 2001). This device measures the vertical distance traveled by a known mass to derive the impulse. An example of the horizontaloriented pendulum is a swing arm that allows the mass pendulum to rotate about a fixed hinge. This concept measures the maximum angular displacement of the pendulum arm and uses this displacement value to calculate the induced impulse. The Mine-Impulse Pendulum Device developed and used under a cooperative agreement between Clemson University and ARL is an example of this concept (Grujicic et al. 2005).

The second design concept for an impulse measurement device is the use of an inertial frame. The key feature of the inertial frame system is a floating test section that is linked to a support frame. The floating test section is accelerated upward by the blast wave of an explosion. The force due to acceleration is measured by a system of load cells. The impulse is calculated from the measured acceleration force, the mass of the system, and any resistance from the spring support system. An example of this concept is the Scientifically Instrumented Impulse Measurement Apparatus (Snyman and Reinecke 2006) developed and tested by the Council for Scientific and Industrial Research (CSIR), South Africa.

After reviewing the advantages and disadvantages of the different impulse measurement devices currently in use, ERDC designed and fabricated a 
device based on the mass-pendulum principle. The ERDC design has a mass piston assembly that moves freely in a vertical direction with minimal resistance other than its own weight and gravity. The basic principle of the design was to measure the vertical displacement and velocity of a known mass with a known surface area that can then be used to derive impulse loads. The piston mass was designed to be displaced vertically by the soil debris and airblast loading produced by an underlying explosion. The piston assembly was instrumented so that its motion, i.e., velocity time-history and maximum height of travel, was measured. The vertical motion of the piston was used to determine the resulting impulse, or change in momentum, delivered to the IMD by the blast loading.

The impulse loading applied to the IMD during the blast events was determined directly from the velocity time-history by using the relation

$$
\mathrm{I}=\mathrm{vm}
$$

where I is the impulse load, $\mathrm{v}$ is the velocity, and $\mathrm{m}$ is the mass of the piston assembly. Alternatively, the total impulsive load imparted to the piston assembly was calculated by assuming conservation of energy without frictional losses, which dictates that the total potential energy must equal the initial kinetic energy for the system. The total displacement or height obtained by the piston mass was used to calculate the potential energy, PE, by

$$
\mathrm{PE}=\mathrm{mgH}
$$

where $\mathrm{m}$ is the mass of the piston assembly, $\mathrm{g}$ is gravity, and $\mathrm{H}$ is the maximum vertical height achieved by the piston. The initial kinetic energy, $\mathrm{KE}$, is given by

$$
\mathrm{KE}=1 / 2 \mathrm{~m}\left(\mathrm{v}_{\mathrm{o}}\right)^{2}
$$

where $v_{0}$ is the maximum upward velocity of the piston assembly. For the case of a short-duration blast loading, we assumed that the maximum upward velocity occurred instantaneously to simplify matters, although the acceleration to peak actually requires some 5 to $20 \mathrm{msec}$. Using this assumption, the potential energy can be set equal to the kinetic energy to calculate the initial velocity of the pendulum mass. 


$$
\mathrm{PE}=\mathrm{mgH}=\mathrm{KE}=1 / 2 \mathrm{~m}\left(\mathrm{v}_{\mathrm{o}}\right)^{2}
$$

Eliminating the mass terms and solving for $\mathrm{v}_{0}$, we have

$$
\mathrm{v}_{\mathrm{o}}=(2 \mathrm{gH})^{1 / 2} \text { and } \mathrm{I}(\max )=\mathrm{m}(2 \mathrm{gH})^{1 / 2}
$$

The goal was to capture both the initial peak velocity and the total displacement of the mass piston during the experiments. Several methods were used to capture the displacement, including cable extension position transducers (yo-yo gages) that provide a displacement time-history, scratch gages to measure total net displacement, and high-speed video. High-speed video was also used to capture the initial peak velocity of the piston by means of measuring the piston assembly position relative to a graduated backdrop. For all cases, acceleration time-histories of the piston assembly were captured and used to derive velocity time-histories and approximate displacement time-histories throughout the event.

The IMD was designed with the knowledge that it would need to withstand the harsh environment of an explosive charge detonated at close proximity and to be reusable with very few maintenance requirements. The general device design was predicated on the concept that the loaded end of the piston assembly would be quite close to the explosive and would thus be subjected to extremely high airblast pressures and high-velocity soil ejecta. Meanwhile, it was considered advantageous to place the support frame for the piston assembly at the greatest standoff distance possible from the explosive device in order to reduce its loading, and consequently, its displacement and the likelihood of damage. The device was designed and fabricated at ERDC and was installed at Fort Polk, LA, for field testing. A 3-D illustration of the IMD is shown in Figure 2.1.

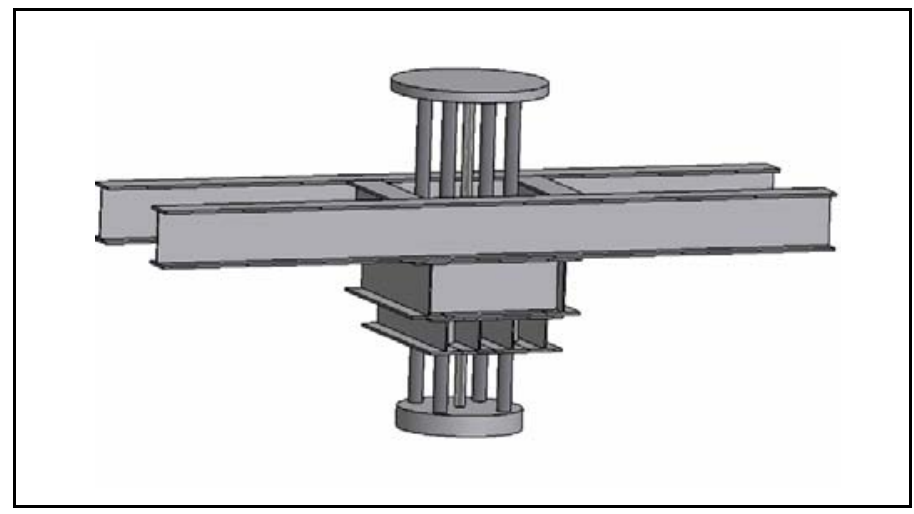

Figure 2.1. Three-dimensional view of the IMD. 
The IMD consists of several key components that include the primary support structure, the free translating vertical impulse measurement piston assembly, and a mechanical safety-stop system. All three components were designed for a variety of different loading conditions. The explosive charge was assumed to detonate in close proximity to the primary loading surface of the impulse system. The IMD design considered several different explosive charge sizes and positions, including the possibility of a small offset from center, which would create some lateral loading on the system. The design of the support structure not only considered the dynamic loading from the blast, but also the loading created when bringing the mass to a stop. The design assumed a fully restrained boundary condition in all directions except vertical. The mechanical safety-stop system was designed to allow for free vertical motion as the impulse system moved up but would lock and prevent a free-fall of the impulse mass. The support structure and impulse system were fully assembled in a controlled environment at ERDC to allow for calibration and checkout before the system went to the field. Upon completion of the checkout, the system was disassembled and shipped to Fort Polk, LA, for final installation and testing. Figure 2.2 shows a cross section of a typical test layout.

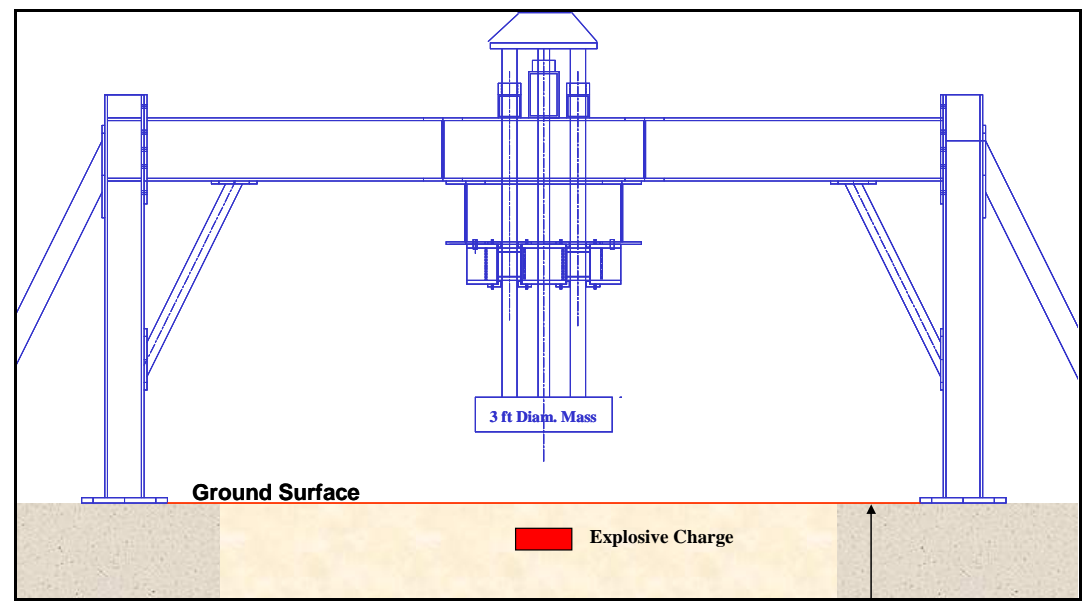

Figure 2.2. Cross section of a typical test layout.

\section{Support structure design}

The support structure for the IMD was designed for two purposes. The primary purpose was for support of the piston assembly and the safetystop system. The secondary purpose was to support a series of side-on pressure gage mounts to capture pressure data at the same vertical position as the impulse impact plate. 
Figure 2.3 shows a section view of the support structure with the impulse device and a view of the support structure with the gage mounts. The structure is approximately $29 \mathrm{ft}$ long by $5 \mathrm{ft}$ wide at the base and stands approximately $9 \mathrm{ft}$ tall above the ground surface. The design and fabrication of the support structure was based on the American Institute of Steel Construction's “Load and resistance factor design" (1994). The structure was constructed with various structural steel members, primarily standard wide-flange beams and I-beams. Moment connections were bolted to allow for assembly and disassembly as needed. The structural support system was designed to minimize both global movement and vibration of the structure when subjected to the blast environment.

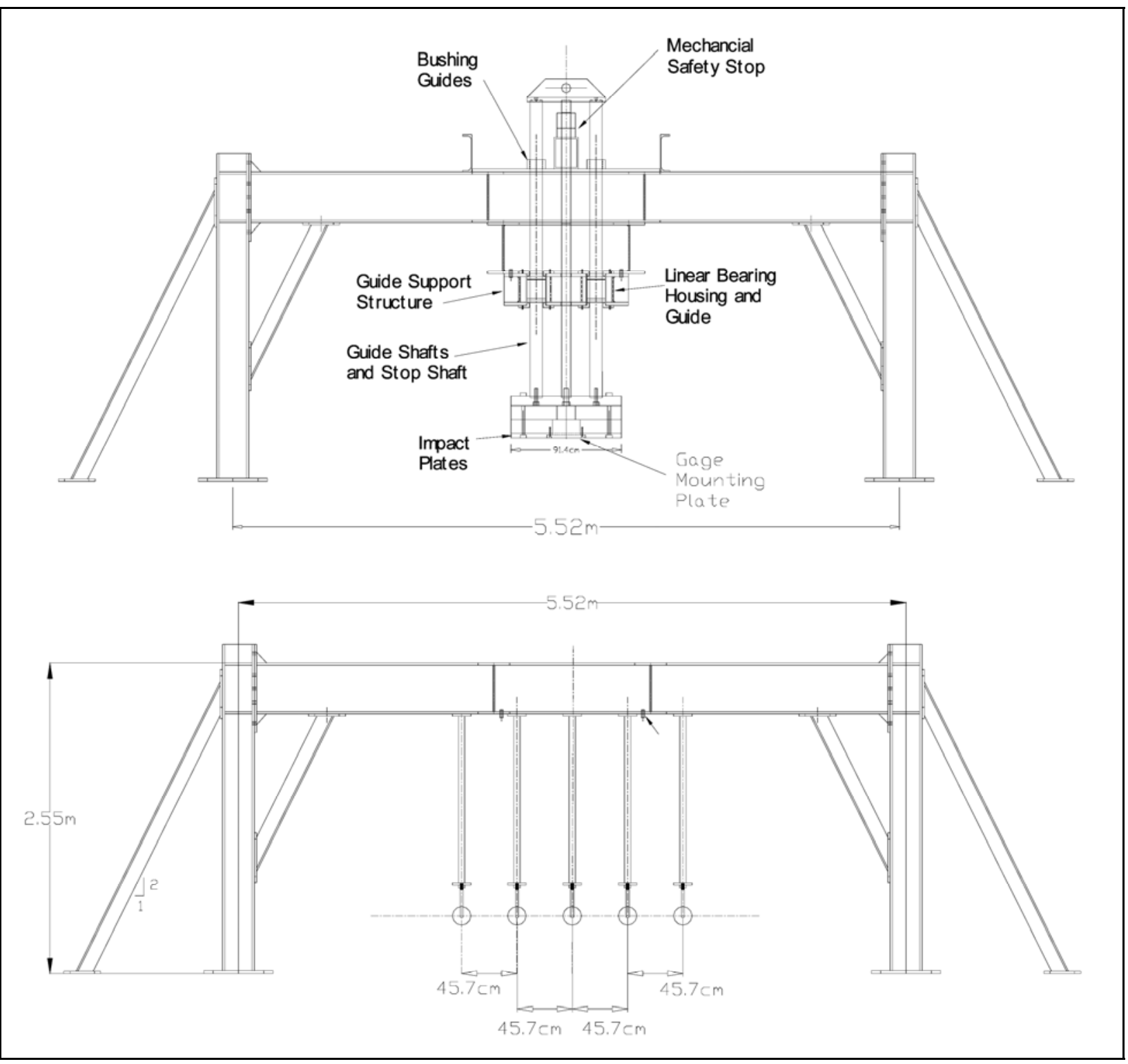

Figure 2.3. Section view of support structure with impulse device and gage mounts. 
The loading conditions used in the design and analysis of the support structure consisted of the blast loading produced during the detonation and the dynamic loading produced by the safety-stop catching the impulse mass. The design blast-loading environment was based on a 10-lb Composition $\mathrm{C} 4$ (C4) explosive charge placed on the soil surface. Although the structural design was based on a 10-lb surface charge, the charge mass was limited to $5 \mathrm{lb}$ during testing due to enhanced loading developed from a shallow-buried charge, as indicated by pretest calculations. The supporting structure was designed for the maximum possible standoff from the blast location in order to reduce the loading on the structure and to reduce displacement and vibration of the support system. Based on this standoff distance, a simplified design approach was used for the blast loading on the structure. The SBEDS and SPAn32 government-owned, single-degreeof-freedom computer codes (U.S. Army Corps of Engineers (USACE) Protective Design Center 2006 and 2002, respectively) were used to calculate the displacement and motion time-histories of the two primary support beams (see Figure 2.1). The limiting factor for this design was not structural capacity, but the displacement limitations that were established for the support structure. Limiting the displacement in the structure to small or moderate values was critical, because large displacements could distort the motion of the piston assembly relative to the support structure, thus complicating the analysis of the piston displacement due solely to direct loading. To monitor the motion of the support structure during testing, accelerometers were mounted on the structure, and high-speed video was used. The actual motion captured during testing was used to evaluate the global movement of the support structure for comparison with the movement of the IMD.

The second primary loading condition considered in the design of the support structure was the downward force produced by the safety-stop catching the free-falling piston mass assembly. The safety-stop system was designed to allow for free motion upward but would lock as the mass began to fall. The lock system would allow for a maximum of $4 \mathrm{in}$. of freefall that would produce a dynamic load on the support structure. A detailed structural analysis was performed using the structural engineering software STAAD.Pro (Research Engineers International 2005). The support structure was also designed for repeated loading from the safetystop so that structural fatigue would not occur or would be minimized. As an added precaution, the support structure was designed to withstand the 
failure of the safety-stop system and free-fall of the impulse mass without catastrophic structural failure.

The IMD structure was supported on two large mat foundations. The foundations were offset under the columns to maximize the distance from the blast. Several design load conditions were considered for the footing design, i.e., the upward loading due to the blast load on the structure, the downward loading on the structure during the safety-stop of the piston mass, and the coupling of the blast load through the soil. For the blast load coupled through the soil, a worst-case scenario was considered using the largest expected explosive charge size fully coupled in the soil at a set standoff from the footing. The size and mass of the footing were designed to minimize displacement from all three load conditions. From the results of the footing analysis, the predicted footing displacement was calculated and used as input for the structural model.

\section{Design of the piston assembly}

The primary components of the free-translating piston assembly consist of (a) four 8-ft-long, steel guide shafts, (b) a 13-in.-high, 36-in.-diam stack of four impact plates, (c) a guide support structure, and (d) a single 8-ft-long notched stop shaft located along the centerline. A detailed cross section of the impulse system and photographs of the components are shown in Figure 2.4. The total weight of the piston assembly is approximately 5,500 lb. The four guide rods extend vertically up from the impact plates through a guide support structure. The guide rods are tied together at the top of the impulse device with a 1-in.-thick steel plate. The plate was designed with a lifting eye on top to allow for lifting and maintenance on the IMD. The four guide rods are 4-in.-diam, A1045 turned, ground, and polished steel rods. These rods were turned and polished to minimize friction as they move through the guides. The guide support structure contains a set of linear bearing guides and a set of guide bushings. The bottom of the guide support housing frame contains the four linear bearing cylinders. These cylinders are contained inside cylindrical tubes. The cylinder tubes were fabricated with an inside diameter 1/ 32 in. greater than the outside diameter of the linear bearing cylinders. This allowed the cylinders to float in the horizontal direction inside the cylinders tubes to account for minor variations over the shaft length. The guide support structure was designed for easy removal and cleaning of the linear bearing cylinders. A series of wiper bushings were installed along the bottom face of the linear bearing 


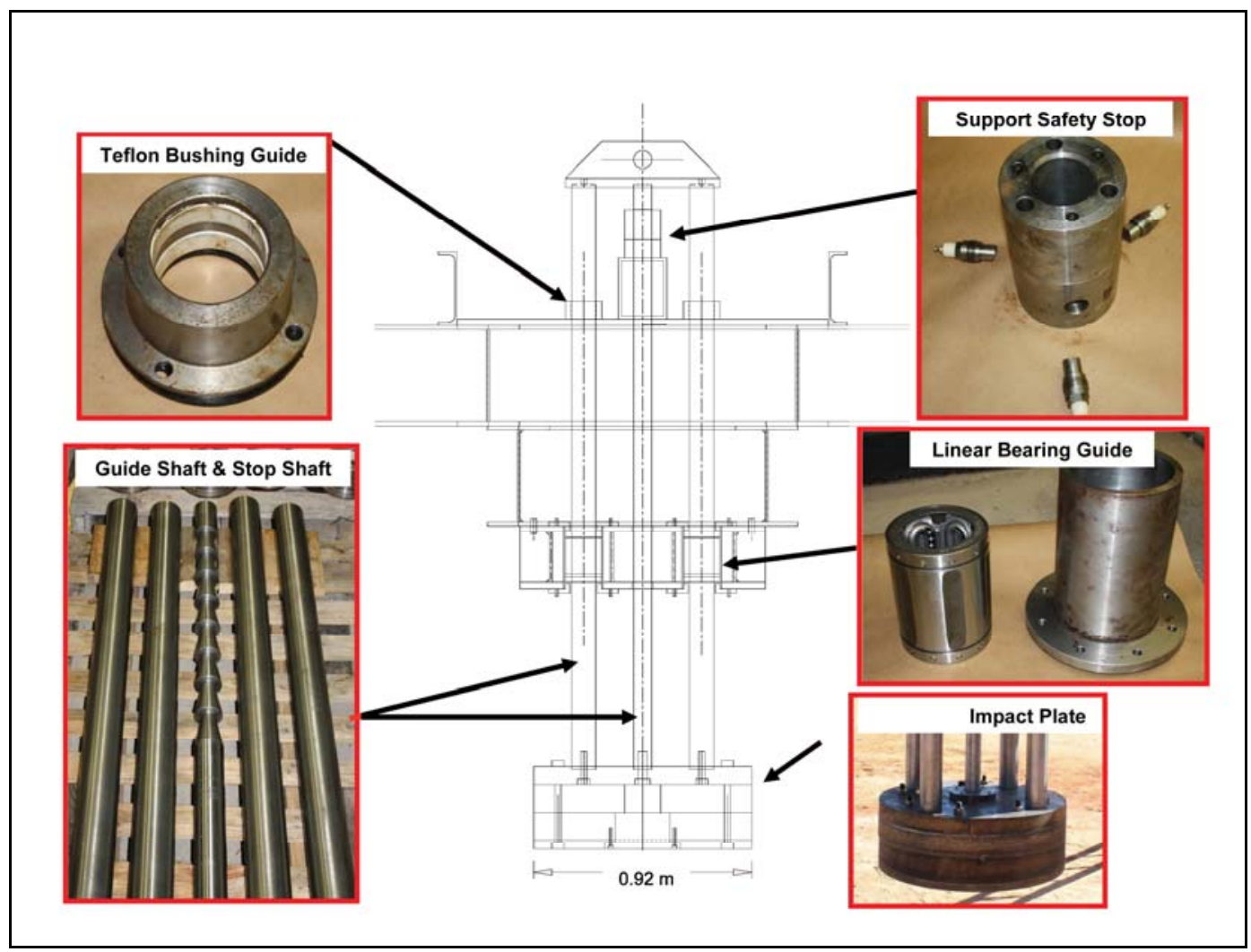

Figure 2.4. Section view of the impulse measurement device and photographs of components.

cylinders to minimize the possibility of debris entering the bearing housing. Teflon bushing guides were located at the top of the guide support structure. The four Teflon guides were designed to provide support for the shafts and limit lateral motion and vibration of the guide rods during testing.

The four bottom steel impact plates provide the majority of the mass for the piston system. A detailed section view of the bottom plates is shown in Figure 2.5. The bottom plate that is directly exposed to the blast consists of high-strength quenched and tempered A514 steel. The remaining steel plates were fabricated from type 4340 steel. The plates are connected using eight Grade 7, 1-in.-diam sock-head bolts that are embedded flush with the bottom surface. The bottom two steel plates were designed to house a gage-mounting assembly. The gage mounts were designed to be removable to allow for repair and replacement as needed. 


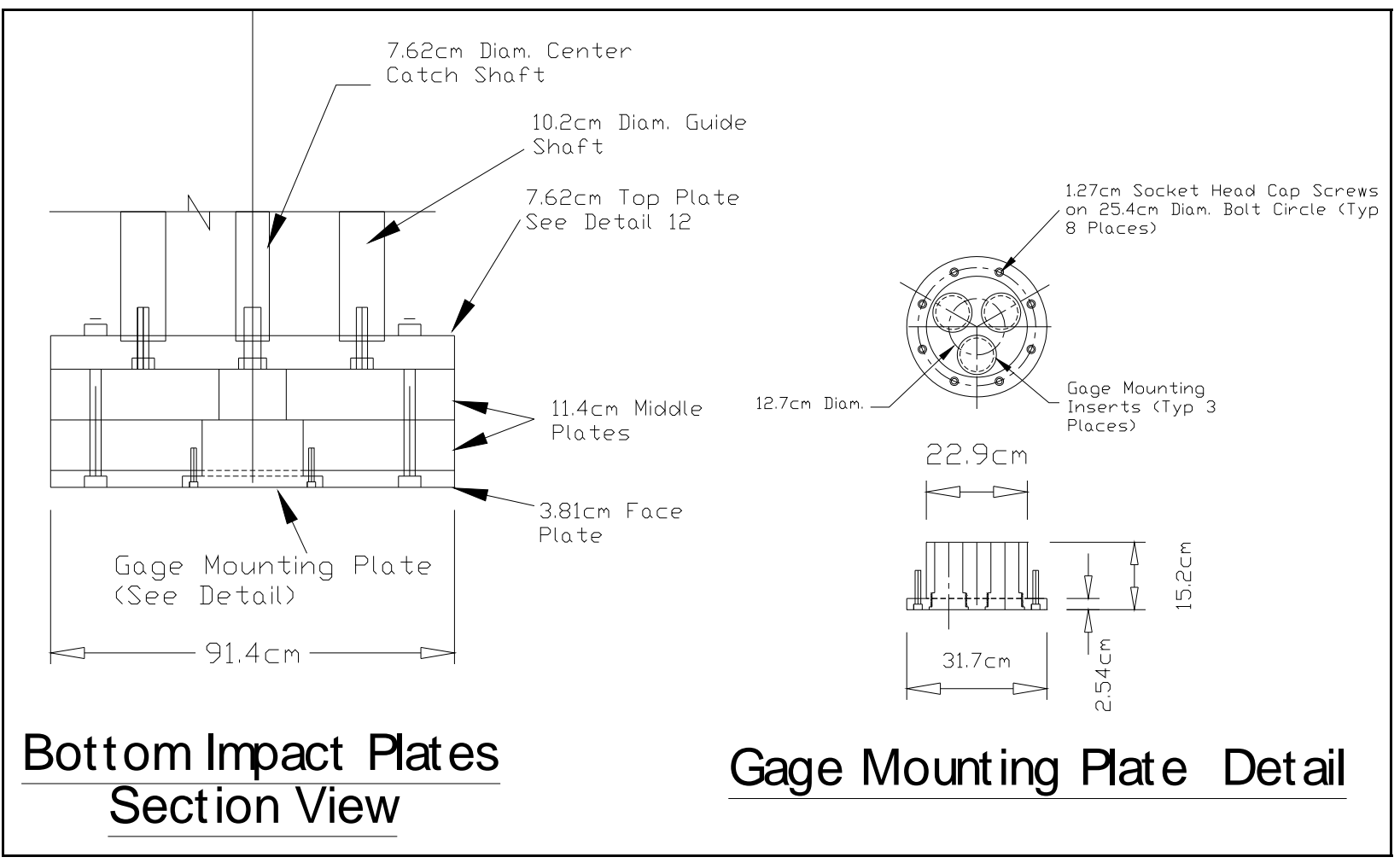

Figure 2.5. Section view of bottom plates and gage mounts.

\section{Mechanical safety-stop device}

The mechanical safety-stop device was designed to stop the 5,500-lb piston assembly at the pinnacle of its vertical travel and to minimize freefall loads on the IMD support structure. If the safety-stop were not in place, the piston could free-fall up to $26 \mathrm{in}$. and produce a significant dynamic load on the support structure. During a blast event, the piston assembly travels up to its peak height and then begins to free-fall, coming to rest due to the engagement of the mechanical safety-stop device. The mechanical safety-stop device is shown in Figure 2.6 and consists of three major components: the catch rod (Figure 2.7a), the catch housing (Figure $2.7 \mathrm{~b}$ ), and the catch lugs (Figure 2.7c). Figure 2.8 shows the total assembly installed on the IMD. The materials used in the shaft, catch lugs, and the center-catch housing are listed in Table 2.1. 


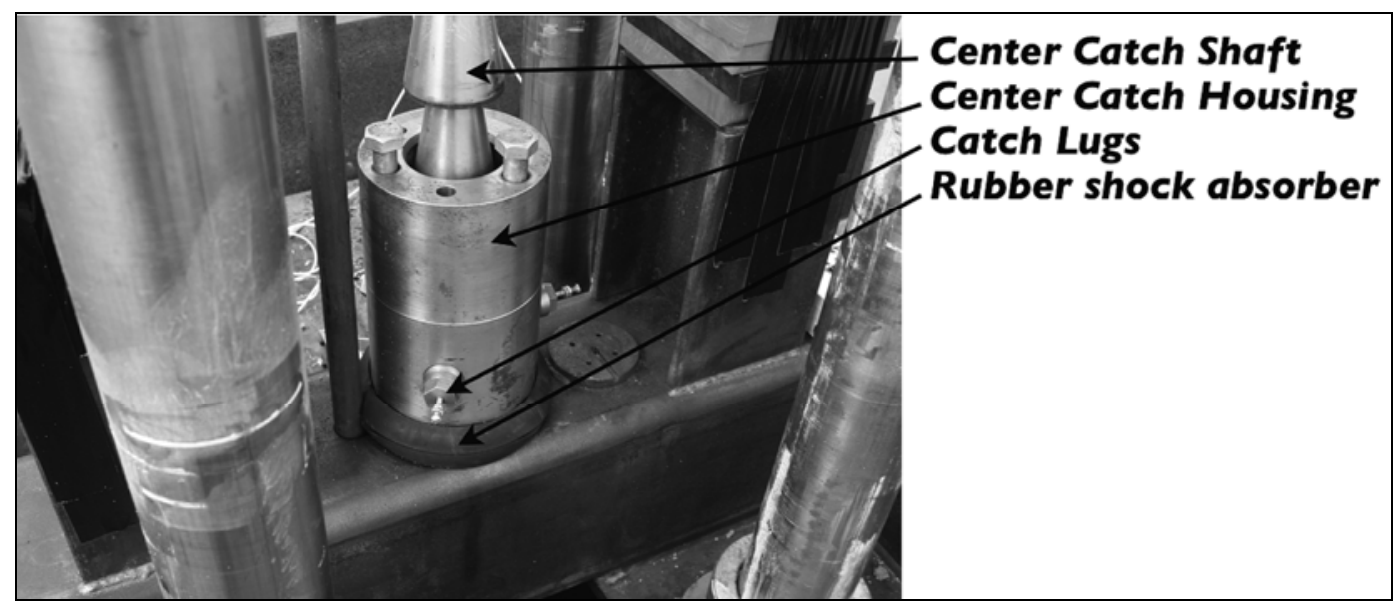

Figure 2.6. The mechanical safety-stop device.
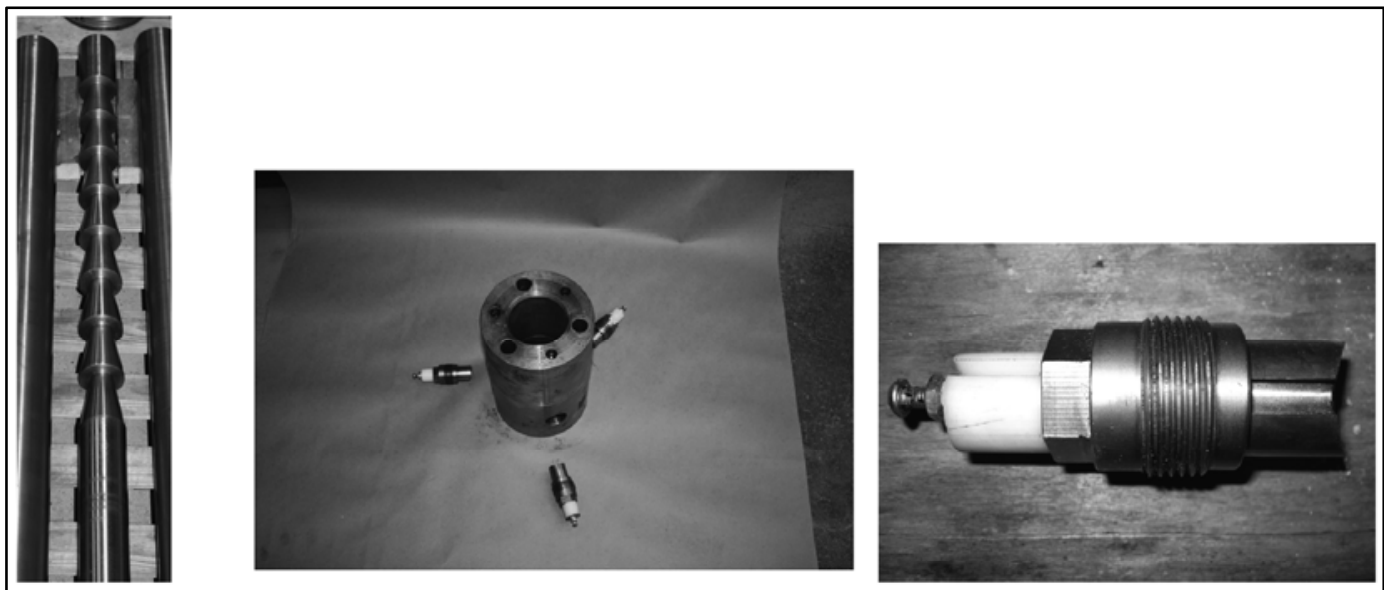

a. Catch rod.

b. Catch housing.

c. Catch lug.

Figure 2.7. Components of the mechanical safety-stop device.

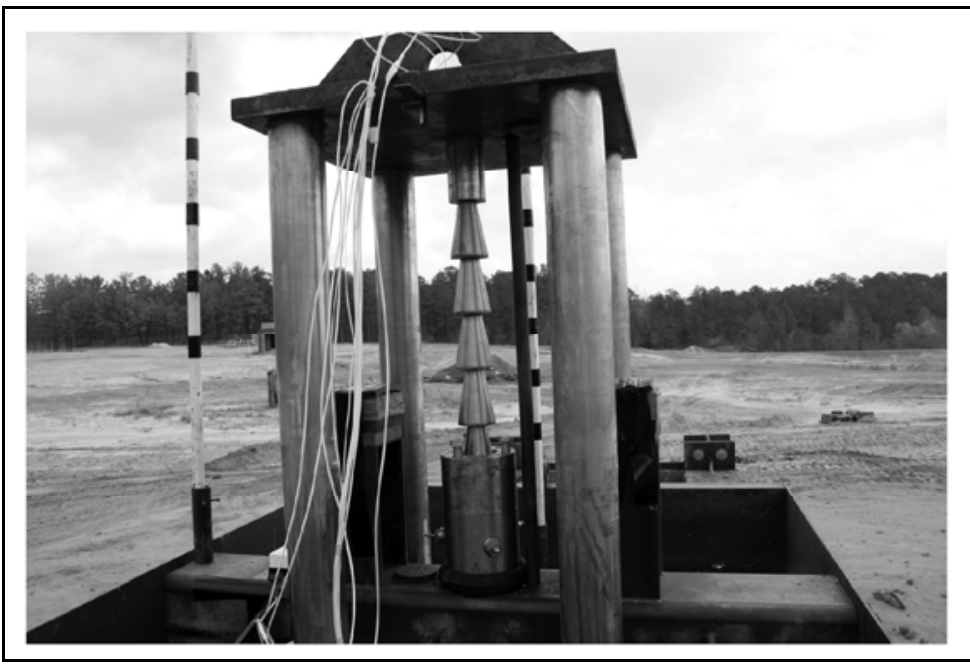

Figure 2.8. Mechanical safety-stop device installed on the IMD. 
Table 2.1. Design characteristics of the safety-stop device components.

\begin{tabular}{|l|l|l|}
\hline Component & Material Name & $\begin{array}{l}\text { Material Yield Strength } \\
\text { psi }\end{array}$ \\
\hline Catch lug & $\begin{array}{l}\text { Carpenter Custom } \\
630(17 \mathrm{Cr}-4 \mathrm{NI})\end{array}$ & 183,000 \\
\hline Catch shaft & 4142 & 102,750 \\
\hline Center catch housing & 4340 & 68,500 \\
\hline
\end{tabular}

The design load on the mechanical safety-stop device was dependent on the distance that the piston assembly would fall before it stopped on the support collar. Therefore, the maximum force that could be exerted to the free-falling piston assembly was directly related to the collar-to-collar distance on the safety rod. This collar-to-collar distance was dependent on several factors, including the contact area for the catch lugs and the slope angle between the collars. The collar-to-collar distance is 4-5/ 16 in. The load is distributed throughout the three catch lugs, the center rod, and the center-catch housing. To reduce the impact loading on the safety-stop components, a 2-in.-thick piece of 40-durometer rubber was placed under the center-catch housing. This increased the stopping distance and thus reduced the impact load on the safety-stop components.

As shown in Figure 2.4, the safety-stop rod was centered in the piston assembly, extended vertically up from the impact plates through the mechanical safety-stop device to the top lifting plate, and bolted to the top and bottom plates like the guide shafts. The rod was fabricated from a 3-in.-diam, 4142 steel rod and machined over the full length of available travel distance for the piston. The rod (Figure 2.7a) has $42 \mathrm{in.} \mathrm{of} \mathrm{repeating}$ machined collars with a large diameter of $3 \mathrm{in}$. and small diameter of $1.5 \mathrm{in}$.

The safety-catch housing (Figure 2.7b) contains the catch lugs and encompasses the catch shaft. The housing is mounted on the rubber shock absorption material and then fastened to the test structure. The safetycatch housing has a 6-in. outside diameter and was center-bored with a 3-in.-diam hole to accommodate the catch shaft; the housing is $12 \mathrm{in.} \mathrm{long.}$ The height of the center-catch housing was designed so that it always encased at least two of the collars on the catch rod in order to keep the shaft centered while moving. 
The catch lug assembly shown in Figure 2.7c stops the piston assembly as it begins to fall. The lugs are spring-loaded and contoured with the catch rod in order to stay in full contact with the shaft. The catch lug assembly is a cylindrically machined piece of hardened custom carpenter 630 (17Cr$4 \mathrm{~N}$ ) stainless steel with a keyway cut the length of the lug to keep it aligned with the central housing (see Figure 2.7c). The lugs also have a tapered radius cut into the face. This allows the lug to mount in full contact with the center-catch rod's tapered radius. Each lug is 1 in. in diameter and 3 in. long. The catch lug assembly threads into the center-catch housing and cannot rotate because of the keyway in the housing and the tapered radius on both the lug and shaft. The opposite end of the lug was drilled and tapped allowing the bolt to go through the threaded cap and a spring and then threaded to the lug holding the assembly together. The nylon spacer shown in Figure 2.7c retains the spring in a compressed state and allows the IMD to move freely. Once all three catch lugs are inserted into the housing, the housing is placed over the center catch rod and fastened to the IMD support frame (Figure 2.8). The nylon spacers are then removed, and the lugs are allowed to mate with the shaft. When the piston travels up, the lugs follow the contour of the rod. When the rod reaches its maximum travel distance and begins to fall, the lugs catch the first collar on the rod and stop the free fall of the piston assembly.

\section{Instrumentation}

The IMD was instrumented with airblast, acceleration, and displacement gages. The general arrangement of the instrumentation is shown in Figure 2.9. The primary goal was to capture the displacement and velocity time-histories of the piston assembly as the mass traveled upward after the blast. Details of the instrumentation are in Chapter 3.

\section{Field installation and checkout}

After completing the fabrication and checkout of the IMD at ERDC, the device was transported and installed at the Fort Polk test site. Once in place, a checkout was performed on the device using both a static and dynamic approach. For the static approach, a hydraulic jack and load cell were placed under the impact plates. First, the jack was used to lift the piston assembly to a set height. The jack was held in position to allow the load cell to record the total weight of the system including instrumentation and wiring. This procedure was also followed before each experiment to verify the total weight of the system. The piston assembly was lifted a 


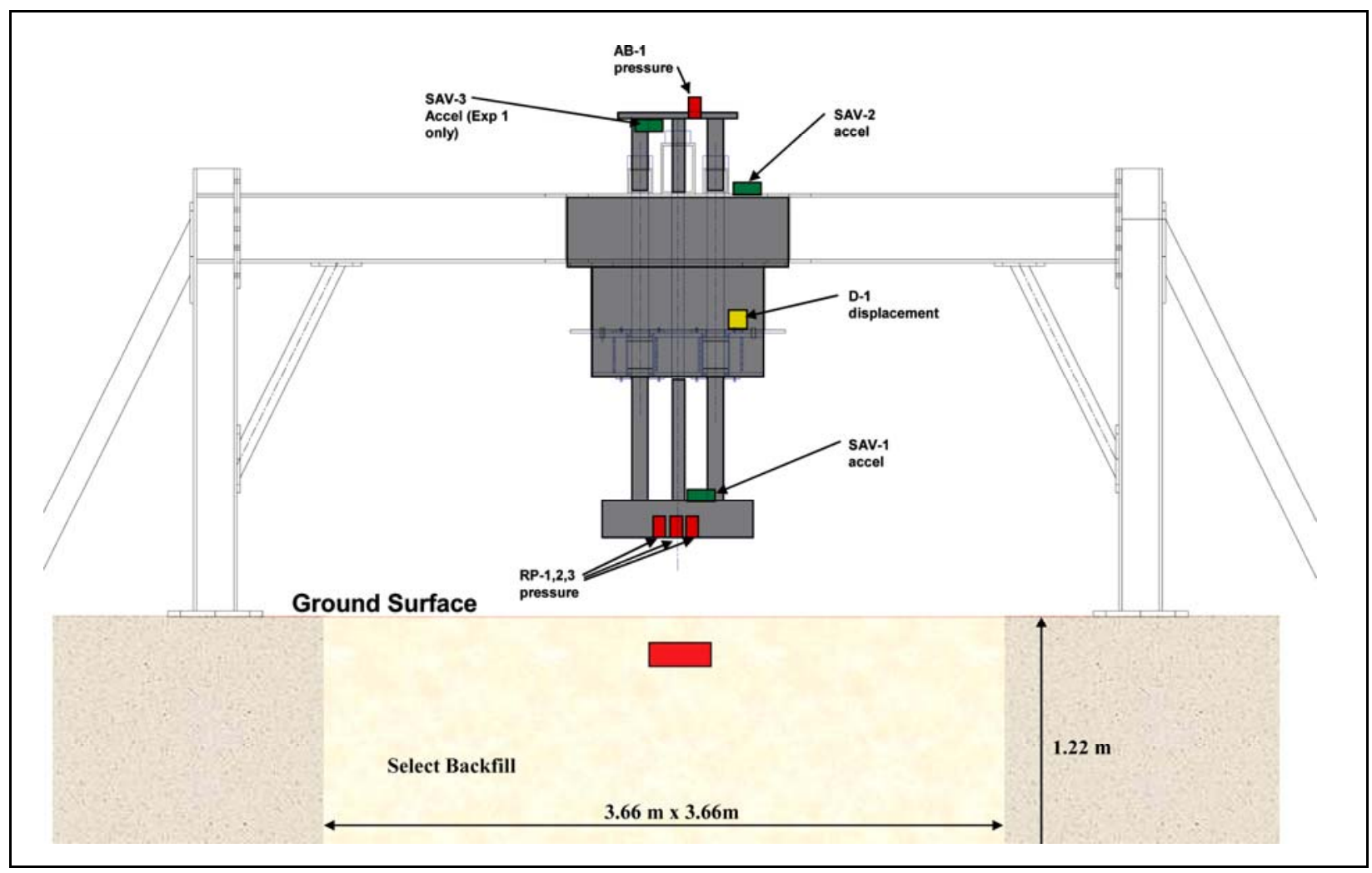

Figure 2.9. Instrumentation layout for the IMD experiments.

minimum of 6 in. during the checkout. The jack was then used to lift the piston mass at a constant rate while measuring the vertical force acting on the load cell. The drag or friction of the moving impulse system was then calculated by comparing the vertical force measured during motion to the actual static weight measured for the system. Because of the slow rate of lift used for this calibration, the loading captured was more representative of a static drag, which should be initially higher than the dynamic drag in the system. The use of the jack and load cell to calculate drag was also performed before each experiment to ensure that the drag in the system was at a minimum. In all the experiments, the calculated friction load was less than $4 \%$ of the total weight of the system.

As a dynamic check on the system, a test shot was performed using approximately $2.5 \mathrm{lb}$ of $\mathrm{C} 4$. This test verified the structural integrity of the system and the instrumentation settings. For this test, the $\mathrm{C} 4$ explosive charge was placed on top of a loosely compacted soil testbed. The IMD survived the blast without any damage, and all instrumentation worked as planned. During this test, the response of the structure was monitored for vibration and vertical displacement. The peak piston displacement of the 
IMD assembly was $2.5 \mathrm{in}$., and the total impulse load imparted to the piston was approximately $640 \mathrm{lb}$-sec.

After the test shot, an experiment was performed with a 5-lb C4 charge sitting on a concrete slab below the IMD (Figure 2.10). The standoff distance between the top of the charge and the bottom of the plate was 20 in. Prior to this experiment, pretest predictions were performed using the CTH code (McGlaun et al. 1990). The CTH code was selected because it has been proven to perform well for open-air blast events (Baylot and Bevins 2007; J oachim et al. 1999; Namburu et al. 1998). The goal was to compare the computational results with experimental results for a charge sitting on a rigid surface. Although it is still a very complex numerical simulation, it is greatly simplified and better validated when compared to a charge sitting on soil or buried in soil. The concrete slab was used instead of a soil surface to act more like a rigid surface. This test was performed with the fully instrumented IMD. The acceleration time-history and total displacement for the IMD piston assembly and the support structure were obtained from the test. These data were compared with the results of the $\mathrm{CTH}$ calculation and structural analysis of the support structure as a means of checking the validity of the IMD test data.

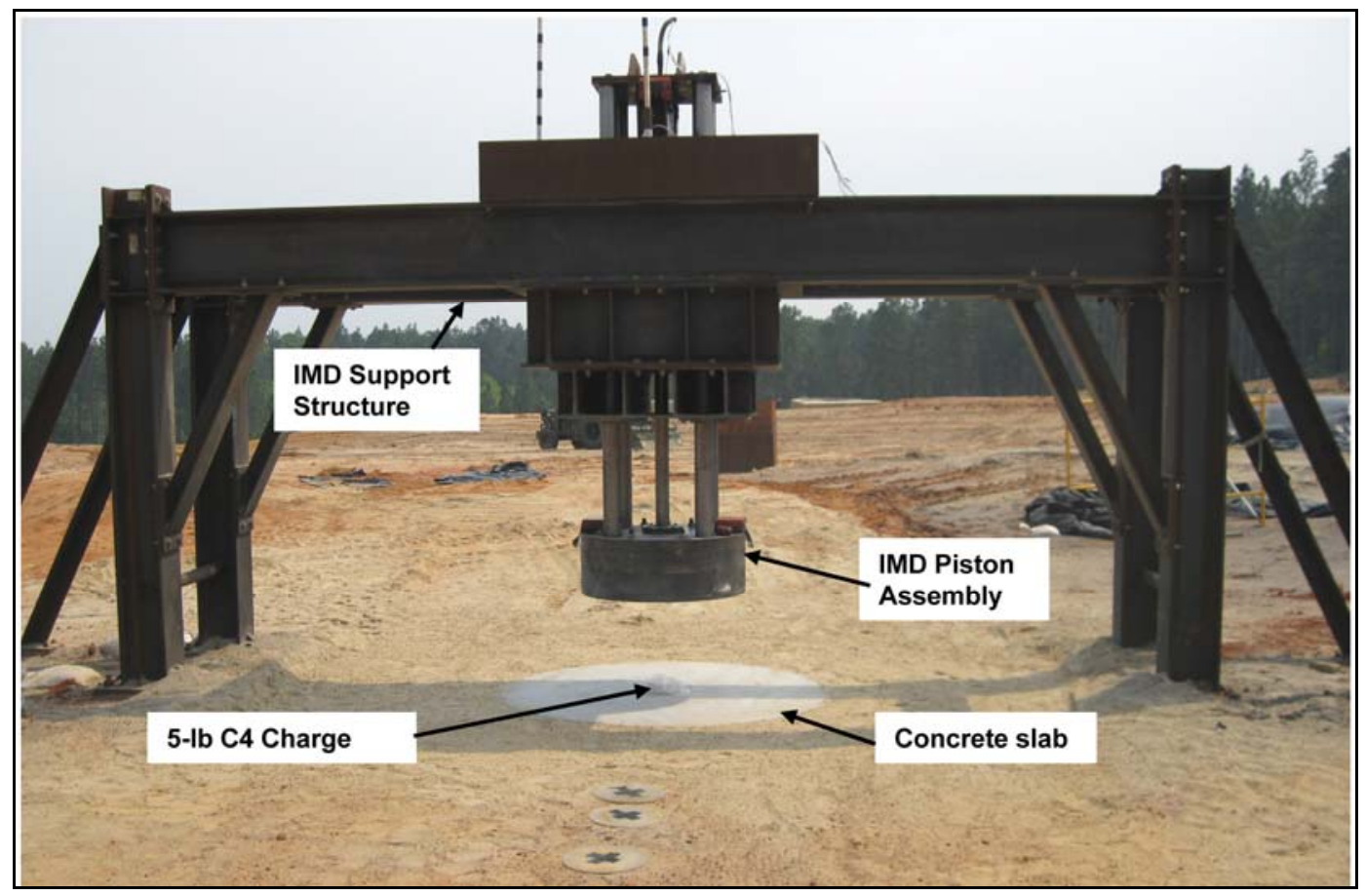

Figure 2.10. Pretest photograph of IMD experimental test layout. 
Figure 2.11a shows the displacement time-histories for the IMD piston assembly integrated from the accelerometer data, the displacement timehistory from the yo-yo gage, the total displacement measured from the scratch gage, and the computed displacement time-history from the results of the CTH calculation. The measured peak displacement compared reasonably well with the calculated peak displacement. The average total displacement using the acceleration data, the yo-yo gage, and the scratch gage was approximately $3.35 \mathrm{in}$., compared to a total displacement of $3.51 \mathrm{in}$. calculated from CTH. Due to the slow reaction time of the yo-yo gage, it does not record a reasonable time-history, but it does record an acceptable value of peak displacement. The slope of the displacement time-history integrated from the accelerometer data varied slightly from the CTH calculated displacement time-history. This is probably due to the high-frequency noise recorded in the front end of the acceleration record. The time of peak (TOP) displacement from the acceleration record compared reasonably well with the CTH calculation, with TOP of $125 \mathrm{msec}$ in the double-integrated acceleration record and 136 msec in the CTH calculation.

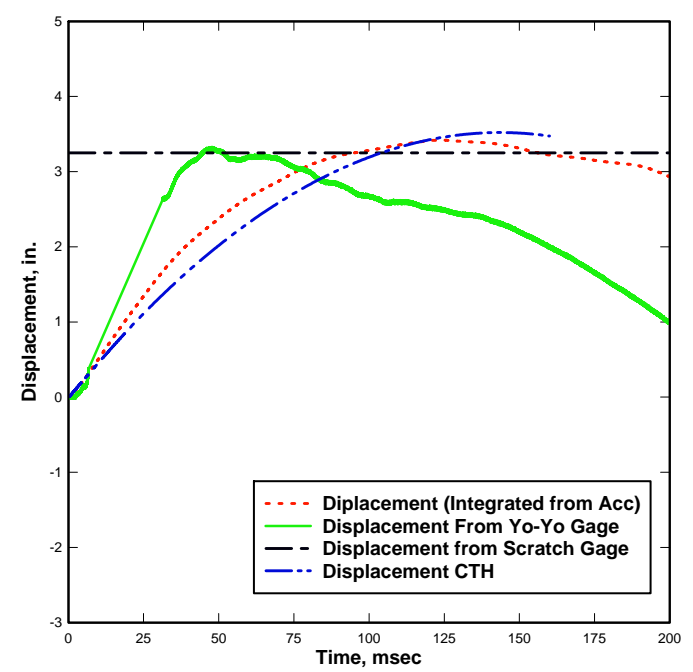

a. Displacement.

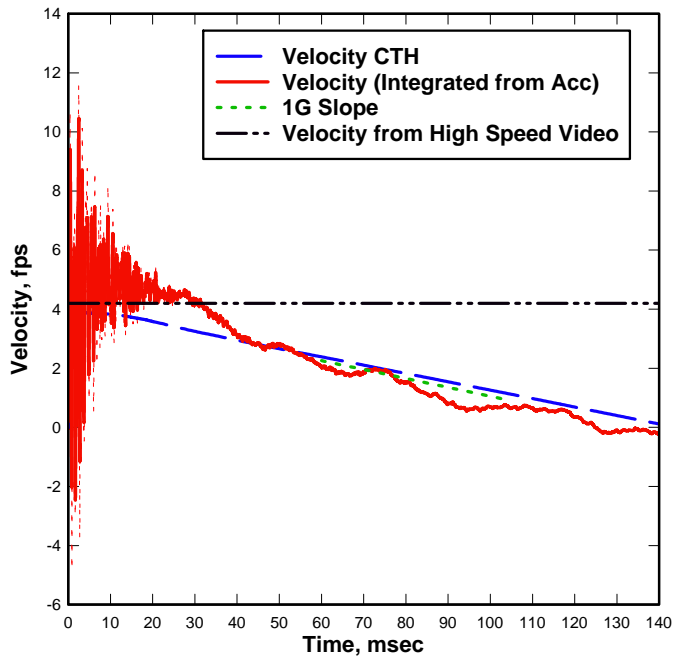

b. Velocity.

Figure 2.11. Measured and calculated displacements and velocities of the IMD piston assembly.

To monitor the movement of the support structure, an accelerometer was mounted on the structure near the center where the IMD piston assembly was supported. Figure 2.12 shows the velocity and displacement timehistories integrated from the support structure accelerometer data. 


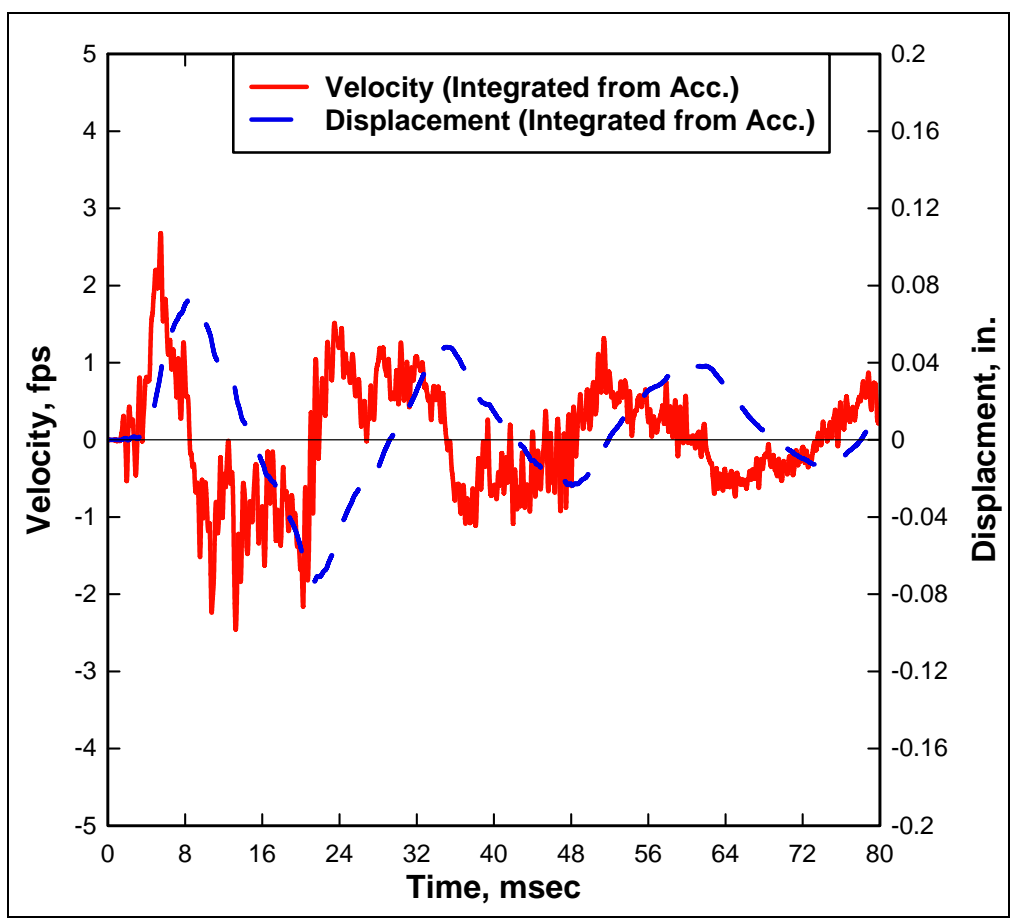

Figure 2.12. Measured velocity and displacement time-histories of the support structure.

The peak displacement recorded at the center of the support structure was approximately $0.08 \mathrm{in}$. with a natural frequency of the structure of approximately $14 \mathrm{msec}$. These measured results matched reasonably well with the structural design analysis. As described earlier, the design analysis considered a 10-lb charge on the surface, rather than a 5-lb charge; the analysis results were somewhat conservative. The peak displacement from the structural design analysis was approximately $0.15 \mathrm{in}$. with a natural frequency of approximately $15 \mathrm{msec}$. The maximum displacement in the support structure obtained from the test data was well below the design goal and is expected to have a negligible influence on the data collected with the IMD. 


\section{Description of Experiments}

\section{Experimental parameters}

Key factors that appear to affect the blast loading on a structure above a surface flush or shallow-buried charge include the standoff distance from the charge, the explosive charge size and mass, the charge shape, the type of explosive, depth of burial below the surface, and the surrounding soil properties and soil conditions (Williams et al. 2008). For the experiments conducted during this program, the primary focus was the effects of soil properties on the blast environment. Therefore, the experimental program was designed to reduce the effects of as many of the key parameters as possible. The key factors that were held constant included the charge mass, charge shape, charge geometry, explosive type, and standoff distance. Table 3.1 lists the experimental constants and the values selected for the experiments.

Table 3.1. Experimental constants.

\begin{tabular}{|l|l|}
\hline Description & Constant Value \\
\hline Charge Mass & $5 \mathrm{lb}$ \\
\hline Charge Shape & Cylinder (Aspect Ratio 3) \\
\hline Charge Geometry & 6.9 -in. diam x 2.3-in. height \\
\hline Explosive Type & $\mathrm{C} 4$ \\
\hline Standoff Distance & 20 in. (top of charge to measured surface) \\
\hline
\end{tabular}

The primary variables for the experimental program included the soil type in which the charge was buried and the depth of burial. The experiments were conducted using three different soil types that bound the effects of soil on the blast environments. The depth of burial selected was based on common location for buried mines. Based on the two variables selected, a test matrix was developed in an attempt to gather as much experimental data as possible with the funds available. Table 3.2 shows the experimental matrix that was developed and the variables selected for each experiment. 
Table 3.2. Experimental matrix.

\begin{tabular}{|c|c|c|c|c|c|c|}
\hline $\begin{array}{l}\text { Test } \\
\text { Number }\end{array}$ & $\begin{array}{l}\text { Charge } \\
\text { Mass, Ib }\end{array}$ & Soil Type & $\begin{array}{l}\text { Charge } \\
\text { Position }\end{array}$ & $\begin{array}{l}\text { Depth of } \\
\text { Burial, in. }\end{array}$ & $\begin{array}{l}\text { Target } \\
\text { Standoff, in. }\end{array}$ & $\begin{array}{l}\text { Test } \\
\text { Configuration }\end{array}$ \\
\hline BM-I-01 & 5 & SM & TSA & - & 20 & $\begin{array}{l}\text { Side-on } \\
\text { Overpressure }\end{array}$ \\
\hline BM-I-02 & 5 & SM & TSB & - & 20 & $\begin{array}{l}\text { Side-on } \\
\text { Overpressure }\end{array}$ \\
\hline BM-I-03 & 5 & SM & Buried & 4 & 20 & $\begin{array}{l}\text { Side-on } \\
\text { Overpressure }\end{array}$ \\
\hline BM-I-04 & 5 & SM & TSA & - & 20 & IMD \\
\hline BM-I-05 & 5 & SM & Buried & 4 & 20 & IMD \\
\hline BM-C-01 & 5 & $\mathrm{CL}$ & TSA & - & 20 & $\begin{array}{l}\text { Side-on } \\
\text { Overpressure }\end{array}$ \\
\hline BM-C-02 & 5 & $\mathrm{CL}$ & TSB & - & 20 & \begin{tabular}{|l} 
Side-on \\
Overpressure
\end{tabular} \\
\hline BM-C-03 & 5 & $\mathrm{CL}$ & Buried & 4 & 20 & $\begin{array}{l}\text { Side-on } \\
\text { Overpressure }\end{array}$ \\
\hline BM-C-04 & 5 & $C L$ & TSA & - & 20 & IMD \\
\hline BM-C-05 & 5 & $C L$ & Buried & 4 & 20 & IMD \\
\hline BM-S-01 & 5 & SP & TSA & - & 20 & $\begin{array}{l}\text { Side-on } \\
\text { Overpressure }\end{array}$ \\
\hline BM-S-02 & 5 & SP & TSB & - & 20 & \begin{tabular}{|l} 
Side-on \\
Overpressure
\end{tabular} \\
\hline BM-S-03 & 5 & SP & Buried & 4 & 20 & $\begin{array}{l}\text { Side-on } \\
\text { Overpressure }\end{array}$ \\
\hline BM-S-04 & 5 & SP & TSA & - & 20 & IMD \\
\hline BM-S-05 & 5 & SP & Buried & 4 & 20 & IMD \\
\hline
\end{tabular}

Notes:

Soil Type: CL for Sandy Clay, SM for Silty Sand, and SP for Poorly Graded Sand per the Unified Soil Classification System. Charge Positions: TSA for Tangent Surface Above and TSB Tangent Surface Below.

Depth of burial is measured from top of charge to ground surface.

Target standoff is measured from top of charge to bottom of IMD or centerline of side-on overpressure gages.

\section{Experimental configuration}

The test site was located at Fort Polk, LA, on Range 19. The experimental configuration consisted of three test series, each conducted on a different soil type. The three soil types selected included a silty sand or intermediate soil for the first test series, a wet clay soil for the second test series, and a dry sand soil for the third test series. Each of the three test series consisted 
of five experiments. Two of the experiments were conducted using the IMD in order to measure total impulse imparted to the plate-piston assembly, referred to as the IMD layout. The layout for the two IMD experiments consisted of a charge detonated on the surface of the testbed and a charge detonated at a depth of $4 \mathrm{in}$. below the surface of the testbed. For both experiments the standoff distance between the top of the charge and the face of the IMD was held constant at 20 in. The geometry and configuration of the two IMD experiments are presented in Figure 3.1.

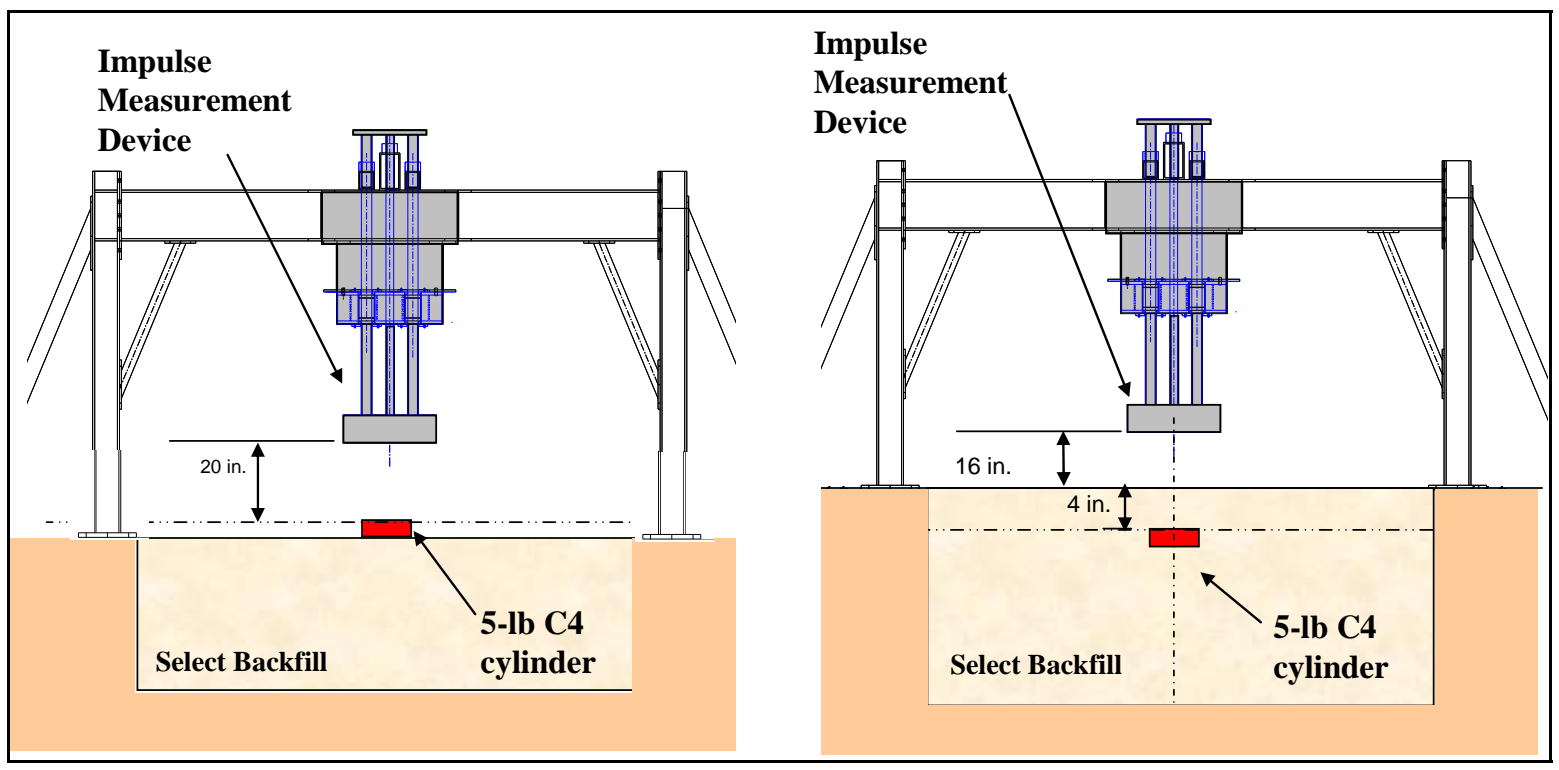

Figure 3.1. Layout for the IMD experiments.

The three remaining experiments in each test series were conducted using a series of five side-on overpressure gages above the testbed surface, referred to as side-on layout. The layout for the three side-on experiments consisted of one with the charge detonated on the surface, i.e., tangent surface above (TSA); one with the charge buried with its top surface flush with the top surface of the testbed, i.e., tangent surface below (TSB); and one with the charge detonated at a depth of $4 \mathrm{in}$. below the surface of the testbed. For all three experiments, the standoff distance between the top of the charge and the vertical elevation of the side-on gages was held constant at $20 \mathrm{in}$. The side-on overpressure gages were located with one gage directly above the charge, two with a horizontal offset of 18 in., and two with a horizontal offset of $36 \mathrm{in}$. All five gages were located at the same vertical elevation above the testbed that matched the standoff used for the IMD. Figure 3.2 shows a detailed layout of the side-on overpressure gages located relative to the charge and the geometry and configuration of the three side-on overpressure experiments. 


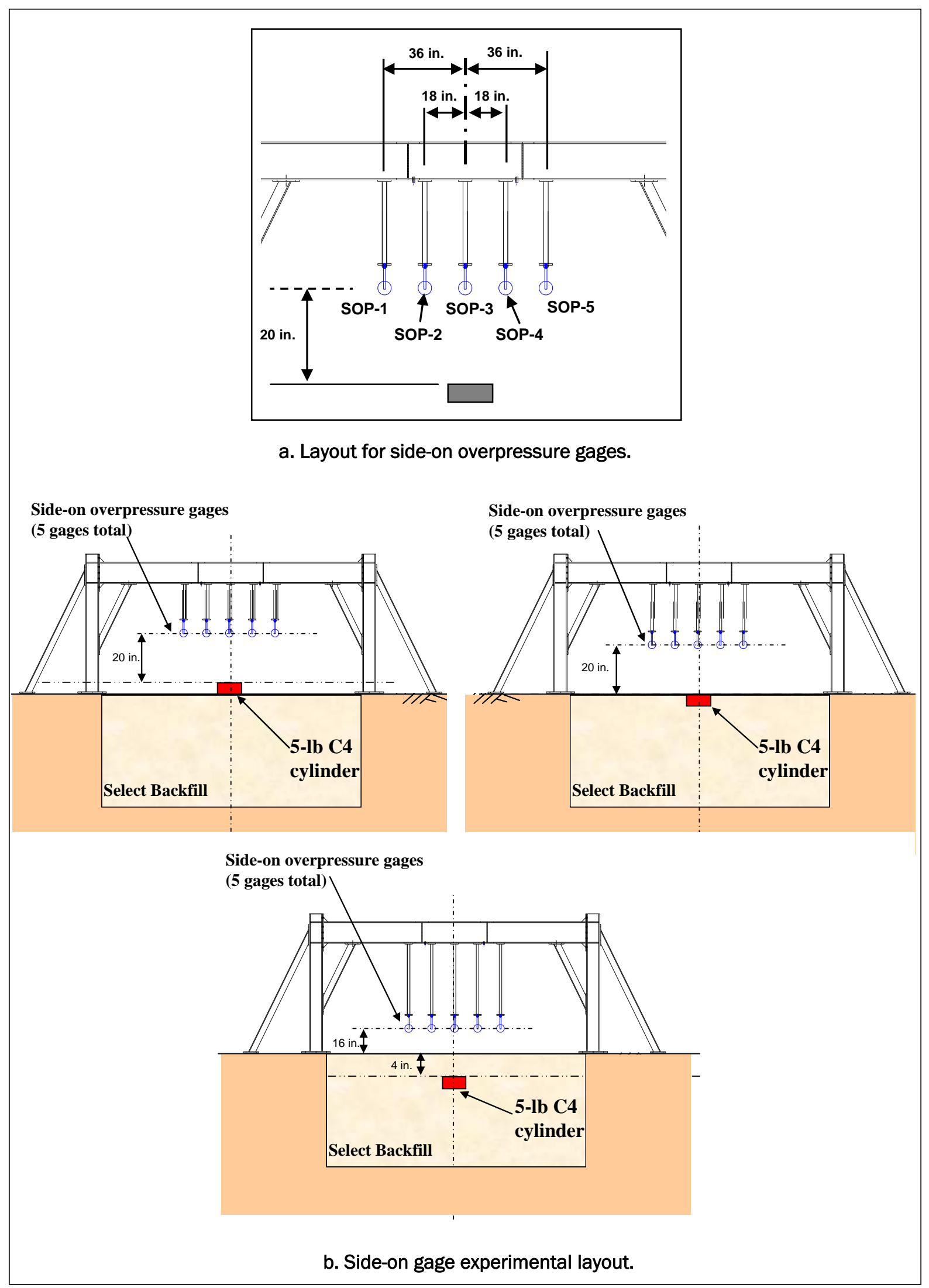

Figure 3.2. Layout for the side-on overpressure gages and the experiment layout. 


\section{Explosive charge}

In the design of the experiments, several charge configurations were considered. The type of explosive, mass of explosive, and geometry of explosive were all considered key parameters in the experimental layout. For the type of explosive, Composition $\mathrm{C} 4$ was chosen, because the detonation properties for this explosive are readily available and have been validated by numerous experiments and analyses. The mass of explosive was limited by the capability of the IMD. A charge mass of $10 \mathrm{lb}$ was first considered based on surface detonation and a standoff distance of $20 \mathrm{in}$. The explosive mass was reduced to $5 \mathrm{lb}$ after a review of recent experimental results indicating that the impulse created by a buried charge could be as much as 2 to 3 times that of the same charge mass sitting on the surface. The two geometries considered for the experiments were spherical shape and a cylindrical shape. The spherical charge provides a more symmetric loading around the charge, especially at close proximity to the charge, when compared to a cylinder charge. However, after reviewing literature, it was clear that a large number of buried mines in circulation around the world have a current geometry consisting of no more than $30 \mathrm{lb}$ of explosive and are usually pancake-shape or cylindrically shaped with a thickness of 1/ 3 to 1/ 4 the diameter (Wenzel and Esparza 1972). The final charge geometry chosen for the experiments consisted of a 5-lb cylindrical charge with a height of $2.30 \mathrm{in}$. and a diameter of $6.90 \mathrm{in}$. The charge was created by packing $\mathrm{C} 4$ into a plastic form. A picture of the form is shown in Figure 3.3. The charge was detonated using a Reynolds FS-17 firing system and a RISI RP-87 exploding bridge wire (EBW) detonator placed at the bottom center of the charge. This FS-17 firing system is designed specifically for EBW detonators.

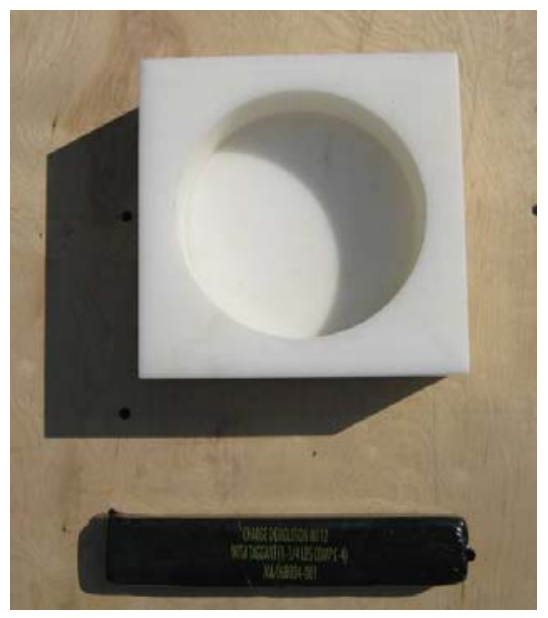

Figure 3.3. The 5-lb C4 charge mold. 
The standoff distance for the experiments was selected based on a range of common standoff distances for structures of primary concern with buried mines. The common standoff distance investigated for these structures ranged from $16 \mathrm{in}$. to $20 \mathrm{in}$. above the surface of the testbed. The final standoff distance selected for these experiments was $20 \mathrm{in}$. from the top of the charge to the bottom of the IMD impact plate or centerline elevation of the side-on overpressure gages. Measurements at this close proximity can be very problematic due to high pressure levels and the potential detrimental effects of detonation products on instrumentation.

The charge location, relative to the ground surface, was selected to account for the common locations of buried mines. Current practice in mine warfare calls for burial of pressure-fused mines with 2 to $4 \mathrm{in}$. of soil coverage above the top of the mine. Depths much deeper than 4 in. are not common because of the emplacement time and the shock absorbing characteristics of soil (Wenzel and Esparza 1972). The first location selected for the experiments was on the surface or tangent surface above. The second location selected was the charge buried 4 in. below the surface, measured from the top of charge to the top of ground surface. The third and final location selected was with the charge buried such that the top of charge was flush with the ground surface or tangent surface below. All three locations were used in the three soils selected. The first and second location, TSB and buried, were both tested using the IMD and the side-on pressure gages. The third location, TSA, was only tested with the side-on pressure gage arrangement.

\section{Soil backfill materials and testbed construction}

Results of grain-size distribution and classification tests (USACE 1980) for the three backfill materials are shown in Figure 3.4. The intermediate soil classified according to the Unified Soil Classification System (U.S. Army Engineer Waterways Experiment Station 1960) as a silty sand (SM) with a specific gravity of soil solids of 2.69; the clay material classified as a sandy clay (CL) with a specific gravity of 2.72; and the dry sand material classified as a poorly graded sand (SP) with a specific gravity of 2.67. Results of Proctor compaction tests (USACE 1980) for the silty sand and sandy clay materials are shown in Figures 3.5 and 3.6, respectively. Also shown in these figures are lines representing zero air voids, the bounding specifications for water content and dry density for backfill placement, and the average values of water content and dry density obtained from each 


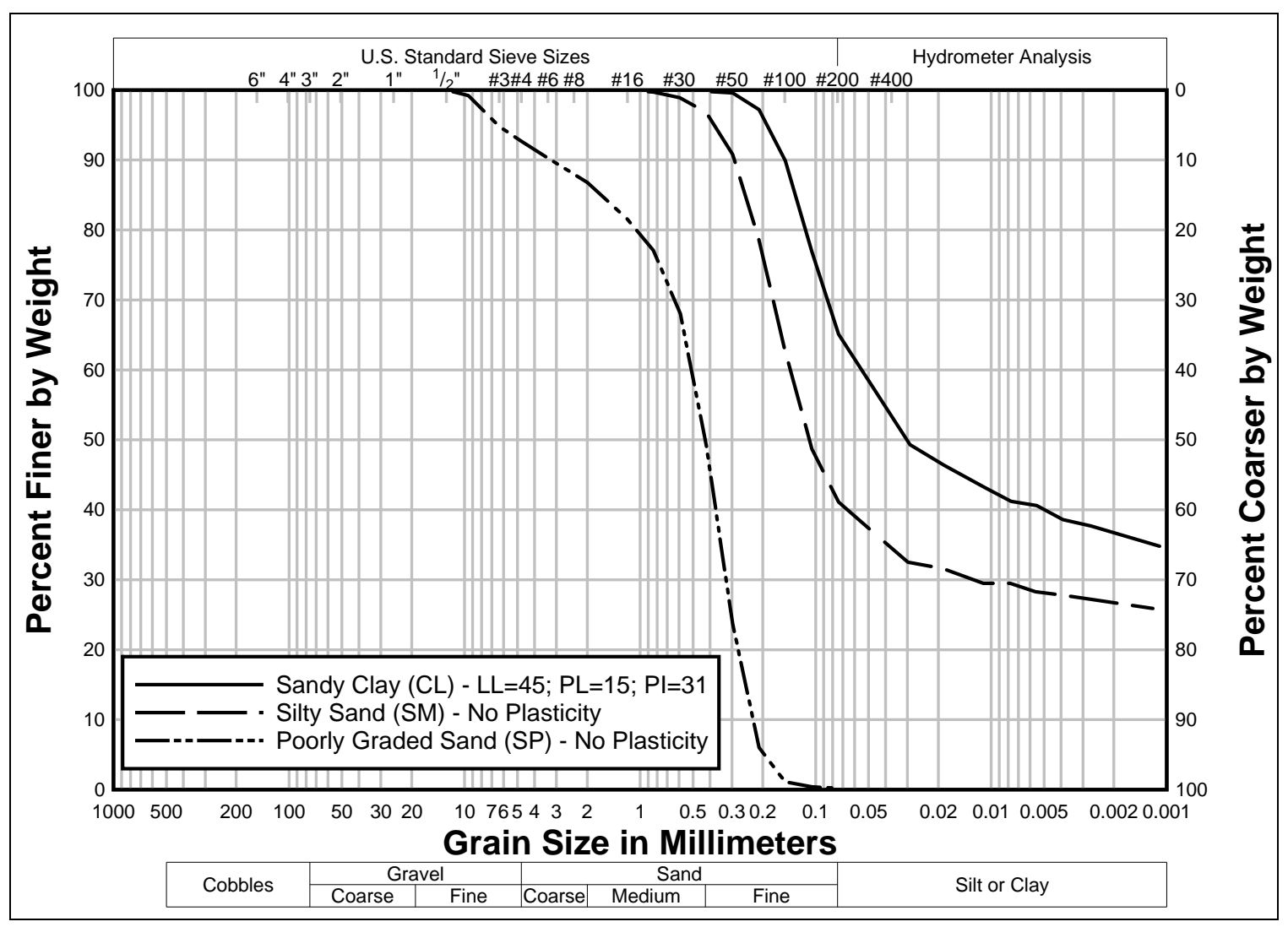

Figure 3.4. Grain-size distributions and Atterberg limits for backfill soils.

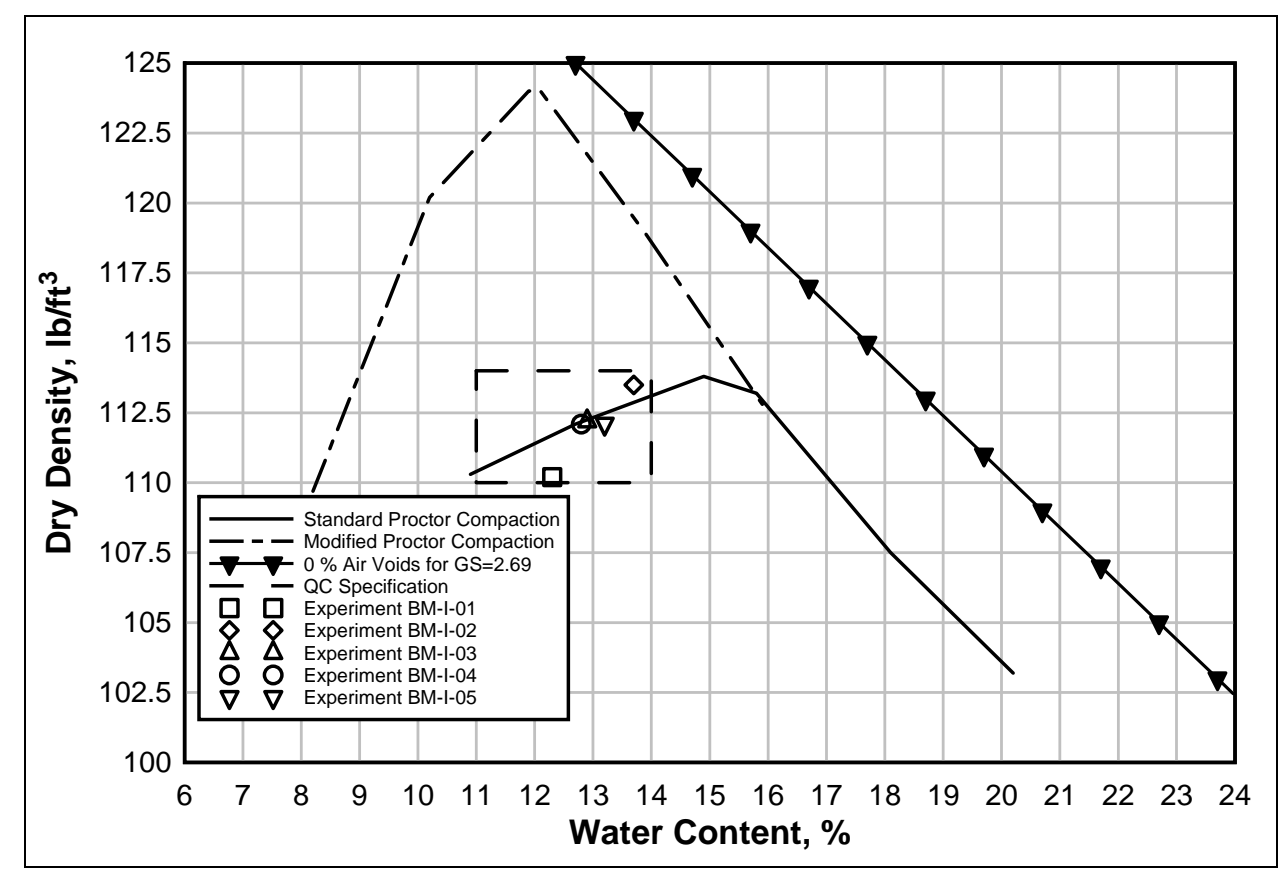

Figure 3.5. Summary of QC specifications and test results for silty sand testbed. 


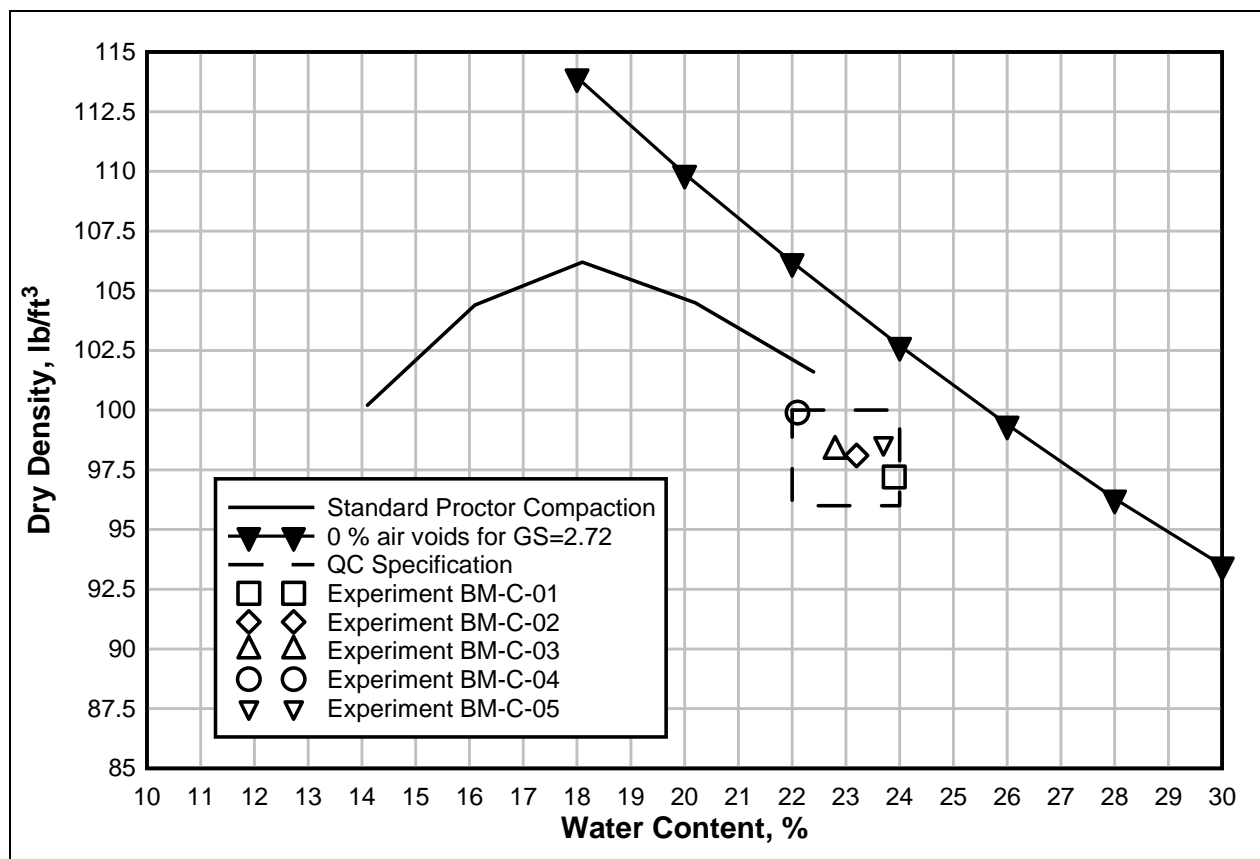

Figure 3.6. Summary of QC specifications and test results for clay testbed.

experiment. Results of maximum relative density tests (USACE 1980) conducted on samples with different water contents for the sand material are shown in Figures 3.7 along with the bounding specifications for water content and dry density for backfill placement and the average values of water content and dry density obtained from each of these experiments. The basis for the selection of each backfill material and their respective target as-placed values of water content and dry density are documented in a companion report along with the results of all quality control tests conducted on the backfill materials.

The testbeds were constructed in an excavation surrounded by the native soil and located below the IMD side-on gage support structure. The testbed size was approximately $12 \mathrm{ft}$ by $12 \mathrm{ft}$ by $4 \mathrm{ft}, 6 \mathrm{in}$. deep. The size was selected to minimize the boundary effects between the native soil and the select backfill. The testbed was initially excavated to the desired size and depth. A plastic liner was then laid down over the native soil before the backfill was placed to avoid cross contamination between the native soil and selected backfill.

The placement and compaction of the intermediate soil and clay backfills were performed in a similar manner. The backfill was placed in approximately 6-in.-thick lifts and compacted with a minimum of three passes of a pneumatic compactor, referred to as a "jumping jack" compactor. In each 


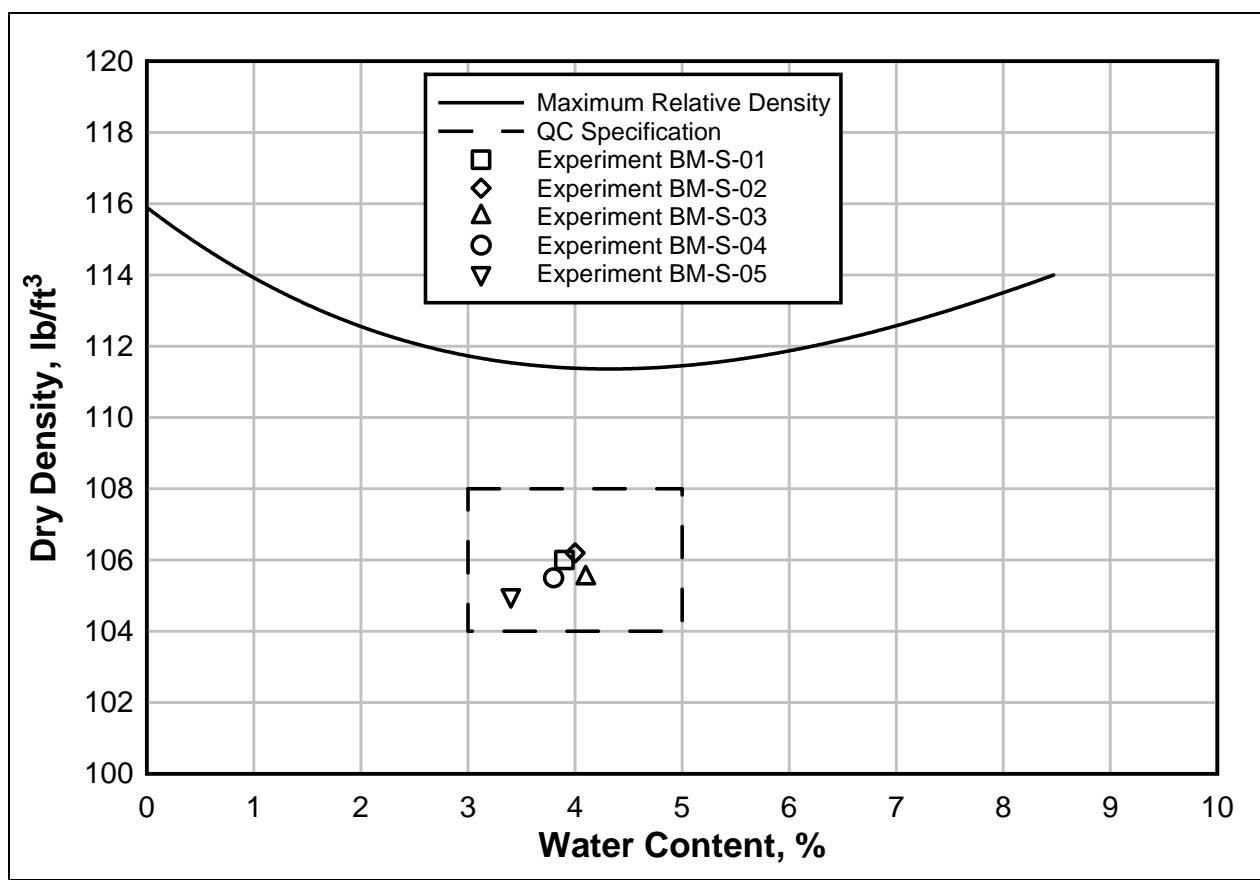

Figure 3.7. Summary of QC specifications and test results for dry sand testbed.

lift, the quality control inspector made three to four measurements of wet density and water content with a nuclear moisture-density gage and also obtained two samples of the material from the mid-depth for determination of microwave water contents and four samples for standard oven-dry water contents. The microwave water content measurement was taken to ensure that the water content of the material was within the target specification before proceeding to the next lift. The oven-dry water contents are reported as the final water contents. An elevation survey was performed at the top of each lift. Determination of acceptance or rejection of each lift was based on the calculated values of dry density and water content. Adjustments were made to the lift when variations outside the specifications were found. A representative bulk sample of material was retained from each lift for use in subsequent grain-size distribution and classification tests.

The placement and compaction of the sand backfill was slightly different from that for the intermediate soil and clay. The backfill was placed in approximately 8-in.-thick lifts and compacted with a minimum of three passes of a vibratory compactor, referred to as a "plate" compactor. The quality control testing was similar to that of the intermediate soil and clay material. After the backfill was placed to the desired elevation, the testbed was covered with a plastic tarp to minimize any change in the moisture content as the remaining experimental pre-work was completed. 


\section{Charge placement and arming}

The charge was placed at three locations during the experimental series, i.e., tangent surface above or TSA, buried with top surface flush (TSB), and buried 4-in. from top of charge to top of ground surface. For the buried and TSB testbeds, a section of plastic pipe was placed in the backfill and extended from the charge location to the free surface. After the backfill was complete, the 5-lb C4 charge was constructed by measuring the desired weight of $\mathrm{C} 4$ explosive and forming it into the plastic mold. Plastic wrap was used to line the mold to ensure that the charge could be removed and would maintain its shape. The pipe was then removed from the testbed and the charge was lowered into the testbed to the correct location. The charge position was verified against the IMD or side-on gage elevation to ensure that the 20 -in. standoff was achieved. The void space above the buried charge was backfilled with soil to the correct grade elevation of the testbed. The soil above and around the charge was carefully packed using a weighted plate to achieve the desired density. For the TSA layout, the final testbed surface was brought to correct elevation and verified off the bottom of the IMD impact plate. The charge was then placed on the ground surface at the correct location centered under the IMD impact plates. Figure 3.8 shows the placement of a charge for a TSA experimental layout.

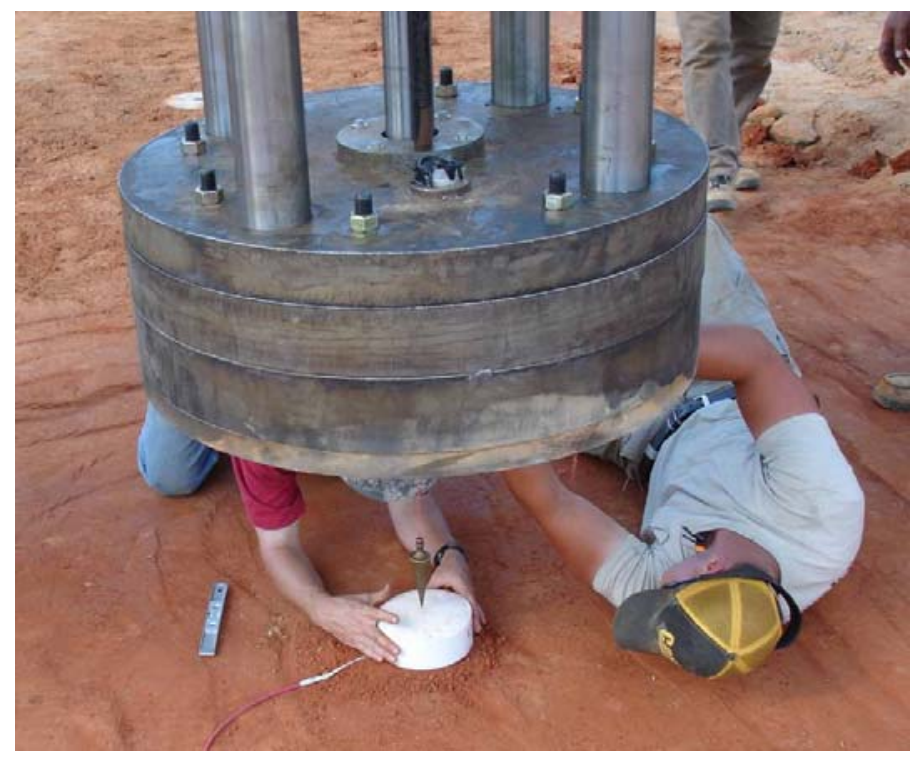

Figure 3.8. The charge being placed into position. 


\section{Data collection}

\section{Pretest}

During preparation for the experiment, pretest data were collected and recorded for comparison with the posttest data. For all the experiments, detailed photographs and surveys of the soil testbed were obtained and recorded. Backfill placement elevations were recorded for each lift. As the instrumentation was placed in the backfill, the elevation and radius from ground zero (GZ) were also surveyed and recorded. After the backfill was completed and prior to installing the charge, surveyed cross sections were taken along the 0- to 180-deg and the 90- to 270-deg axes (shown in Figure 3.9) relative to the GZ location. Cross sections were used for comparison with crater profiles along the same lines after detonation. After the surveys were completed, the charge was placed into position, and the final measurements were taken to ensure the correct standoff existed between the top of the charge and bottom of the IMD plate or centerline of the side-on gages.

\section{Posttest}

Posttest data collection began as soon as the test site was cleared for entry. Photographs of the testbed were taken, and surveys across the testbed were conducted. The surveys were along the same lines as recorded pretest. After the surveys were completed, the diameter of the crater created in the soil was measured at the ground surface, at mid-depth, and at the bottom of the crater. When the IMD was used, the final resting elevation of the impact plate was recorded to compare with the instrumentation data.

\section{High-speed video}

To capture detailed time and distance data on displacement of the IMD piston assembly, high-speed digital cameras were utilized. For each experiment, the layout consisted of two high-speed cameras focusing on the IMD. One camera was a front view of the device, and the second was a side view of the device. Figure 3.9 shows a plan view of the experimental layout and the locations of the cameras relative to the test structure. Both cameras were mounted on heavy duty tripods placed inside steel bunkers. The bunkers contained view portals covered by clear protective plastic to reduce the risk of damage to the cameras. A soil berm was also constructed 
around the front of the bunkers to help minimize the effects of the blast on the high-speed video equipment.

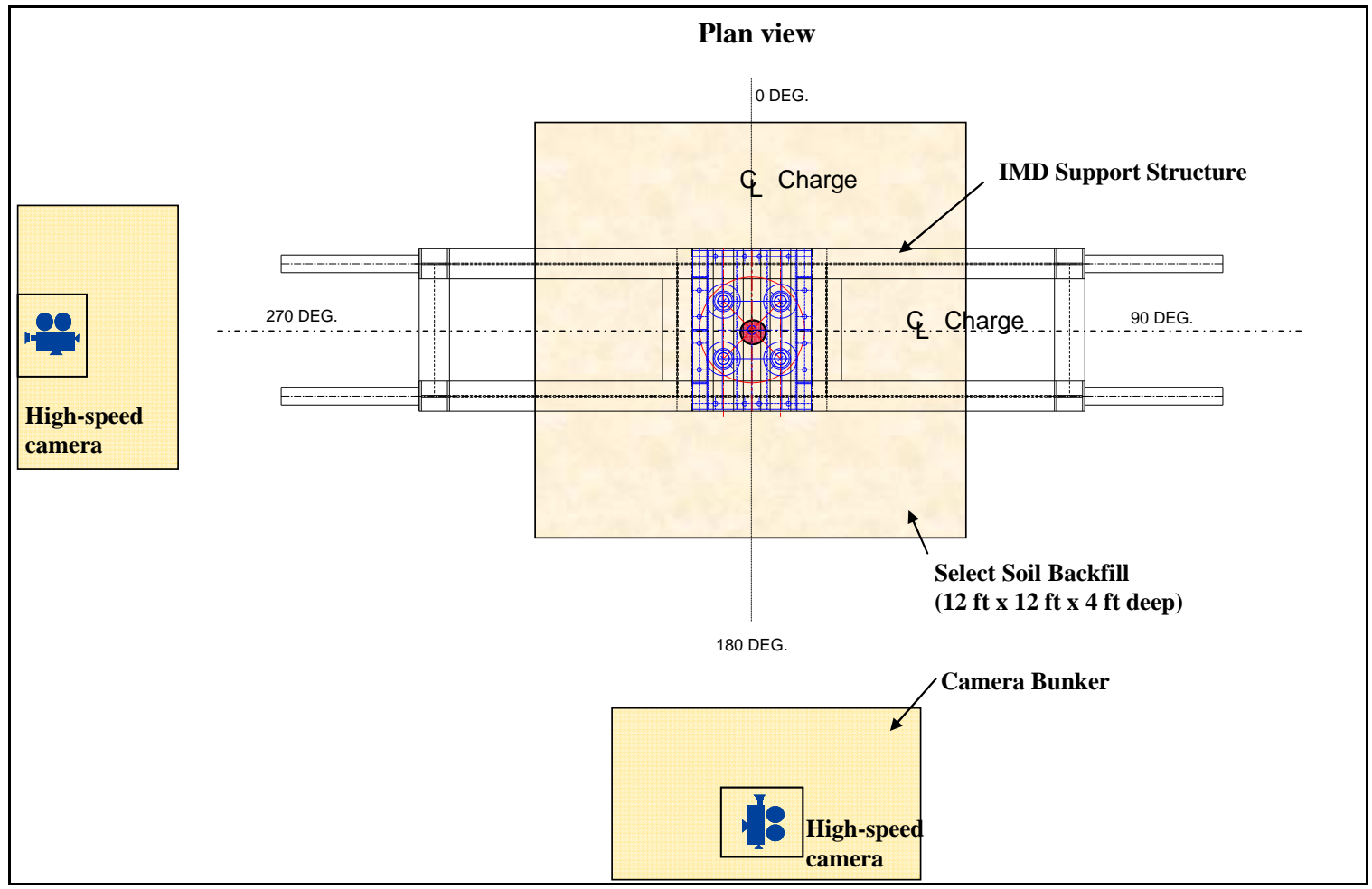

Figure 3.9. Experimental layout showing high-speed camera locations.

The cameras used during the experiments were two Phantom V7.3 digital cameras (Vision Research 2009) as shown in Figure 3.10. The 85mm and $50 \mathrm{~mm}$ lens were used to achieve the desired view and focus. The cameras were operated at speeds of 2000 to 5000 frames per second. The selection of the frame rate, exposure time, and resolution varied and was dependent on the lighting conditions at the time of the shot and the field of view selected for each shot. 


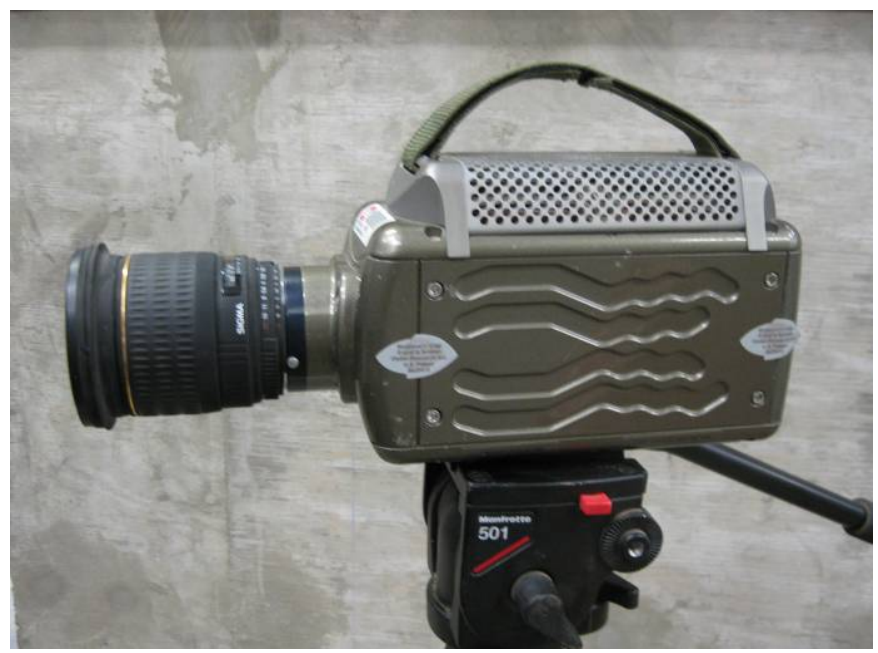

Figure 3.10. Phantom V7.3 high-speed digital camera.

The data from the camera were stored in the camera memory and then transferred to a laptop computer. The camera contained 8 gigabytes of memory and could capture over 10,000 pictures at full resolution. The cameras were triggered during the experiments by tying a closure system (switch) into the Reynolds firing unit.

Once the high-speed digital video was recorded and transmitted to a laptop computer, the data were analyzed using a proprietary software distributed by Phantom Camera Control Version: 9.0.640.0-C PhCon:640 (Vision Research 2009). The software has the ability to zoom and filter imagery to improve and sharpen the picture. The software also provides detailed information about the time step for each frame and the resolution used during the recording. A screen shot showing the software used to analyze the high-speed videos is shown in Figure 3.11. 


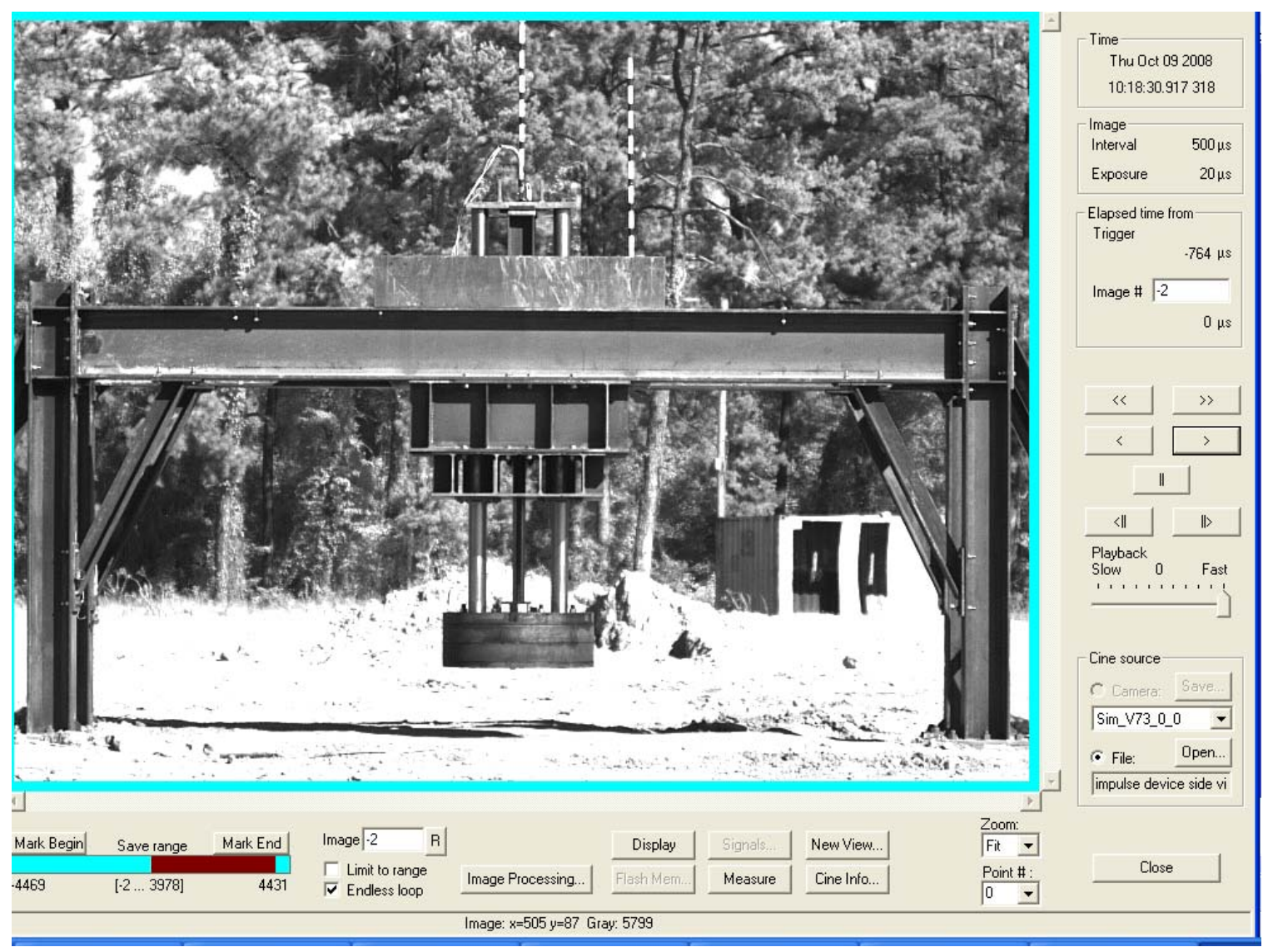

Figure 3.11. Screen view from Phantom camera control software. 
For the analysis of the IMD, the software allows the user to record movement, scale distance from a reference, and determine angular and linear acceleration and velocity. To assist in the analysis, reference poles with known graduated markings were placed on the IMD support frame and were visible from both camera views. The primary goal was to capture both the initial peak velocity and total displacement of the IMD mass piston assembly during the experiments. To reduce user error and improve accuracy, the video was analyzed multiple times using different reference points. From the analysis, the average initial peak velocity and peak displacement were obtained for each shot. In some cases, the total displacement obtained in the video for the mass piston was obstructed from view by dust and soil debris. In those cases, other instrumentation on the IMD was used to obtain the total displacement, such as the scratch gage, yo-yo gage, and accelerometers.

\section{Instrumentation}

The experiments were instrumented to capture key results as a function of time. The instrumentation consisted of buried ground shock instrumentation, aboveground blast pressure instrumentation, and IMD instrumentation. The amount and type of the instrumentation varied depending on the type of experiment conducted and the charge location. The experiments were separated into two categories based on the use of the IMD or the use of side-on overpressure gages above the testbed. Table 3.3 provides a summary of the instrumentation used in the IMD test configuration, and Table 3.4 provides a summary of the instrumentation used in the side-on overpressure test configuration. The two tables provide the gage number assigned to the particular gage location, gage type or manufacturer used, gage location, approximate range (upper limit capability) of the gage, and the gage mount used in the experiment.

\section{Ground shock instrumentation}

Ground shock instrumentation was installed in all the experiments with the charge buried 4 in. below the surface. The instrumentation in the backfill consisted of three free-field soil stress gages and three accelerometers. The accelerometers and soil stress gages were installed in each backfill to monitor the motion and stress due to the detonation of the explosive charge. The gages were identified in Tables 3.3 and 3.4 by a two-part number, i.e., (1) SR indicates a free-field soil stress gage, and AR indicates a free-field soil accelerometer, and (2) the gage number. The gages were 
Table 3.3. Instrumentation summary for IMD configuration.

\begin{tabular}{|c|c|c|c|c|c|}
\hline \multicolumn{6}{|c|}{ IMD Experiments } \\
\hline Measurement & Gage No. & Gage Type & Location & Range & Mount \\
\hline $\begin{array}{l}\text { Ground Surface } \\
\text { Overpressure }\end{array}$ & OP - 1 & Kulite Overpressure & $8 \mathrm{ft}$ from GZ & $50 \mathrm{psi}$ & XTS \\
\hline $\begin{array}{l}\text { Ground Surface } \\
\text { Overpressure }\end{array}$ & OP - 2 & Kulite Overpressure & $10 \mathrm{ft}$ from GZ & 25 psi & XTS \\
\hline $\begin{array}{l}\text { Ground Surface } \\
\text { Overpressure }\end{array}$ & OP - 3 & Kulite Overpressure & $14 \mathrm{ft}$ from GZ & $10 \mathrm{psi}$ & XTS \\
\hline $\begin{array}{l}\text { Reflected } \\
\text { Pressure on IMD }\end{array}$ & RP - 1 & PCB Reflective Pressure & $\begin{array}{l}\text { Bottom of IMD } \\
\text { Piston }\end{array}$ & $100,000 \mathrm{psi}$ & $\begin{array}{l}\text { Bare with Tape } \\
\text { and Grease } \\
\text { Covering }\end{array}$ \\
\hline $\begin{array}{l}\text { Reflected } \\
\text { Pressure on IMD }\end{array}$ & RP - 2 & Kulite Reflective Pressure & $\begin{array}{l}\text { Bottom of IMD } \\
\text { Piston }\end{array}$ & 30,000 psi & Debris Shield \\
\hline $\begin{array}{l}\text { Reflected } \\
\text { Pressure on IMD }\end{array}$ & RP - 3 & Kulite Reflective Pressure & $\begin{array}{l}\text { Bottom of IMD } \\
\text { Piston }\end{array}$ & 30,000 psi & (2) Debris Shields \\
\hline IMD Acceleration & SAV - 1 & Endevco Accelerometer & Top of IMD Piston & $6 k$ g's & On Steel Plate \\
\hline IMD Acceleration & SAV - 2 & Endevco Accelerometer & $\begin{array}{l}\text { Top of Support } \\
\text { Frame }\end{array}$ & $6 k$ g's & On Steel Plate \\
\hline Displacement & $D-1$ & $\begin{array}{l}\text { Cable Extension Position } \\
\text { Transducer }\end{array}$ & \begin{tabular}{|l} 
Inside IMD \\
Enclosure
\end{tabular} & 30 inches & Steel mount \\
\hline $\begin{array}{l}\text { Ground Shock } \\
\text { Acceleration }\end{array}$ & AR - 1 & Endevco Accelerometer & $\begin{array}{l}\text { Soil, 3-ft range, C.L. } \\
\text { Charge Depth }\end{array}$ & $60 \mathrm{k} \mathrm{g's}$ & HiFi Can \\
\hline $\begin{array}{l}\text { Ground Shock } \\
\text { Acceleration }\end{array}$ & AR - 2 & Endevco Accelerometer & $\begin{array}{l}\text { Soil, 4-ft range, C.L. } \\
\text { Charge Depth }\end{array}$ & 20k g's & HiFi Can \\
\hline $\begin{array}{l}\text { Ground Shock } \\
\text { Acceleration }\end{array}$ & AR - 3 & Endevco Accelerometer & $\begin{array}{l}\text { Soil, 5-ft range, C.L. } \\
\text { Charge Depth }\end{array}$ & 20k g's & HiFi Can \\
\hline $\begin{array}{l}\text { Ground Shock } \\
\text { Stress }\end{array}$ & SR -1 & Kulite Radial Soil Stress & $\begin{array}{l}\text { Soil, 3-ft range, C.L. } \\
\text { Charge Depth }\end{array}$ & $\begin{array}{l}3,000 \text { or } \\
4,000 \text { psi }\end{array}$ & LRSW Mount \\
\hline $\begin{array}{l}\text { Ground Shock } \\
\text { Stress }\end{array}$ & SR - 2 & Kulite Radial Soil Stress & $\begin{array}{l}\text { Soil, 4-ft range, C.L. } \\
\text { Charge Depth }\end{array}$ & $\begin{array}{l}3,000 \text { or } \\
4,000 \text { psi }\end{array}$ & LRSW Mount \\
\hline $\begin{array}{l}\text { Ground Shock } \\
\text { Stress }\end{array}$ & SR - 3 & Kulite Radial Soil Stress & $\begin{array}{l}\text { Soil, 5-ft range, C.L. } \\
\text { Charge Depth }\end{array}$ & $\begin{array}{l}3,000 \text { or } \\
4,000 \text { psi }\end{array}$ & LRSW Mount \\
\hline
\end{tabular}


Table 3.4. Instrumentation summary for side-on pressure configuration.

\begin{tabular}{|c|c|c|c|c|c|}
\hline \multicolumn{6}{|c|}{ Side-on Pressure Experiment } \\
\hline Measurement & $\begin{array}{l}\text { Gage } \\
\text { No. }\end{array}$ & Gage Type & Location & Range & Mount \\
\hline $\begin{array}{l}\text { Ground Surface } \\
\text { Overpressure }\end{array}$ & OP - 1 & Kulite Overpressure & $8 \mathrm{ft}$ from GZ & 50 psi & XTS \\
\hline $\begin{array}{l}\text { Ground Surface } \\
\text { Overpressure }\end{array}$ & OP - 2 & Kulite Overpressure & $10 \mathrm{ft}$ from GZ & $25 \mathrm{psi}$ & XTS \\
\hline $\begin{array}{l}\text { Ground Surface } \\
\text { Overpressure }\end{array}$ & OP - 3 & Kulite Overpressure & $14 \mathrm{ft}$ from GZ & $10 \mathrm{psi}$ & XTS \\
\hline Side-On Overpressure & SOP - 1 & Kulite Overpressure & $2.78 \mathrm{ft}$ from GZ & $500 \mathrm{psi}$ & SOP Mount \\
\hline Side-On Overpressure & SOP - 2 & Kulite Overpressure & $2.31 \mathrm{ft}$ from GZ & 2000 psi & SOP Mount \\
\hline Side-On Overpressure & SOP - 3 & Kulite Overpressure & $1.76 \mathrm{ft}$ from GZ & 5000 psi & SOP Mount \\
\hline Side-On Overpressure & SOP - 4 & Kulite Overpressure & $2.31 \mathrm{ft}$ from GZ & 2000 psi & SOP Mount \\
\hline Side-On Overpressure & SOP - 5 & Kulite Overpressure & $2.78 \mathrm{ft}$ from GZ & $500 \mathrm{psi}$ & SOP Mount \\
\hline $\begin{array}{l}\text { Ground Shock } \\
\text { Acceleration }\end{array}$ & AR - 1 & $\begin{array}{l}\text { Endevco } \\
\text { Accelerometer }\end{array}$ & $\begin{array}{l}\text { Soil, 3-ft range, C.L. } \\
\text { Charge Depth }\end{array}$ & $60 \mathrm{~kg}$ g's & HiFi Can \\
\hline $\begin{array}{l}\text { Ground Shock } \\
\text { Acceleration }\end{array}$ & AR - 2 & $\begin{array}{l}\text { Endevco } \\
\text { Accelerometer }\end{array}$ & $\begin{array}{l}\text { Soil, 4-ft range, C.L. } \\
\text { Charge Depth }\end{array}$ & 20k g's & HiFi Can \\
\hline $\begin{array}{l}\text { Ground Shock } \\
\text { Acceleration }\end{array}$ & AR - 3 & $\begin{array}{l}\text { Endevco } \\
\text { Accelerometer }\end{array}$ & $\begin{array}{l}\text { Soil, 5-ft range, C.L. } \\
\text { Charge Depth }\end{array}$ & $20 \mathrm{~kg}$ 's & HiFi Can \\
\hline Ground Shock Stress & SR - 1 & $\begin{array}{l}\text { Kulite Radial Soil } \\
\text { Stress }\end{array}$ & $\begin{array}{l}\text { Soil, 3-ft range, C.L. } \\
\text { Charge Depth }\end{array}$ & 3,000 or 4,000 psi & $\begin{array}{l}\text { LRSW } \\
\text { Mount }\end{array}$ \\
\hline Ground Shock Stress & SR - 2 & $\begin{array}{l}\text { Kulite Radial Soil } \\
\text { Stress }\end{array}$ & $\begin{array}{l}\text { Soil, 4-ft range, C.L. } \\
\text { Charge Depth }\end{array}$ & 3,000 or $4,000 \mathrm{psi}$ & $\begin{array}{l}\text { LRSW } \\
\text { Mount }\end{array}$ \\
\hline Ground Shock Stress & SR - 3 & $\begin{array}{l}\text { Kulite Radial Soil } \\
\text { Stress }\end{array}$ & $\begin{array}{l}\text { Soil, 5-ft range, C.L. } \\
\text { Charge Depth }\end{array}$ & 3,000 or $4,000 \mathrm{psi}$ & $\begin{array}{l}\text { LRSW } \\
\text { Mount }\end{array}$ \\
\hline
\end{tabular}

installed in the top of the backfill lift that coincided with the centerline of the cylindrical charge. The gages were aligned so that their faces were perpendicular to the center of the charge. One accelerometer and one stress gage were placed at the 3-, 4-, and 5-ft ranges from the center of the charge (GZ). Layouts showing the backfill instrumentation for the buried charge experiments using the IMD and side-on pressure gages are shown in Figures 3.12 and 3.13, respectively. All data were recorded with meDAQ model $600 \mathrm{E}$ digital transient recorders (Hi-Techniques, Inc. 2004). Backfill data were recorded with a sampling frequency of $500 \mathrm{kHz}$ corresponding to a data point every $2 \mu$-sec. 


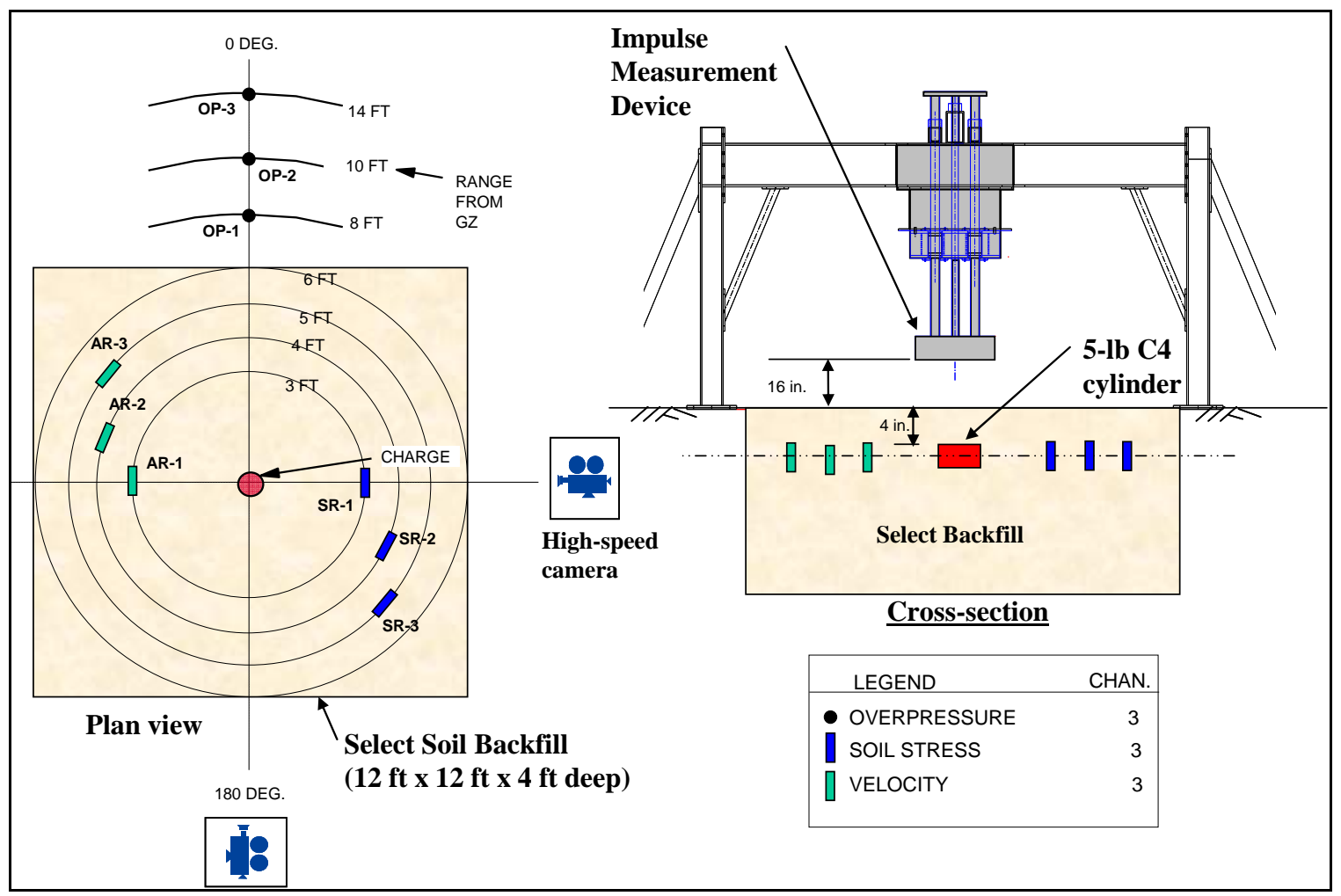

Figure 3.12. Backfill instrumentation layout for buried charge using the IMD.

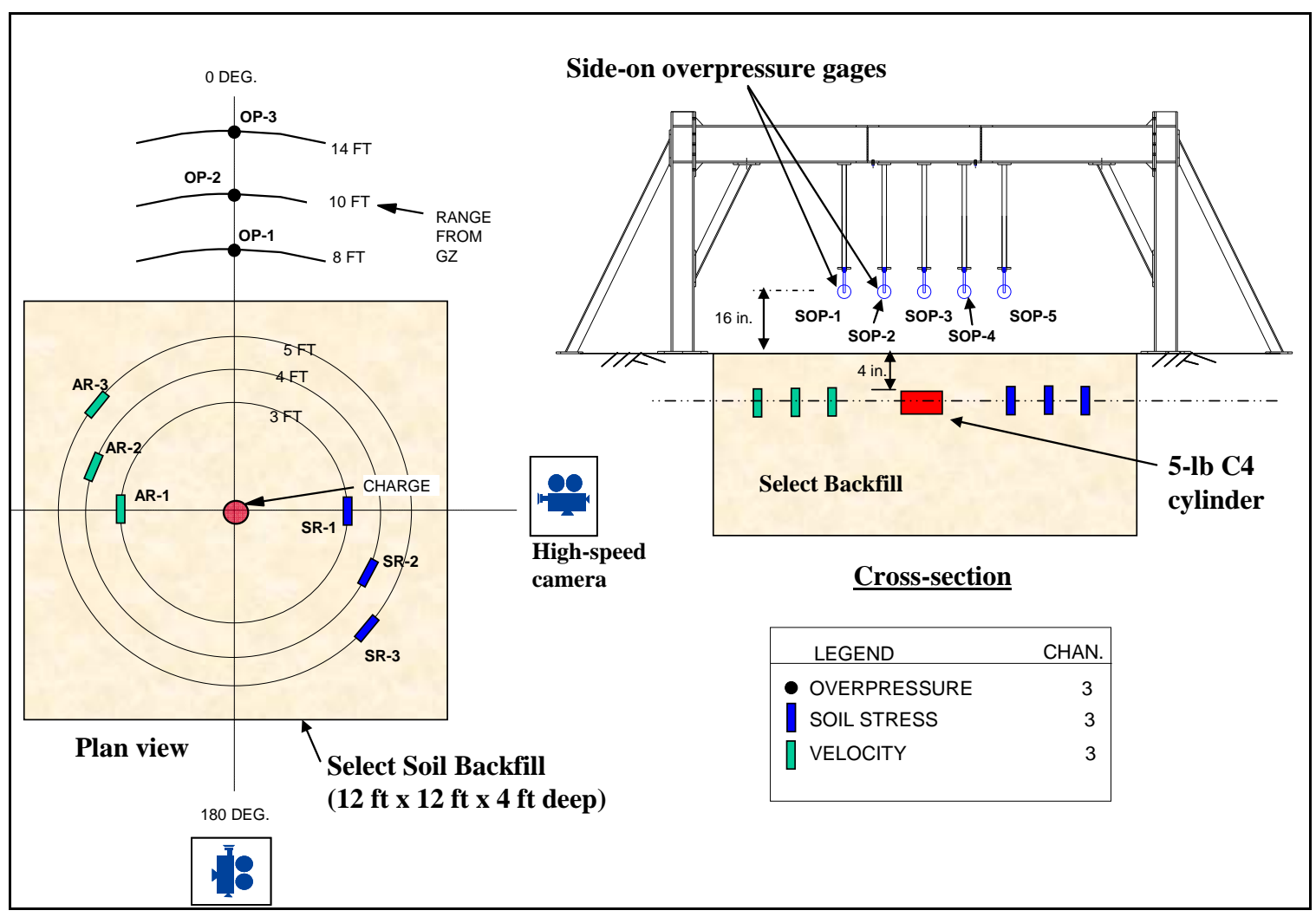

Figure 3.13. Backfill instrumentation layout for buried charge using side-on pressure gages. 
The backfill accelerometers were Endevco Model 7270A instruments (Endevco Corp. 2005). These gages are miniature, undamped, piezoresistive accelerometers with a useful frequency response range of $100 \mathrm{kHz}$ for the 60,000-g version and a useful frequency response range of $50 \mathrm{kHz}$ for the 20,000-g version. These accelerometers were mounted in aluminum "hi-fi" canisters shown in Figure 3.14. These canisters employ a semihard mount that isolates the accelerometer from base straining but does not shock-isolate.

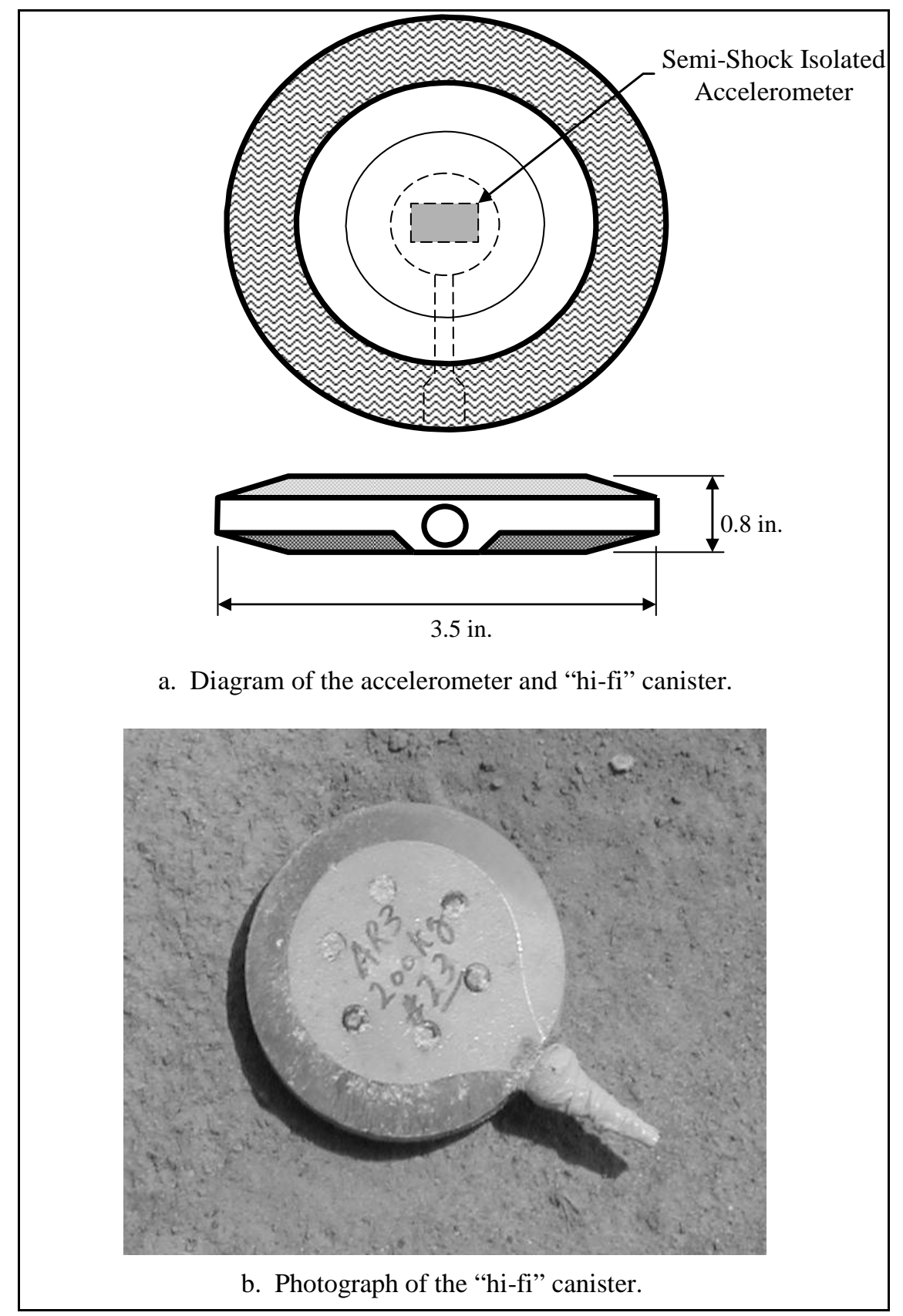

Figure 3.14. Accelerometers mounted in aluminum "hi-fi" canisters. 
The radial stress measurements were made with Kulite model LQV-080-U gages (Kulite Semiconductor 2007) with upper limits of approximately 3,000 and 4,000 psi. These gages are referred to as low-range soil stress gages. The gage and its confining ring are shown in Figure 3.15. A steel ring surrounds the gage, isolates the gage from lateral stresses, and provides the optimal diameter-to-thickness ratio for stress measurements in soil. The gage is separated from the isolator ring by a soft silicon rubber material. The natural frequency of the gage is approximately $40 \mathrm{kHz}$. The end of the steel ring that surrounds the gage is threaded to accept a coupling to connect the ring to copper tubing that protects the cable.

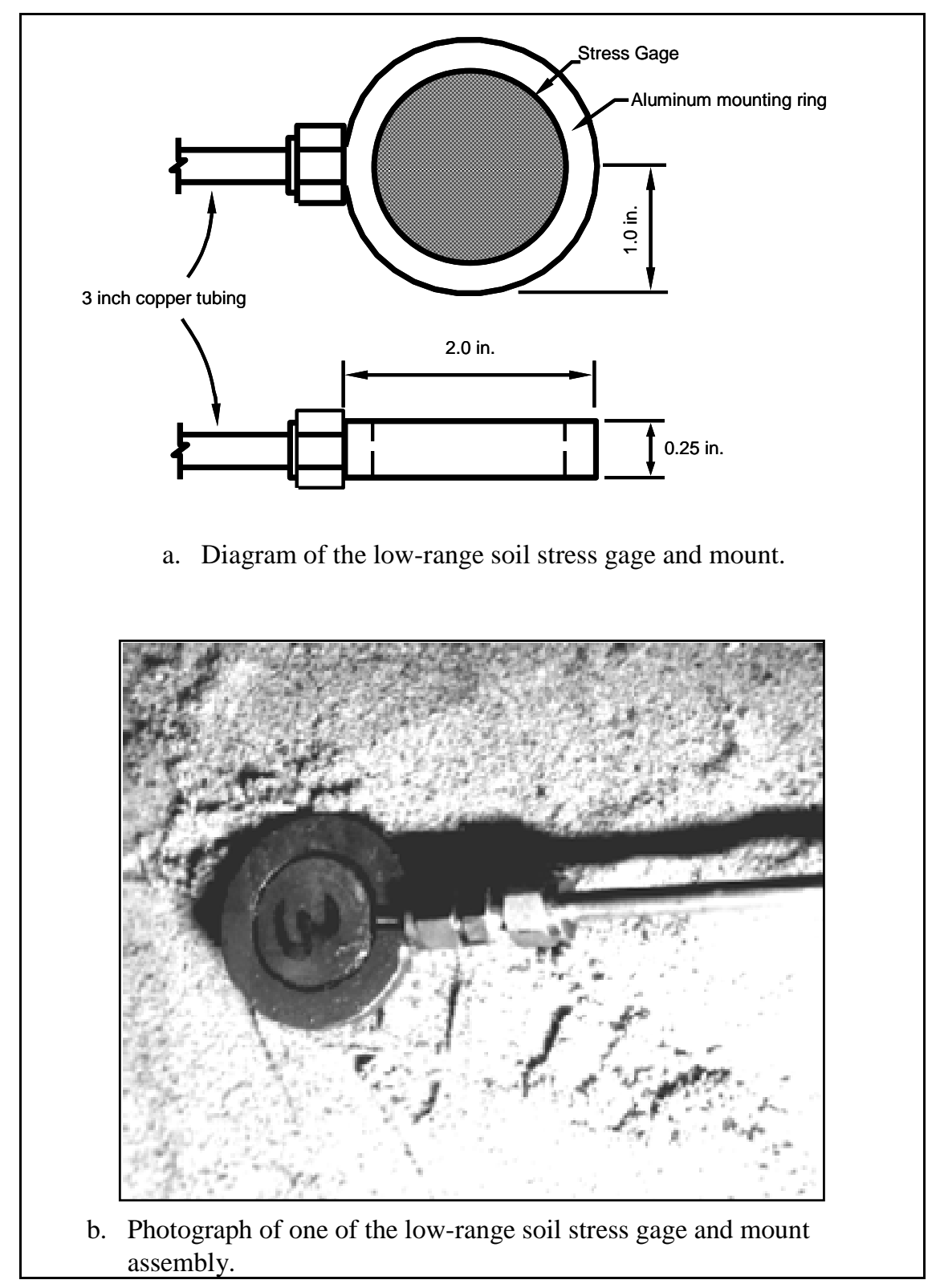

Figure 3.15. Low-range soil stress gage. 


\section{Blast pressure instrumentation}

Side-on overpressure

The gage arrangement for side-on overpressure measurements consisted of five gages mounted in a horizontal plane $20 \mathrm{in}$. above the top of the charge surface to match the standoff used for the IMD tests. The side-on overpressure gages were located in line with one gage directly above the charge, two with horizontal offsets of $18 \mathrm{in}$. from the center of the charge, and two with horizontal offsets of 36 in. as shown in Figure 3.2. The overpressure measurements were made with Kulite gages (Kulite Semiconductor 2007) with upper limits of approximately 5,000 psi at the center gage (SOP3), 2000 psi at the 18-in. offset gages (SOP2 and SOP4), and 500 psi at the 36-in. offset gages (SOP1 and SOP5). The gages used in the experiment were mounted in side-on disc mounts and were supported on the same structure that supported the IMD. The gage mount and a photograph of the gage are shown in Figure 3.16. The gage mounts were suspended below the structure using a "V" shape support structure. Figure 3.17 shows a photograph of the five side-on overpressure gages suspended below the support structure.

\section{Ground surface overpressure}

Three ground surface overpressure gages were used in both the side-on and the IMD experiments. The gages were located at horizontal distances of 8,10 , and $14 \mathrm{ft}$ from GZ. The overpressure measurements were made with Kulite gages with upper limits of approximately 50 psi at the 8-ft range (OP1), $25 \mathrm{psi}$ at the 10 - $\mathrm{ft}$ range (OP2), and $10 \mathrm{psi}$ at the 14- $\mathrm{ft}$ range (OP3). The gages were flush-mounted with the ground surface in an overpressure mount. The mount was cast in a 12-in.-diam by 6-in.-tall concrete cylinder that was buried below ground to minimize movement of the gage during testing. The gage mount is shown in Figure 3.18. A photograph showing the ground surface overpressure gages located in a test arrangement is shown in Figure 3.19. 


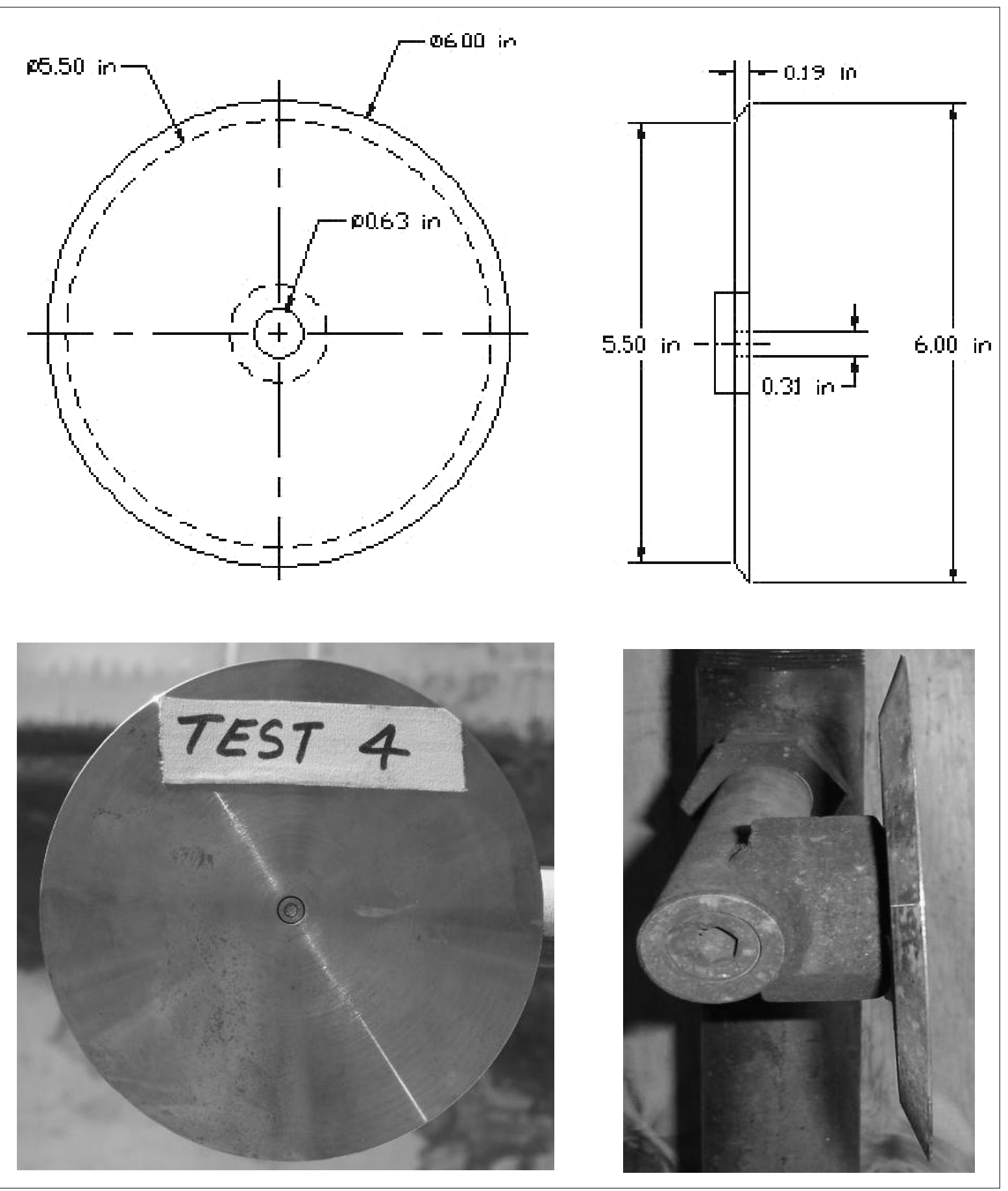

Figure 3.16. Side-on overpressure gage photograph and detail. 


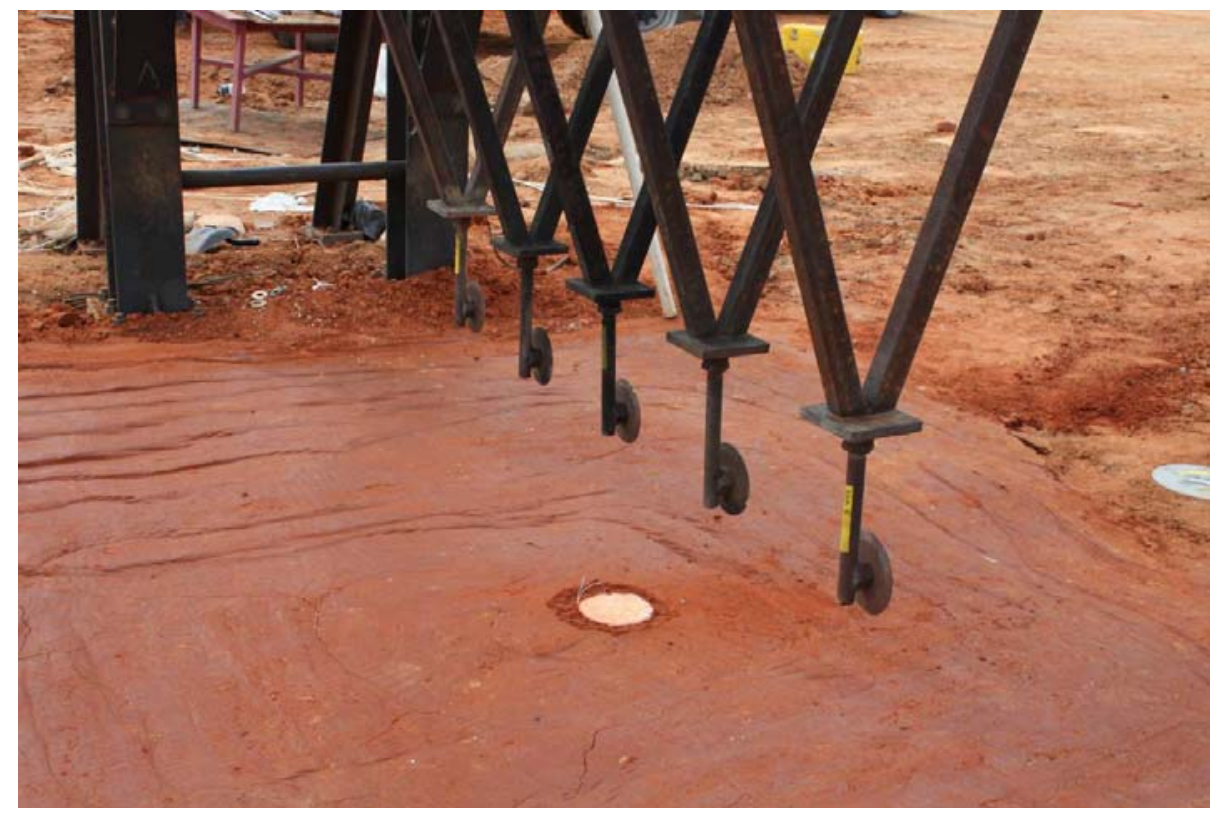

Figure 3.17. The side-on overpressure gages located above a testbed.

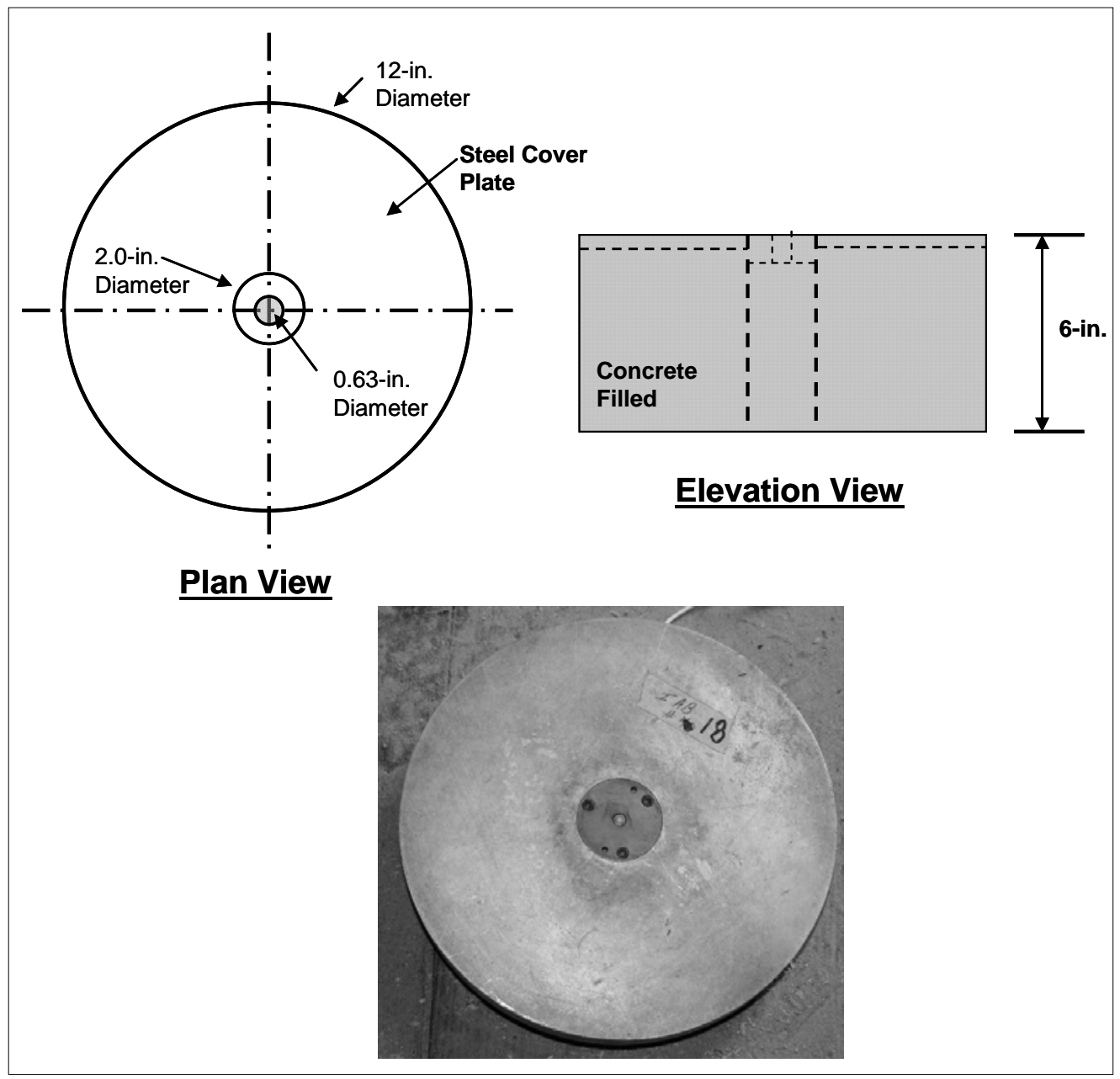

Figure 3.18. Ground surface overpressure gage mount details and photograph. 


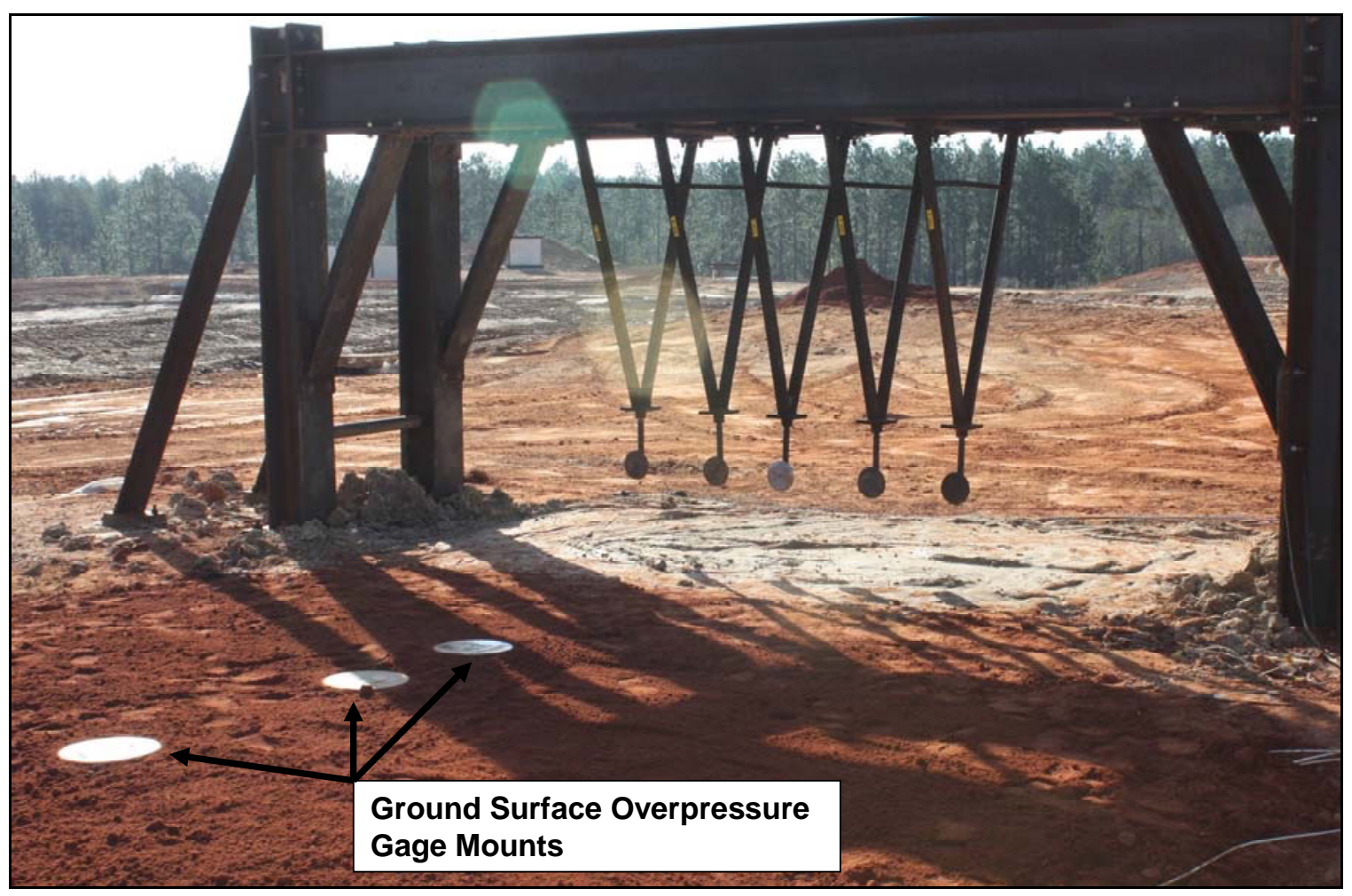

Figure 3.19. Ground surface overpressure gages.

\section{IMD instrumentation}

The IMD was instrumented with airblast, acceleration, and displacement gages. The general arrangement of the instrumentation is shown in Figure 3.20. The primary goal was to capture the displacement and velocity time-histories of the piston assembly. A cable extension position transducer (Intertechnology, Inc. 2007), referred to as a yo-yo gage, was mounted on the inside of the support structure and attached to the piston assembly. The yo-yo gage uses a spring tension wire to measure deflection. Figure 3.21 is a photograph of a yo-yo gage. Due to the relatively slow reaction time of the yo-yo gage, it was not useful in capturing the initial velocity of the system but was used to capture total upward displacement. Figure 3.22a shows a photograph of the "yo-yo" gage placed on the IMD.

Accelerometers were mounted on the top surface of the impact plates to capture the motion of the mass piston assembly and on the stationary support beams near the piston assembly to capture global motion of support frame. The structural acceleration measurements were made with Endevco 7270A accelerometers (Endevco Corp. 2005). The accelerometers 


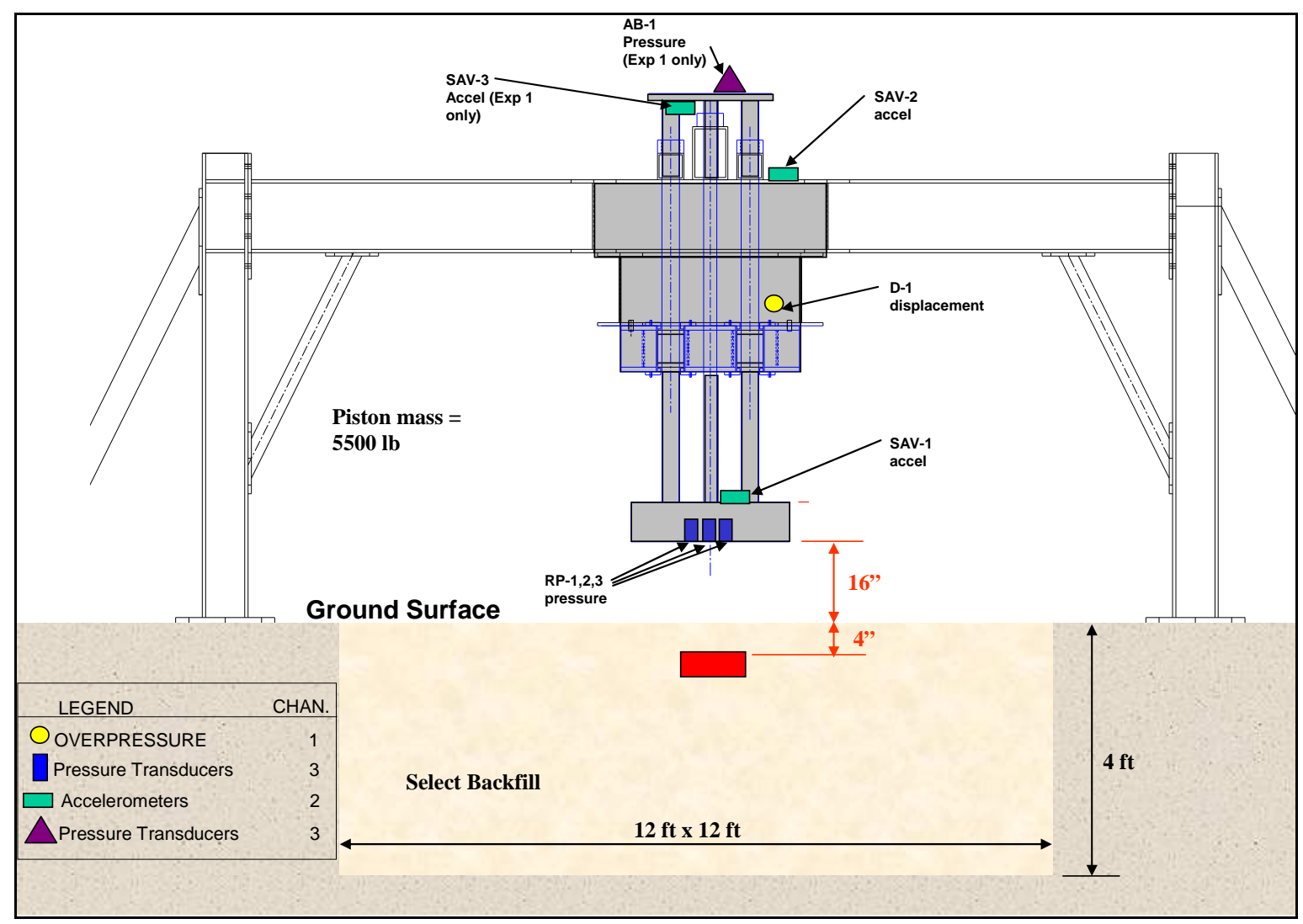

Figure 3.20. Instrumentation layout for IMD experiments.

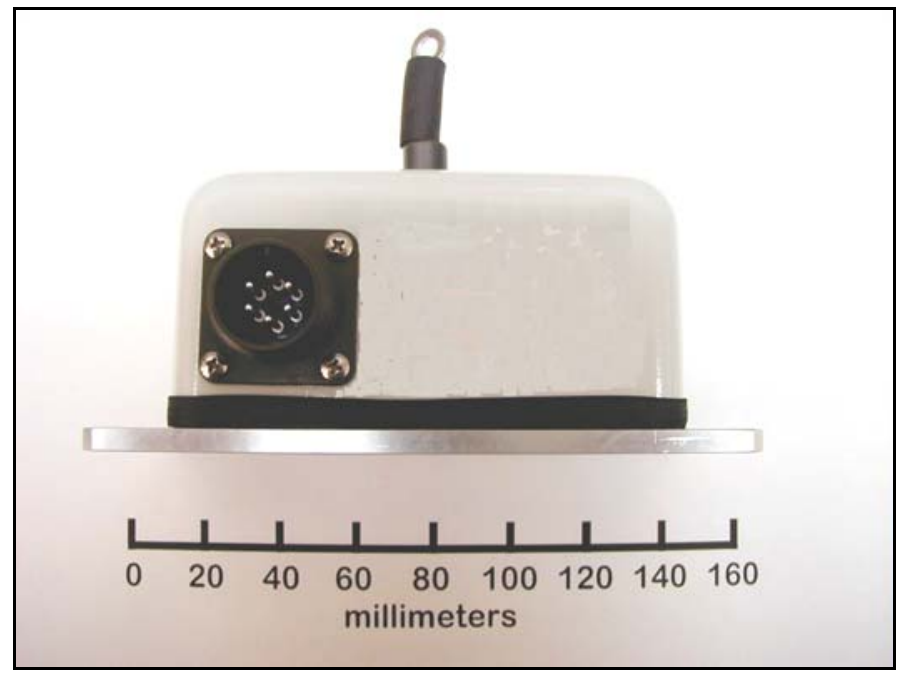

Figure 3.21. A cable extension position transducer "yo-yo" gage. 


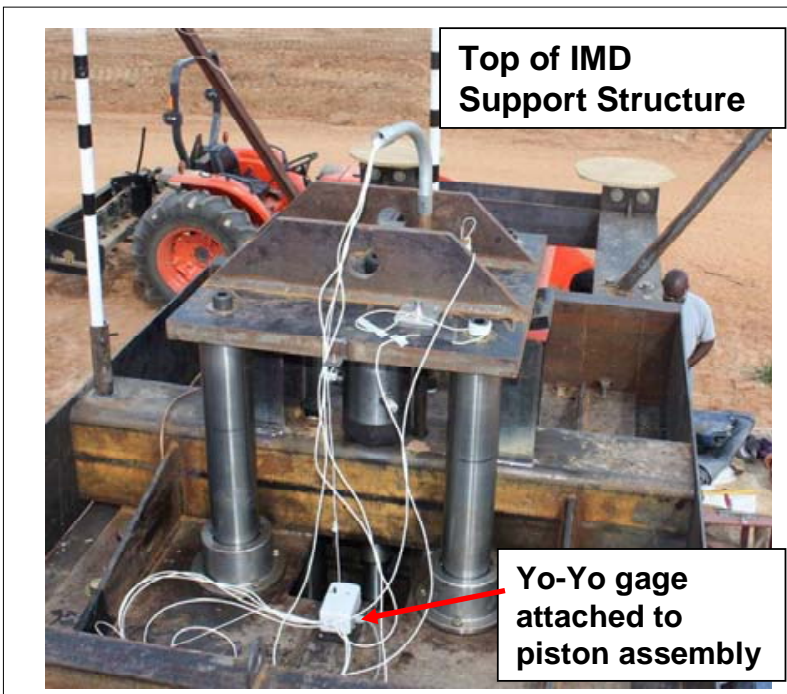

a. "Yo-yo" gage on the top of the IMD.

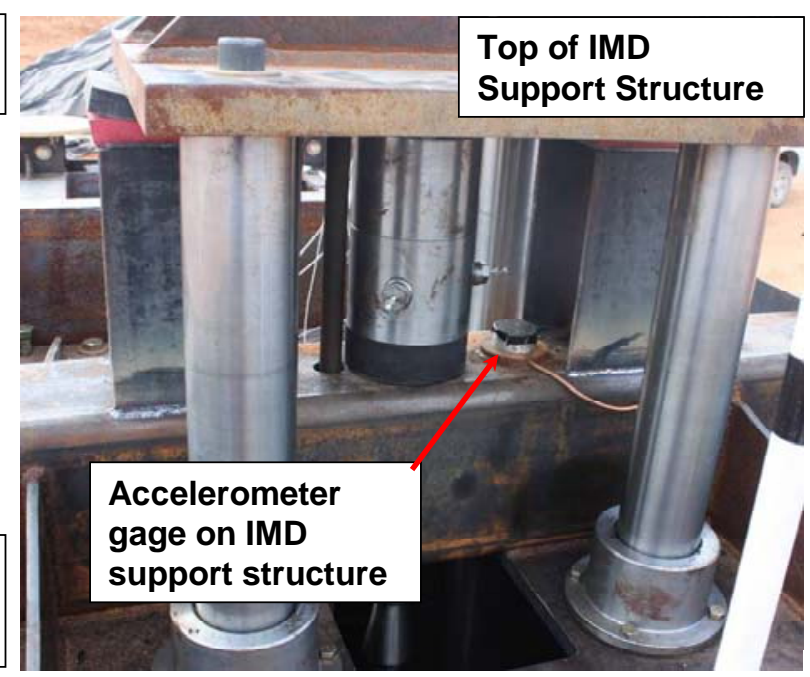

b. Accelerometer on the support structure.

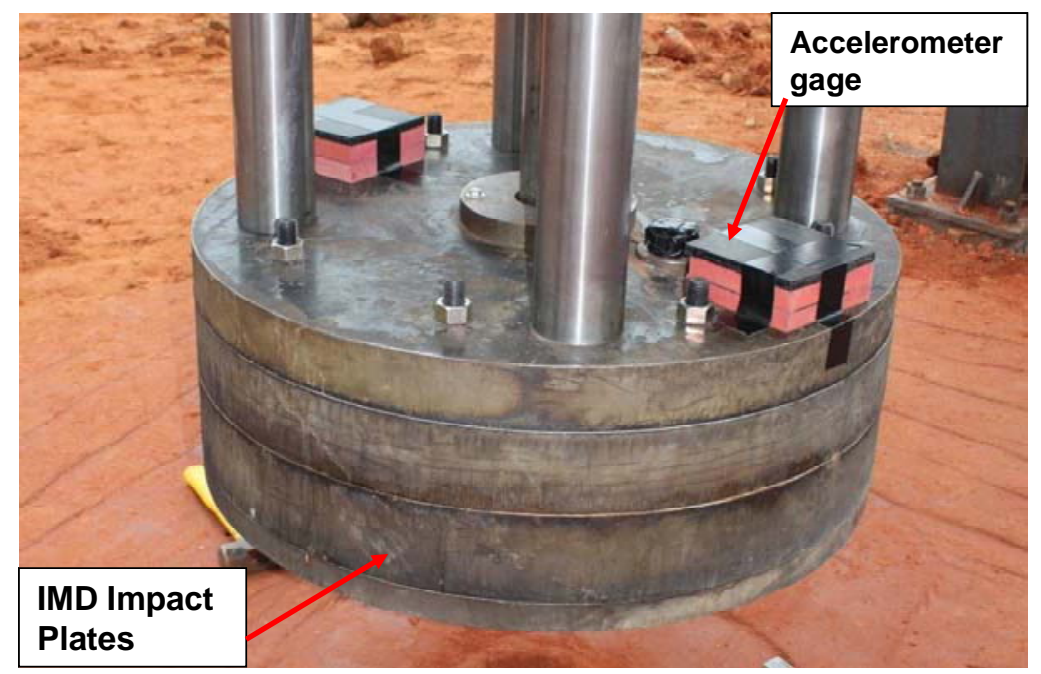

c. Accelerometer on the IMD piston assembly.

Figure 3.22. The IMD instrumentation.

on the IMD and support structure were placed in ERDC/WES-designed shock mounts (Figure 3.23). The shock mount was designed to attenuate high-frequency accelerations that may damage accelerometers while allowing accurate derivation of the integrated velocity and displacement waveforms. The acceleration time-histories of the piston assembly were used to derive velocity time-histories and approximate displacement timehistories throughout the events. Figures $3.22 \mathrm{~b}$ and $3.22 \mathrm{c}$ are photographs of the accelerometer gages on the support structure and on the IMD piston assembly, respectively. 


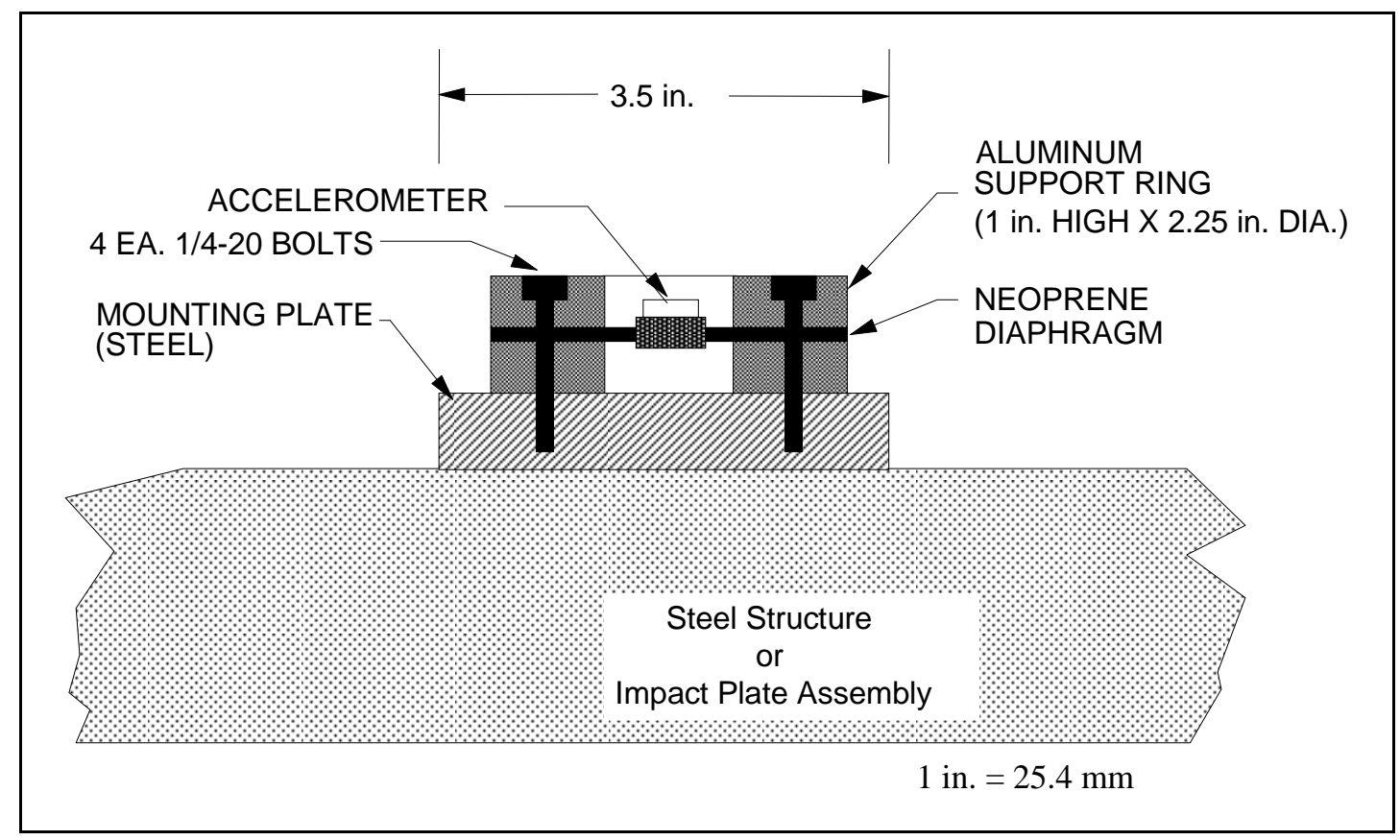

Figure 3.23. Diagram of ERDC/WES-designed shock mount for the accelerometer used on the IMD.

Three pressure transducers were flush-mounted on the bottom plate of the piston assembly to measure the reflected pressure on the exposed surface. Figure 3.24 shows the locations of the pressure transducers on the bottom plate. In most cases, two of the pressure transducers were piezoresistive sensors (Kulite Semiconductor 2007). These sensors were protected by a cover plate to prevent loading by soil particles or detonation products. Air inlet ports allowed measurement of only reflected airblast pressures. The third transducer was a piezoelectric sensor (PCB Piezotronics Inc. 2008). This sensor was exposed directly to the reflected pressure as well as any loading due to soil and detonation products. Figure 3.25 shows a photograph of the three pressure transducers on the exposed surface of the IMD impact plate. These airblast measurements were designed to isolate and identify the separate loads produced by the soil debris and the airblast pressure. All data were recorded with meDAQ Model 600E digital transient recorders (Hi-Techniques, Inc. 2004). 


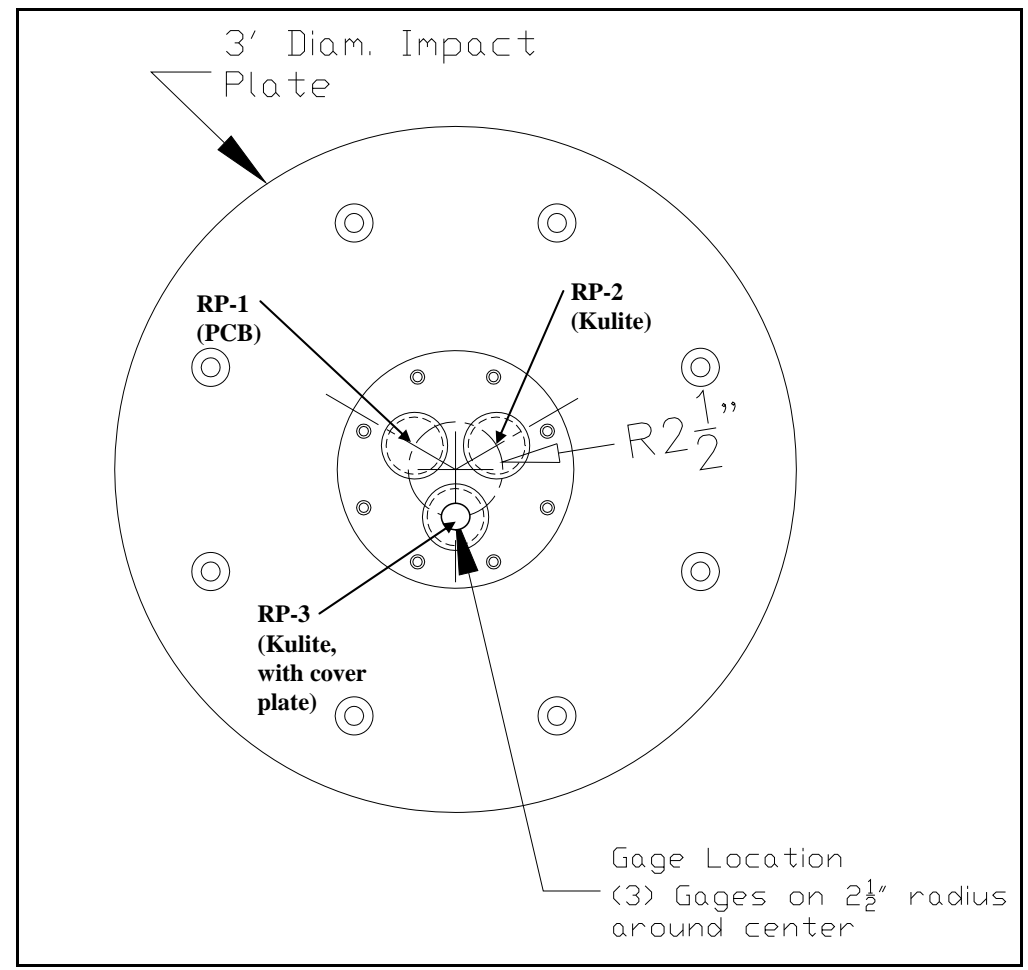

Figure 3.24. Three flush-mounted pressure transducers located on bottom of impact plate.

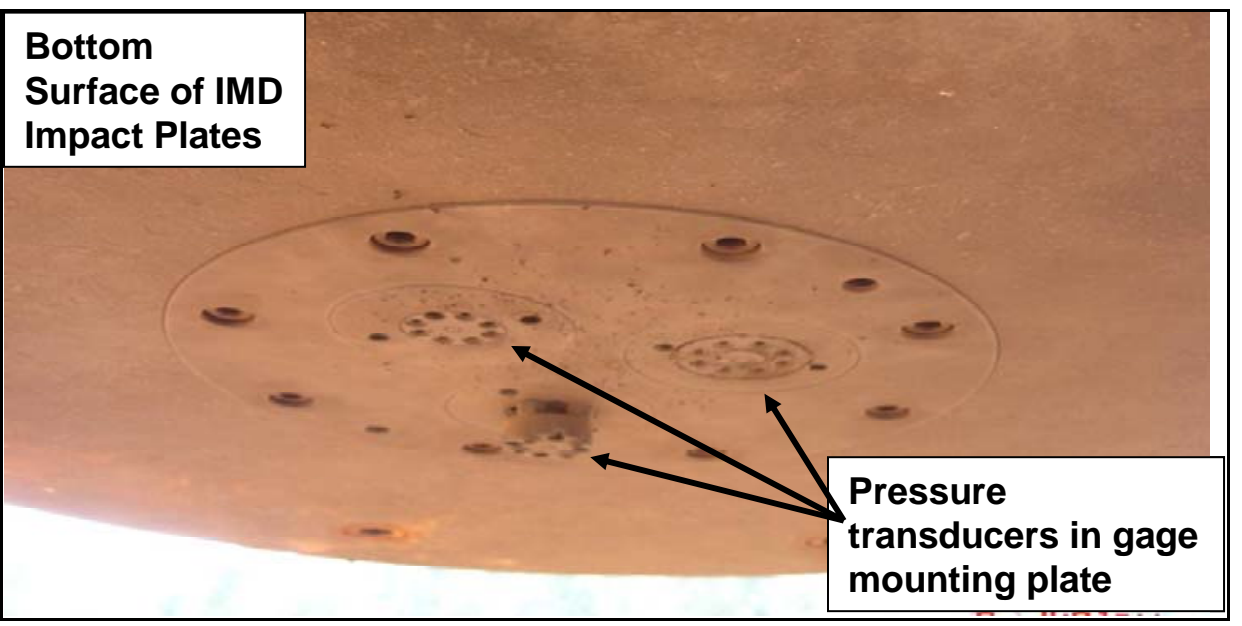

Figure 3.25. The three pressure transducers on the IMD impact plate. 


\section{Results of Experiments}

A series of experiments was performed using the IMD during fall 2008 and spring 2009. The general geometry and configuration of the experiments were shown in Figures 2.1 and 2.2. The primary variables for the experiments were the depth of burial of the explosive charge and the backfill soil type. The primary objective was to determine the influence of soil properties on the aboveground blast environment produced by the detonation of a bare charge placed at elevations ranging from sitting on the ground surface to shallow burial. The goal was to capture sufficient information during the experiments to understand this complex blast environment. Figures 4.1 and 4.2 show pretest and posttest photographs, respectively, from one of the IMD experiments. Figure 4.3 shows snapshots at different times from the high-speed video illustrating the effects of the blast on the IMD. Data captured from the instrumentation and high-speed video indicated that the IMD functioned correctly and captured the impulse loading from the experiments.

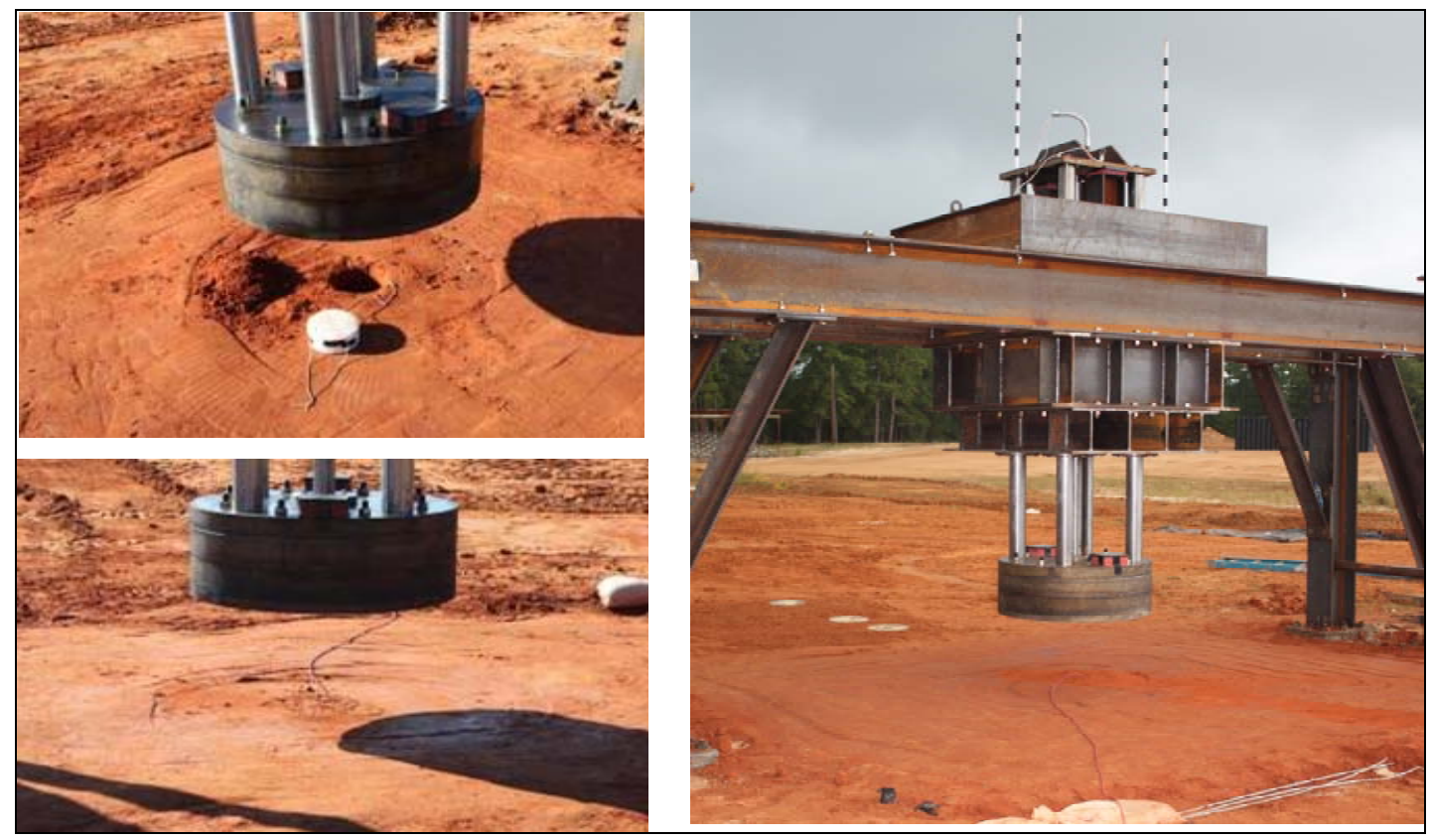

Figure 4.1. Pretest photographs of the IMD testbed. 


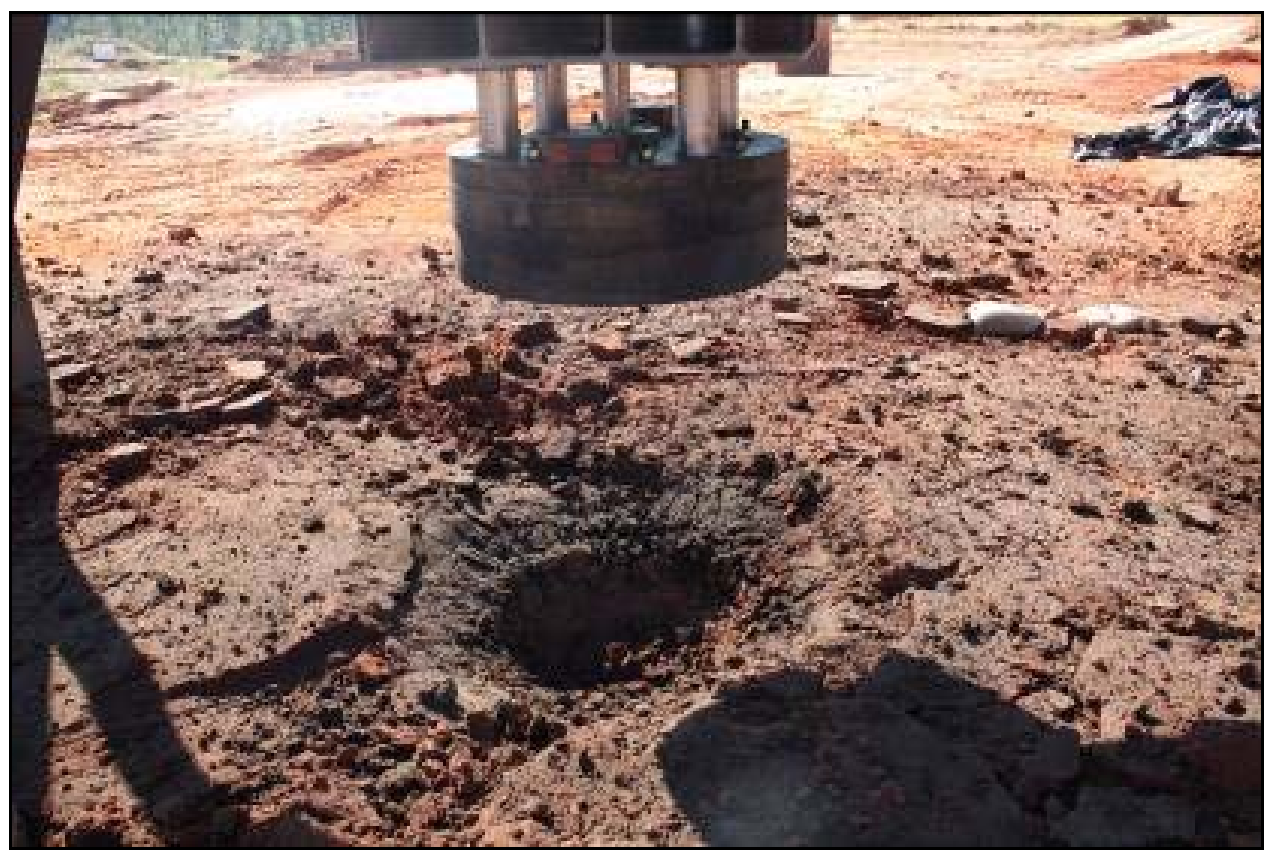

Figure 4.2. Posttest photograph of the IMD testbed.

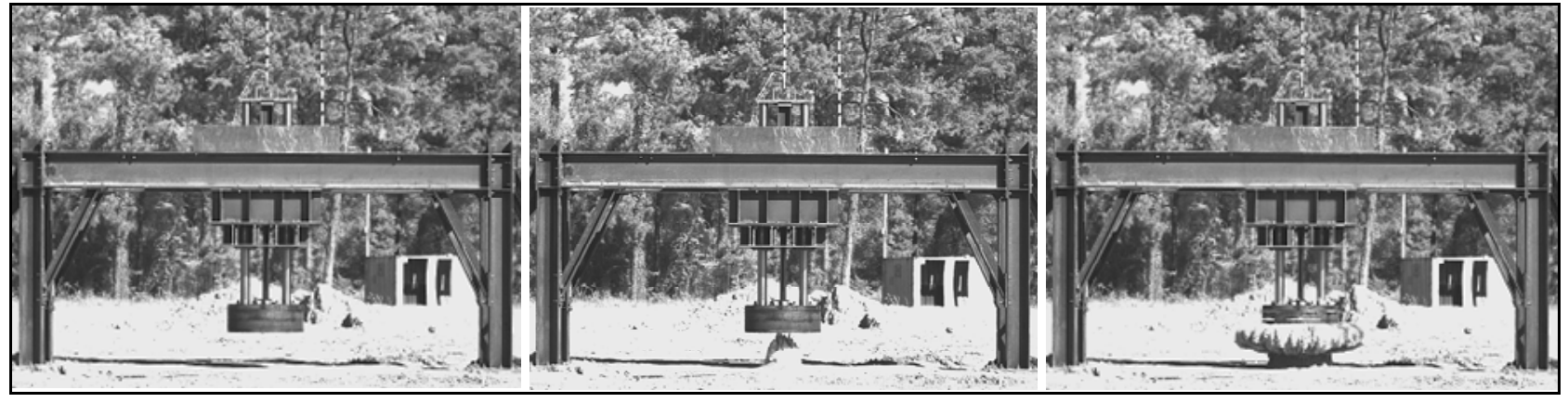

Figure 4.3. Captured frames from high-speed video of an IMD experiment.

The experiments were divided into three test series. The first test series used the intermediate $10.8 \%$ air-filled voids silty sand backfill, the second test series used the $5.6 \%$ air-filled voids wet clay backfill, and the third test series used the $29.8 \%$ air-filled voids dry sand backfill. The results from each test series are presented in this chapter and are grouped by soil type. Presented are results of backfill quality control tests, testbed crater surveys, time-histories of ground shock stress and particle velocity, ground surface overpressure, side-on overpressure above the charge, and the responses of the IMD, which include the high-speed video, displacement, motion, and total impulse. 


\section{Intermediate (silty sand) soil}

\section{Backfill quality control measurements}

The backfill was placed in lifts approximately 6 to 8 in. thick, as described in Chapter 3. Quality control measurements for the as-placed soil were made in each lift. These measurements included the wet density obtained with a nuclear moisture-density gage and microwave and oven-dried water contents. The average values for all measurements of wet density, ovendried water content, and calculated dry density in each testbed are presented in Table 4.1. For all the intermediate soil experiments, the designated value of wet density was $125.4 \mathrm{lb} / \mathrm{ft}^{3}$, and the designated value of water content was $13 \%$. The calculated dry density was $110.9 \mathrm{lb} / \mathrm{ft}^{3}$, and the calculated air voids content was $10.8 \%$ based on a specific gravity of 2.69. The soil was classified as a silty sand (SM) according to the Unified Soil Classification System as discussed in Chapter 3.

Table 4.1. Summary of intermediate soil test series.

\begin{tabular}{|l|l|l|l|l|l|l|}
\hline $\begin{array}{l}\text { Experiment } \\
\text { Number }\end{array}$ & $\begin{array}{l}\text { Charge } \\
\text { Position }\end{array}$ & $\begin{array}{l}\text { Avg Wet } \\
\text { Density, } \\
{\mathrm{lb} / \mathrm{ft}^{3}}^{3}\end{array}$ & $\begin{array}{l}\text { Avg Dry } \\
\text { Density, } \\
{\mathrm{lb} / \mathrm{ft}^{3}}^{3}\end{array}$ & $\begin{array}{l}\text { Avg Water } \\
\text { Content, \% }\end{array}$ & $\begin{array}{l}\text { Crater } \\
\text { Diameter } \\
\mathrm{ft}\end{array}$ & $\begin{array}{l}\text { Crater } \\
\text { Depth, } \mathrm{ft}\end{array}$ \\
\hline BM-I-01 & TSA & 123.7 & 110.1 & 12.3 & 4.10 & 1.45 \\
\hline BM-I-02 & TSB & 129.1 & 113.5 & 13.7 & 4.20 & 1.41 \\
\hline BM-I-03 & Buried & 126.7 & 112.2 & 12.9 & 4.92 & 1.88 \\
\hline BM-I-04 & TSA & 126.4 & 112.1 & 12.8 & 2.80 & 1.10 \\
\hline BM-I-05 & Buried & 126.8 & 112.1 & 13.2 & 5.60 & 1.89 \\
\hline
\end{tabular}

\section{Crater surveys}

For each of the five intermediate soil experiments, pretest and posttest cross-sectional grade surveys were conducted along the primary axes (see Figure 3.9) through the GZ. From these surveys, the resulting crater diameter and crater depth were calculated. A summary of these data for the intermediate soil testbeds is also provided in Table 4.1, which includes the experiment number, charge position, average soil composition properties, and approximate soil crater diameter and depth. Figures 4.4-4.8 present the pretest and posttest cross sections for each of the intermediate soil experiments along with a photograph of each posttest testbed crater. 


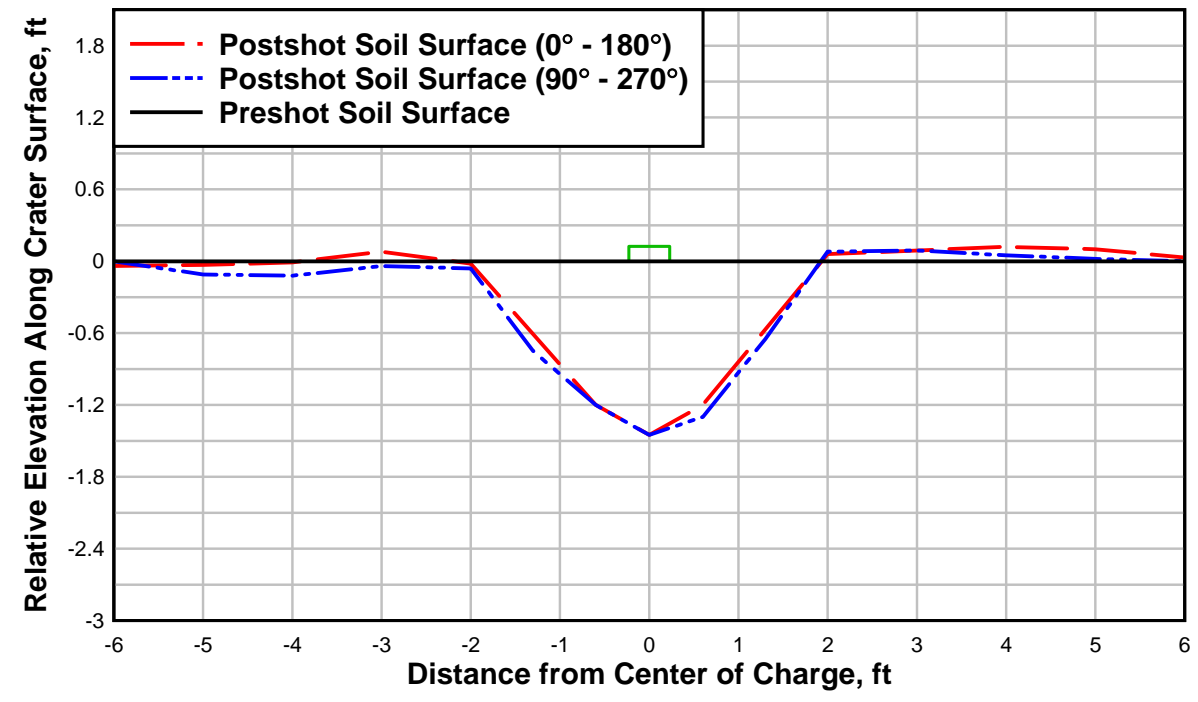

a. Measured posttest crater cross sections in BM-I-01.

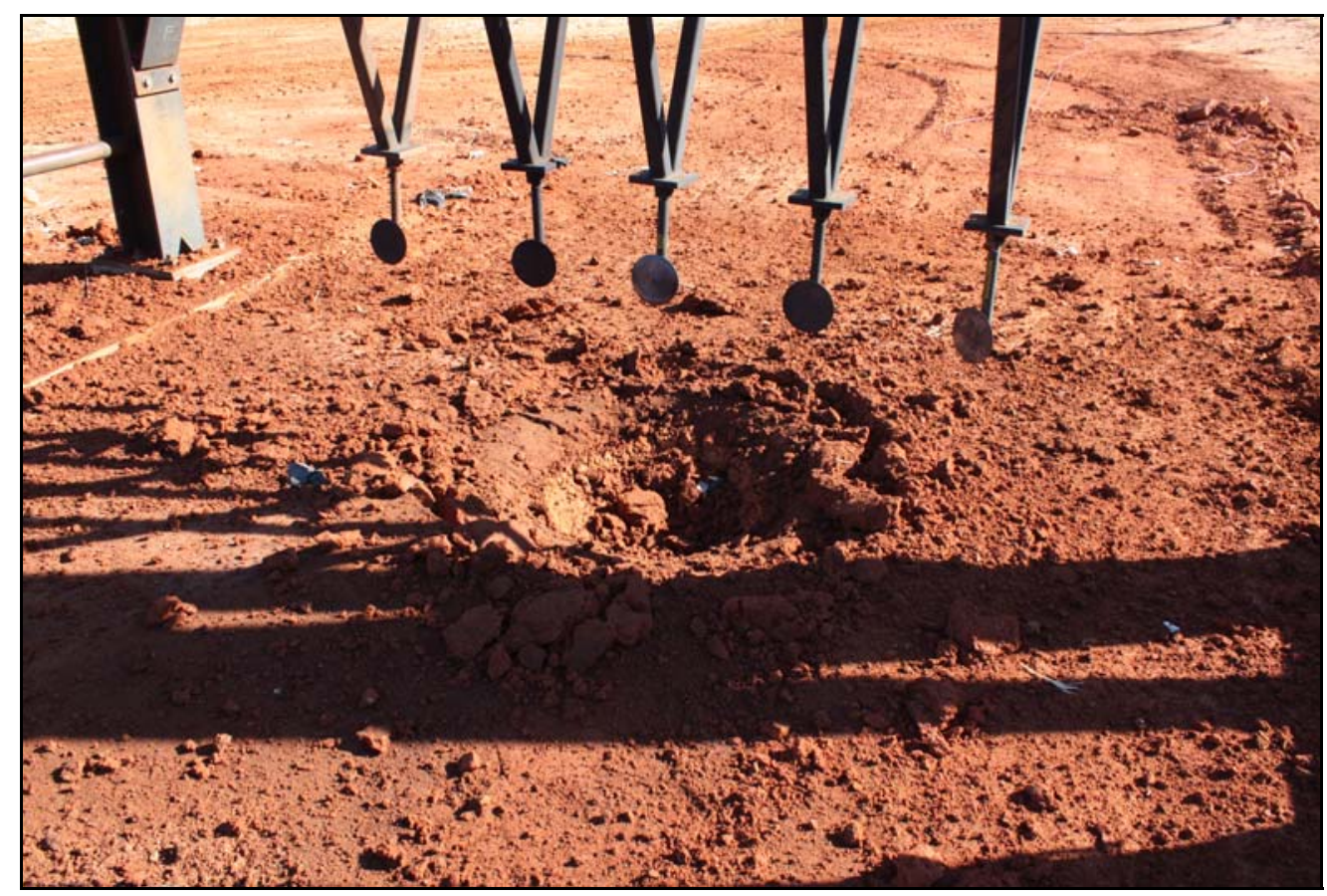

b. Photograph of posttest crater in BM-I-01.

Figure 4.4. Photograph and cross-section surveys of testbed crater in BM-I-01. 


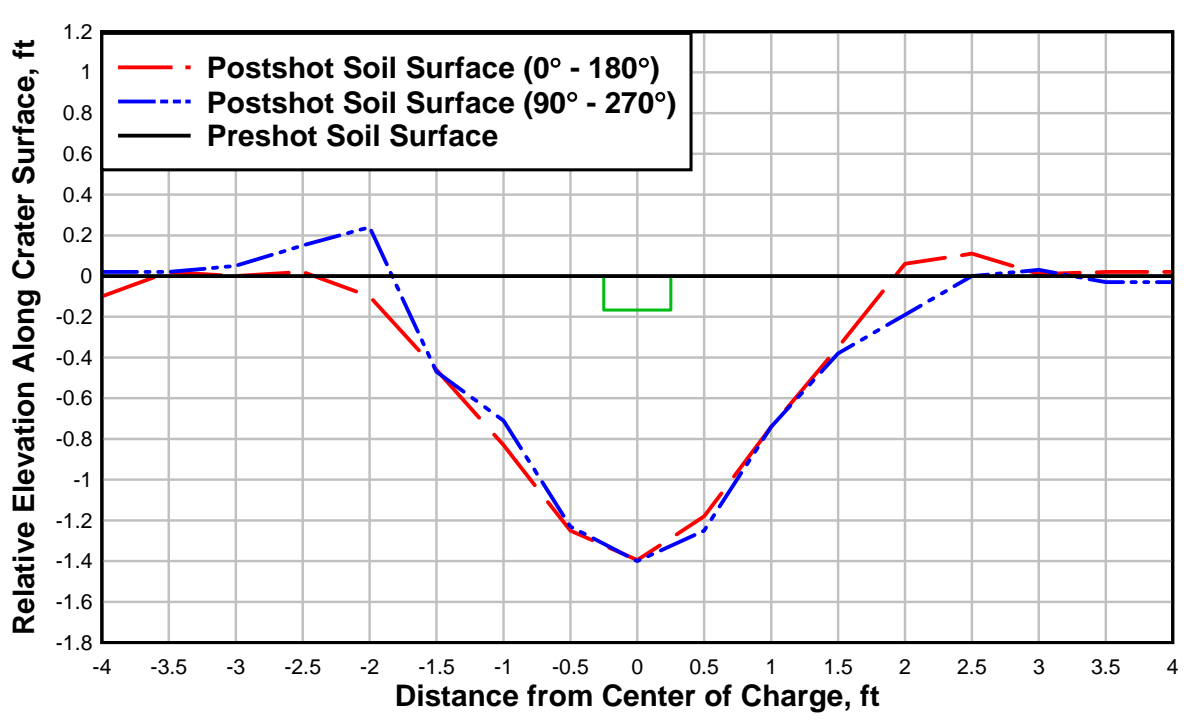

a. Measured posttest crater cross sections in BM-I-02.

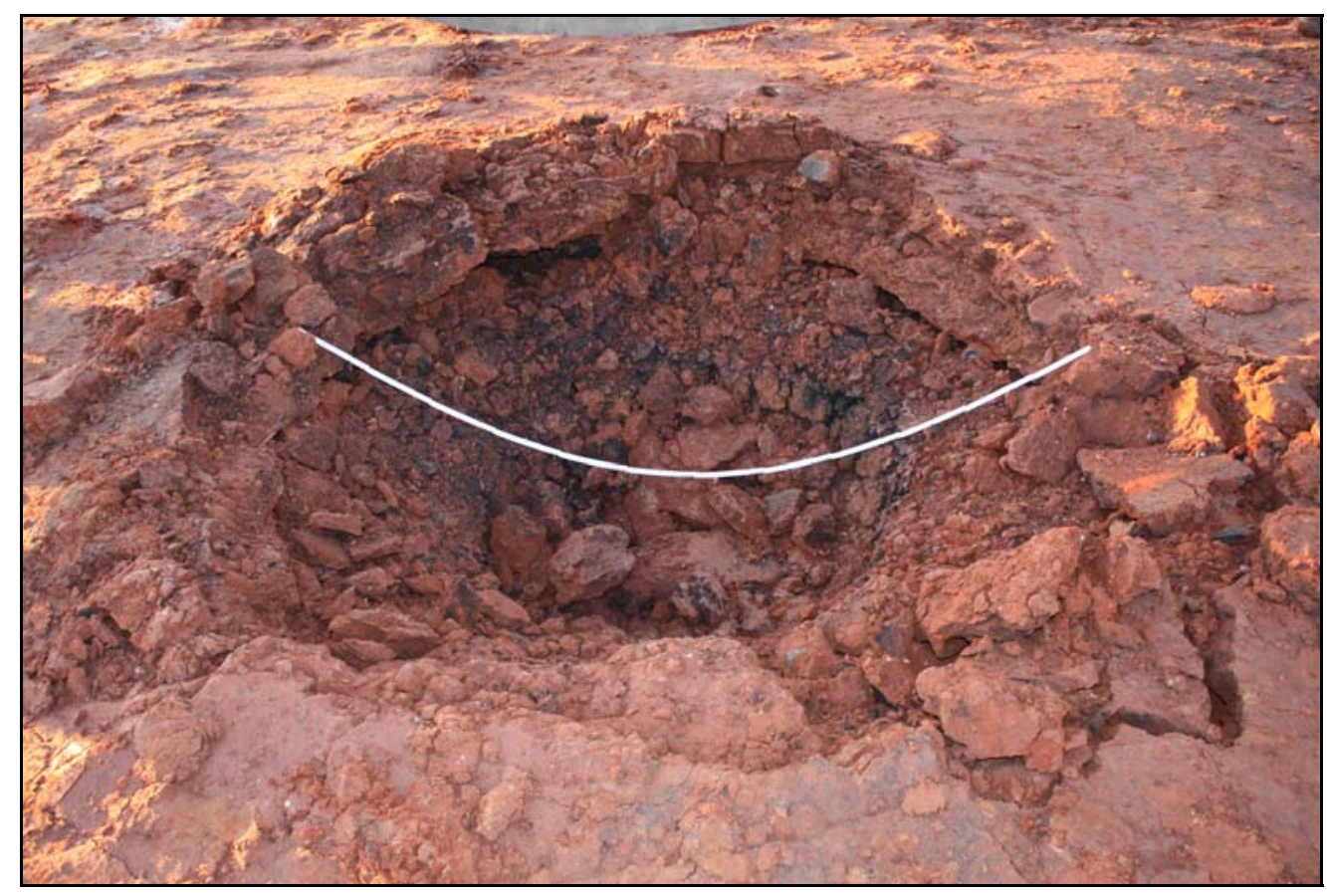

b. Photograph of posttest crater in BM-I-02.

Figure 4.5. Photograph and cross-section surveys of testbed crater in BM-I-02. 


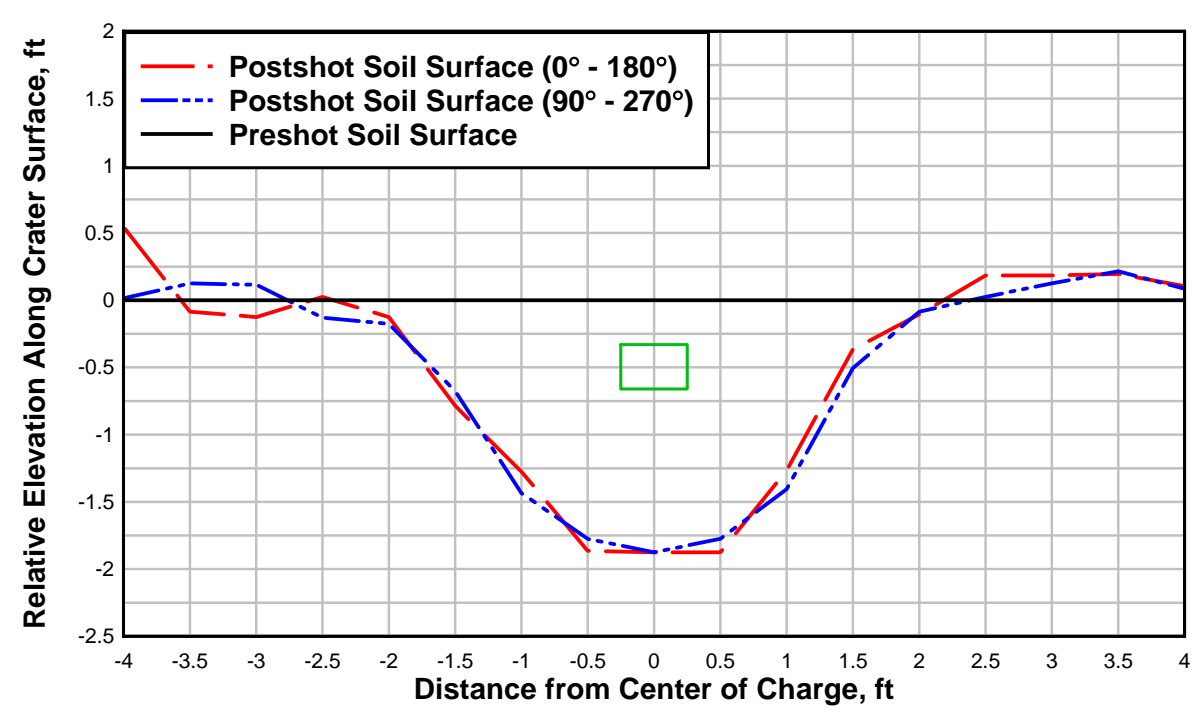

a. Measured posttest crater cross sections in BM-I-03.

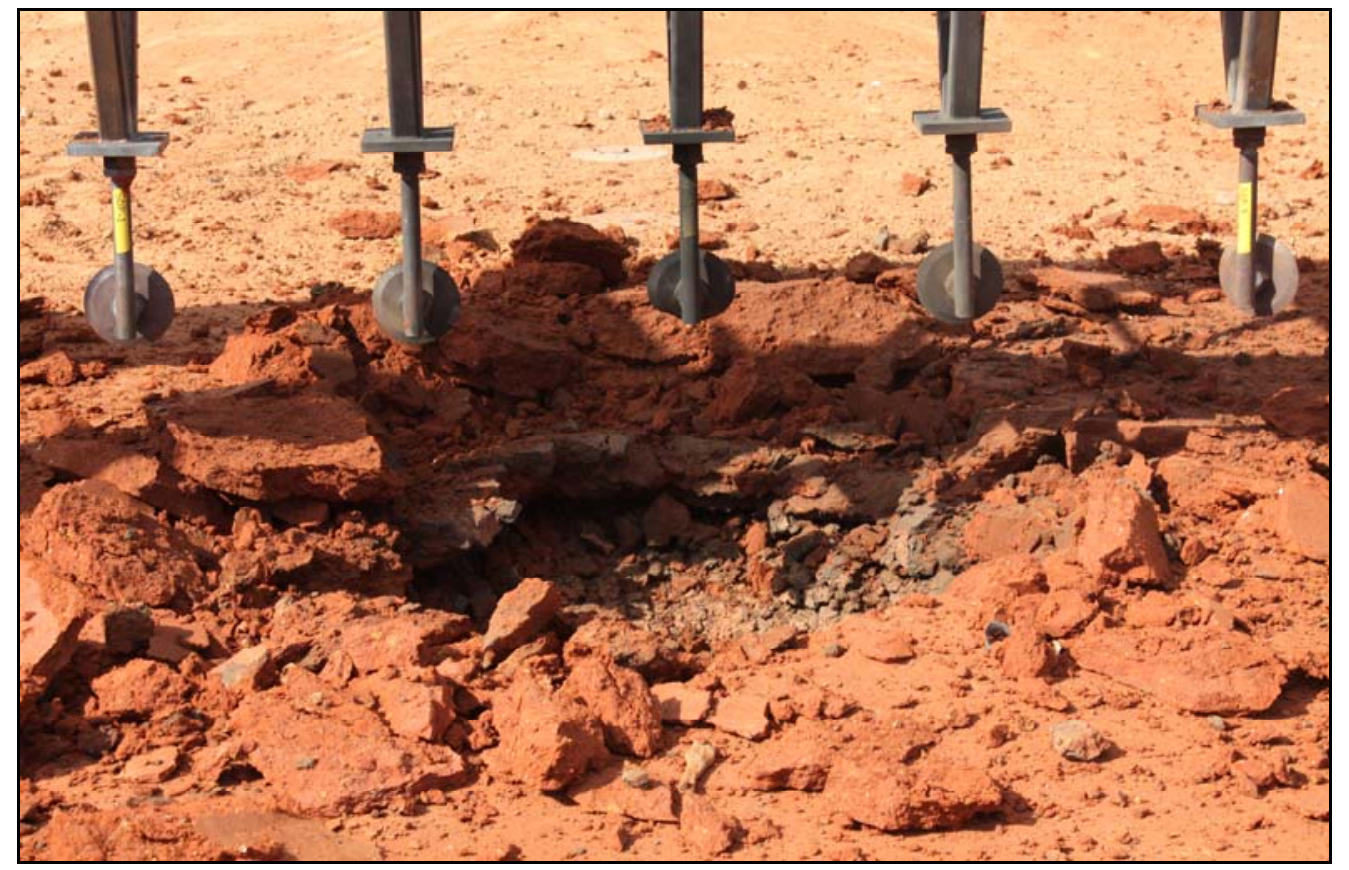

b. Photograph of posttest crater in BM-I-03.

Figure 4.6. Photograph and cross-section surveys of testbed crater in BM-I-03. 


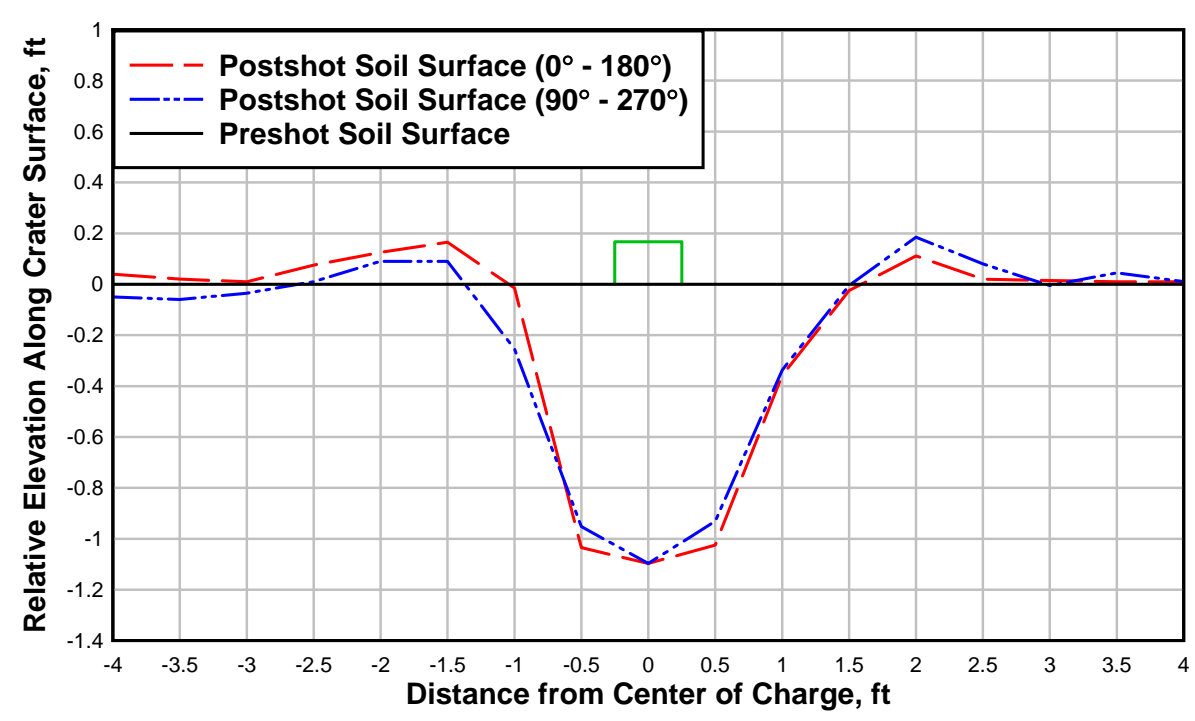

a. Measured posttest crater cross section in BM-I-04.

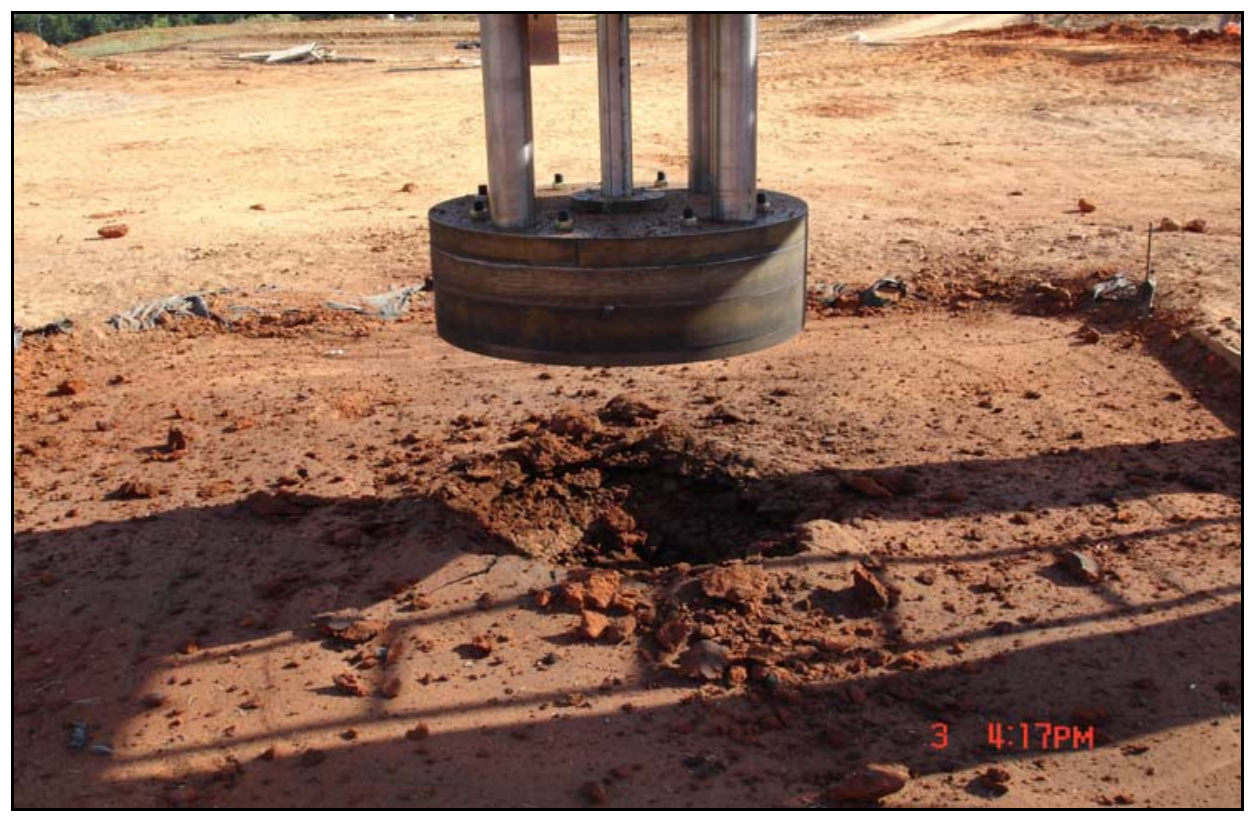

b. Photograph of posttest crater in BM-I-04.

Figure 4.7. Photograph and cross-section surveys of testbed crater in BM-I-04. 


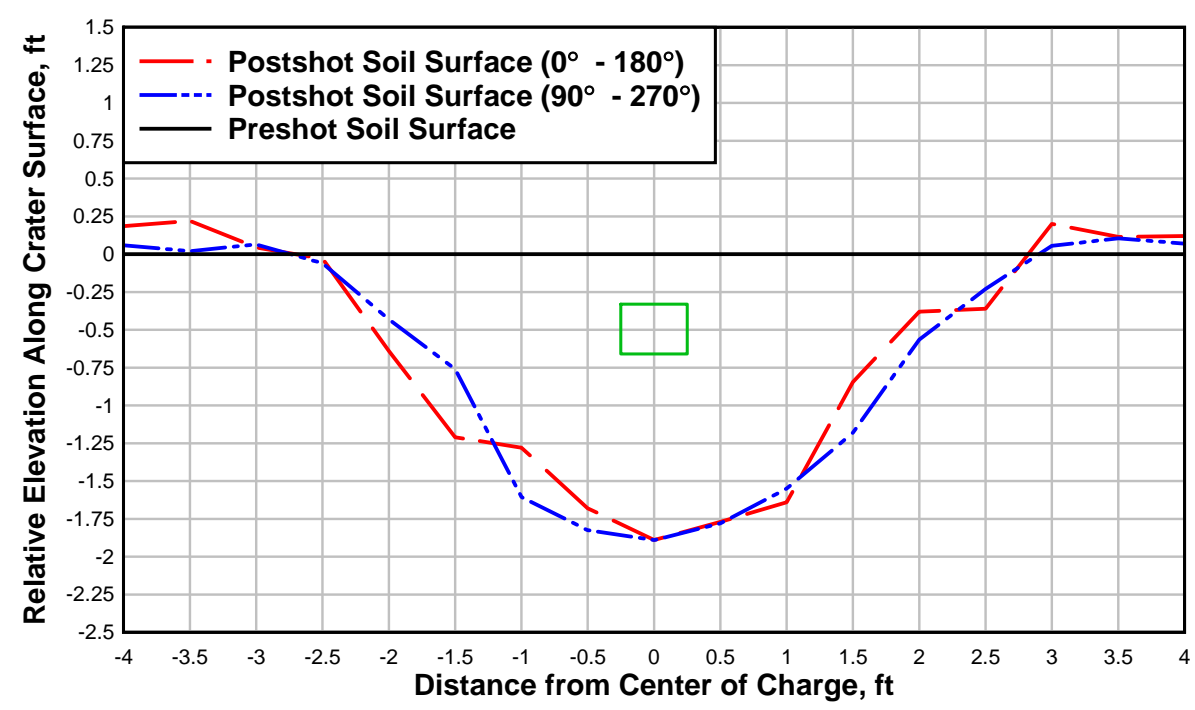

a. Measured posttest crater cross section in BM-I-05.

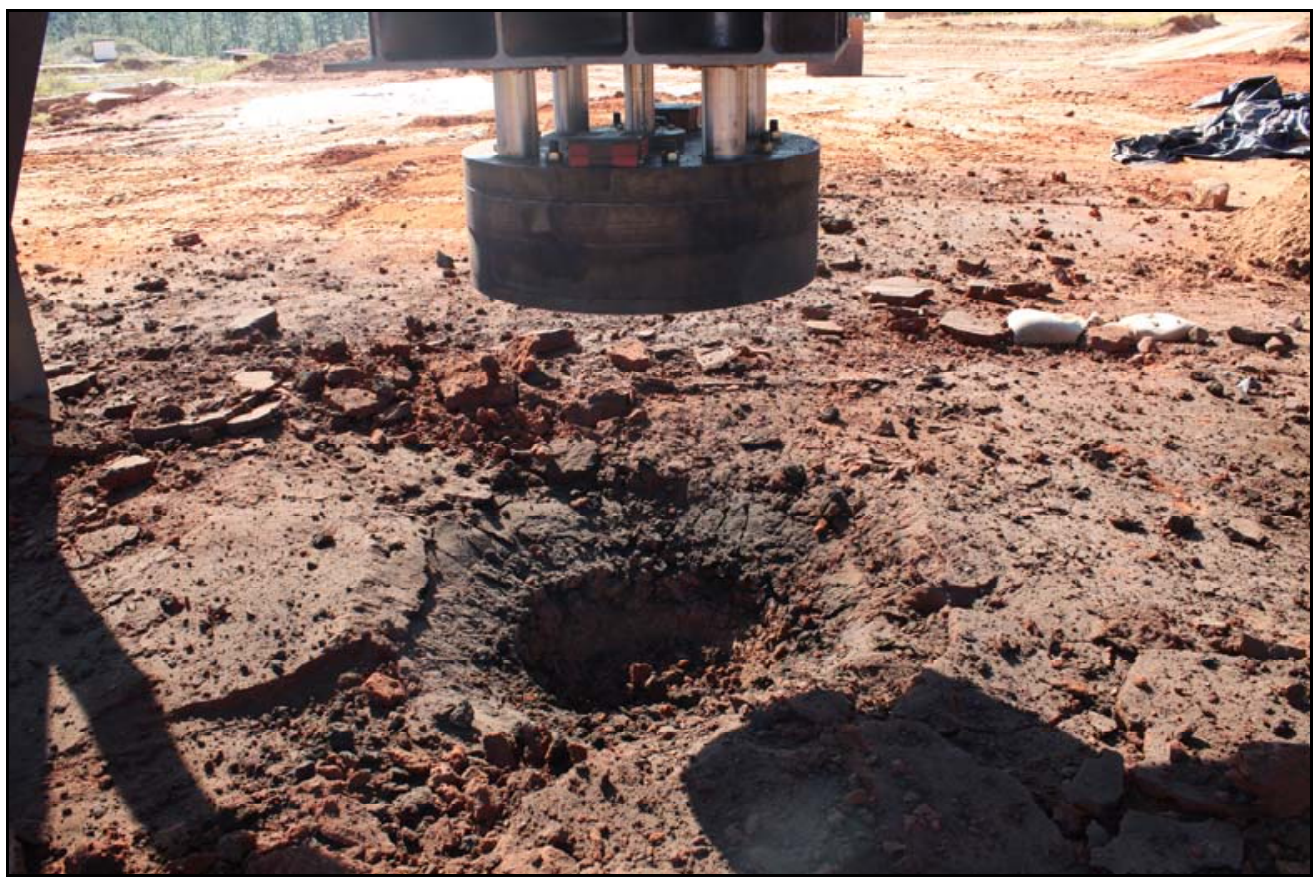

b. Photograph of posttest crater in BM-I-05.

Figure 4.8. Photograph and cross-section surveys of testbed crater in BM-I-05. 


\section{Ground shock stress and particle velocity}

The intermediate soil test series contained ground shock instrumentation in the two experiments with the charge buried 4 in. below the ground surface, i.e., experiments BM-I-03 and BM-I-05. The center of each gage was at the same depth, $5.15 \mathrm{in}$. below the ground surface, as the center of the explosive charge. The as-placed gage locations and a summary of the measured soil stress and particle velocity data at each gage location in the backfill for experiments BM-I-03 and -05 are given in Table 4.2 and include the experiment number, gage number, range (radial distance) from GZ, time of shock arrival, peak velocity, and peak stress. Selection of the peak amplitude values and the times of arrival of peak amplitudes can be difficult in an environment where reflections are occurring rapidly from a number of sources, and gages are undergoing large motions. As always, the values shown in Table 4.2 are subject to different interpretations. In some cases, two peaks were recorded in the time-history records for both the radial stress and radial particle velocity. When a second peak was clearly present, it was included in the summary table. Possible causes for the second peaks include reflected waves from the testbed surface, aboveground pressures traveling along the ground surface, and reflections off the IMD device.

Table 4.2 Ground shock instrumentation summary for intermediate soil experiments.

\begin{tabular}{|l|l|l|l|l|l|l|l|l|}
\hline $\begin{array}{l}\text { Experiment } \\
\text { Number }\end{array}$ & $\begin{array}{l}\text { Gage } \\
\text { Number }\end{array}$ & $\begin{array}{l}\text { Radius } \\
\text { from GZ, } \\
\text { ft }\end{array}$ & $\begin{array}{l}\text { Depth Below } \\
\text { Ground } \\
\text { Surface, in. }\end{array}$ & $\begin{array}{l}\text { Time of } \\
\text { Arrival, } \\
\text { msec }\end{array}$ & $\begin{array}{l}\text { Peak } \\
\text { Velocity, } \\
\text { fps }\end{array}$ & $\begin{array}{l}\text { Second } \\
\text { Peak } \\
\text { Velocity, fps }\end{array}$ & $\begin{array}{l}\text { Peak } \\
\text { Stress, } \\
\text { psi }\end{array}$ & $\begin{array}{l}\text { Second Peak } \\
\text { Stress, psi }\end{array}$ \\
\hline BM-I-03 & AR1 & 3 & 5.15 & 0.97 & 19.8 & & - & - \\
\hline BM-I-03 & AR2 & 4 & 5.15 & 1.97 & 5.6 & 6.7 & - & - \\
\hline BM-I-03 & AR3 & 5 & 5.15 & 2.70 & 3.8 & & - & - \\
\hline BM-I-03 & SR1 & 3 & 5.15 & 0.73 & - & - & 220 & - \\
\hline BM-I-03 & SR2 & 4 & 5.15 & 0.96 & - & - & 135 & - \\
\hline BM-I-03 & SR3 & 5 & 5.15 & 1.67 & - & - & 43 & 43 \\
\hline BM-I-05 & AR1 & 3 & 5.15 & 1.26 & 19.4 & & -- & - \\
\hline BM-I-05 & AR2 & 4 & 5.15 & 2.05 & 5.2 & & - & - \\
\hline BM-I-05 & AR3 & 5 & 5.15 & 2.51 & 6.5 & & -- & - \\
\hline BM-I-05 & SR1 & 3 & 5.15 & 0.91 & -- & - & 86 & - \\
\hline BM-I-05 & SR2 & 4 & 5.15 & 1.15 & - & - & 31 & 32 \\
\hline BM-I-05 & SR3 & 5 & 5.15 & 1.61 & -- & - & 24 & 25 \\
\hline
\end{tabular}


Most of the backfill radial stress waveforms recorded in the experiments contained some very high-frequency noise transients. The waveforms presented herein represent "low-pass-filtered" records that capture the trends but eliminate the noise frequencies when present. Figure 4.9 shows a typical waveform as recorded. Using digital-signal processing techniques, the data were filtered, and the resulting waveform is overlaid over the original response to indicate how the character of the waveform was preserved.

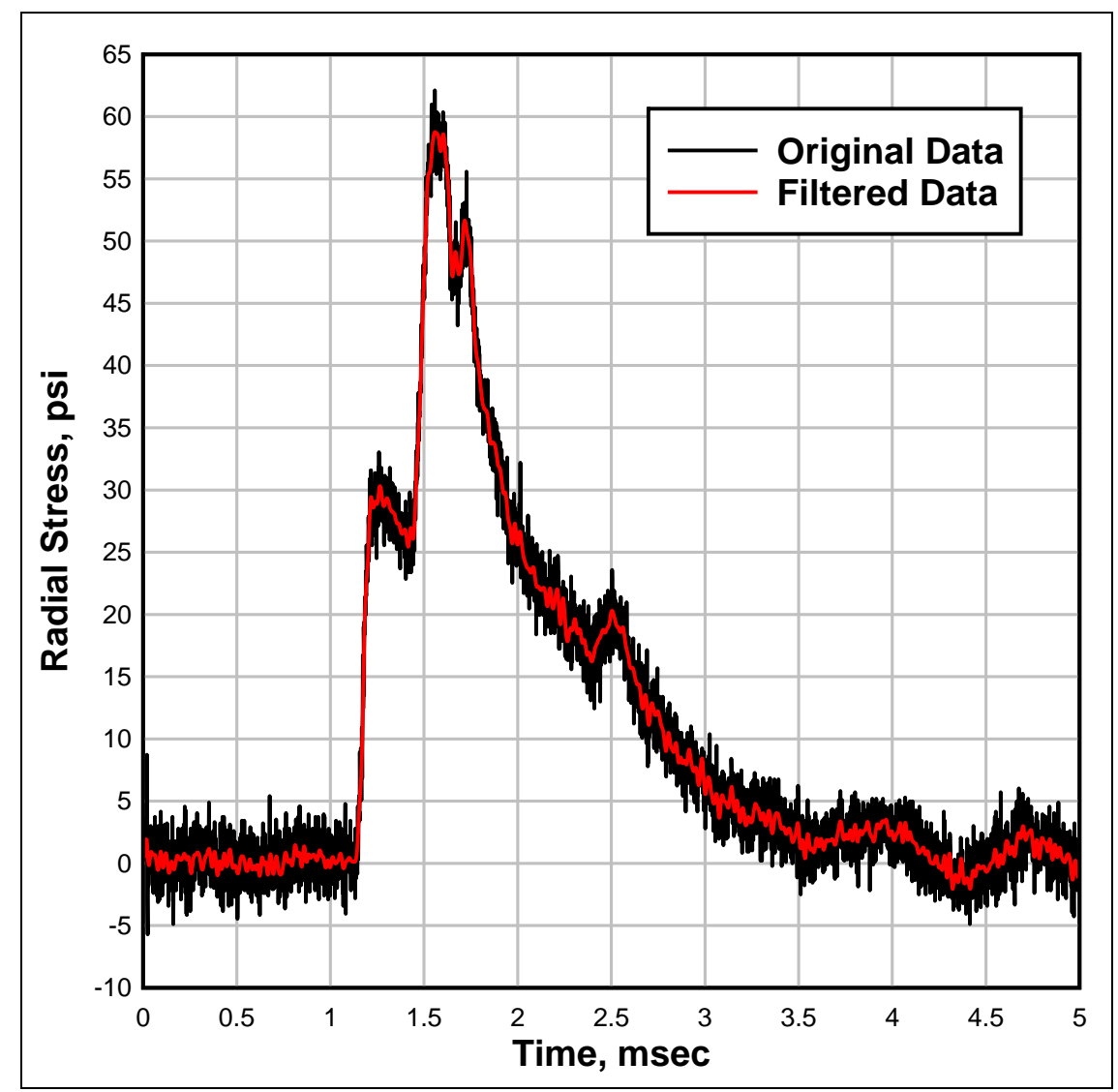

Figure 4.9. Example of changes made to radial stress records to "filter" the records.

\section{Soil stress measurements}

The radial stress time-histories obtained in the intermediate soil backfill in tests BM-I-03 and BM-I-05 at nominal ranges from GZ of 3, 4, and $5 \mathrm{ft}$ are presented in Figures 4.10 and 4.11, respectively, to a time of $20 \mathrm{msec}$. The resulting peak stresses and times of arrival follow the expected trend with the 3-ft range data recording the largest peak stress and earliest time of arrival and the 5-ft range data recording the smallest peak stress and the latest time of arrival. The peak stresses versus range for tests BM-I-03 and BM-I-05 are presented in Figure 4.12. The peak stress value for all three 


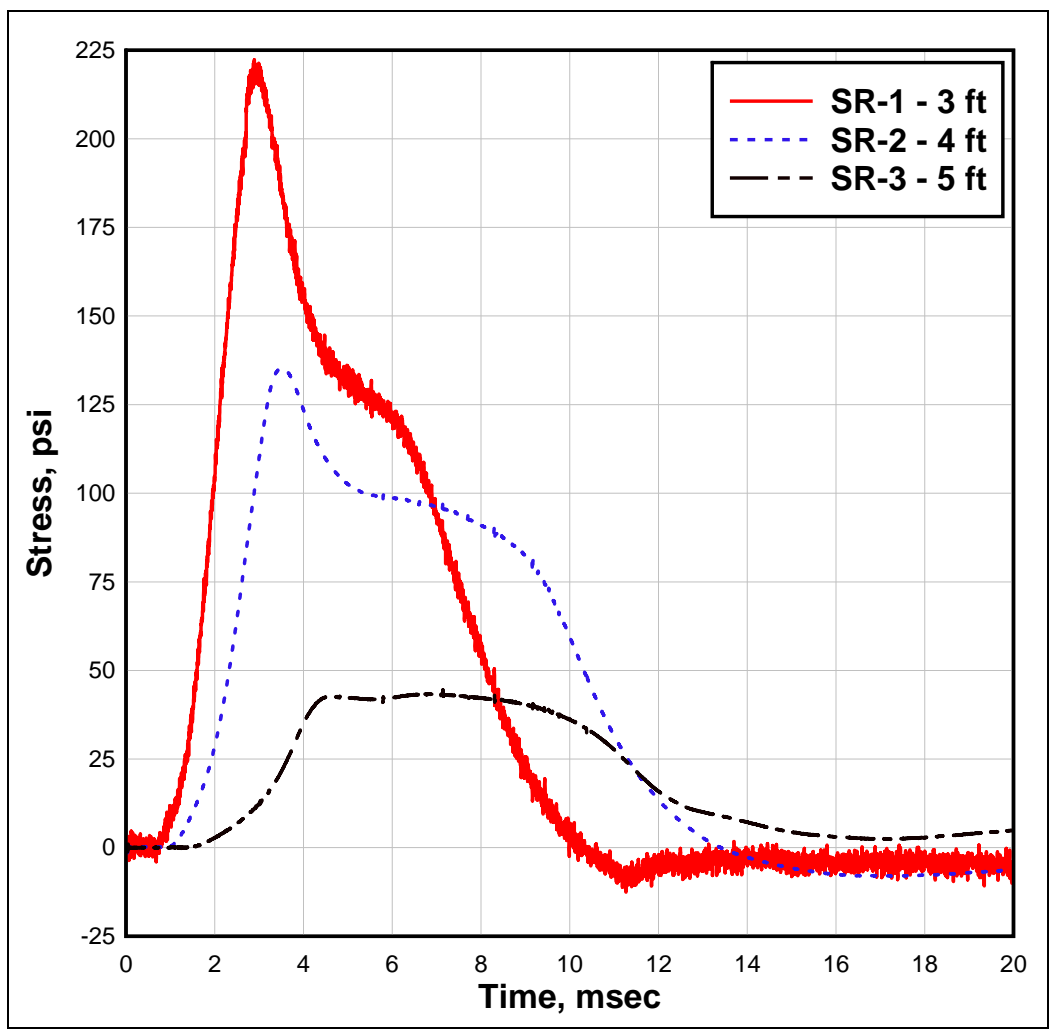

Figure 4.10. Radial stress time-histories measured in the experiment BM-I-03 backfill.

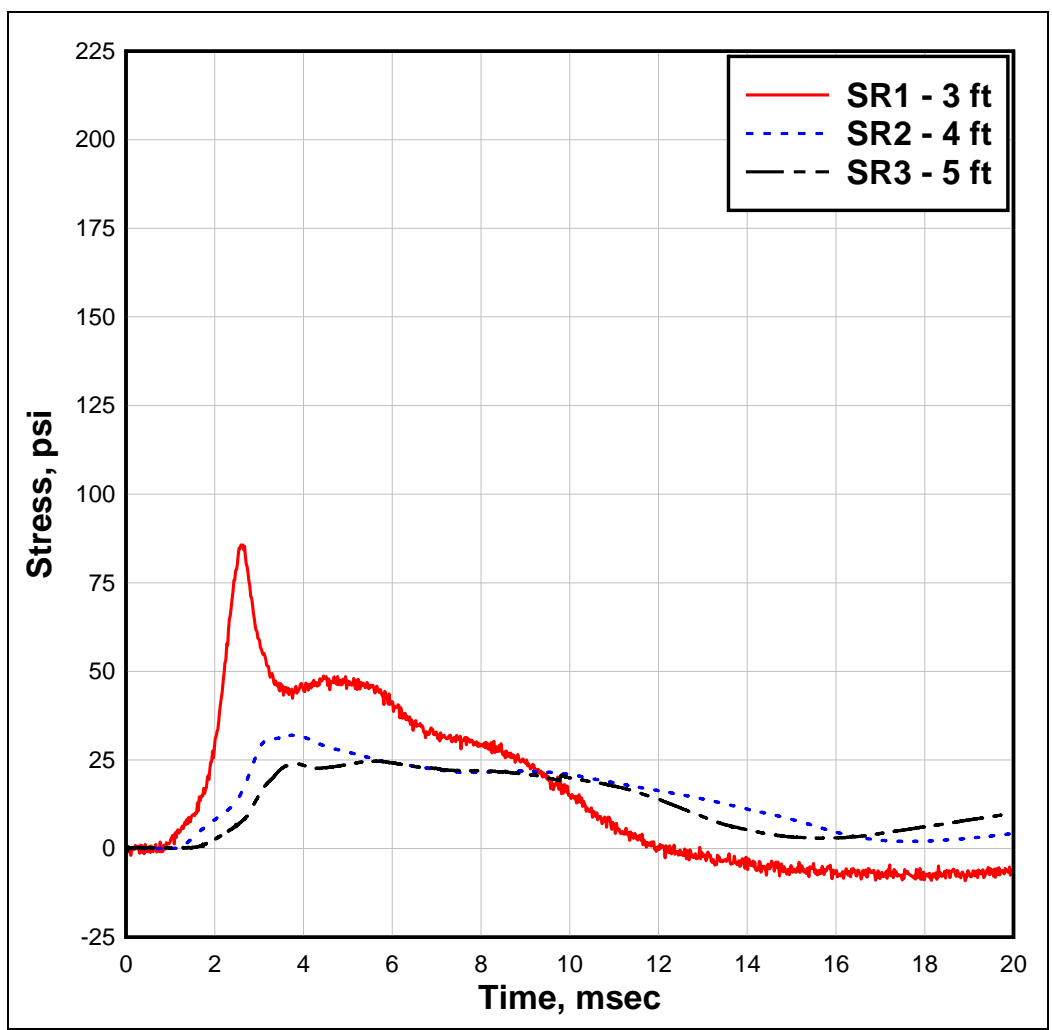

Figure 4.11. Radial stress time-histories measured in the experiment BM-I-05 backfill. 


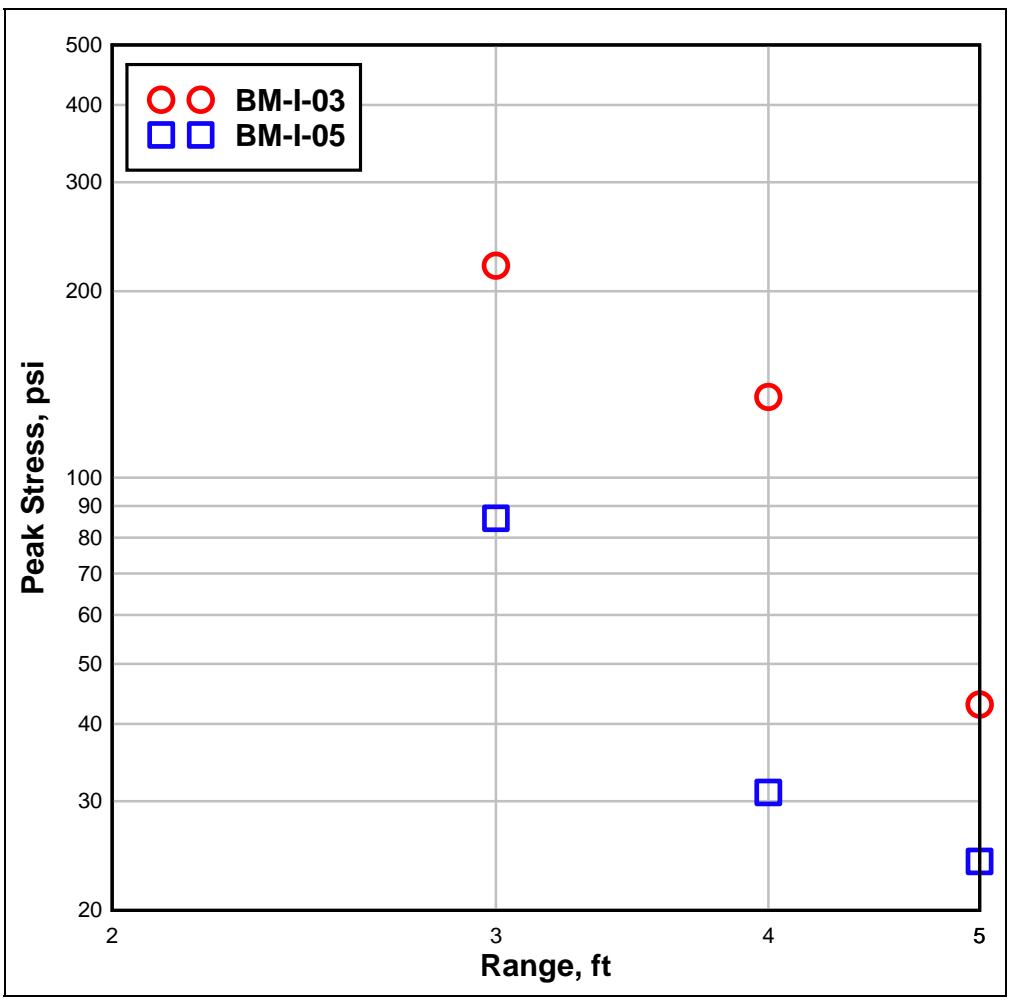

Figure 4.12. Peak stress versus range in the experiment BM-I-03 and BM-I-05 backfills.

ranges in experiment BM-I-03 were significantly greater than the peak values recorded in experiment BM-I-05. It is not clear why such a significant difference occurred in the peak stress values. Very limited ground shock measurement data are available at such a close proximity to the ground surface, so it is difficult to make a clear assessment of the validity of the results.

\section{Soil motions}

The radial particle velocity time-histories obtained in intermediate soil backfill experiments BM-I-03 and BM-I-05 at nominal ranges from GZ of 3,4 , and $5 \mathrm{ft}$ are in Figures 4.13 and 4.14, respectively, to a time of $25 \mathrm{msec}$. The responses were obtained by integrating the accelerometer data to obtain particle velocity. The peak velocities and times of arrival for test BM-I-03 and BM-I-05 agreed reasonably well with each other. The resulting peak particle velocities and times of arrival follow the expected trend, with the gages at the 3-ft range recording the largest peak velocities and earliest times of arrival and the gages at the 5- $\mathrm{ft}$ range recording the latest times of arrival. In test BM-I-05, the times of arrival follow the trend in BM-I-03, but the peak value recorded at $5 \mathrm{ft}$ was slightly higher than 


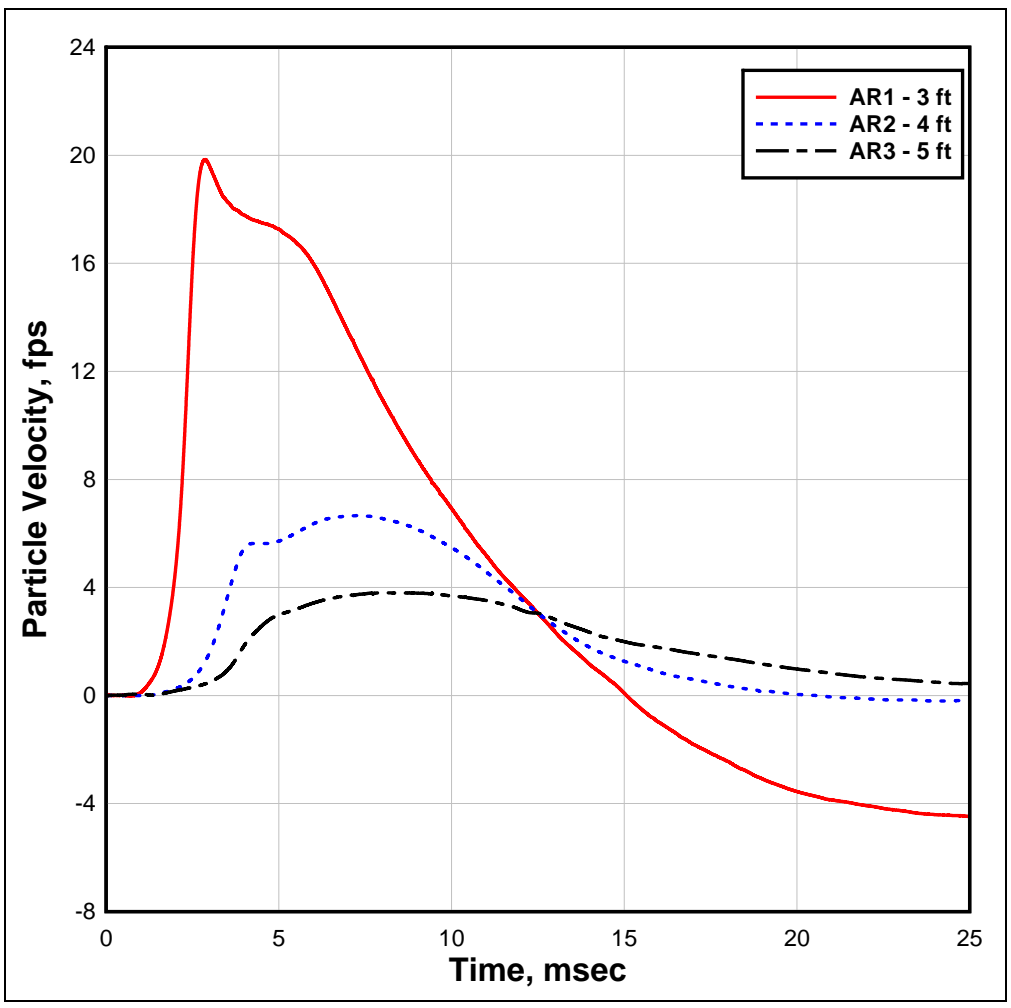

Figure 4.13. Radial particle velocity time-histories measured in the experiment BM-I-03 backfill.

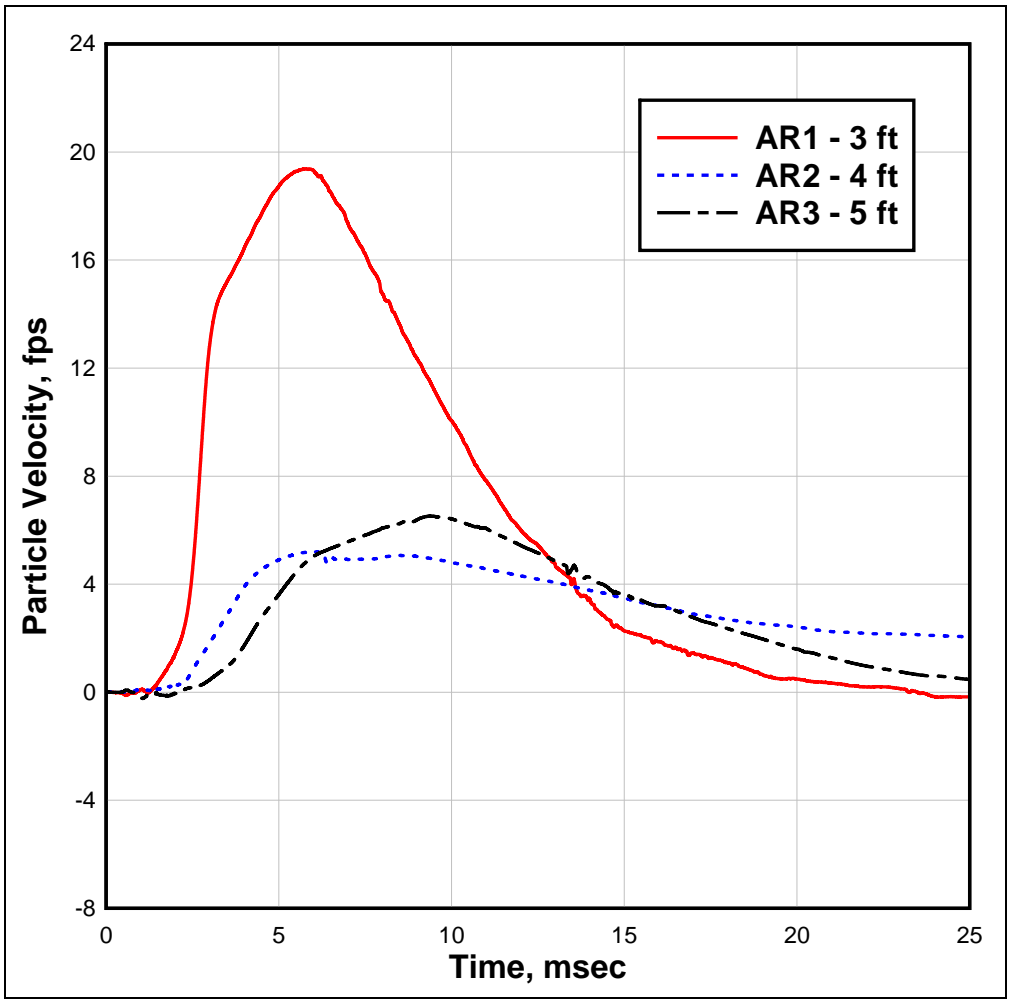

Figure 4.14. Radial particle velocity time-histories measured in experiment the BM-I-05 backfill. 
that recorded at $4 \mathrm{ft}, 5.19 \mathrm{fps}$ versus $6.52 \mathrm{fps}$. The peak particle velocities versus range for experiments BM-I-03 and BM-I-05 are presented in Figure 4.15. In BM-I-05, the velocity waveforms exhibited a pronounced second peak or increase in velocity after the initial velocity rise. This second peak was responsible for the higher net peak velocity observed at the 5- $\mathrm{ft}$ range in BM-I-05. The second peak is probably caused by a reflected wave from the IMD impact plate.

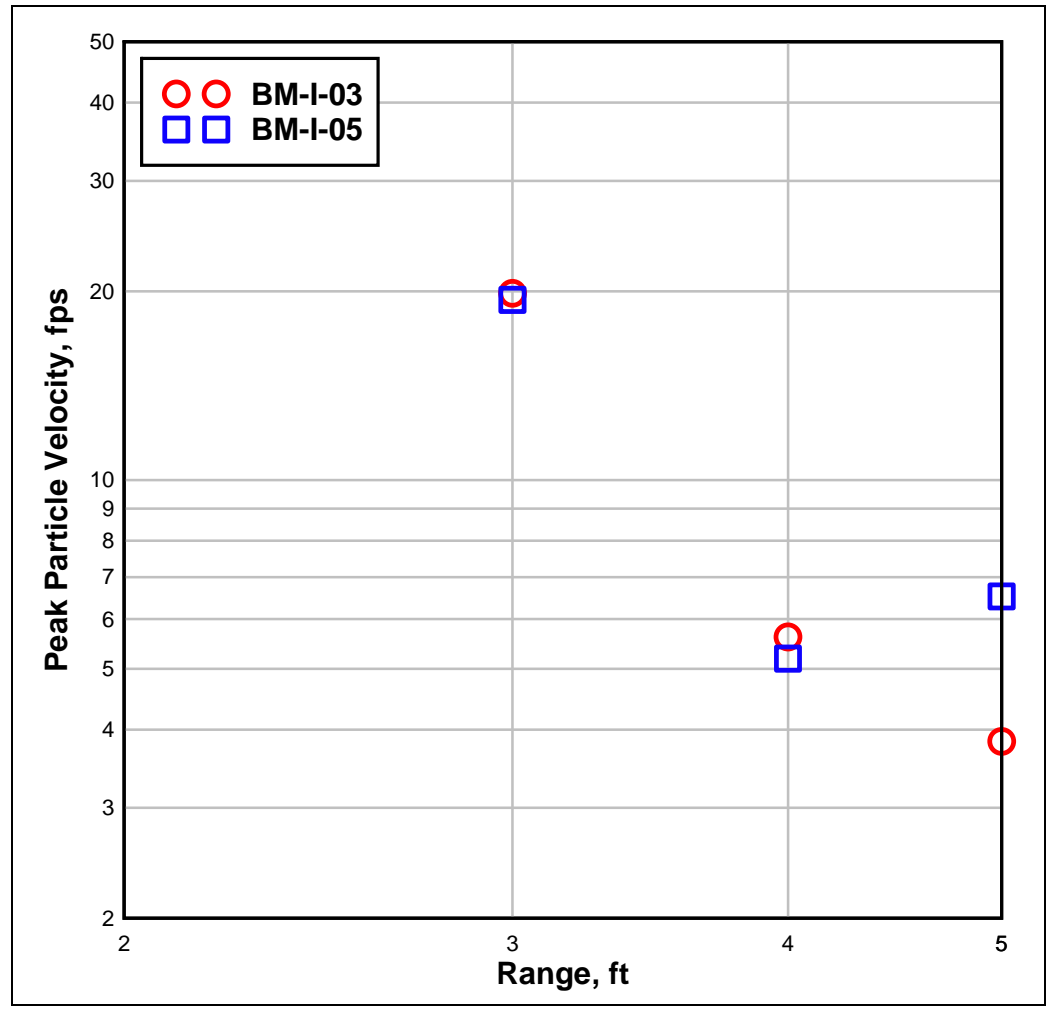

Figure 4.15 Peak particle velocity versus range in the experiment BM-I-03 and BM-I-05 backfills.

\section{Backfill ground shock arrival times}

The initial times of arrival for the ground shock measurements in the intermediate soil backfill are plotted versus range from the GZ of the charge in Figure 4.16. The times of arrival follow the expected trend with an increase in time of arrival with an increase in range from the charge. At all three ranges, the times of arrival of the stress occur slightly earlier than the times of arrival of the motion. In some records, a clear arrival time was not present in the records due to high-frequency noise in the acceleration record or an unexplained gradual early rise prior to the sharp rise to peak. Therefore, some engineering judgment was required, and the values selected are subject to multiple interpretations. 


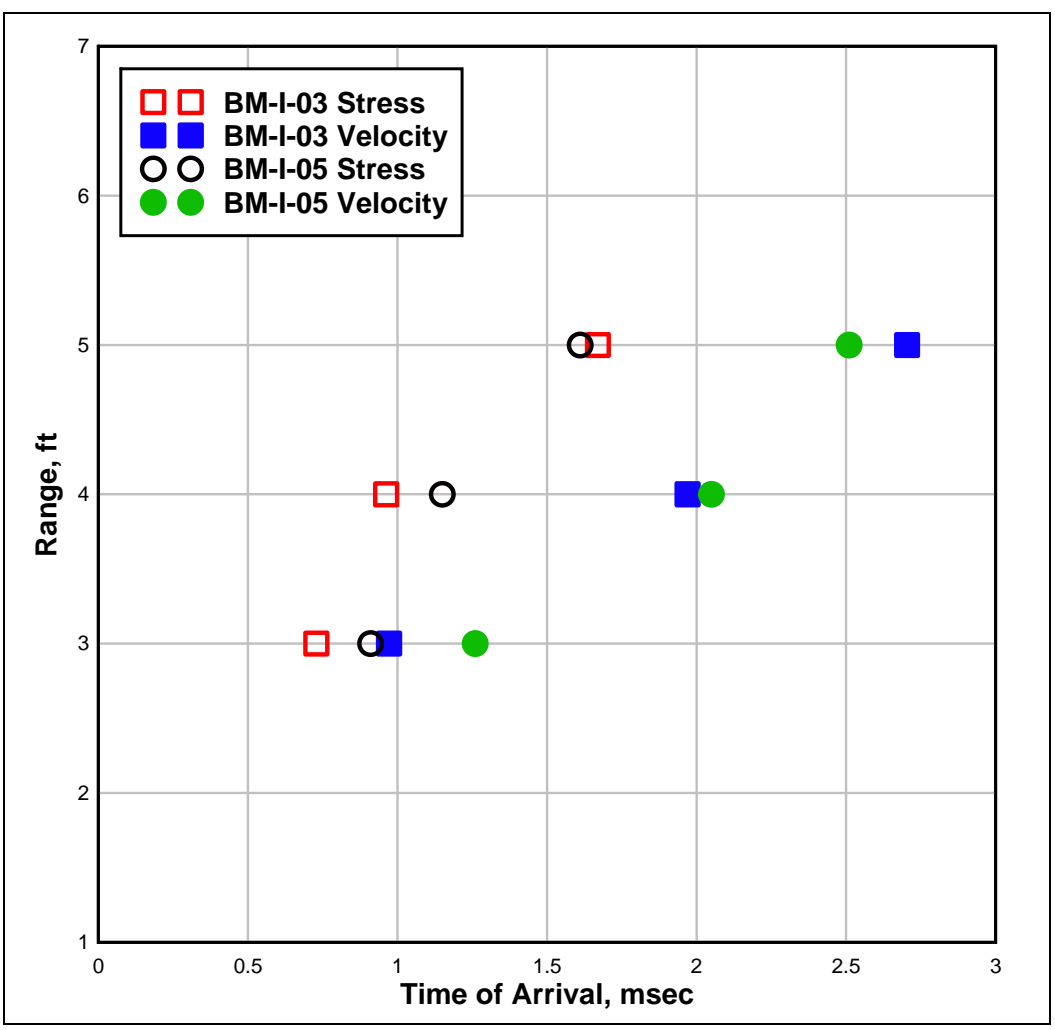

Figure 4.16. Initial ground shock times of arrival versus range from the CG of the charge in the experiment BM-I-03 and BM-I-05 backfills.

\section{Ground surface overpressure}

Three ground surface overpressure gages were used in all five intermediate soil experiments. The gages were located at a range of $8 \mathrm{ft}(\mathrm{OP} 1), 10 \mathrm{ft}$ (OP2), and $14 \mathrm{ft}$ (OP3) from GZ. A summary of the measured data from each gage is in Table 4.3. The table includes the experiment number, gage number, range from GZ, time of shock arrival, peak overpressure, time of peak overpressure, time to peak (rise time), and peak overpressure impulse. The overpressure time-histories obtained at nominal ranges of 8,10 , and $14 \mathrm{ft}$ in test numbers BM-I-01 through BM-I-05 are presented in Figures 4.17-4.21, respectively. The times of arrival of the overpressure versus range, the peak overpressure versus range, and the time of arrival of the peaks versus range are presented in Figures 4.22-4.24, respectively. In all but one location, the results followed the expected trend with the peak overpressure decreasing with range. The exception occurred in experiment BM-I-05 at the 10 - $\mathrm{ft}$ range where the recorded peak value at $10-\mathrm{ft}$ range was higher than that at the closer range of $8 \mathrm{ft}$. This was likely a singular case of additional peak enhancement due to pressure reflection off the IMD. When the results of BM-I-05 are compared with the results of BM-I-03, both with the explosive charge buried 4 in., the results compare 
Table 4.3 Ground surface overpressure summary for intermediate soil.

\begin{tabular}{|l|l|l|l|l|l|l|l|}
\hline $\begin{array}{l}\text { Experiment } \\
\text { Number }\end{array}$ & $\begin{array}{l}\text { Gage } \\
\text { Number }\end{array}$ & $\begin{array}{l}\text { Range from } \\
\text { GZ, ft }\end{array}$ & $\begin{array}{l}\text { Shock Time } \\
\text { of Arrival, } \\
\text { msec }\end{array}$ & $\begin{array}{l}\text { Peak } \\
\text { Pressure, } \\
\text { psi }\end{array}$ & $\begin{array}{l}\text { Time of } \\
\text { Peak } \\
\text { Pressure, } \\
\text { msec }\end{array}$ & $\begin{array}{l}\text { Rise Time, } \\
\text { msec }\end{array}$ & $\begin{array}{l}\text { Peak } \\
\text { Impulse, psi } \\
\text { sec }\end{array}$ \\
\hline BM-I-01 & OP - 1 & 8 & 1.57 & 36.7 & 1.70 & 0.13 & 0.023 \\
\hline BM-I-01 & OP - 2 & 10 & 2.66 & 24.0 & 2.75 & 0.09 & 0.021 \\
\hline BM-I-01 & OP - 3 & 14 & 5.20 & 10.8 & 5.33 & 0.13 & 0.019 \\
\hline BM-I-02 & OP - 1 & 8 & 3.19 & 17.5 & 3.31 & 0.12 & 0.017 \\
\hline BM-I-02 & OP - 2 & 10 & 4.43 & 15.3 & 4.53 & 0.11 & 0.016 \\
\hline BM-I-02 & OP - 3 & 14 & 7.07 & 10.7 & 7.19 & 0.12 & 0.014 \\
\hline BM-I-03 & OP - 1 & 8 & 5.34 & 7.1 & 5.47 & 0.13 & 0.006 \\
\hline BM-I-03 & OP - 2 & 10 & 6.83 & 5.5 & 6.99 & 0.16 & 0.006 \\
\hline BM-I-03 & OP - 3 & 14 & 9.97 & 4.0 & 10.13 & 0.16 & 0.005 \\
\hline BM-I-04 & OP - 1 & 8 & 1.59 & 49.9 & 1.72 & 0.12 & 0.031 \\
\hline BM-I-04 & OP - 2 & 10 & 2.51 & 28.1 & 2.66 & 0.15 & 0.024 \\
\hline BM-I-04 & OP - 3 & 14 & 4.91 & 18.9 & 5.04 & 0.13 & 0.018 \\
\hline BM-I-05 & OP - 1 & 8 & 4.36 & 9.5 & 4.46 & 0.10 & 0.006 \\
\hline BM-I-05 & OP - 2 & 10 & 5.57 & 12.7 & 5.67 & 0.10 & 0.010 \\
\hline BM-I-05 & OP - 3 & 14 & 8.59 & 5.2 & 8.76 & 0.18 & 0.007 \\
\hline
\end{tabular}

reasonably well at the $8 \mathrm{ft}$ and $14 \mathrm{ft}$ ranges. The data recorded at $10 \mathrm{ft}$ in experiment BM-I-05 were significantly higher than those collected at the $10-\mathrm{ft}$ range in experiment BM-I-03. This variation may be the result of reflections off the IMD impact plate in BM-I-05. The times of arrival of the shocks and the times of arrival of the peaks followed the expected trend with the arrival time increasing with range from GZ. The experiments with the charge buried 4 in., BM-I-03 and -05, had a significant increase in the arrival times at the same ranges when compared with experiments with the charge resting on the surface, TSA, and buried, TSB. Comparing results from experiments with the IMD versus results from identical experiments without the device, those with the IMD exhibited higher peak airblast overpressure in every case. This was due to airblast reflection off the IMD, which enhanced the airblast pressures near the ground surface. 


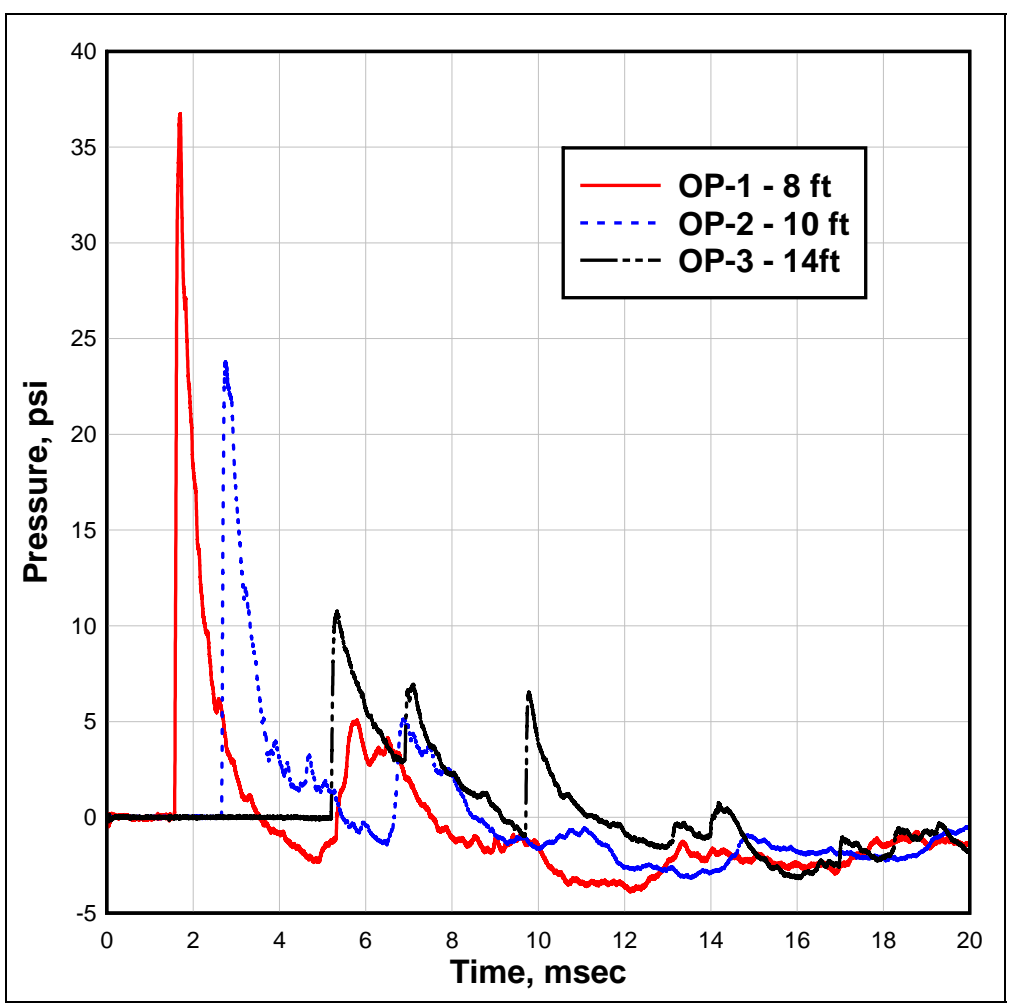

Figure 4.17. Ground surface overpressure time-histories at ranges of 8,10 , and $14 \mathrm{ft}$ from experiment BM-I-01.

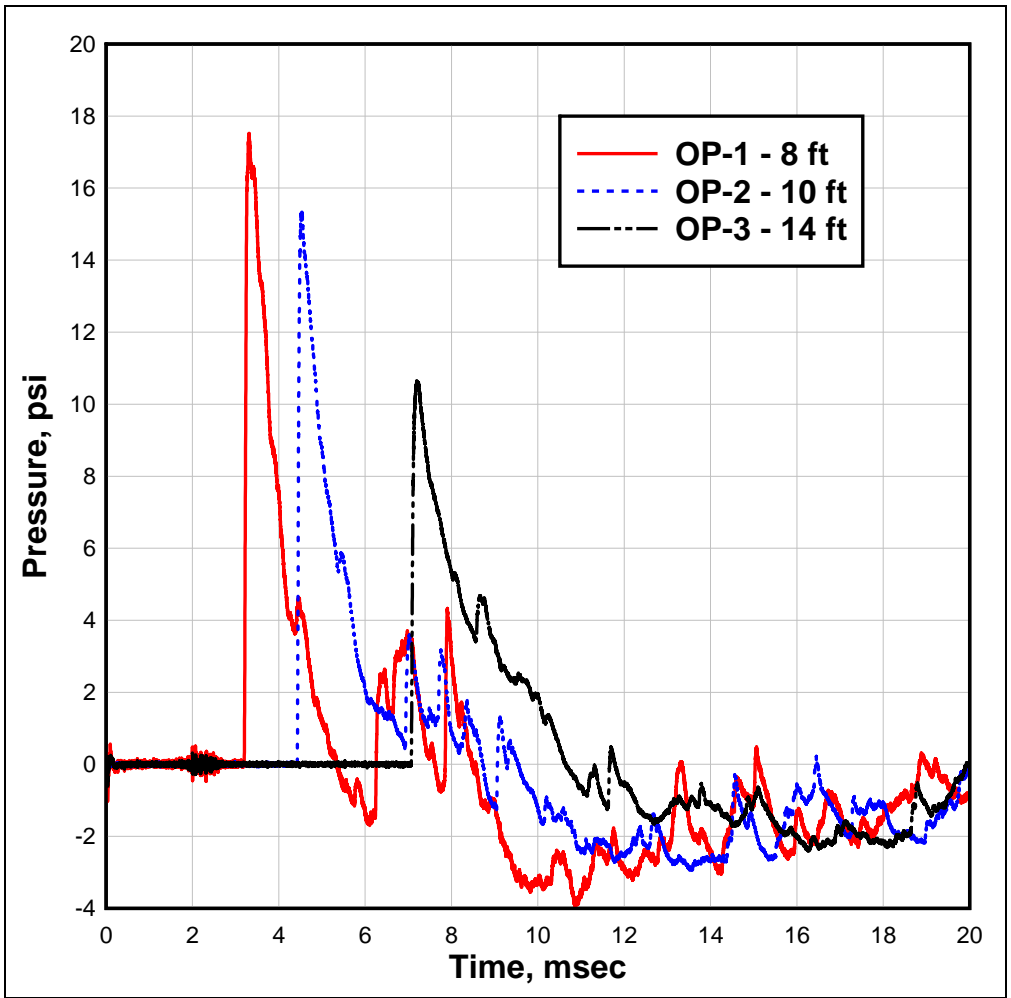

Figure 4.18. Ground surface overpressure time-histories at ranges of 8,10 , and $14 \mathrm{ft}$ from experiment BM-I-02. 


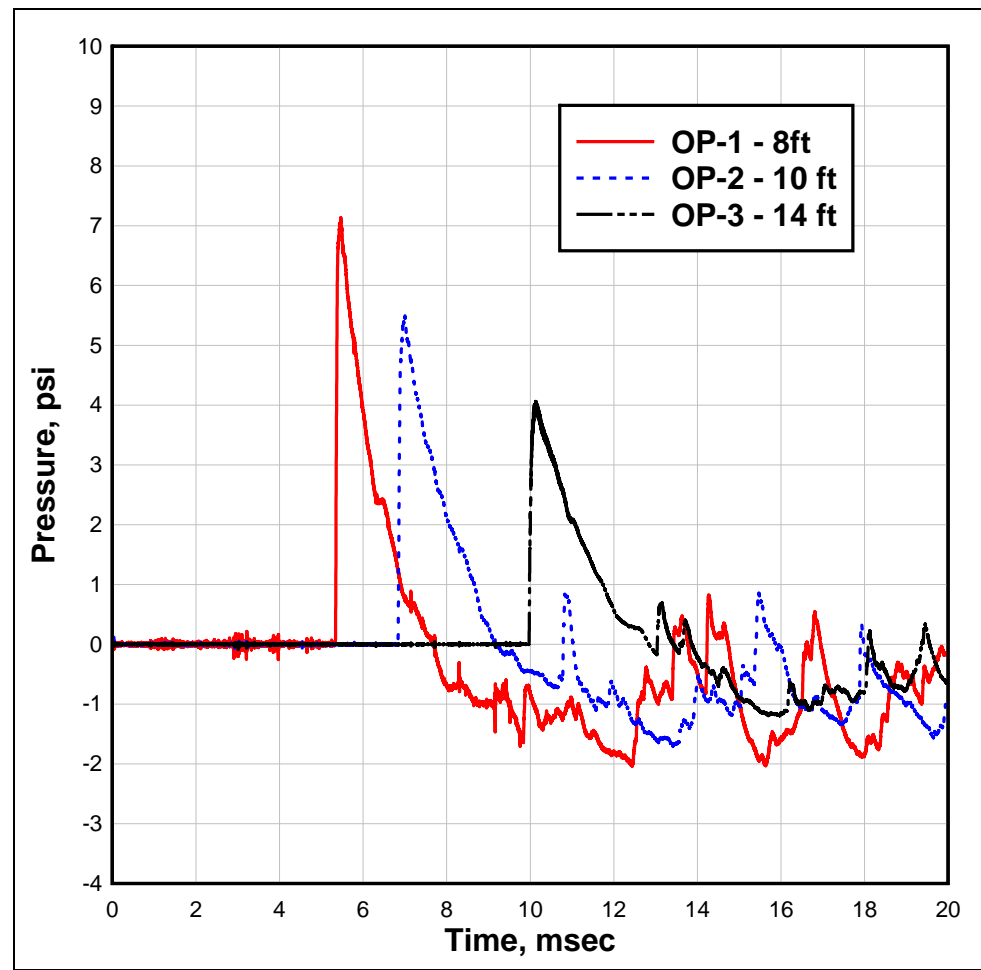

Figure 4.19. Ground surface overpressure time-histories at ranges of 8,10 , and $14 \mathrm{ft}$ from experiment BM-I-03.

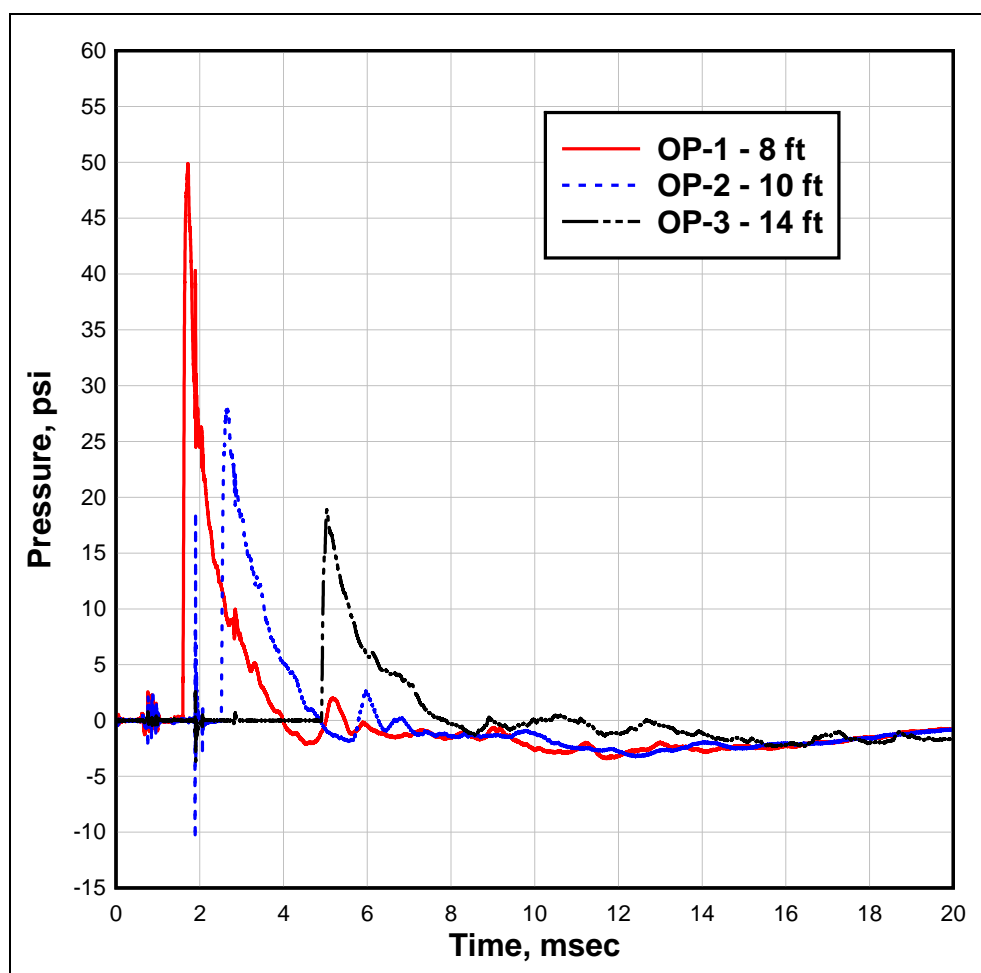

Figure 4.20. Ground surface overpressure time-histories at ranges of 8,10 , and $14 \mathrm{ft}$ from experiment BM-I-04. 


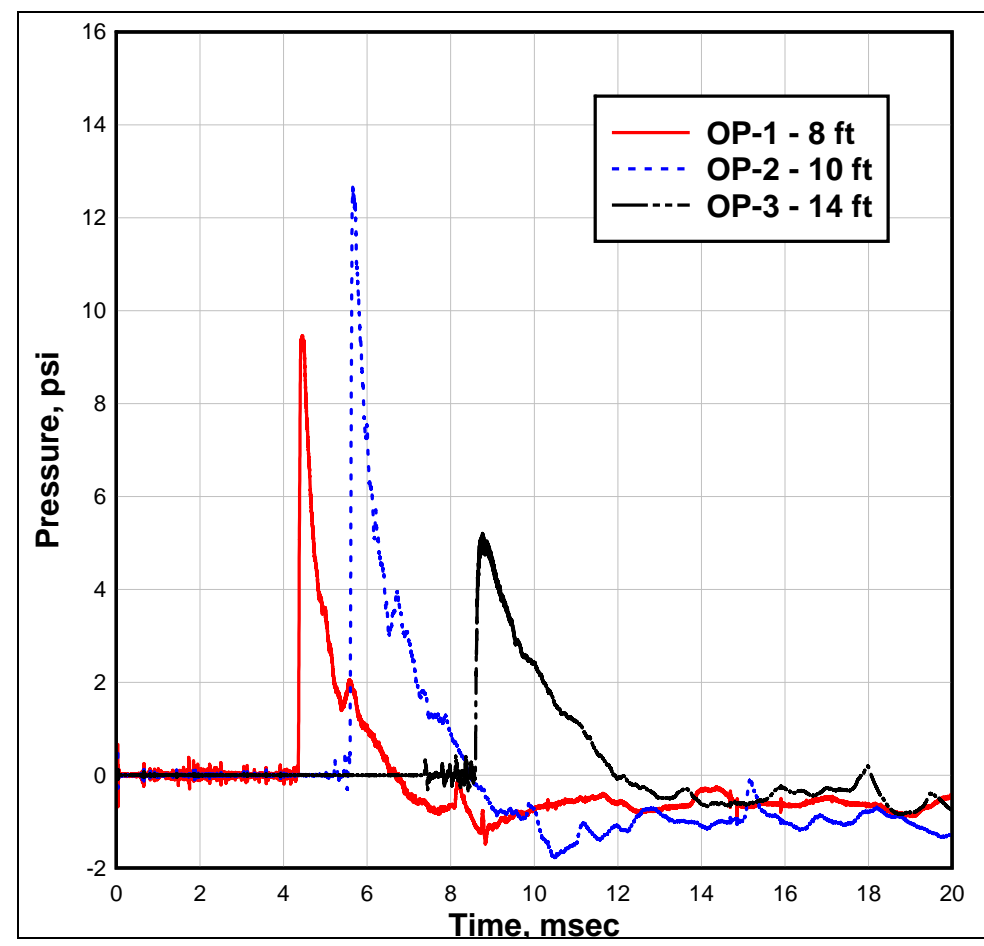

Figure 4.21. Ground surface overpressure time-histories at ranges of 8,10 , and $14 \mathrm{ft}$ from experiment BM-I-05.

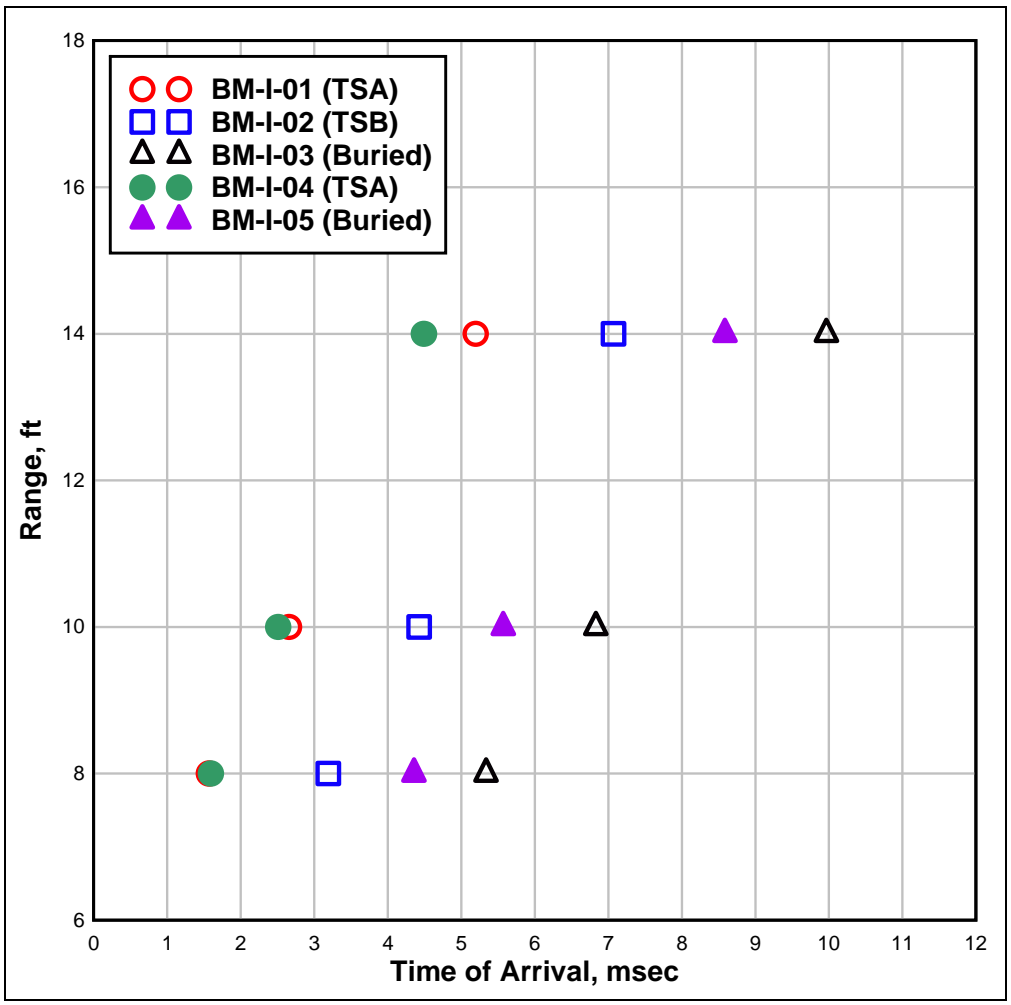

Figure 4.22. Ground surface overpressure times of arrival versus range for experiments $\mathrm{BM}-\mathrm{I}-01$ through $\mathrm{BM}-\mathrm{I}-05$. 


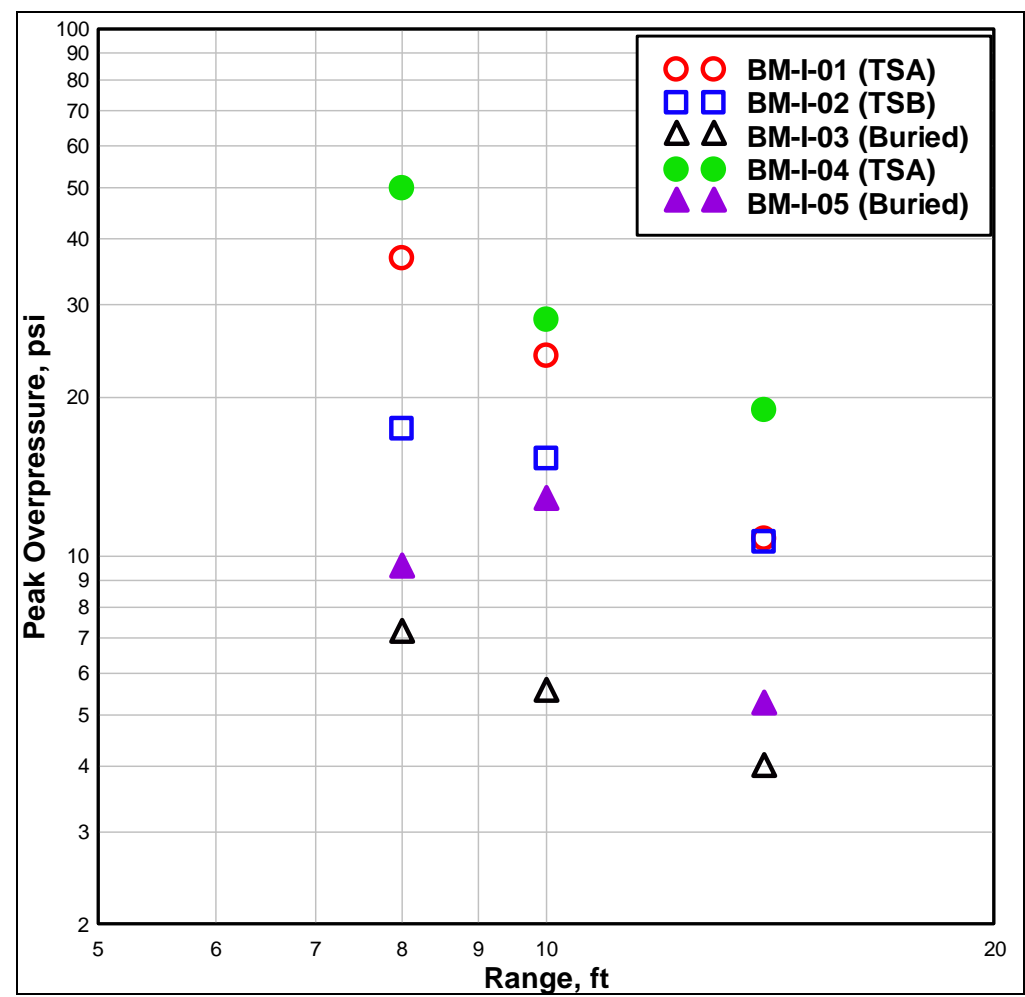

Figure 4.23. Ground surface peak overpressure versus range for experiments BM-I-01 through BM-I-05.

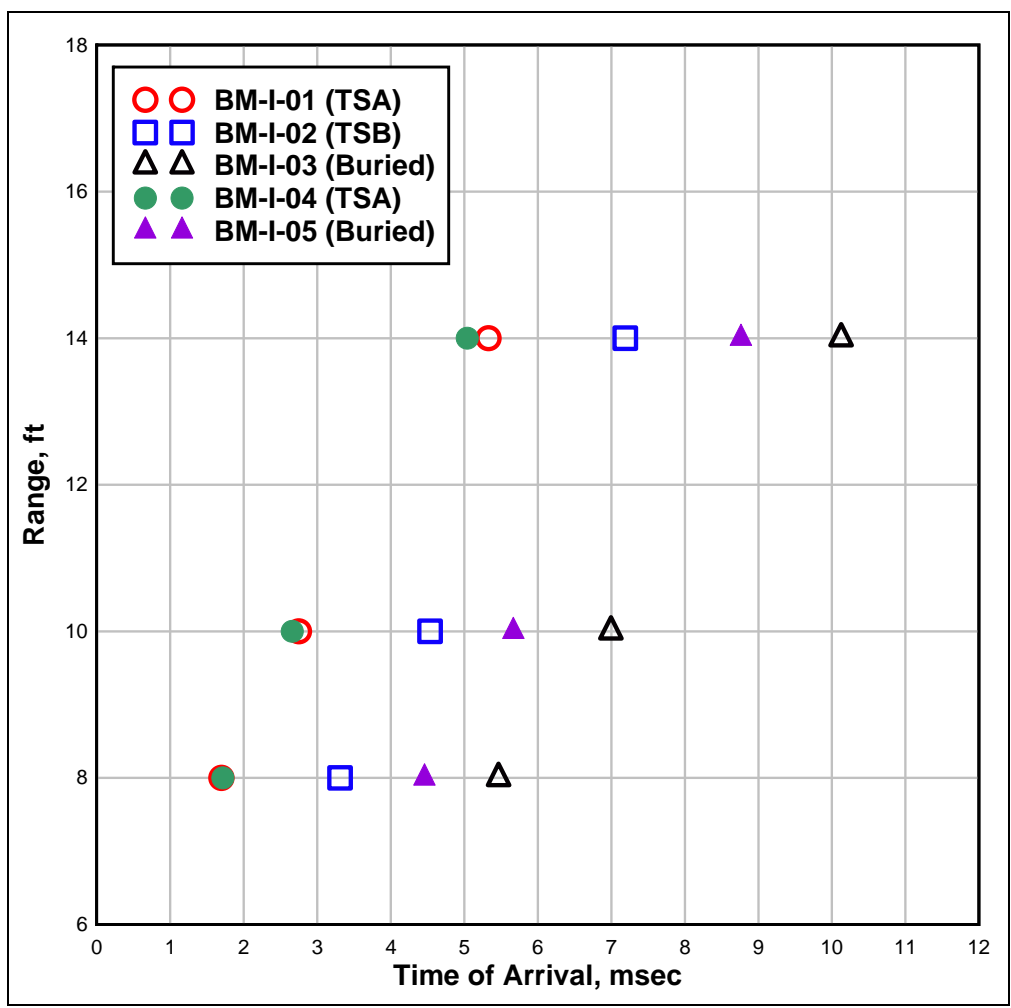

Figure 4.24. Ground surface peak overpressure times of arrival versus range for experiment BM-I-01 through BM-I-05. 


\section{Aboveground side-on overpressure}

Intermediate soil experiments BM-I-01, BM-I-02, and BM-I-03 were conducted with a series of five side-on overpressure gages above the testbed surface. For all three experiments, the standoff distance between the top of the charge and a horizontal plane through the side-on overpressures gages was held constant at $20 \mathrm{in}$. The gages were located in line so that one gage was directly above the charge, two had a horizontal offset of 18 in., and two had a horizontal offset of $36 \mathrm{in}$. A summary of the aboveground side-on overpressure data for the intermediate soil experiments is in Table 4.4. The table includes the experiment number, the gage number, horizontal range from GZ (vertical range held constant at 20 in.), range from the GZ, shock time of arrival, peak overpressure, time of peak pressure, rise time, and peak overpressure impulse. The stress time-histories obtained from in the side-on overpressure gages in experiments BM-I-01, BM-I-02, and BM-I-03 are presented in Figures 4.25- 4.32. The two redundant gages at 18 and 36 in. are shown on the same plots. The shock times of arrival versus range and the peak side-on overpressure stresses versus range for the three experiments are presented in Figures 4.33 and 4.34, respectively.

Table 4.4. Side-on overpressure summary for intermediate soil experiments.

\begin{tabular}{|l|l|l|l|l|l|l|l|l|}
\hline $\begin{array}{l}\text { Experimen } \\
\text { t Number }\end{array}$ & $\begin{array}{l}\text { Gage } \\
\text { Number }\end{array}$ & $\begin{array}{l}\text { Rorizontal } \\
\text { from GZ, } \\
\text { in. }\end{array}$ & $\begin{array}{l}\text { Range } \\
\text { from GZ, } \\
\text { in. }\end{array}$ & $\begin{array}{l}\text { Shock } \\
\text { Time of } \\
\text { Arrival, } \\
\text { msec }\end{array}$ & $\begin{array}{l}\text { Peak } \\
\text { Pressure, } \\
\text { psi }\end{array}$ & $\begin{array}{l}\text { Time of } \\
\text { Peak } \\
\text { Pressure, } \\
\text { msec }\end{array}$ & $\begin{array}{l}\text { Rise Time, } \\
\text { msec }\end{array}$ & $\begin{array}{l}\text { Peak } \\
\text { Impulse, } \\
\text { psi-sec }\end{array}$ \\
\hline BM-I-01 & SOP-1 & 36 & 41.75 & 0.47 & 132.3 & 0.49 & 0.03 & 0.032 \\
\hline BM-I-01 & SOP-2 & 18 & 27.77 & 0.28 & 232.7 & 0.34 & 0.05 & 0.030 \\
\hline BM-I-01 & SOP-3 & 0 & 21.15 & 0.13 & 2397.9 & 0.15 & 0.03 & 0.087 \\
\hline BM-I-01 & SOP-4 & 18 & 27.77 & 0.23 & 229.3 & 0.25 & 0.02 & 0.029 \\
\hline BM-I-01 & SOP-5 & 36 & 41.75 & 0.51 & 154.8 & 0.56 & 0.05 & 0.026 \\
\hline BM-I-02 & SOP-1 & 36 & 41.74 & 0.63 & 65.9 & 0.66 & 0.03 & 0.012 \\
\hline BM-I-02 & SOP-2 & 18 & 27.77 & 0.23 & 373.5 & 0.25 & 0.02 & 0.025 \\
\hline BM-I-02 & SOP-3 & 0 & 21.15 & -- & -- & -- & -- & -- \\
\hline BM-I-02 & SOP-4 & 18 & 27.77 & 0.24 & 311.7 & 0.27 & 0.03 & 0.022 \\
\hline BM-I-02 & SOP-5 & 36 & 41.75 & 0.68 & 69.9 & 0.72 & 0.05 & 0.012 \\
\hline BM-I-03 & SOP-1 & 36 & 41.74 & 1.77 & 16.0 & 1.80 & 0.03 & 0.006 \\
\hline BM-I-03 & SOP-2 & 18 & 27.77 & 0.90 & 42.7 & 1.00 & 0.09 & 0.009 \\
\hline BM-I-03 & SOP-3 & 0 & 21.15 & 0.42 & 385.7 & 0.65 & 0.23 & 0.173 \\
\hline BM-I-03 & SOP-4 & 18 & 27.77 & 0.88 & 29.9 & 0.99 & 0.11 & 0.009 \\
\hline BM-I-03 & SOP-5 & 36 & 41.75 & 1.73 & 18.1 & 1.78 & 0.05 & 0.006 \\
\hline
\end{tabular}




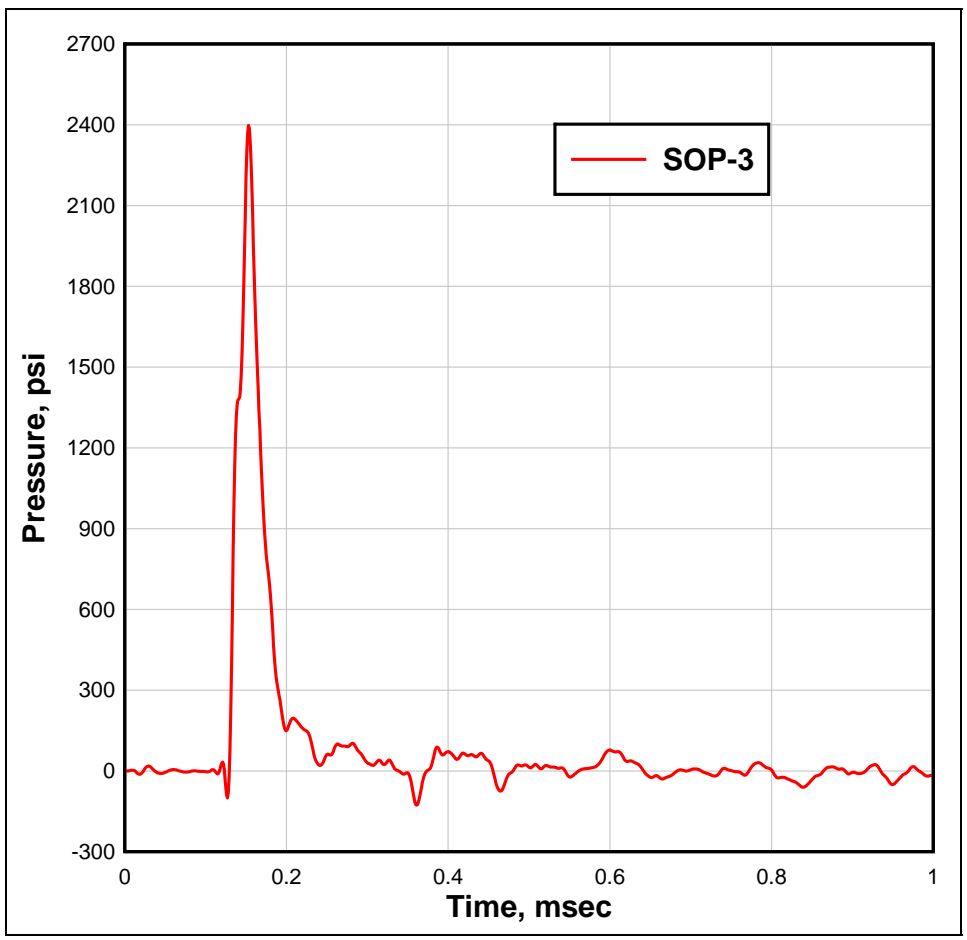

Figure 4.25. Side-on overpressure time-history directly above the charge GZ in experiment BM-I-01.

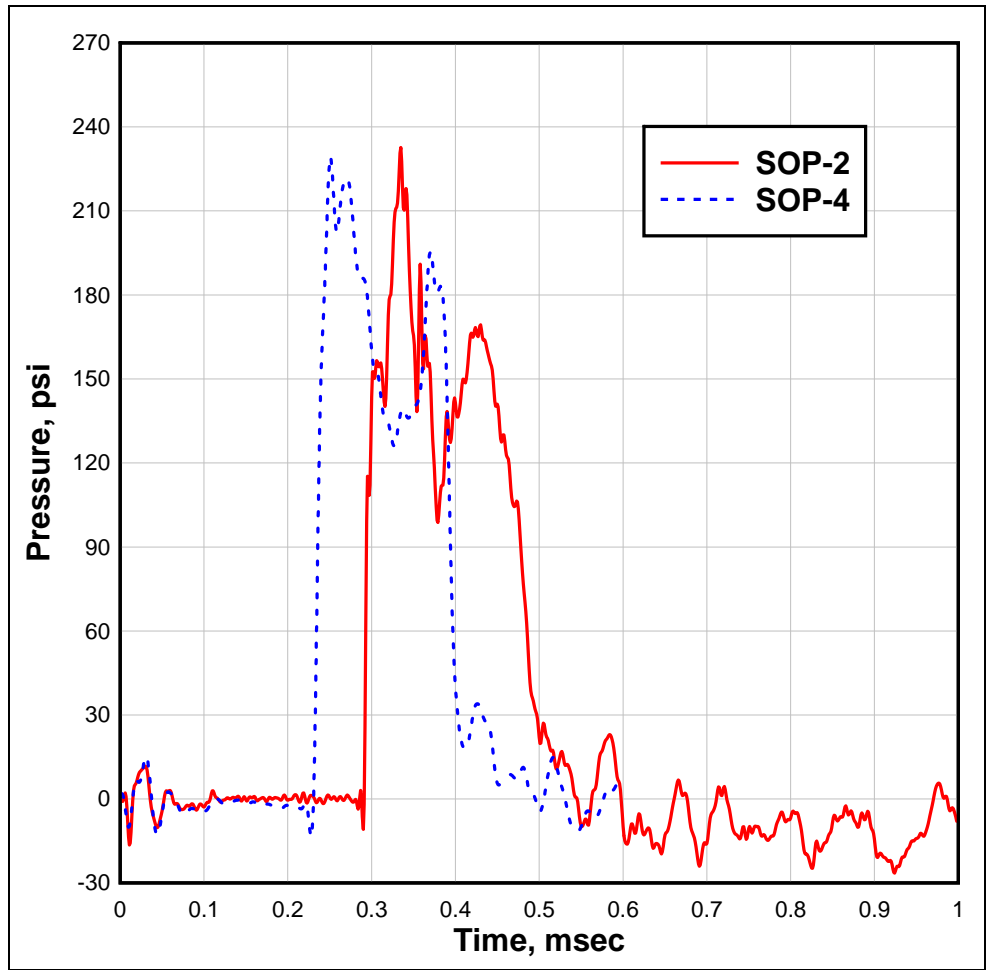

Figure 4.26. Side-on overpressure time-histories at a horizontal range of 18 in. from GZ experiment BM-I-01. 


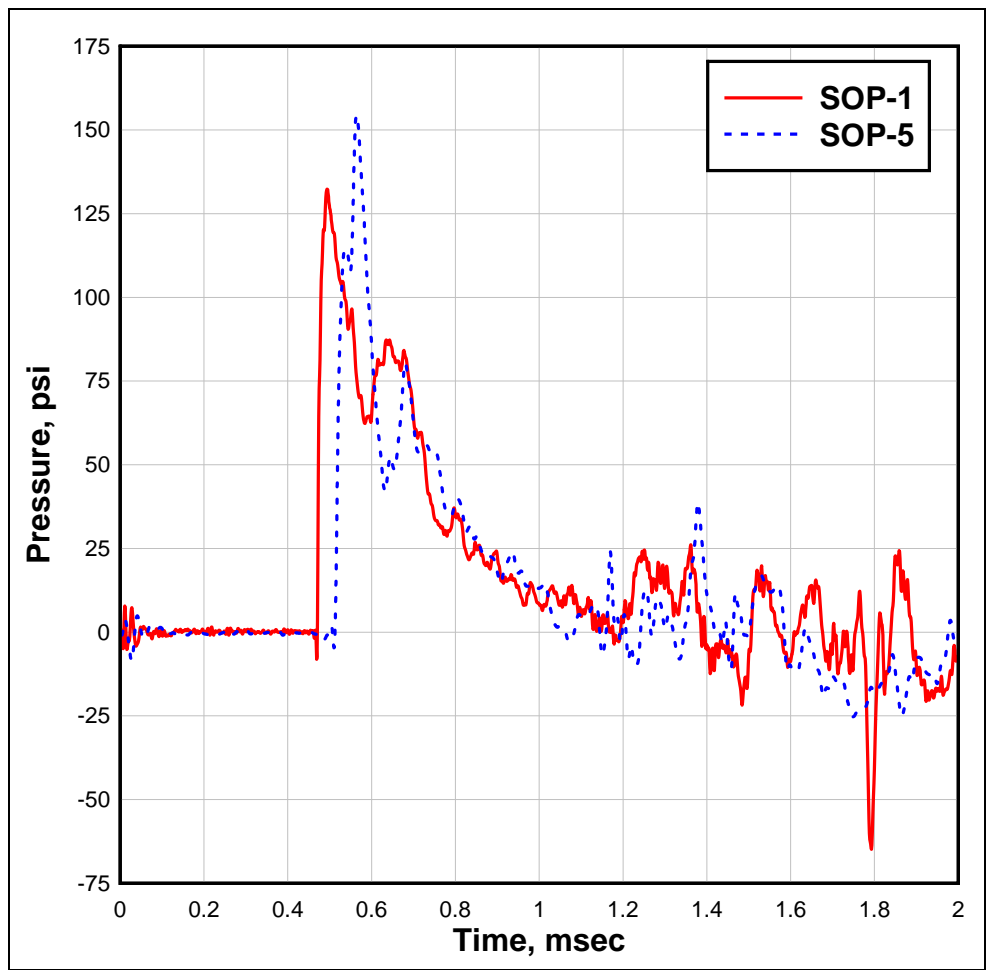

Figure 4.27. Side-on overpressure time-histories at a horizontal range of 36 in. from GZ in experiment BM-I-01.

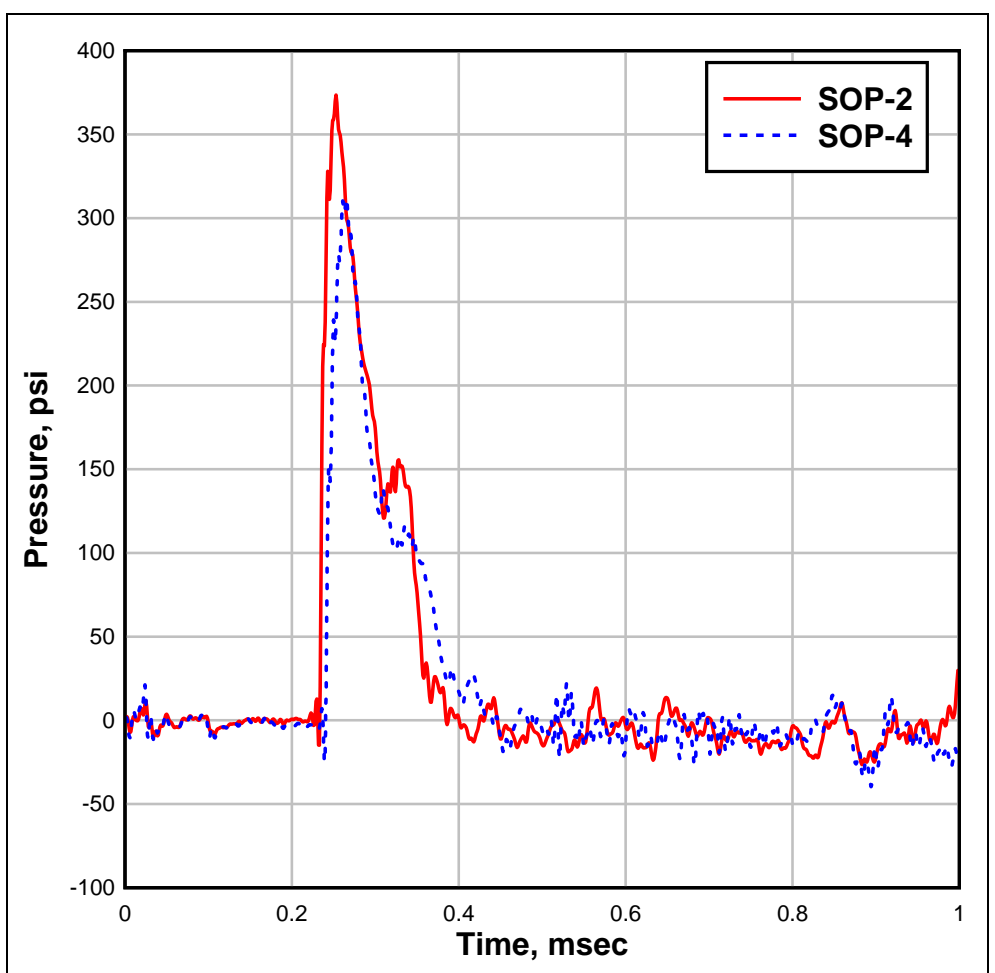

Figure 4.28. Side-on overpressure time-histories at a horizontal range of 18 in. from GZ in experiment BM-I-02. 


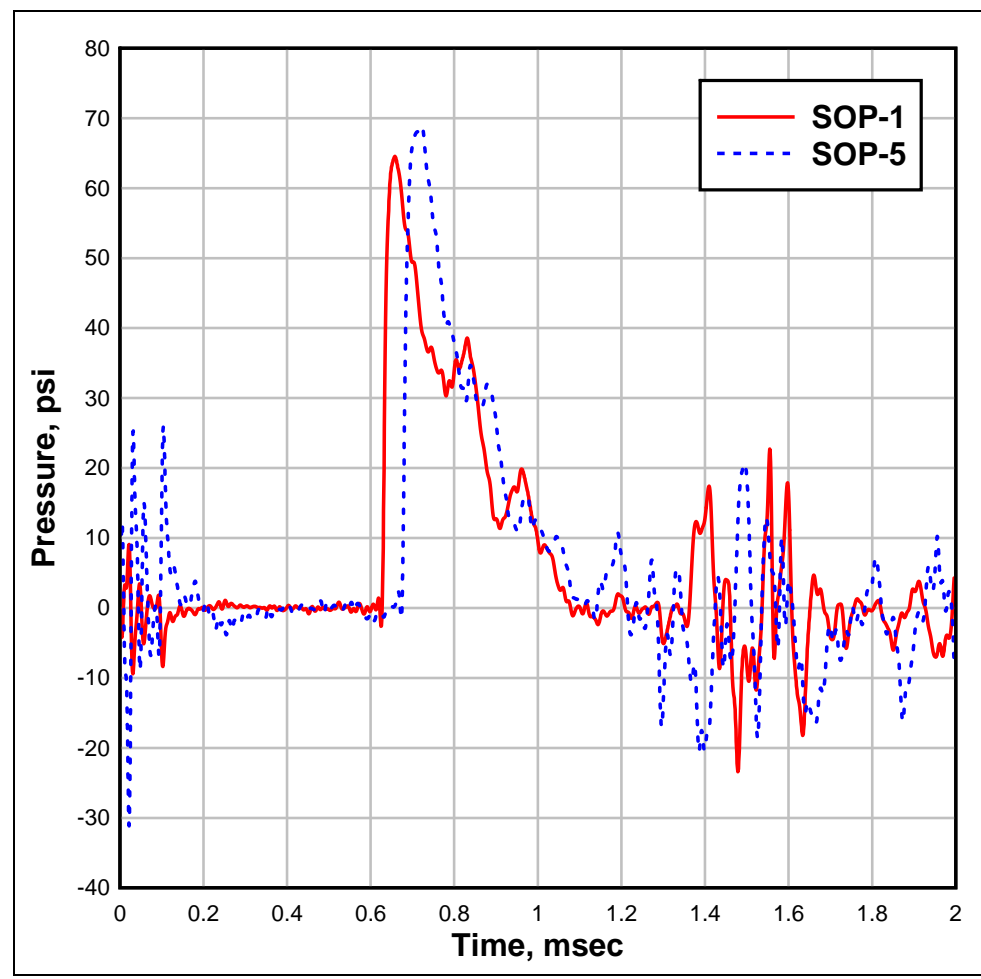

Figure 4.29. Side-on overpressure time-histories at a horizontal range of $36 \mathrm{in}$. from $\mathrm{GZ}$ in experiment BM-I-02.

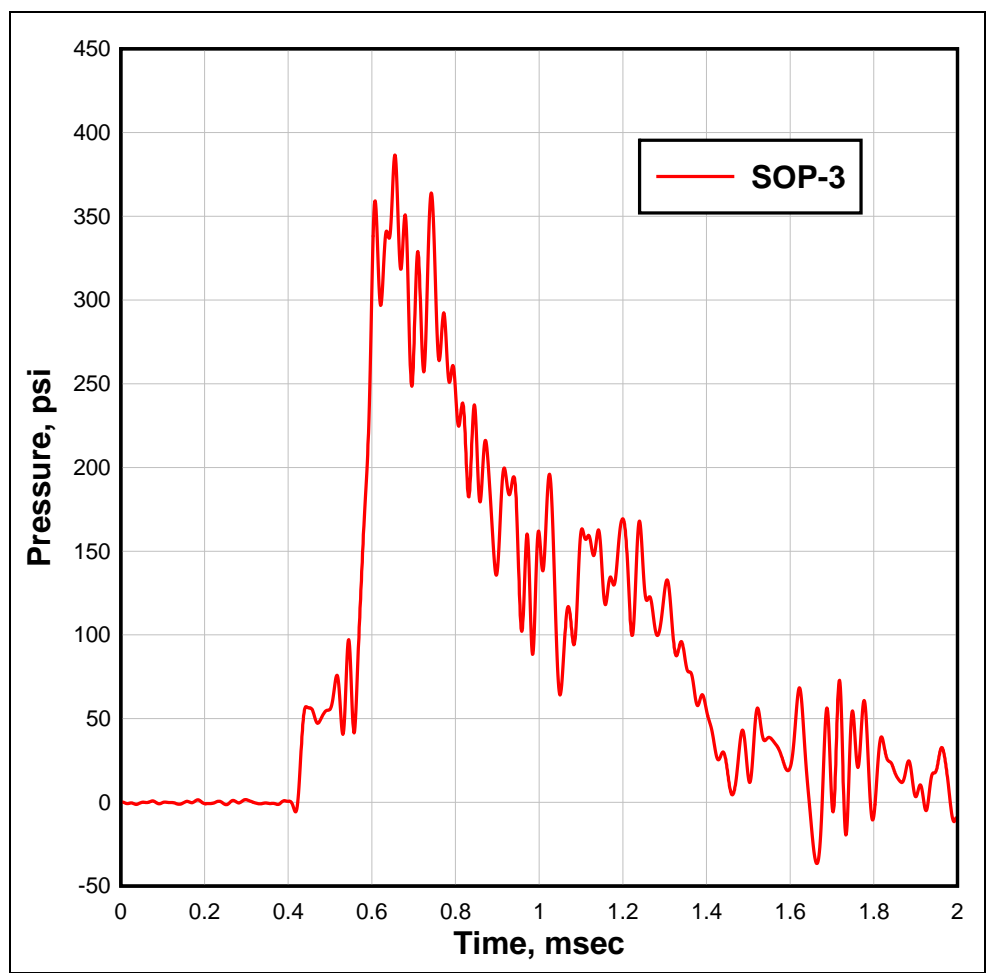

Figure 4.30. Side-on overpressure time-history directly above the charge GZ in experiment BM-I-03. 


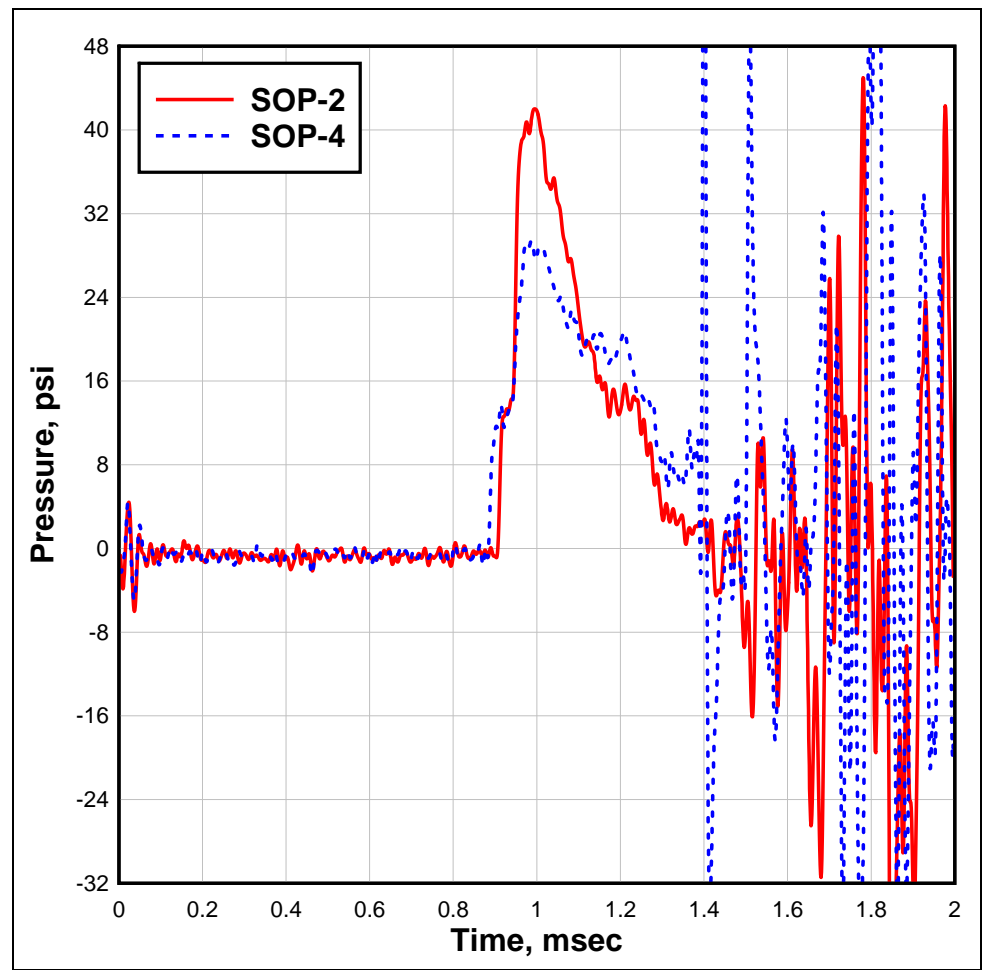

Figure 4.31. Side-on overpressure time-histories at a horizontal range of $18 \mathrm{in}$. from GZ in experiment BM-I-03.

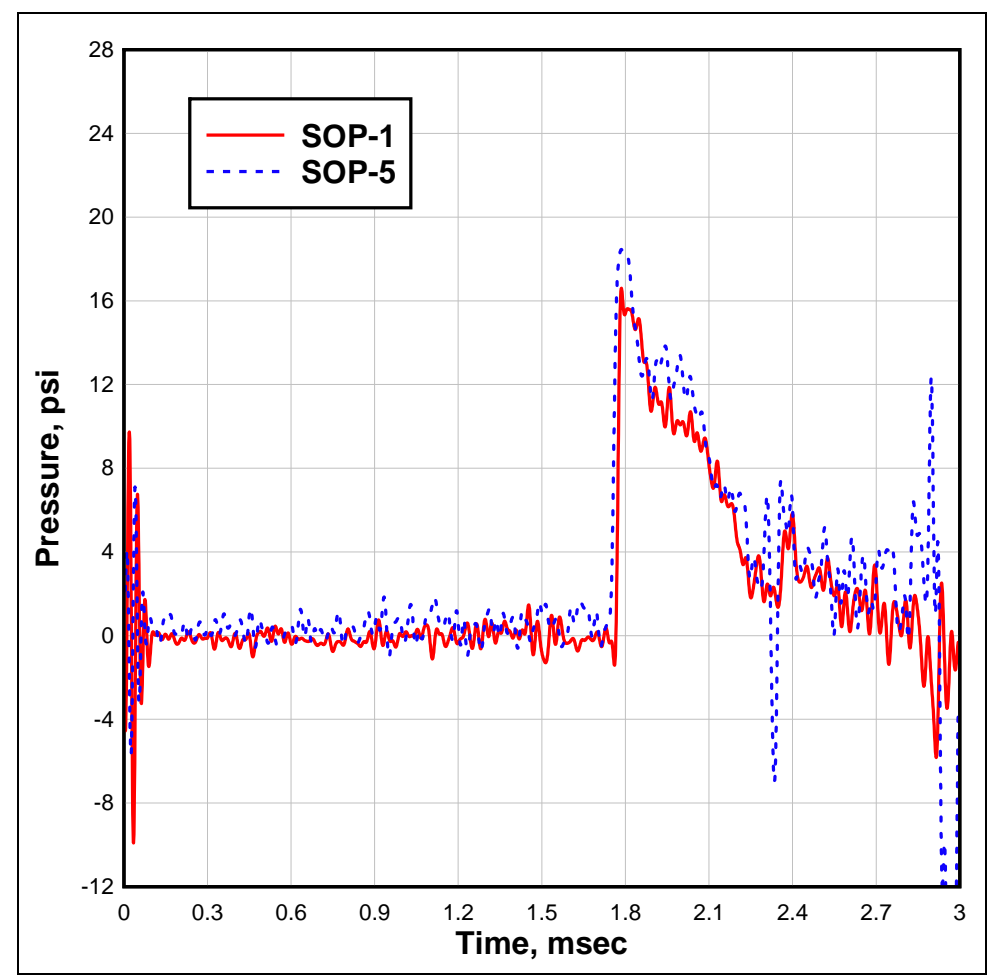

Figure 4.32. Side-on overpressure time-histories at a horizontal range of 36 in. from GZ in experiment BM-I-03. 


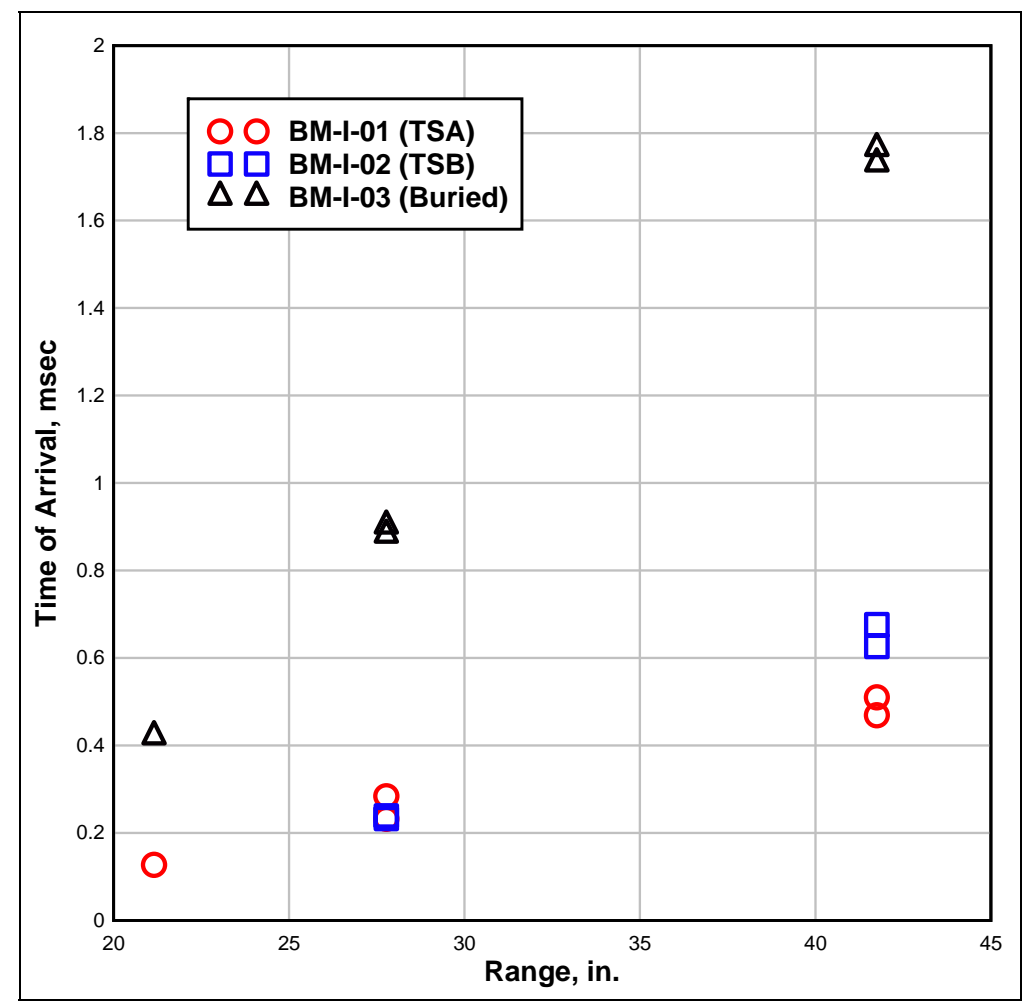

Figure 4.33. Shock times of arrival versus range from side-on overpressure gages in experiments BM-I-01 through BM-I-03.

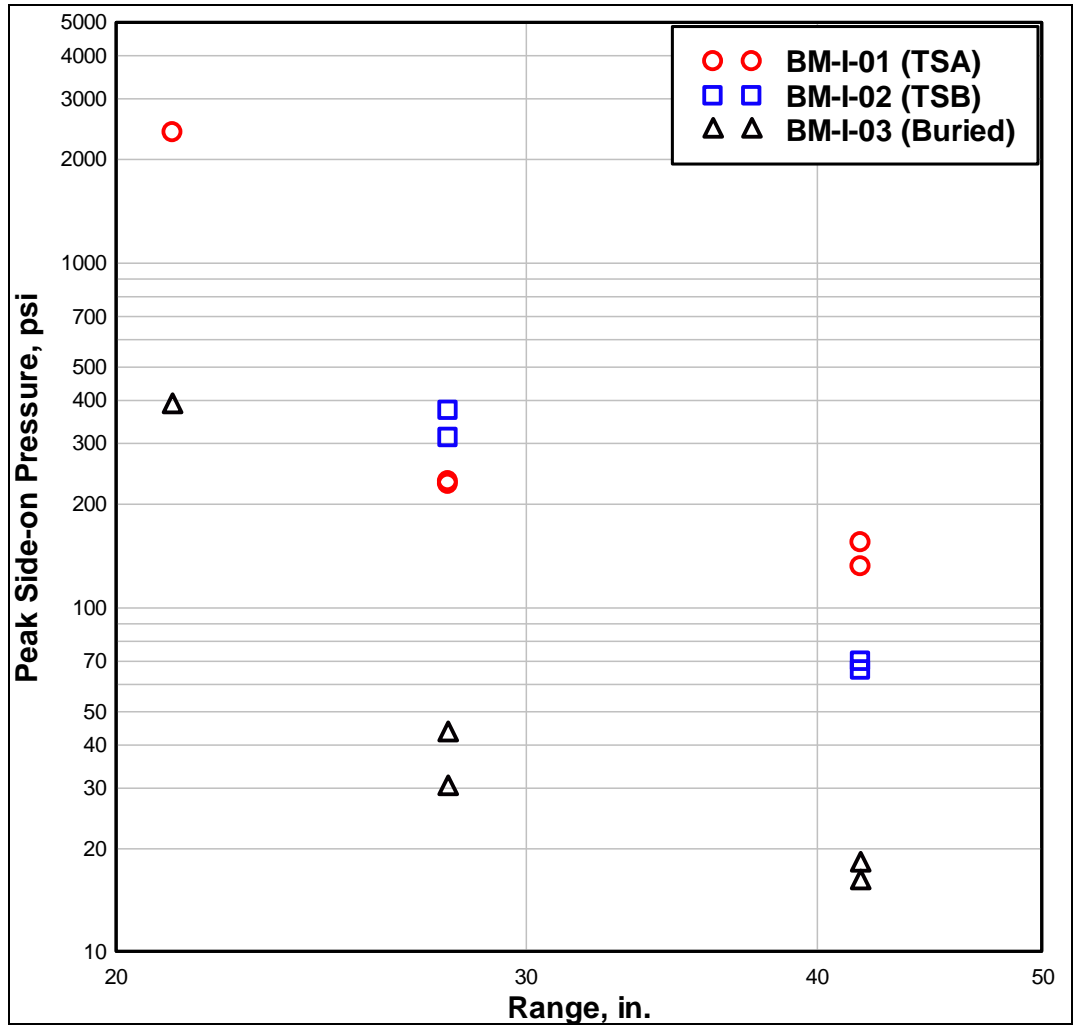

Figure 4.34. Peak side-on overpressures versus range in experiments $\mathrm{BM}-\mathrm{I}-01$ through $\mathrm{BM}-\mathrm{I}-03$. 
The center gage, SOP3, in experiment BM-I-02 was damaged during the experiment and did not provide any useful data. As expected, the center gages, SOP3, directly over the charge and the closest to the charge, recorded the highest peak overpressures compared with the values from gages offset 18 and 36 in. For a given experiment, the gages at 18-in. offset also recorded higher peak pressures when compared with the peaks from gages at 36-in. offset. The comparisons of the data from redundant gages at the 18- and 36-in. offsets agreed reasonably well. There was a small variation in the peak overpressure in the 18-in. offset gages in experiment BM-I-03. When the results of the various experiments are compared, the charge buried 4 in., BM-I-03, had a significant reduction in the peak overpressure (Figure 4.34) and a significant increase in the shock arrival times (Figure 4.33) compared with the experiments with the charge resting on the surface, TSA, and buried, TSB, at the same ranges.

\section{Impulse measurement device}

\section{Piston impulse}

Two of the intermediate soil experiments, BM-I-04 and BM-I-05, were conducted using the IMD to measure the total impulse imparted to the impact plate of the piston assembly. For both experiments, the standoff distance between the top of the charge and the face of the IMD impact plate was held constant at $20 \mathrm{in}$. The total mass of the IMD piston assembly for both experiments was approximately 5,500 lb with an impact plate surface area of $7.07 \mathrm{ft}^{2}$ (3- $\mathrm{ft}$ diameter). During the experiments, the motion of the IMD piston assembly was captured using three independent methods, i.e., an accelerometer located on the IMD piston assembly, a displacement measurement gage (yo-yo gage) located on the top of the support structure, and high-speed video. In some cases, one or two of the measurements were unsuccessful, and the third measurement was used as the source for the measured displacement and velocity. In most cases, the high-speed video was the best source for data on IMD motion. Due to the high initial acceleration of the IMD piston assembly, the yo-yo gage was not dependable in capturing useful data, and, in some cases, the gage broke. Use of the accelerometer was partially successful, but it did experience some high-frequency noise and data shifts that made it difficult to select peak displacements and initial velocities from the records. 
A summary of the IMD measured data obtained for the intermediate soil experiments is in Table 4.5. The table includes the peak displacements determined from the three measurement systems and the initial velocity captured both in the high-speed video and from integration of the acceleration record. The average displacement shown in the summary table is the average of the displacements measured by various methods where data are available. Due to the high-frequency noise in the acceleration records, the initial velocities captured by the accelerometers were suspect. Therefore, the initial velocity captured from the high-speed video was the primary value used in the impulse calculations. As a method to compare the different measurement values, the peak displacement is also calculated using the initial velocity captured from the high-speed video. The calculations are explained in detail in Chapter 2. The peak displacements calculated from the measured initial velocity values compare reasonably well with the average measured peak displacement values. No useful data were obtained from the yo-yo gage during the intermediate soil experiments. Corrections were made to the yo-yo gage setup between each experiment, but initial velocities of the IMD assembly appeared to exceed the ability of the gage to accurately track displacement. For experiment BM-I-05, the final posttest position of the IMD piston assembly was resting on the safety catch at $18 \mathrm{in}$. above its pretest position. Since the safety catch collar-to-collar distance was 4-5/ 16 in., the total piston displacement could be estimated as between $18 \mathrm{in}$. and 22-5/ $16 \mathrm{in}$. A significant data shift was recorded in the acceleration records on both experiments. Before selecting the peak displacement and initial velocity, the record was corrected using the timing captured in the high-speed video and shifting the timing of the acceleration record to match.

Table 4.5. Summary of the IMD measured data.

\begin{tabular}{|c|c|c|c|c|c|c|c|}
\hline \multirow[b]{2}{*}{$\begin{array}{l}\text { Experiment } \\
\text { Number }\end{array}$} & \multicolumn{3}{|c|}{ Peak Displacement, in. } & \multirow[b]{2}{*}{$\begin{array}{l}\text { Average } \\
\text { Displacement, } \\
\text { in. }\end{array}$} & \multicolumn{2}{|c|}{ Initial Velocity, fps } & \multirow{2}{*}{$\begin{array}{l}\text { Calculated } \\
\text { Peak } \\
\text { Displacement } \\
\text { Using Video } \\
\text { Initial } \\
\text { Velocity, in. }\end{array}$} \\
\hline & $\begin{array}{l}\text { Yo-Yo/ } \\
\text { Scratch } \\
\text { Gage }\end{array}$ & $\begin{array}{l}\text { High- } \\
\text { Speed } \\
\text { Video }\end{array}$ & $\begin{array}{l}\text { Acceleration } \\
\text { Record }\end{array}$ & & $\begin{array}{l}\text { High- } \\
\text { Speed } \\
\text { Video }\end{array}$ & $\begin{array}{l}\text { Acceleration } \\
\text { Record }\end{array}$ & \\
\hline BM-I-04 & -- & 2.20 & 1.74 & 1.97 & 3.10 & 4.60 & 1.90 \\
\hline BM-I-05 & -- & 20.73 & 23.6 & 22.17 & 10.82 & 12.6 & 21.8 \\
\hline
\end{tabular}


Using the initial velocity obtained for the high-speed video, the total impulse imparted to the IMD piston assembly was calculated (Table 4.6). The calculated impulse is the total impulse and is directly related to the surface area of the impact plate. The mass of the IMD piston assembly used to calculate the impulse was 5,600 lb, which accounts for the weight of the system and the approximate dynamic drag in the system due to friction. The method used to calculate the total impulse is explained in detail in Chapter 2. As seen in Table 4.6, the total impulse imparted to the IMD increased by a factor of 3.4 when the charge position changed from sitting on the surface to buried $4 \mathrm{in}$. below the surface even though the charge standoff distance was the same for both experiments.

Table 4.6. Total impulse imparted to the IMD.

\begin{tabular}{|l|l|l|l|l|}
\hline $\begin{array}{l}\text { Experiment } \\
\text { Number }\end{array}$ & Charge Position & $\begin{array}{l}\text { Initial Velocity, } \\
\text { fps }\end{array}$ & $\begin{array}{l}\text { Average Total } \\
\text { Displacement, } \\
\text { in. }\end{array}$ & $\begin{array}{l}\text { Peak Impulse, } \\
\text { Ibf-sec }\end{array}$ \\
\hline BM-I-04 & Sitting on Surface & 3.10 & 1.91 & 545 \\
\hline BM-I-05 & Buried & 10.8 & 20.7 & 1880 \\
\hline
\end{tabular}

1 Initial velocity obtained from the high-speed video.

2 Peak impulse calculated using the initial velocity of the system. Impulse directly related to target mass and surface area.

\section{Impact plate pressure measurements}

The three flush-mounted pressure transducers mounted on the bottom plate of the piston assembly, gages RP1, RP2, and RP3, were an attempt to measure the reflected pressure on the surface of the impact plate. Due to the extremely harsh environment from the soil, airblast, and detonation products at this proximity to the charge, the pressure data obtained were somewhat limited. The three gages included one PCB gage and two Kulite gages. The gages were equal distance from the charge at a 2.5-in. radius off the center of the IMD impact plate. Two different Kulite gage cover plates were utilized during the test in an attempt to deflect the loading by soil particles and/ or detonation products. No useful data were collected from the PCB gage. PCB gages are typically more sensitive to accelerations and were also exposed directly to the airblast and soil particles while the Kulite gages used a debris filter. 
The pressure time-histories obtained from Kulite gages RP2 and RP3 from experiments BM-I-04 and BM-I-05 are presented in Figures 4.35 and 4.36, respectively. The pressure data recorded by the two Kulite gages in experiment BM-I-04 compared very well with each other. The pressure data recorded by the two Kulite gages in experiment BM-I-05 had different peak values. The RP-3 peak pressure was approximately three times higher than that measured by the RP-2 gage. Experiment BM-I-05 had the charge fully buried in the soil and produced a much more complex loading condition. The differences in the pressure gage records could have been the result of the soil ejecta partially clogging the debris cover of the RP-2 gage and disrupting the pressure transmitted to the sensor. Gage RP-3 in experiment BM-I- 05 recorded results very similar to those measured by both gages in BM-I-04 except for a later time of arrival in BM-I-05.

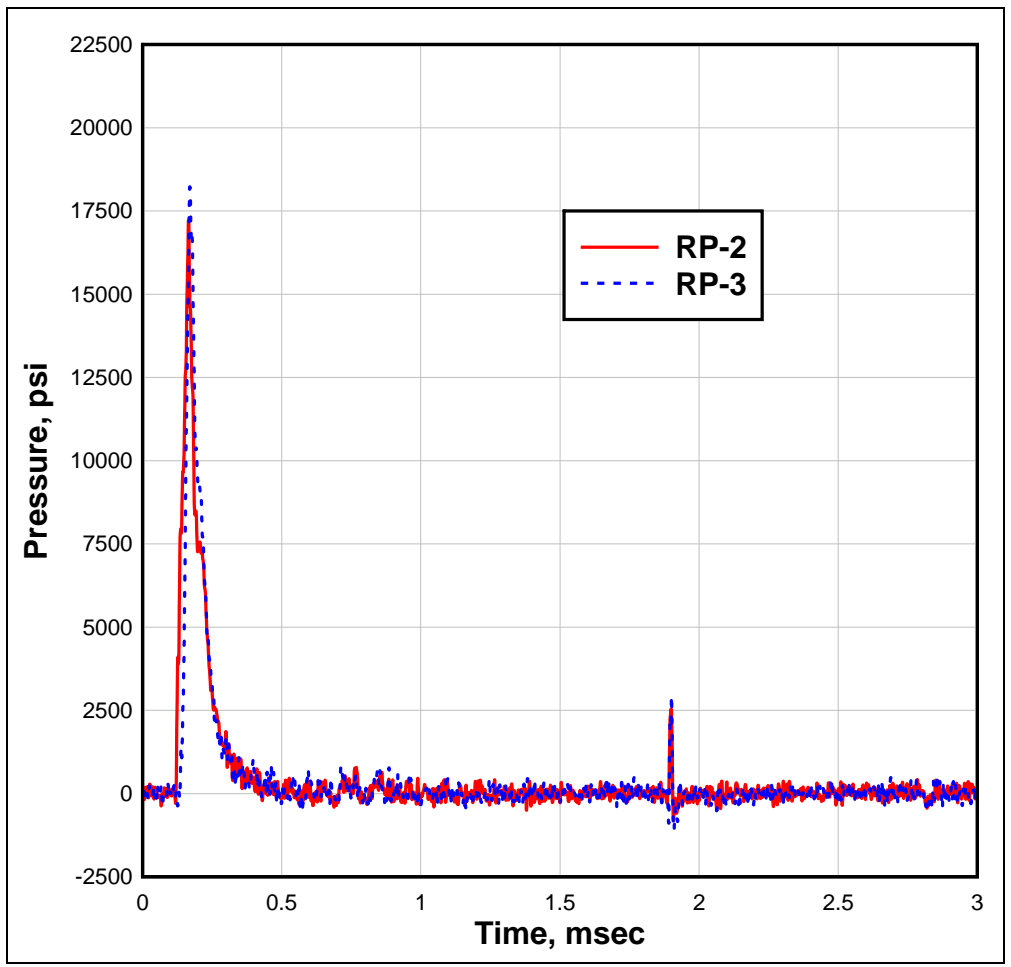

Figure 4.35 Impact-plate pressure time-histories RP2 and RP3 for experiment BM-I-04. 


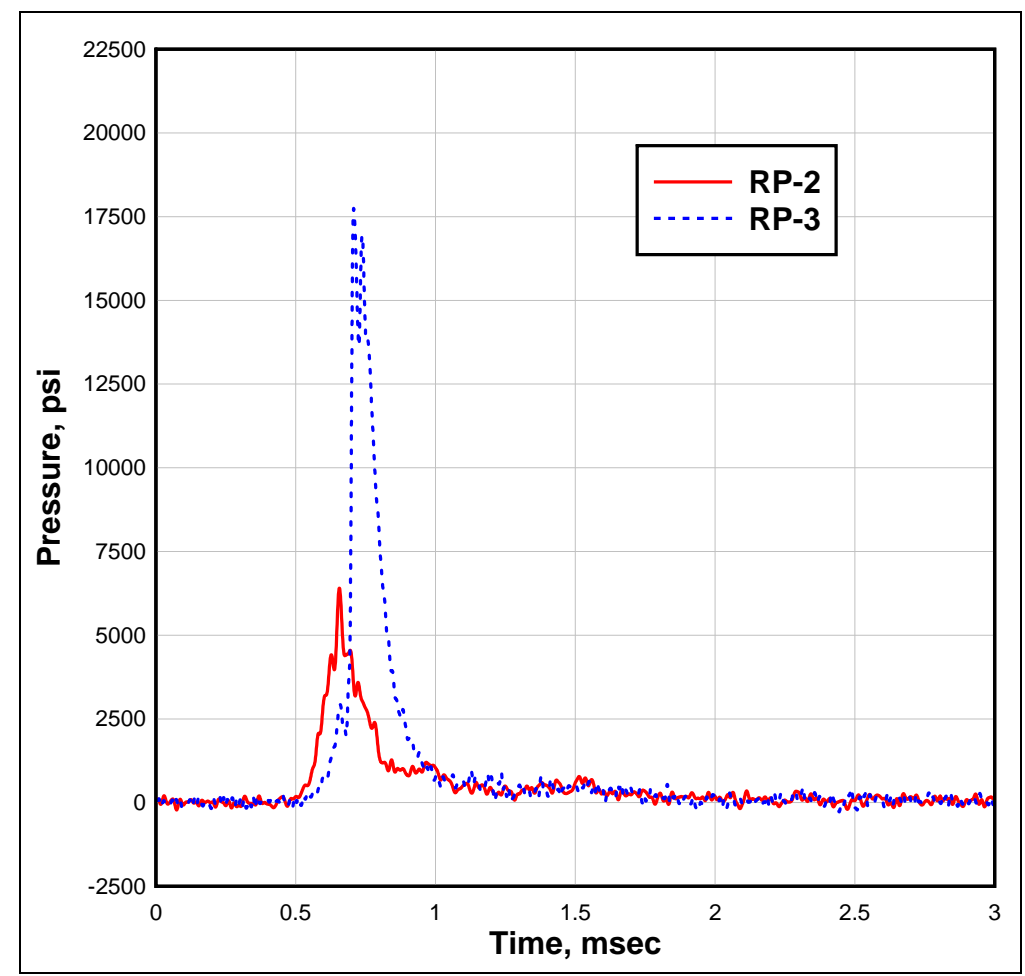

Figure 4.36. Impact-plate pressure time-histories RP2 and RP3 for experiment BM-I-05.

\section{IMD accelerations}

Accelerometer SAV1 was mounted on the IMD piston assembly, and accelerometer SAV2 was mounted on the IMD support structure. The accelerometer on the piston assembly was an attempt to measure the motion, i.e., velocity and displacement, of the piston assembly. The accelerometer mounted on the support structure was an attempt to capture the global motion of the support frame. The accelerometers experienced a significant high-frequency ringing during the experiments. In some cases, this noise overwhelmed the data, and/ or a significant data shift occurred in the record, which made it difficult to extract useful information. Several attempts were made to modify the gage mounts to help isolate this high-frequency noise, but limited improvements were seen in the data.

The integrated velocity and double-integrated displacement time-histories from the accelerometers in experiments BM-I-04 and BM-I-05 are presented in Figures 4.37-4.40. The accelerometer on the support structure recorded the oscillation of the support structure produced by the blast load. The maximum displacement obtained in both experiments was less than 1/ 8 in. The accelerometers on the IMD piston assembly recorded 


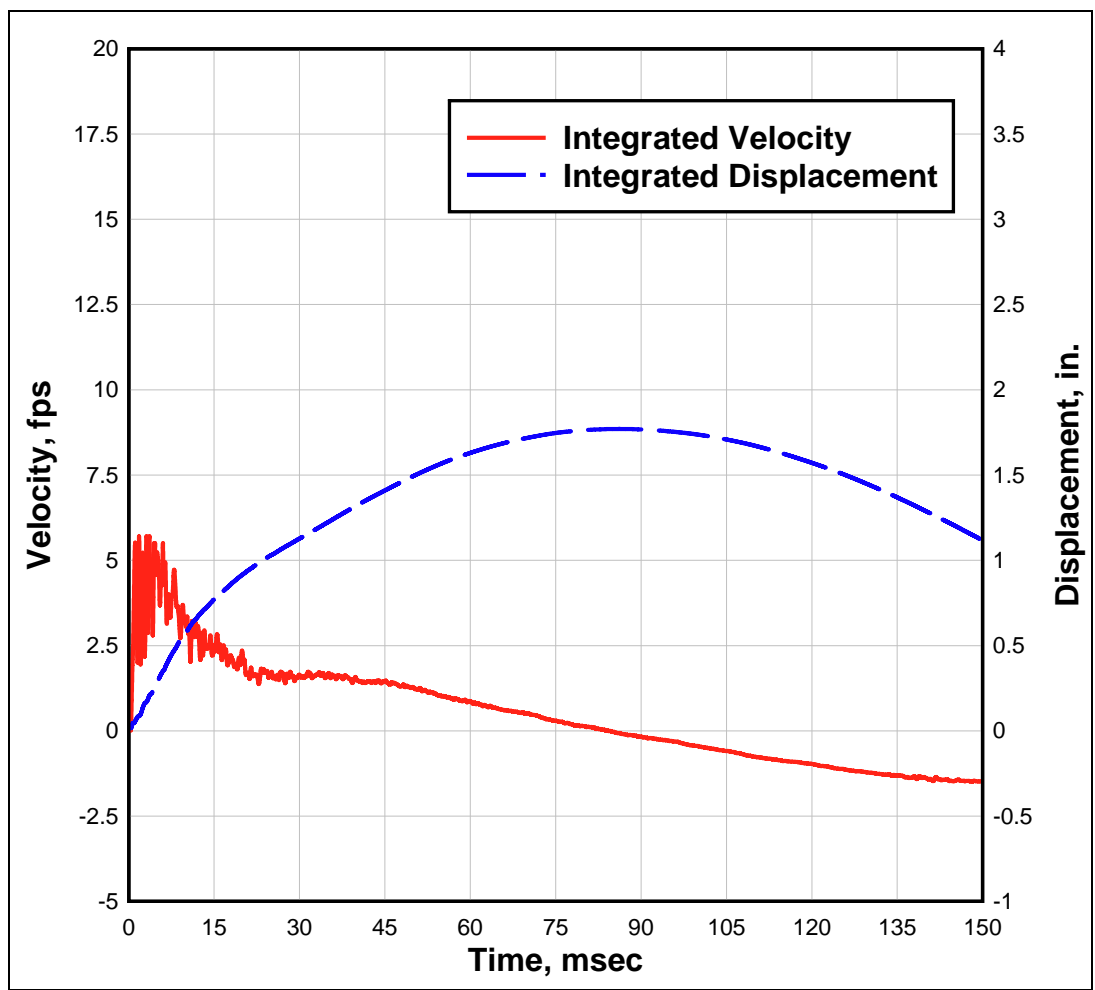

Figure 4.37. Velocity and displacement time-histories from integrated accelerometer SAV1 data in experiment BM-I-04.

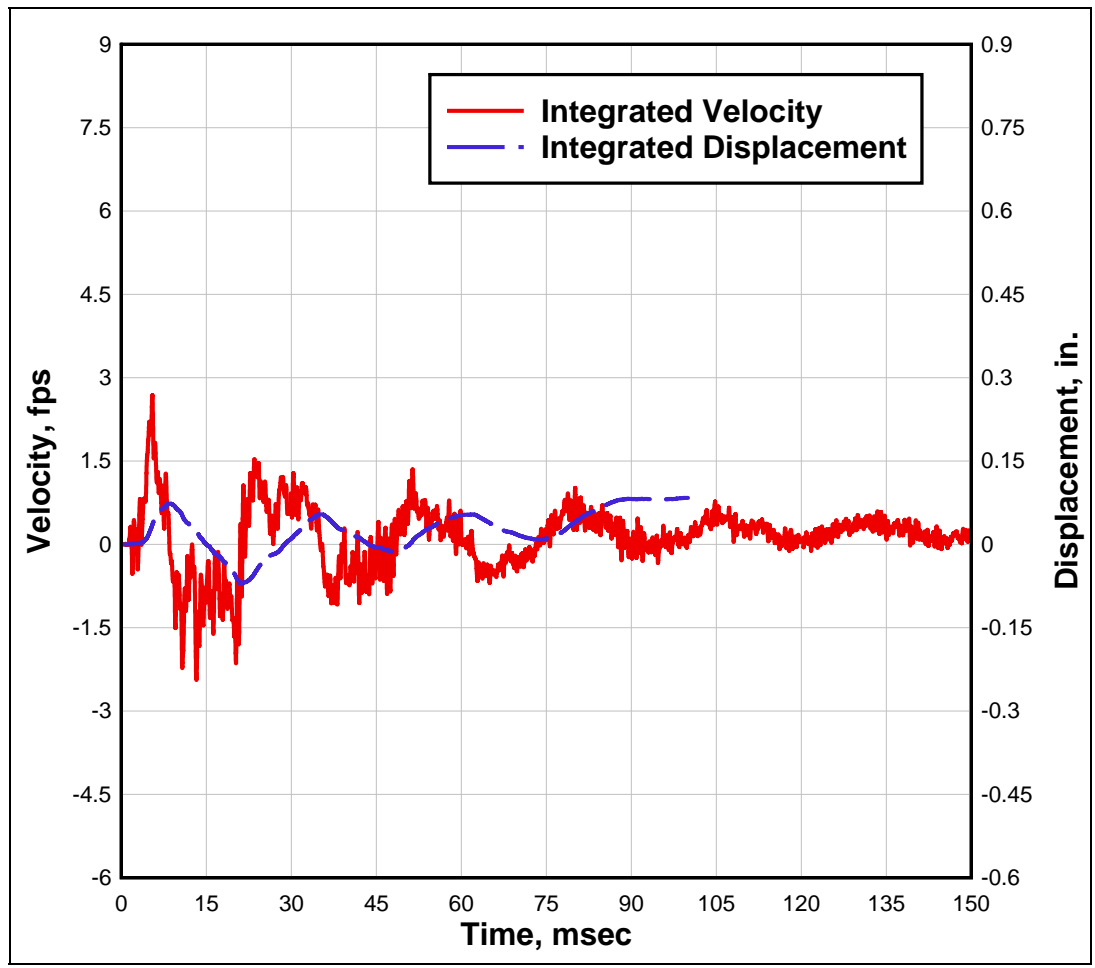

Figure 4.38 Velocity and displacement time-histories from integrated accelerometer SAV2 data in experiment BM-I-04. 


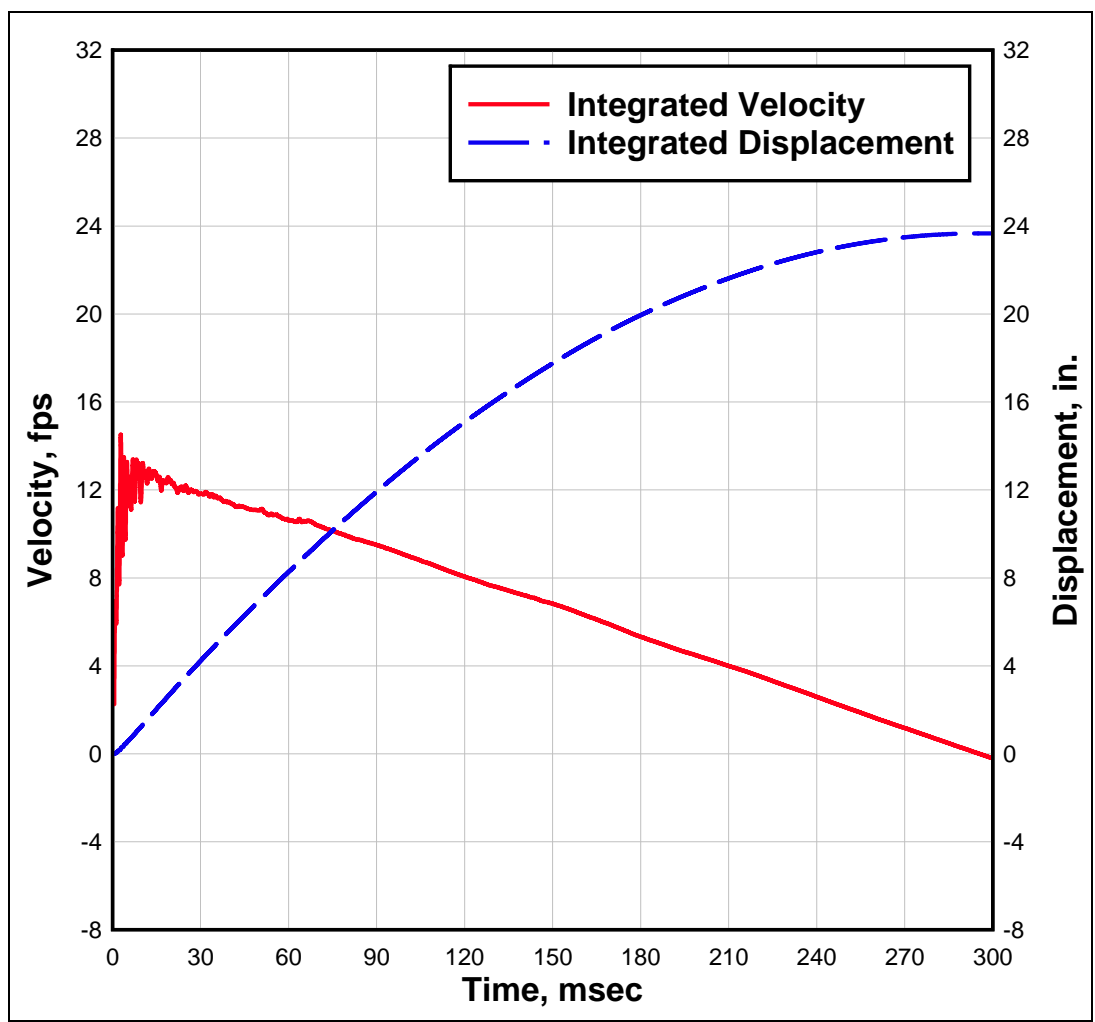

Figure 4.39. Velocity and displacement time-histories from integrated accelerometer SAV1 data in experiment BM-I-05.

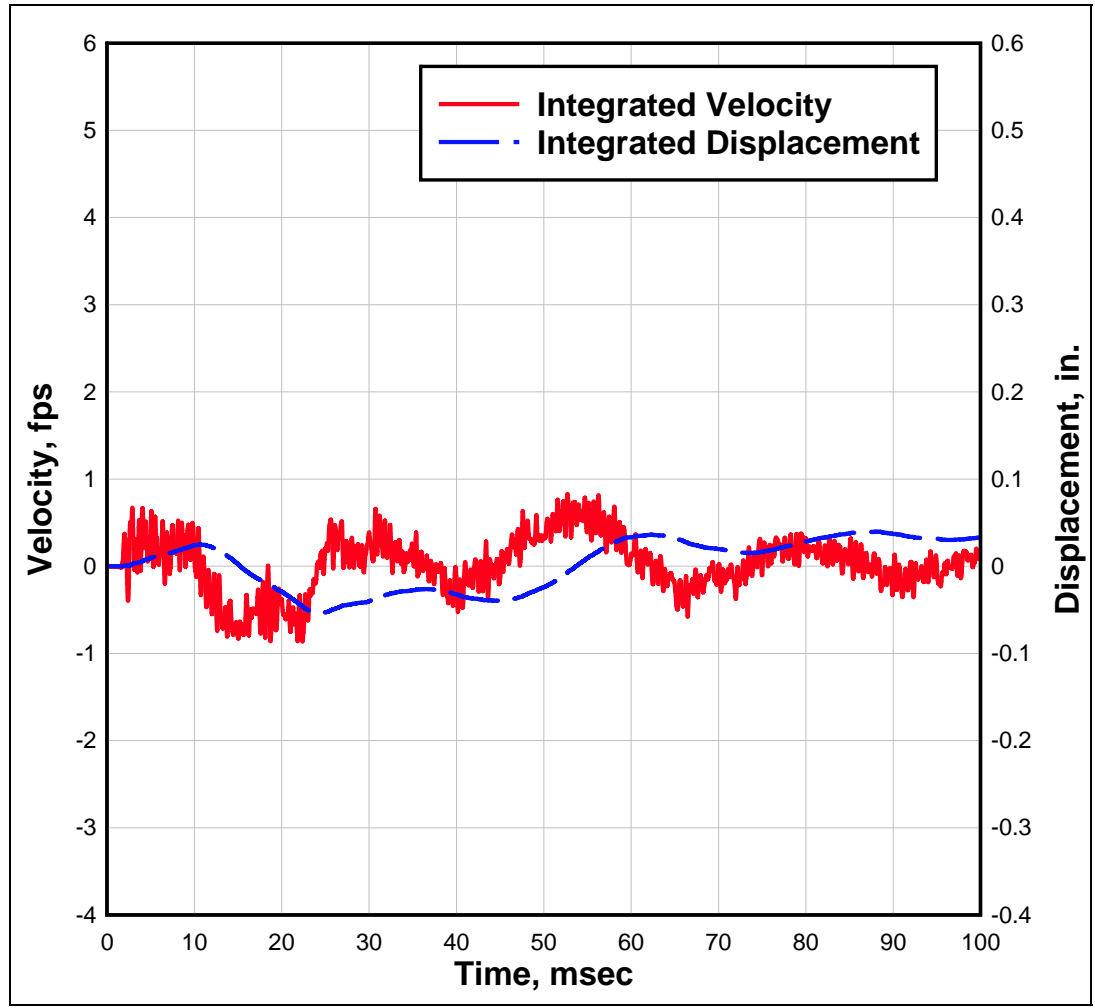

Figure 4.40. Velocity and displacement time-histories from integrated accelerometer SAV2 data in experiment BM-I-05. 
a significant data shift in both experiments. The records shown in Figures 4.37 and 4.39 were corrected by matching the times of peak displacement captured in the high-speed video. The resulting peak displacements and initial velocities from the integrated acceleration data (see Table 4.5) compared reasonably well with the values capture in the high-speed video.

\section{Clay soil}

\section{Backfill quality control measurements}

The backfill was placed in lifts approximately 6 to 8 in. thick as described in Chapter 3. Quality control measurements for the as-placed soil were made in each lift. These measurements included the wet density obtained with a nuclear moisture-density gage and microwave and oven-dried water contents. The average values for all measurements of wet density, ovendried water content, and calculated dry density in each testbed are presented in Table 4.7. For all the clay soil experiments, the mean value of wet density was $121.2 \mathrm{lb} / \mathrm{ft}^{3}$, and the mean value of water content was $23.1 \%$. The calculated mean dry density was $98.4 \mathrm{lb} / \mathrm{ft}^{3}$, and the calculated mean air voids content was $5.6 \%$ based on a specific gravity of 2.72 . The soil was classified as a sandy clay (CL) according to the Unified Soil Classification System as discussed in Chapter 3.

Table 4.7. Summary of clay soil test series.

\begin{tabular}{|l|l|l|l|l|l|l|}
\hline $\begin{array}{l}\text { Experiment } \\
\text { Number }\end{array}$ & $\begin{array}{l}\text { Charge } \\
\text { Position }\end{array}$ & $\begin{array}{l}\text { Avg Wet } \\
\text { Density, } \\
\text { lb/ft }\end{array}$ & $\begin{array}{l}\text { Avg Dry } \\
\text { Density, } \\
\text { lb/ft }{ }^{3}\end{array}$ & $\begin{array}{l}\text { Avg Water } \\
\text { Content, \% }\end{array}$ & $\begin{array}{l}\text { Crater } \\
\text { Diameter, ft }\end{array}$ & $\begin{array}{l}\text { Crater } \\
\text { Depth, ft }\end{array}$ \\
\hline BM-C-01 & TSA & 120.5 & 97.2 & 23.9 & 3.82 & 1.92 \\
\hline BM-C-02 & TSB & 120.8 & 98.1 & 23.2 & 5.89 & 2.40 \\
\hline BM-C-03 & Buried & 120.7 & 98.3 & 22.8 & 7.11 & 3.10 \\
\hline BM-C-04 & TSA & 122.0 & 99.9 & 22.1 & 5.41 & 2.00 \\
\hline BM-C-05 & Buried & 122.0 & 98.6 & 23.7 & 7.56 & 3.50 \\
\hline
\end{tabular}

\section{Crater surveys}

For each of the five experiments conducted with the clay soil, pretest and posttest cross-sectional grade surveys were conducted along the primary axes through GZ. From these surveys, the resulting crater diameter and crater depth were calculated. A summary of these data for the clay soil testbeds is provided in Table 4.7, which includes the experiment number, 
charge position, average soil composition properties, and approximate soil crater diameter and depth. Figures 4.41- 4.45 present the pretest and posttest cross sections for each of the clay experiments along with a photograph of each posttest testbed crater.

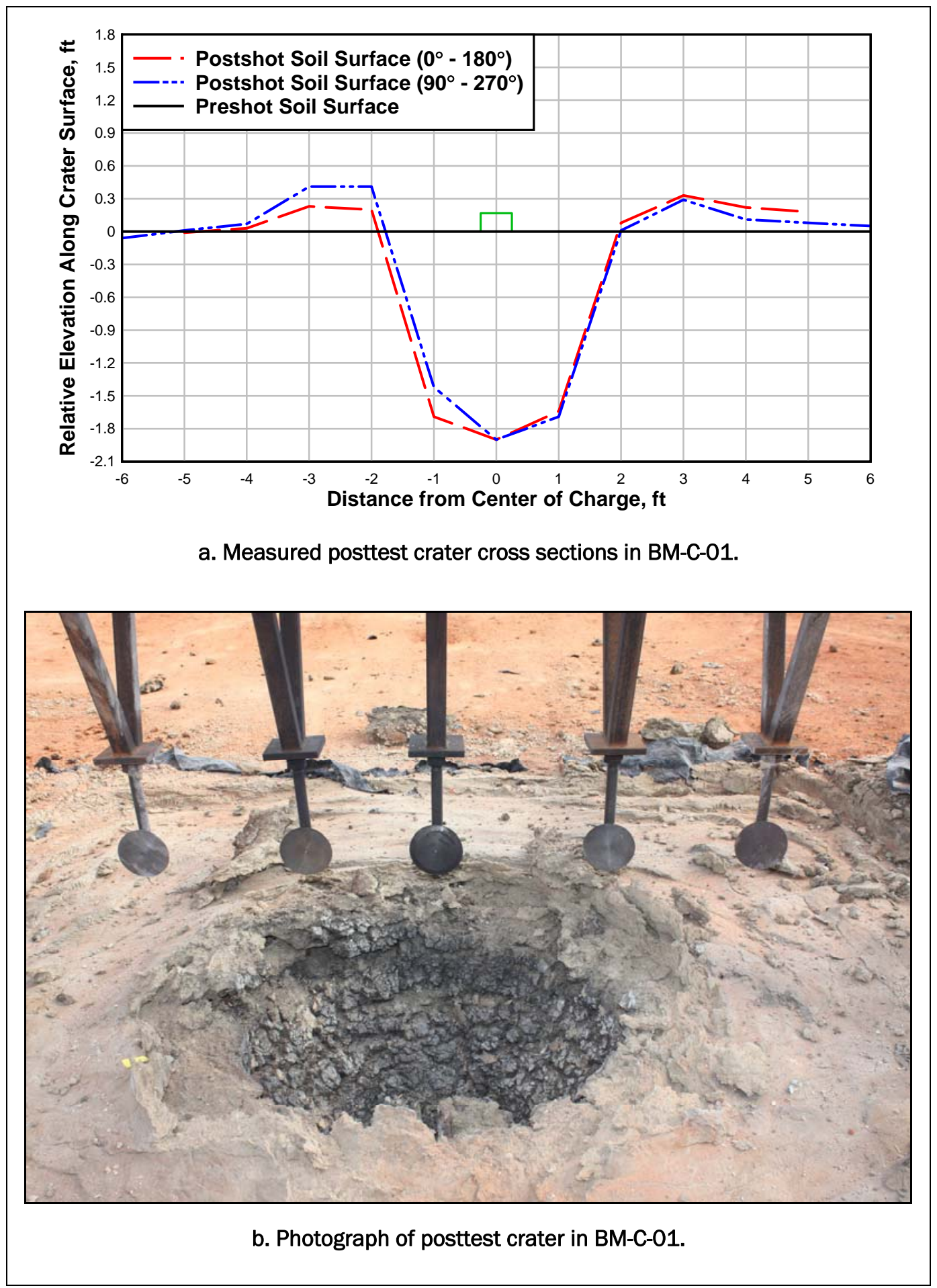

Figure 4.41. Photograph and cross-section surveys of testbed crater in BM-C-01. 


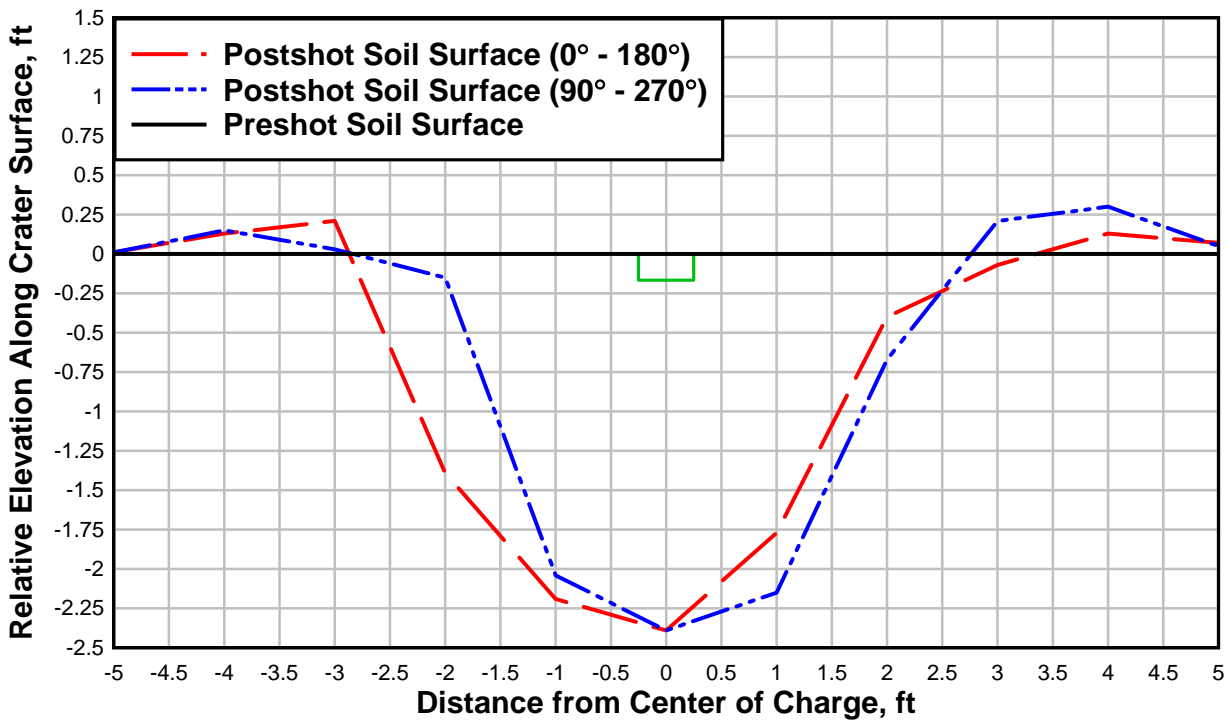

a. Measured posttest crater cross sections in BM-C-02.

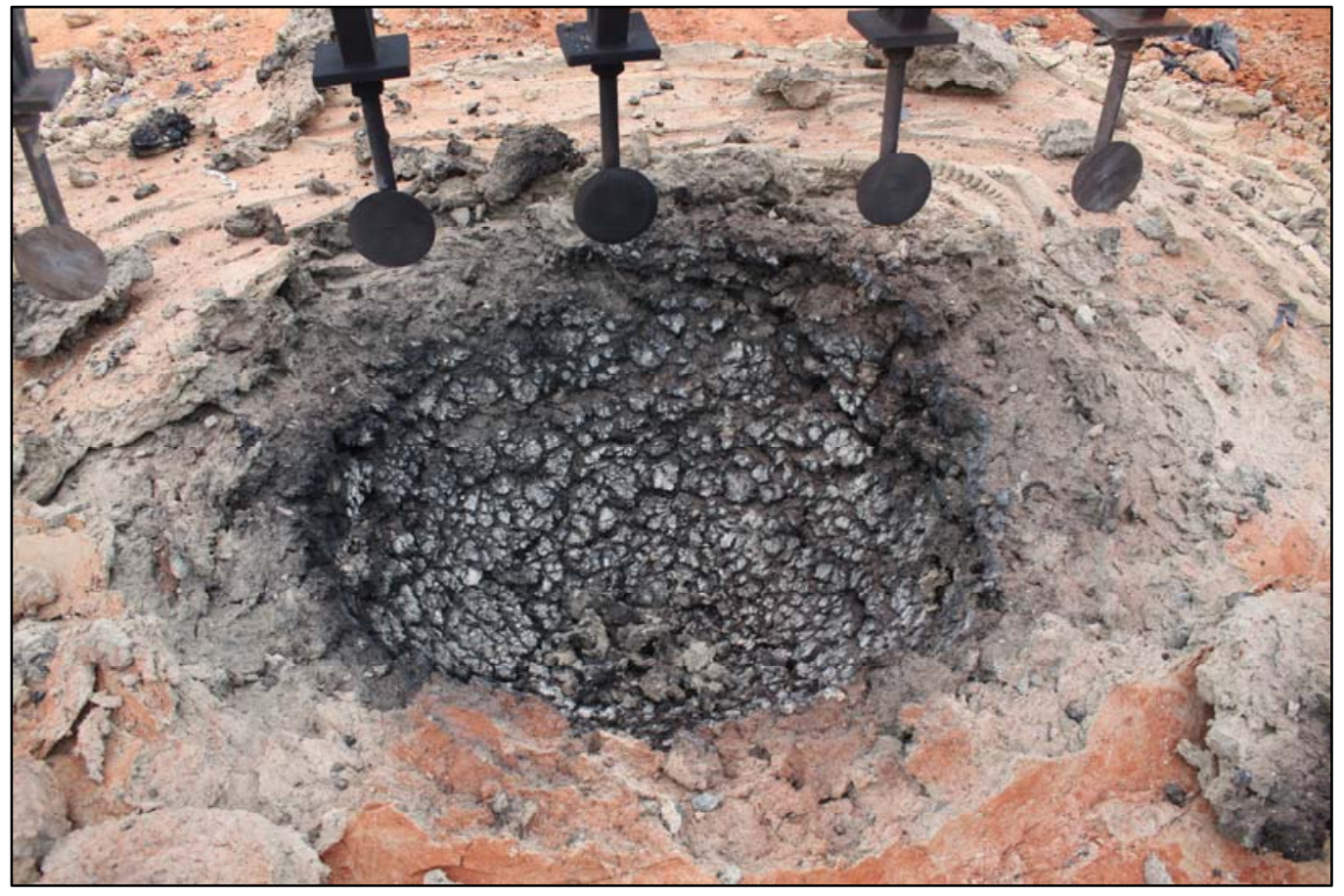

b. Photograph of posttest crater in BM-C-02.

Figure 4.42. Photograph and cross-section surveys of testbed crater in BM-C-02. 


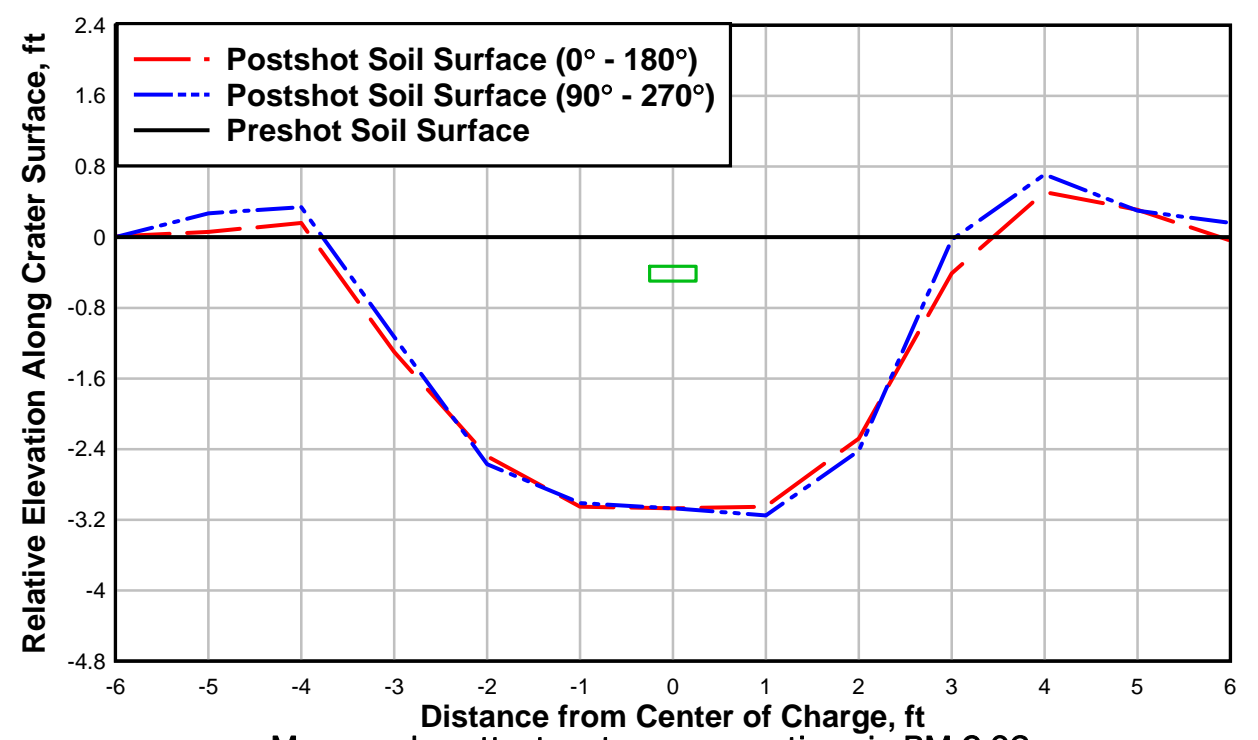

a. Measured posttest crater cross sections in BM-C-03.

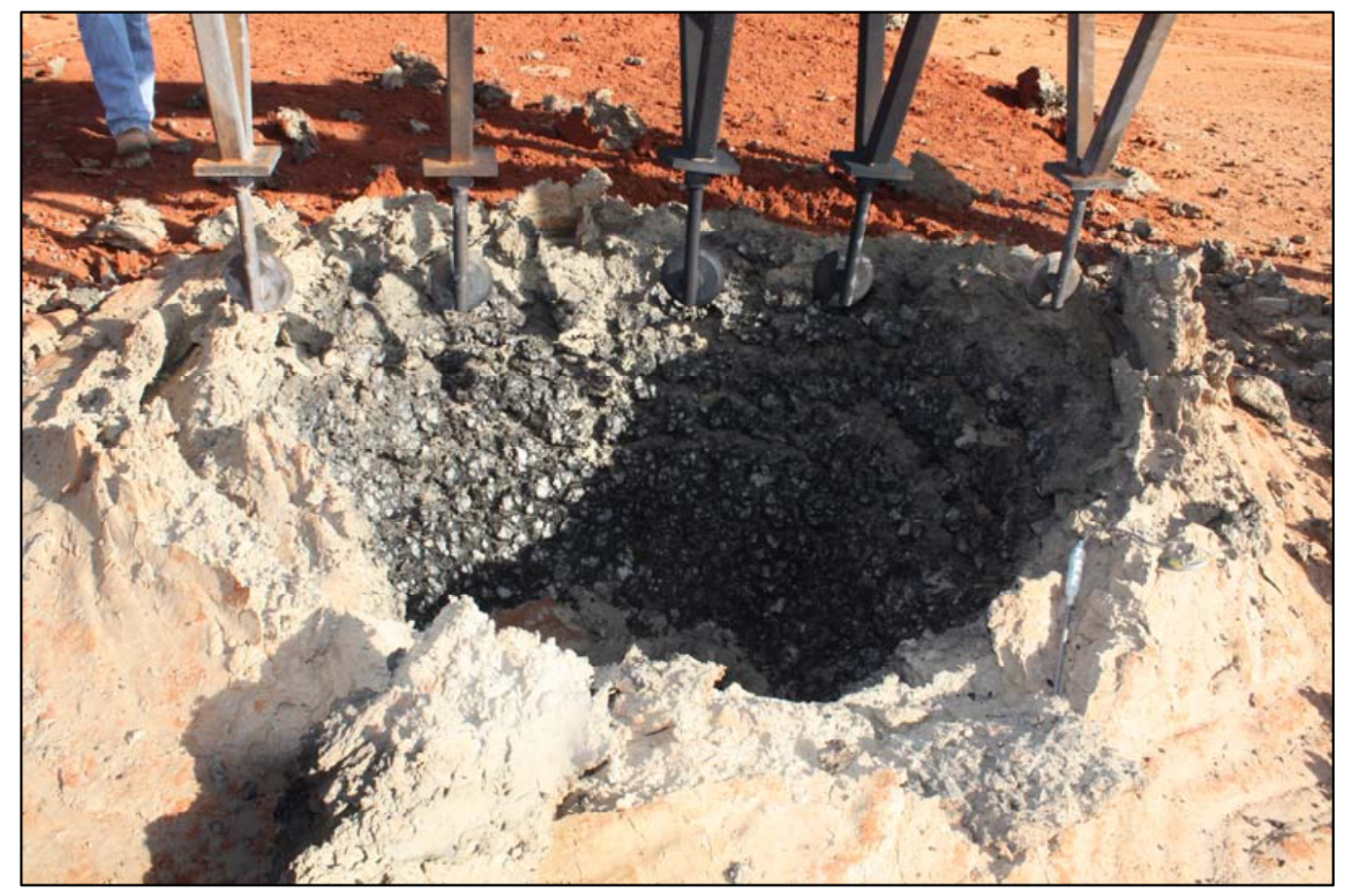

b. Photograph of posttest crater in BM-C-03.

Figure 4.43. Photograph and cross-section surveys of testbed crater in BM-C-03. 


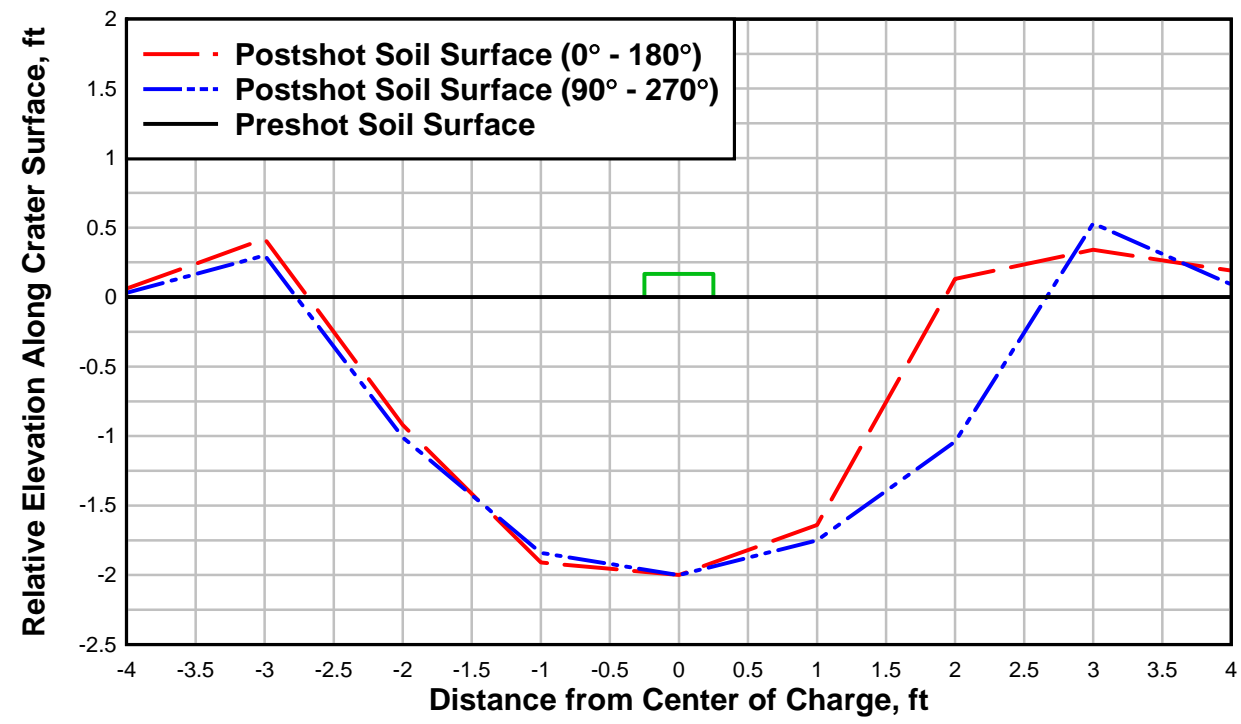

a. Measured posttest crater cross sections in BM-C-04.

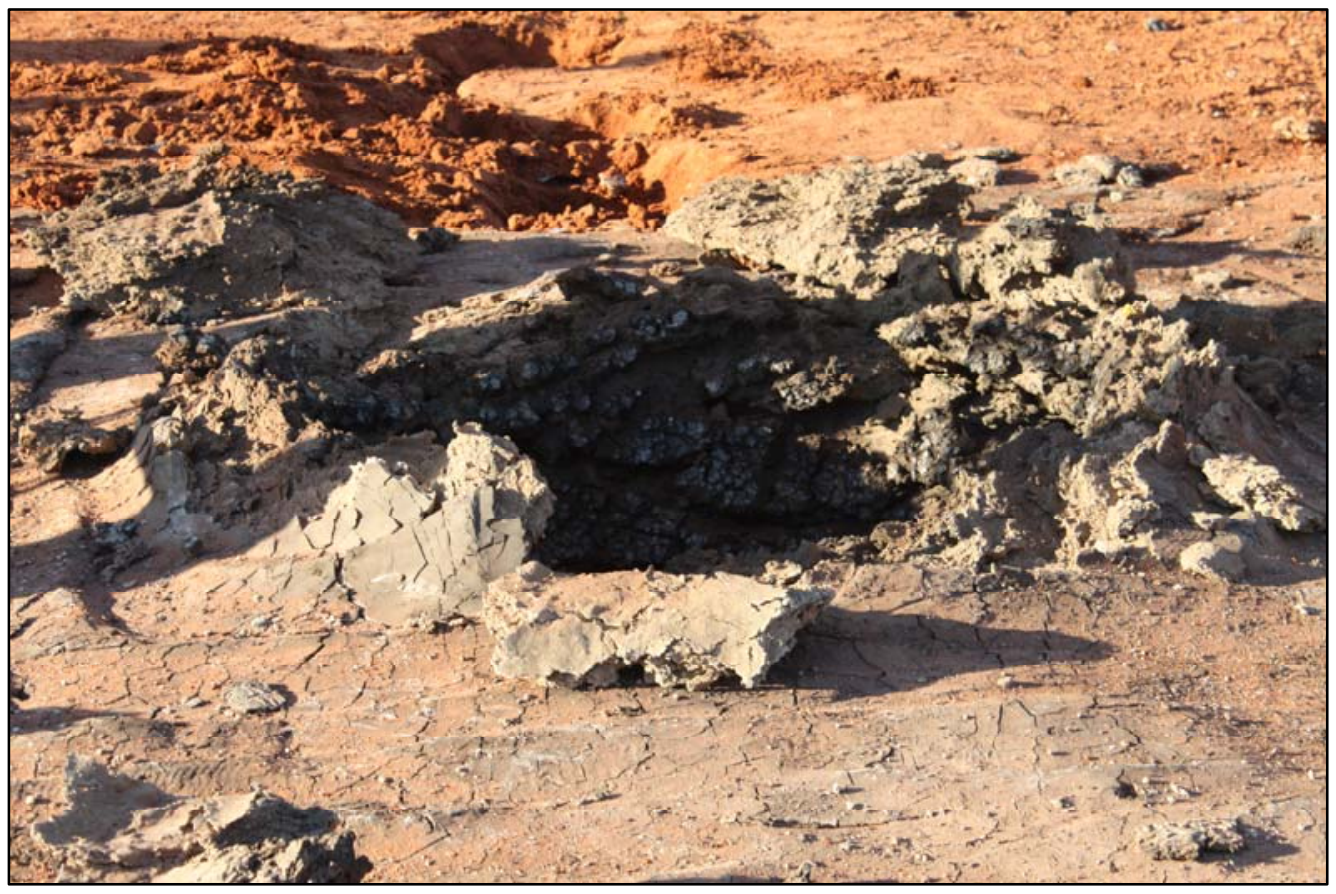

b. Photograph of posttest crater in BM-C-04.

Figure 4.44. Photograph and cross-section surveys of testbed crater in BM-C-04. 


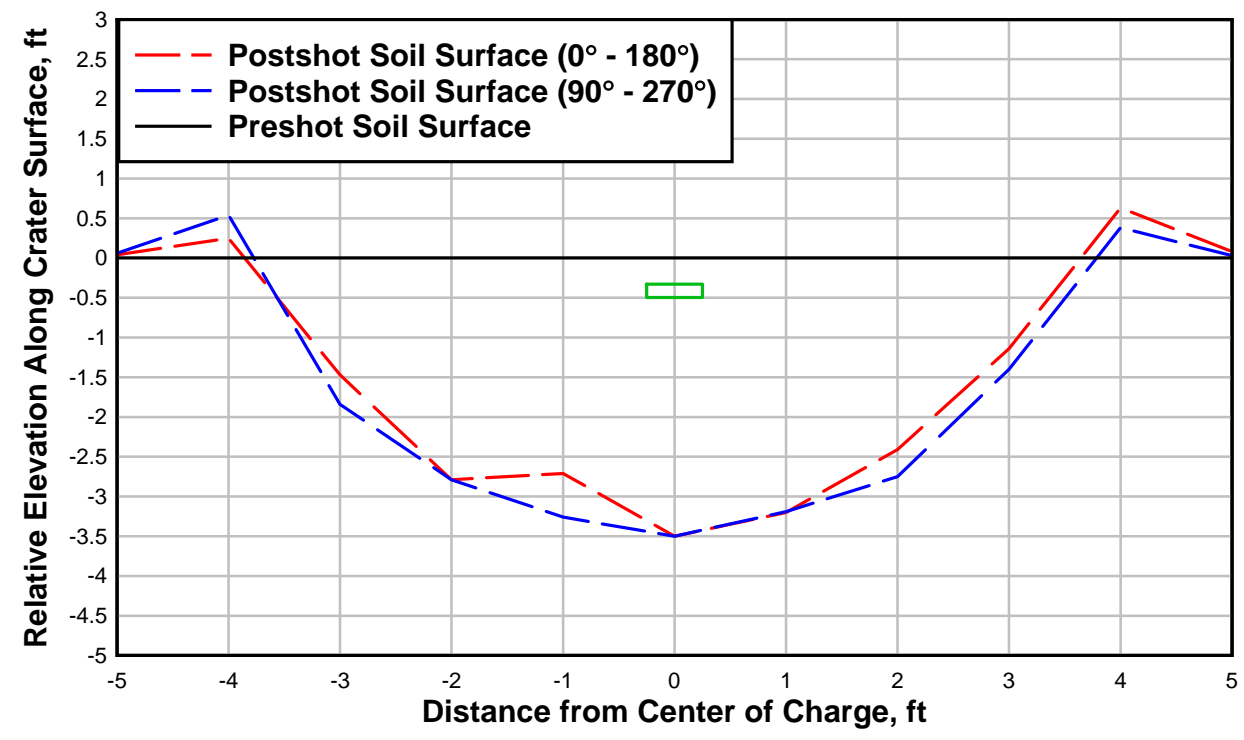

a. Measured posttest crater cross sections in BM-C-05.

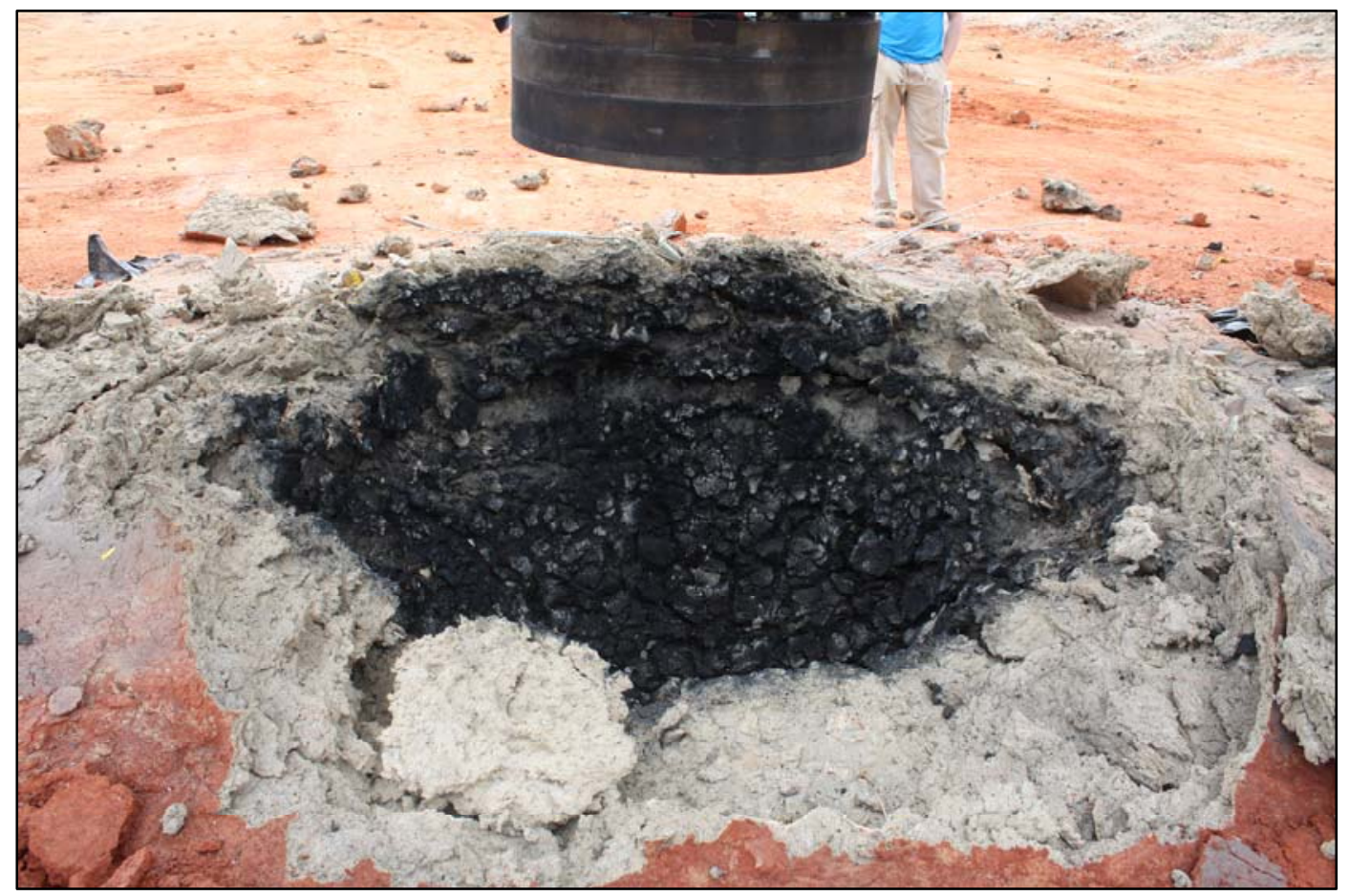

b. Photograph of posttest crater in BM-C-05.

Figure 4.45. Photograph and cross-section surveys of testbed crater in BM-C-05. 


\section{Ground shock stress and particle velocity}

The clay soil test series contained ground shock instrumentation in the two experiments with the charge buried $4 \mathrm{in}$. below the ground surface, i.e., experiments BM-C-03 and BM-C-05. The center of each gage was at the same depth as the center of the explosive charge. The as-placed gage locations and a summary of the measured soil stress and particle velocity data at each gage location in the backfill for experiments BM-C-03 and -05 are given in Table 4.8, which includes the experiment number, gage number, range (radial distance) from the charge CG, time of shock arrival, peak velocity, and peak stress. Selection of the peak amplitude values and the times of arrival of peak amplitudes can be difficult in an environment where reflections are occurring rapidly from a number of sources, and gages are undergoing large motions. As always, the values shown in Table 4.8 are subject to different interpretations. In some cases, two peaks were recorded in the time-history records for both the radial stress and radial particle velocity. When a second peak was clearly present, it was included in the summary table. Possible causes for the second peak include reflected waves from the testbed surface, aboveground pressures traveling along the ground surface, and reflections off the IMD device.

Table 4.8. Ground shock instrumentation summary for clay soil experiments.

\begin{tabular}{|l|l|l|l|l|l|l|l|}
\hline $\begin{array}{l}\text { Test } \\
\text { Number }\end{array}$ & $\begin{array}{l}\text { Gage } \\
\text { Number }\end{array}$ & $\begin{array}{l}\text { Radius from } \\
\text { GZ, ft }\end{array}$ & $\begin{array}{l}\text { Time of } \\
\text { Arrival, } \\
\text { msec }\end{array}$ & $\begin{array}{l}\text { Peak } \\
\text { Velocity, fps }\end{array}$ & $\begin{array}{l}\text { Second } \\
\text { Peak } \\
\text { Velocity, fps }\end{array}$ & $\begin{array}{l}\text { Peak } \\
\text { Stress, psi }\end{array}$ & $\begin{array}{l}\text { Second } \\
\text { Peak } \\
\text { Stress, psi }\end{array}$ \\
\hline BM-C-03 & AR1 & 3 & 1.45 & 17.2 & 19.3 & -- & \\
\hline BM-C-03 & AR2 & 4 & 2.60 & 7.0 & 8.8 & -- & \\
\hline BM-C-03 & AR3 & 5 & 4.52 & 3.3 & 6.3 & -- & \\
\hline BM-C-03 & SR1 & 3 & 1.62 & -- & & 240 & 365 \\
\hline BM-C-03 & SR2 & 4 & 2.51 & -- & & 76 & \\
\hline BM-C-03 & SR3 & 5 & 3.62 & - & & 33 & \\
\hline BM-C-05 & AR1 & 3 & 1.67 & 32.9 & 38.0 & -- & - \\
\hline BM-C-05 & AR2 & 4 & 3.03 & 7.5 & 7.9 & -- & - \\
\hline BM-C-05 & AR3 & 5 & 5.66 & 4.5 & 11.4 & - & - \\
\hline BM-C-05 & SR1 & 3 & 1.82 & -- & - & 521 & 552 \\
\hline BM-C-05 & SR2 & 4 & 3.22 & - & -- & 66 & \\
\hline BM-C-05 & SR3 & 5 & 6.45 & - & - & 31 & \\
\hline
\end{tabular}




\section{Soil stress measurements}

The radial stress time-histories obtained in the clay backfill in experiments BM-C-03 and BM-C-05 at nominal ranges of 3, 4, and $5 \mathrm{ft}$ are presented in Figures 4.46 and 4.47 , respectively, to a time of $20 \mathrm{msec}$. The resulting peak stresses and times of arrival follow the expected trend with the 3-ft range data recording the largest peak stress and earliest time of arrival and the 5- $\mathrm{ft}$ range data recording the smallest peak stress and the latest time of arrival. The peak stresses versus range from experiments BM-C-03 and BM-C-05 are presented in Figure 4.48. The first peak stress value for the 3-ft range in experiment BM-C-03 was significantly less than the first peak value recorded in experiment BM-C-05. The peak values from the two experiments recorded at the 4 - and 5-ft ranges were much closer in magnitude. The difference occurring in the peak stress values at the 3 - $\mathrm{ft}$ range is caused by the large stress gradients from the "point" source and the differences in the air voids of the $5.6 \% \mathrm{AFV}$ wet clay and the $10.8 \% \mathrm{AFV}$ intermediate material. Very limited ground shock measurement data are available for an explosive charge detonated at such a proximity to the ground surface, so it is difficult to make a clear assessment of the validity of the results.

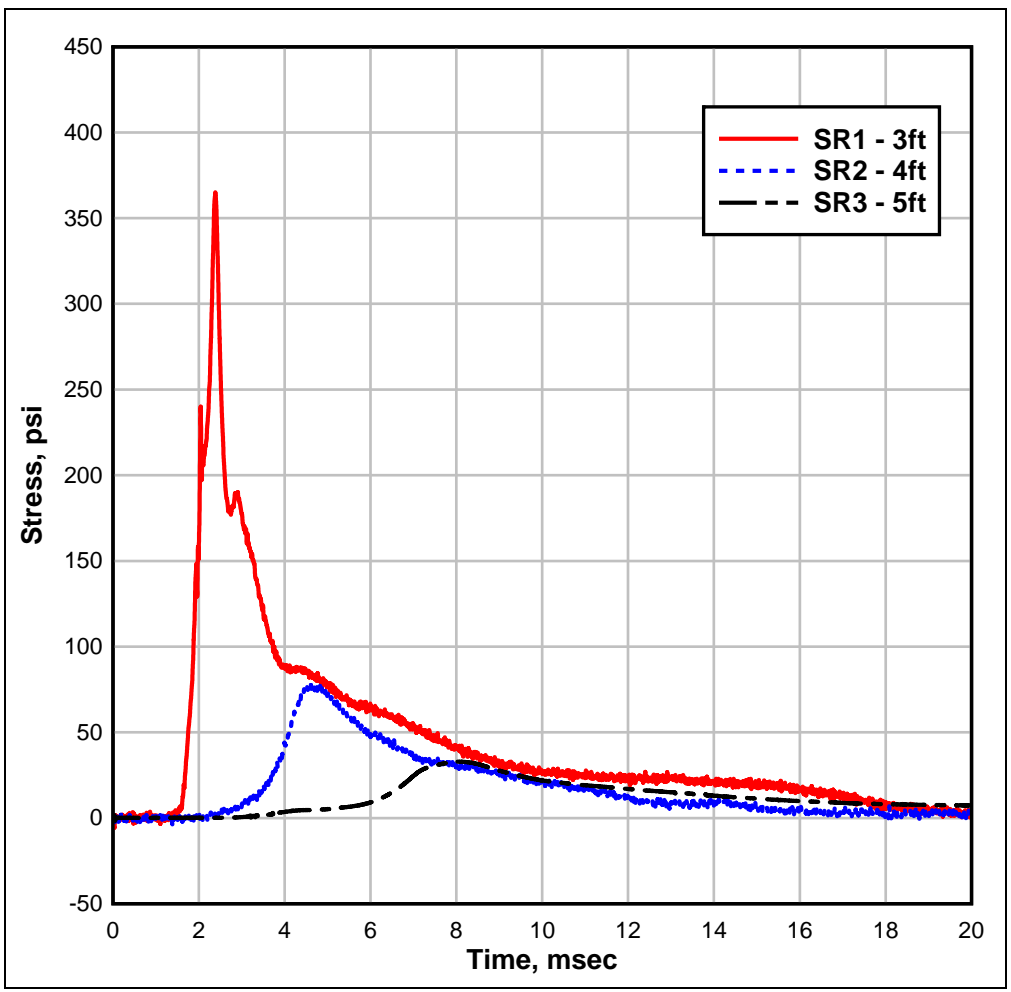

Figure 4.46. Radial stress time-histories measured in the experiment BM-C-03 backfill. 


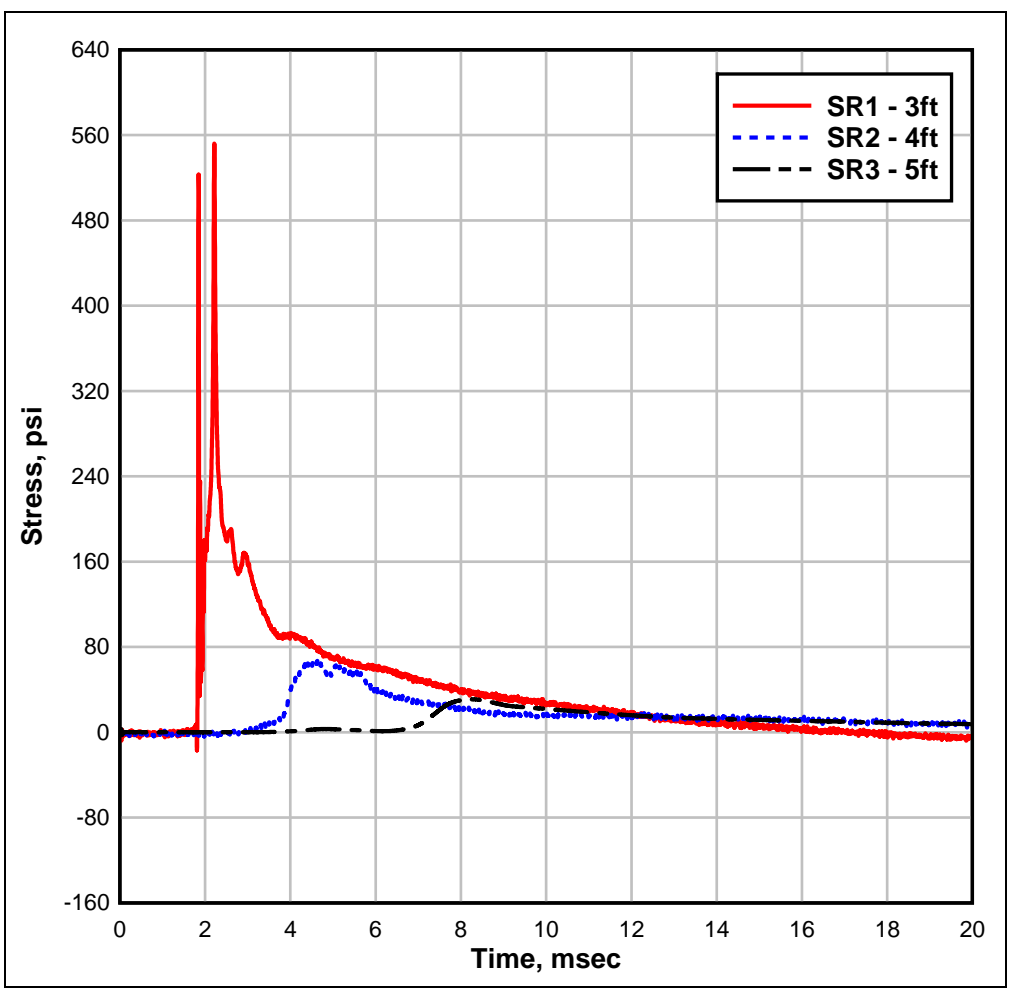

Figure 4.47. Radial stress time-histories measured in the experiment BM-C-05 backfill.

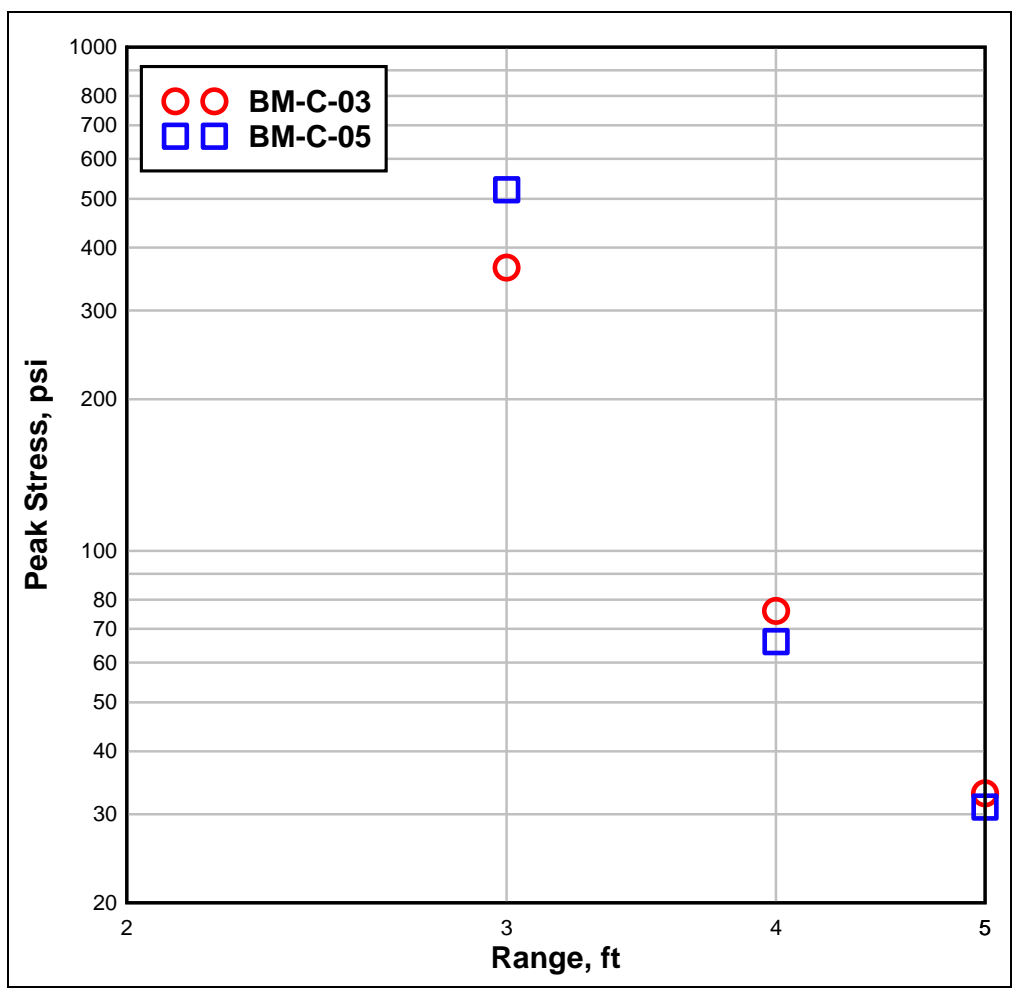

Figure 4.48 Peak stress versus range in the experiment BM-C-03 and BM-C-05 backfills. 


\section{Soil motions}

The radial particle velocity time-histories obtained in clay backfill experiments BM-C-03 and BM-C-05 at nominal ranges of 3, 4, and $5 \mathrm{ft}$ are in Figures 4.49 and 4.50 , respectively, to a time of $60 \mathrm{msec}$. The responses were obtained by integrating the accelerometer data to obtain particle velocity. The resulting first peak particle velocities and times of arrival follow the expected trend, with the gages at the 3 - $\mathrm{ft}$ range recording the largest first peak velocities and earliest times of arrival and the 5-ft range recording the lowest first peak velocities and the latest times of arrival. The times of arrival and first peak velocities recorded in BM-C-03 and BM-C-05 agreed reasonably well at the 4- and 5-ft range, but the peak velocity recorded at the 3 - $\mathrm{ft}$ range in $\mathrm{BM}-\mathrm{C}-03$ was about half that recorded in BM-C-05. A significant slope change occurred in the velocity time-history recorded in BM-C-03 at a value of approximately $16.5 \mathrm{fps}$. The first peak particle velocities versus range from experiments BM-C-03 and BM-C-05 are presented in Figure 4.51. In both experiments, two peak velocities were recorded at each range. The reason for the second peak is not clear, but it could be caused by a reflected wave from the ground surface or the IMD plate.

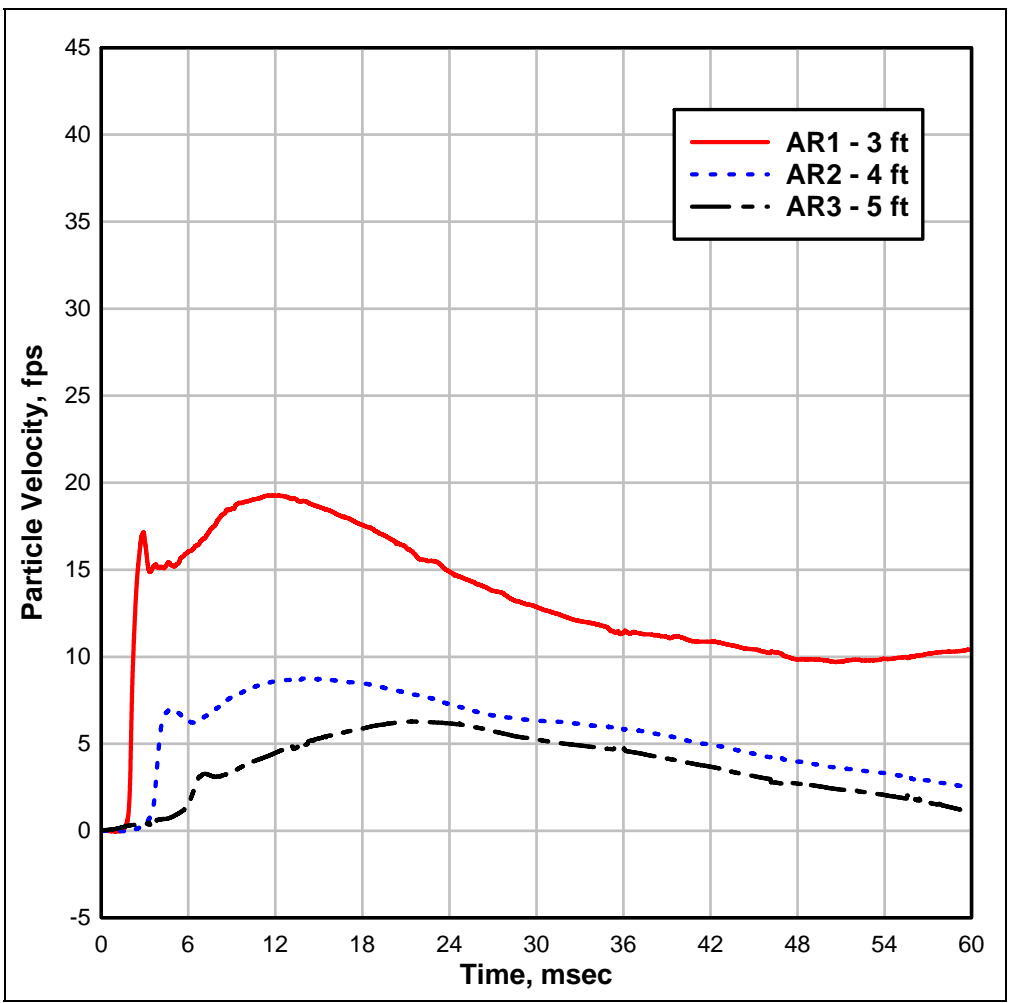

Figure 4.49. Radial particle velocity time-histories measured in the experiment BM-C-03 backfill. 


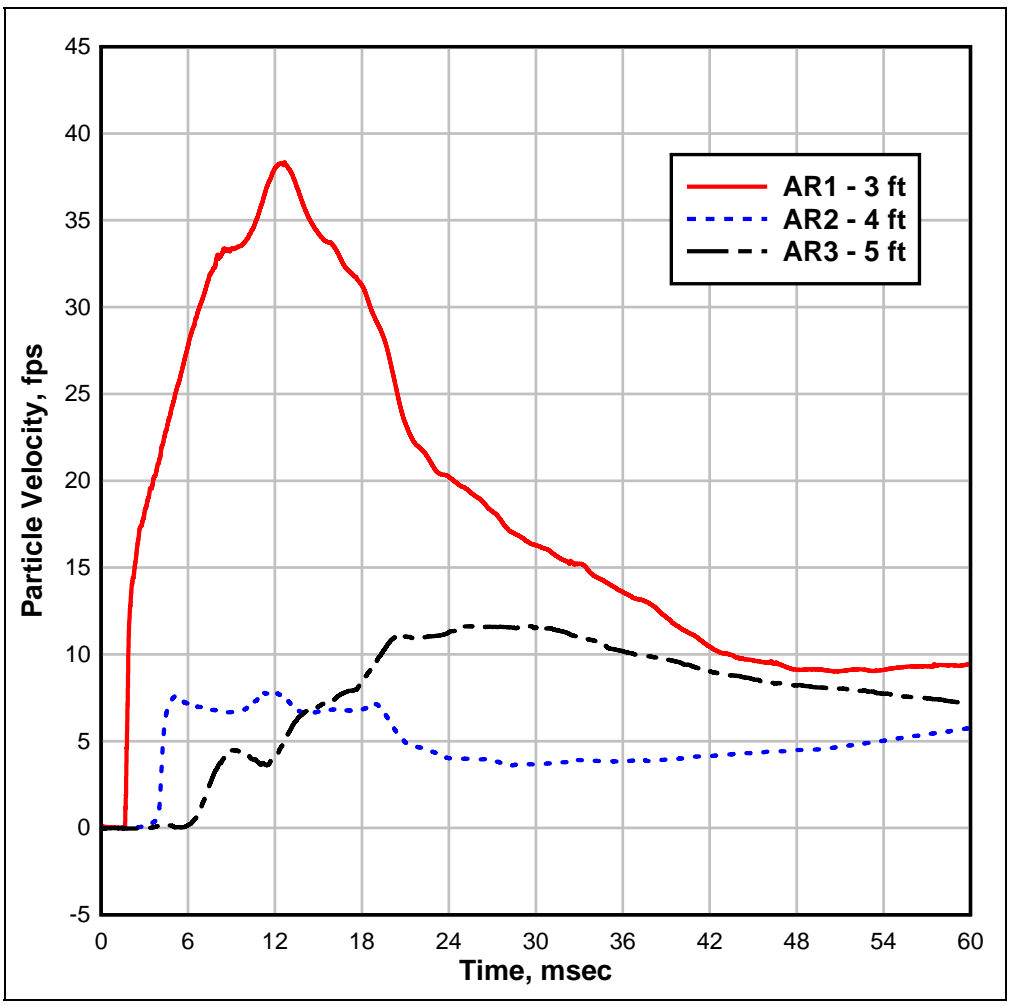

Figure 4.50. Radial particle velocity time-histories measured in the experiment BM-C-05 backfill.

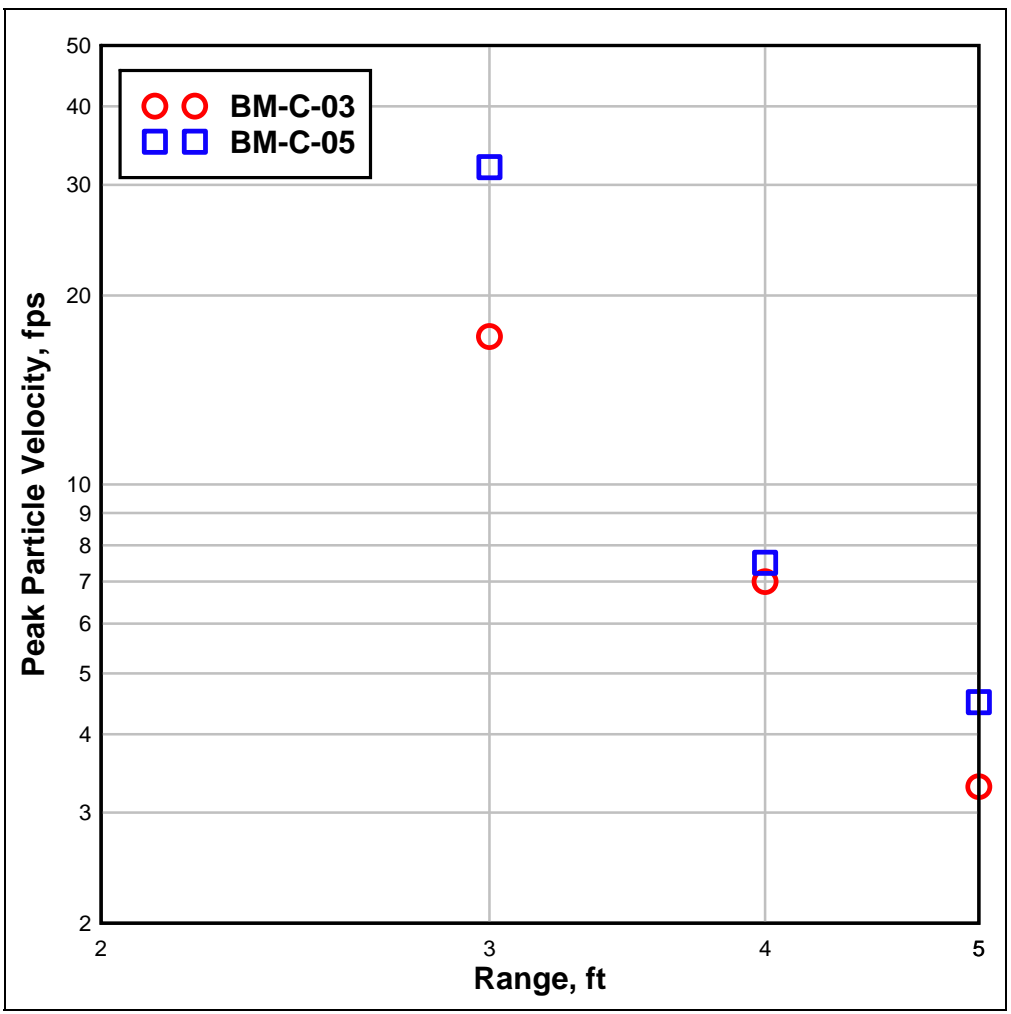

Figure 4.51. Peak particle velocity versus range in the experiment BM-C-03 and BM-C-05 backfill. 


\section{Backfill ground shock arrival times}

The initial times of arrival for the ground shock measurements in the clay backfill are plotted versus range from GZ in Figure 4.52. The times of arrival follow the expected trend with an increase in time of arrival with an increase in range from the charge. At all three ranges, the times of arrival of the stress occur slightly earlier than the times of arrival of the motion. In some records, a clear arrival time was not present in the records due to high-frequency noise in the acceleration record or an unexplained gradual early rise prior to the sharp rise to peak. Therefore, some engineering judgment was required, and as described earlier, the values selected are subject to different interpretations.

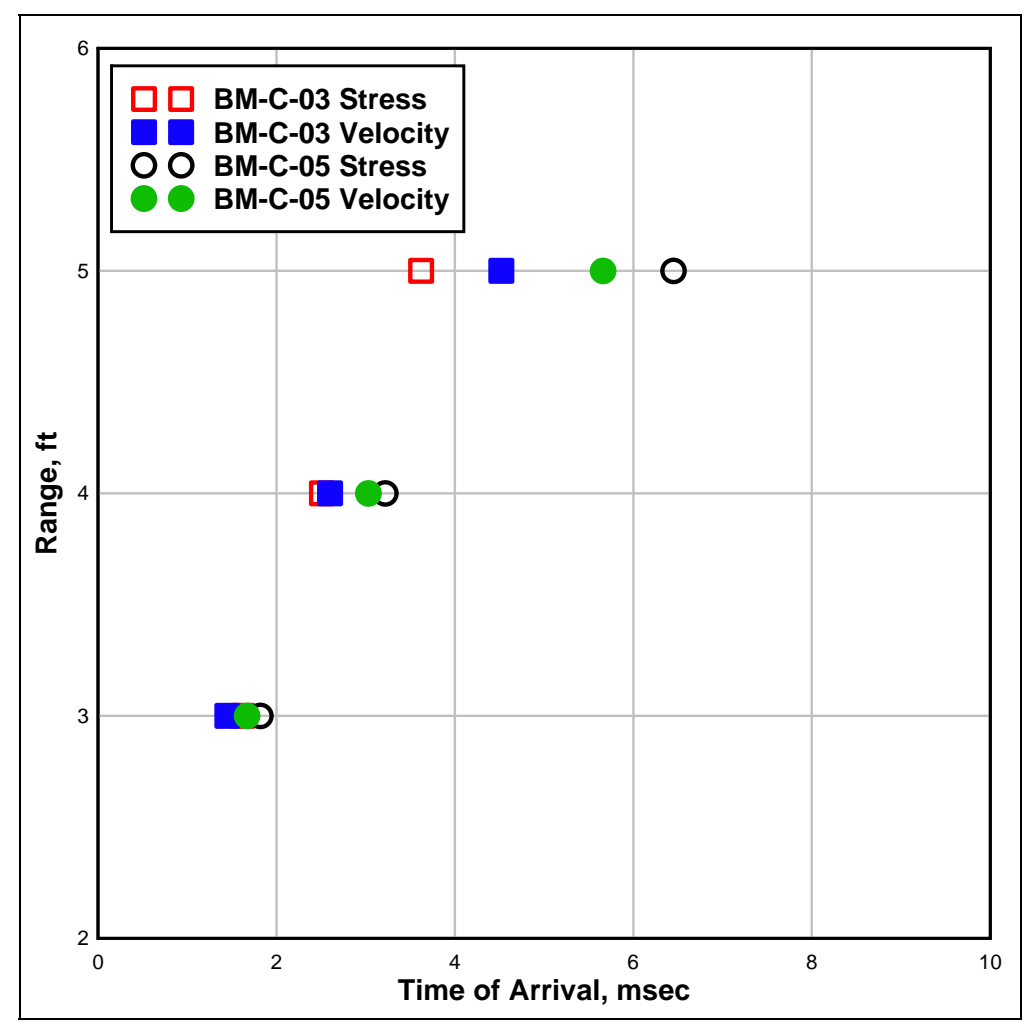

Figure 4.52. Initial ground shock times of arrival versus range from the $\mathrm{CG}$ of the charge in the experiments BM-C-03 and BM-C-05 backfills.

\section{Ground surface overpressure}

Three ground surface overpressure gages were used in all five clay soil experiments. The gages were located at a range of $8 \mathrm{ft}(\mathrm{OP} 1), 10 \mathrm{ft}$ (OP2), and $14 \mathrm{ft}$ (OP3) from ground zero (GZ). A summary of the measured data from each gage is in Table 4.9. The table includes the experiment number, gage number, range from GZ, time of shock arrival, peak overpressure, 
Table 4.9. Ground surface overpressure summary for clay soil.

\begin{tabular}{|l|l|l|l|l|l|l|l|}
\hline $\begin{array}{l}\text { Experiment } \\
\text { Number }\end{array}$ & $\begin{array}{l}\text { Gage } \\
\text { Number }\end{array}$ & $\begin{array}{l}\text { Range } \\
\text { from GZ, ft }\end{array}$ & $\begin{array}{l}\text { Shock } \\
\text { Time of } \\
\text { Arrival, } \\
\text { msec }\end{array}$ & $\begin{array}{l}\text { Peak } \\
\text { Pressure, } \\
\text { psi }\end{array}$ & $\begin{array}{l}\text { Time of } \\
\text { Peak } \\
\text { Pressure, } \\
\text { msec }\end{array}$ & $\begin{array}{l}\text { Rise Time, } \\
\text { msec }\end{array}$ & $\begin{array}{l}\text { Peak } \\
\text { Impulse, } \\
\text { psi - sec }\end{array}$ \\
\hline BM-C-01 & OP - 1 & 8 & 1.42 & 52.8 & 1.54 & 0.12 & 0.027 \\
\hline BM-C-01 & OP - 2 & 10 & 2.37 & 24.5 & 2.48 & 0.11 & 0.021 \\
\hline BM-C-01 & OP - 3 & 14 & 4.95 & 11.1 & 5.04 & 0.09 & 0.019 \\
\hline BM-C-02 & OP - 1 & 8 & 3.44 & 17.9 & 3.55 & 0.11 & 0.017 \\
\hline BM-C-02 & OP - 2 & 10 & 4.68 & 15.0 & 4.80 & 0.12 & 0.018 \\
\hline BM-C-02 & OP - 3 & 14 & 7.46 & 11.1 & 7.57 & 0.11 & 0.016 \\
\hline BM-C-03 & OP - 1 & 8 & 5.71 & 6.0 & 5.84 & 0.13 & 0.006 \\
\hline BM-C-03 & OP - 2 & 10 & 7.29 & 5.0 & 7.43 & 0.14 & 0.005 \\
\hline BM-C-03 & OP - 3 & 14 & 10.46 & 3.7 & 10.62 & 0.16 & 0.004 \\
\hline BM-C-04 & OP - 1 & 8 & 1.53 & 12.6 & 1.60 & 0.07 & 0.016 \\
\hline BM-C-04 & OP - 2 & 10 & 2.53 & 46.2 & 2.68 & 0.15 & 0.021 \\
\hline BM-C-04 & OP - 3 & 14 & 4.90 & 6.0 & 5.53 & 0.63 & 0.011 \\
\hline BM-C-05 & OP - 1 & 8 & 4.73 & 12.8 & 4.84 & 0.11 & 0.011 \\
\hline BM-C-05 & OP - 2 & 10 & 5.92 & 8.7 & 6.08 & 0.16 & 0.009 \\
\hline BM-C-05 & OP - 3 & 14 & 8.82 & 5.1 & 8.99 & 0.17 & 0.006 \\
\hline
\end{tabular}

time of peak overpressure, time to peak (rise time) and peak overpressure impulse. The overpressure time-histories obtained at nominal ranges of 8,10 , and $14 \mathrm{ft}$ in test numbers BM-C-01 through BM-C-05 are presented in Figures 4.53-4.57, respectively. The times of arrival of overpressure versus range, the peak overpressure versus range, and the times of arrival of the peaks versus range are presented in Figures 4.58-4.60, respectively.

In all but one location, the results followed the expected trend, with the peak overpressure decreasing with range. The exception occurred in experiment BM-C-04 at the 8-ft range, where the recorded peak value at 8 - $\mathrm{ft}$ range was lower than that at $10 \mathrm{ft}$. This also occurred in experiment BM-I-05 (see Figure 4.21). When the results of BM-C-04 are compared with the results of BM-C-01, both with the explosive charge sitting on the ground surface, the times of arrival compare well at all three ranges (Figure 4.58) but the peak values vary significantly (Figure 4.59). 


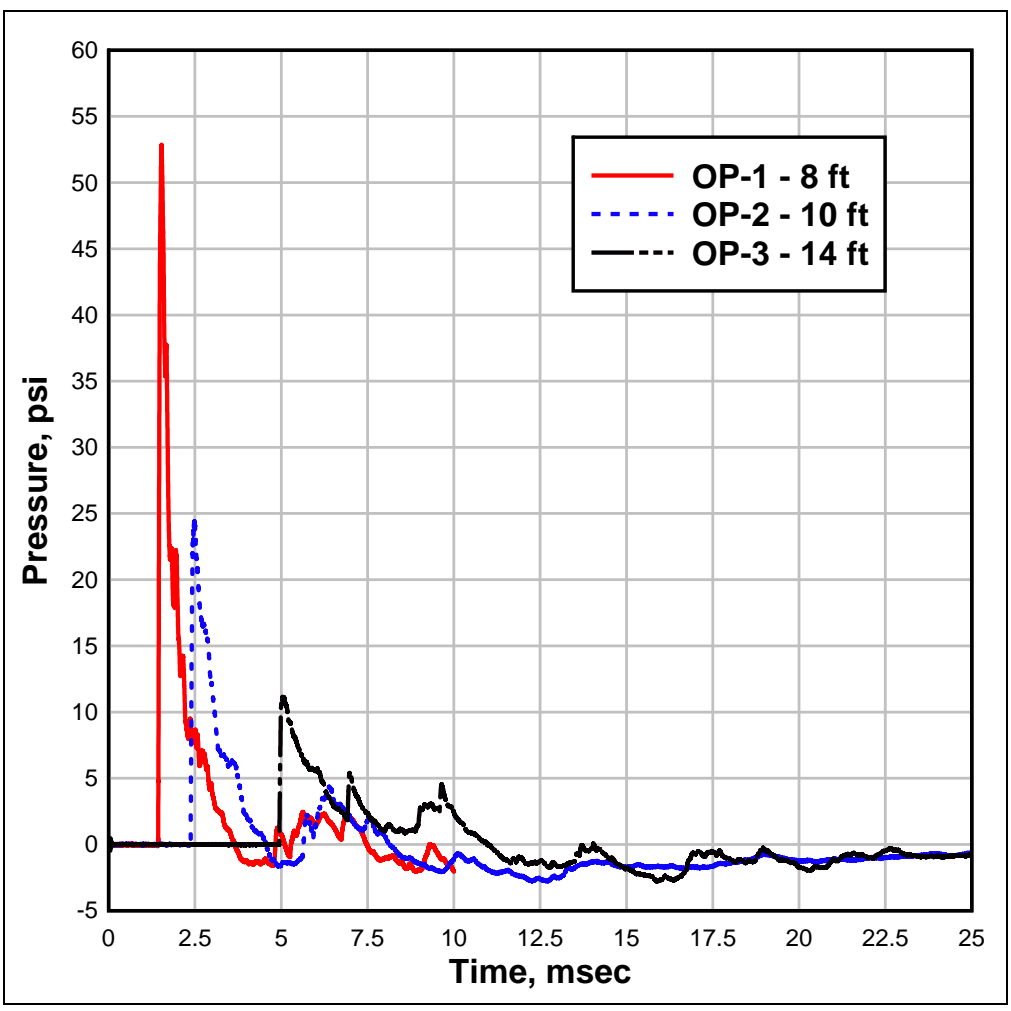

Figure 4.53. Ground surface overpressure time-histories at ranges of 8,10 , and $14 \mathrm{ft}$ from experiment BM-C-01.

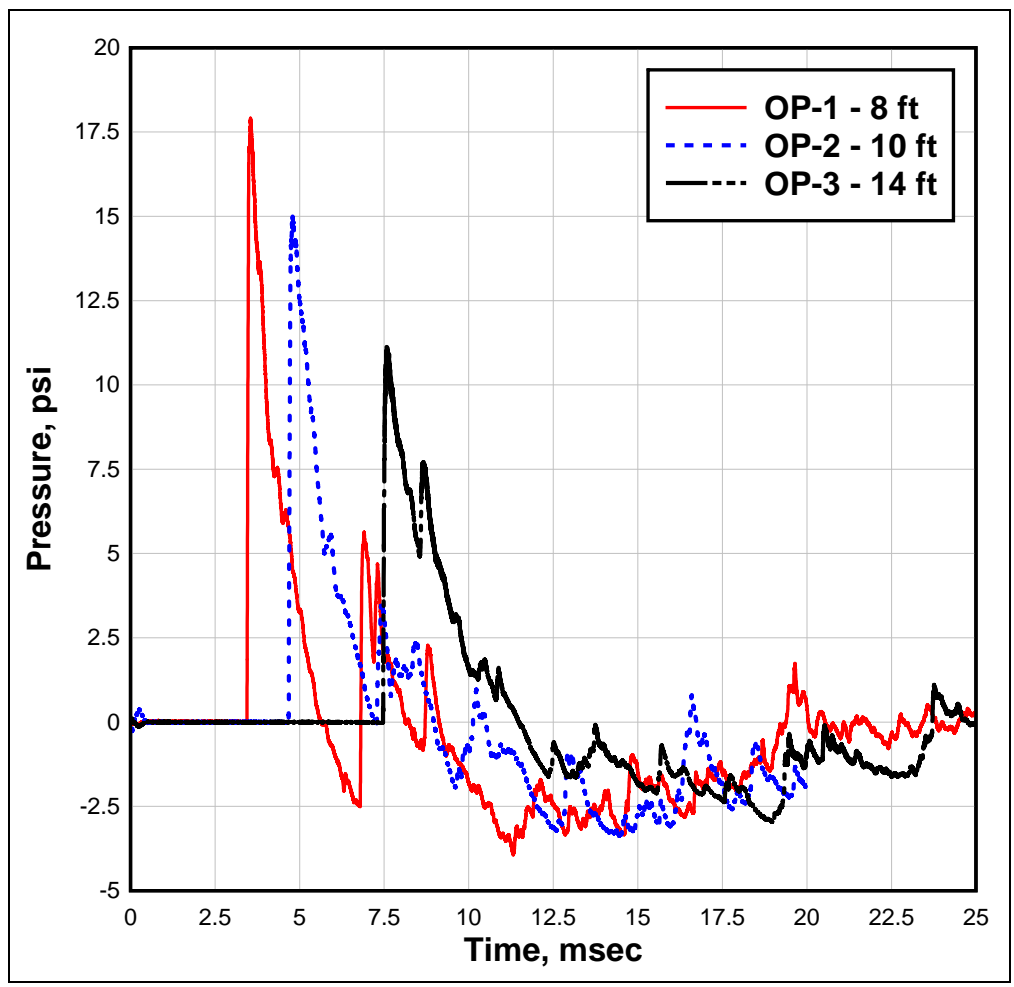

Figure 4.54. Ground surface overpressure time-histories at ranges of 8,10 , and $14 \mathrm{ft}$ from experiment BM-C-02. 


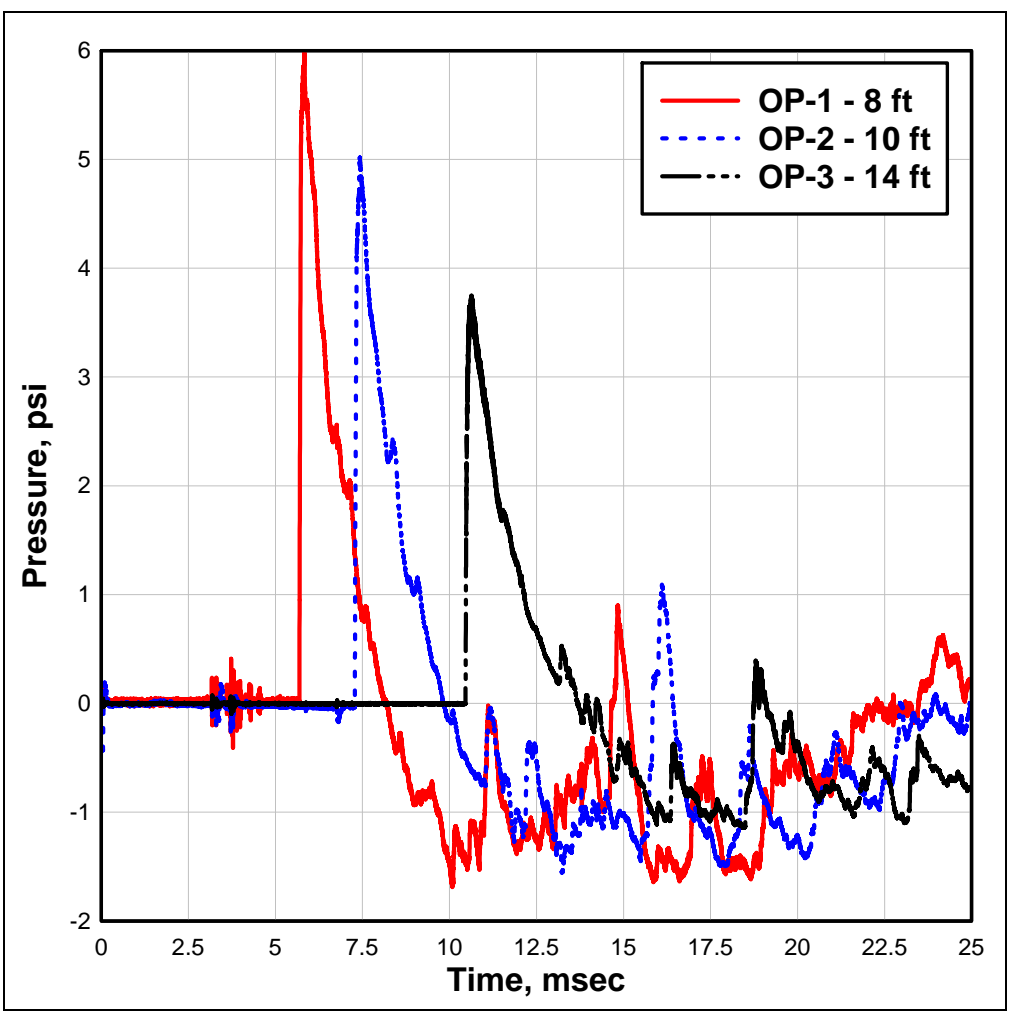

Figure 4.55. Ground surface overpressure time-histories at ranges of 8,10 , and $14 \mathrm{ft}$ from experiment BM-C-03.

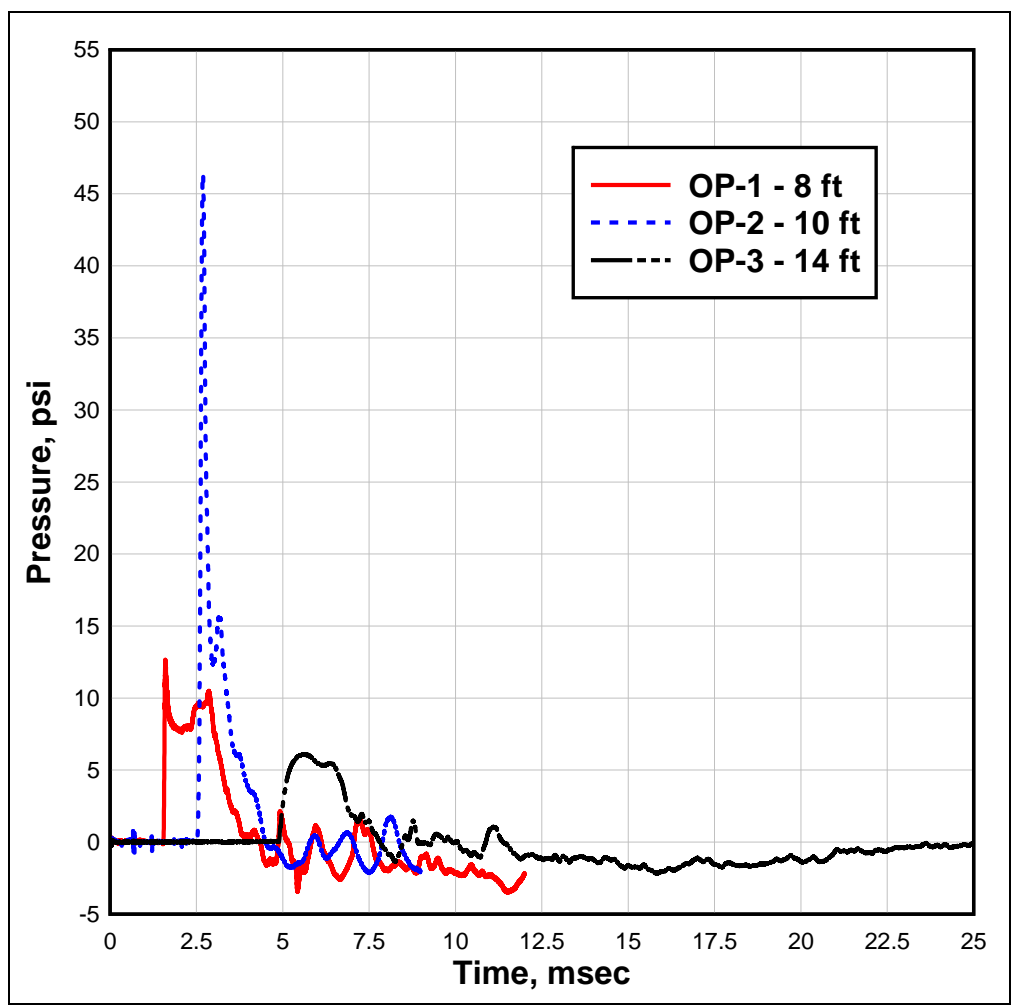

Figure 4.56. Ground surface overpressure time-histories at ranges of 8,10 , and $14 \mathrm{ft}$ from experiment BM-C-04. 


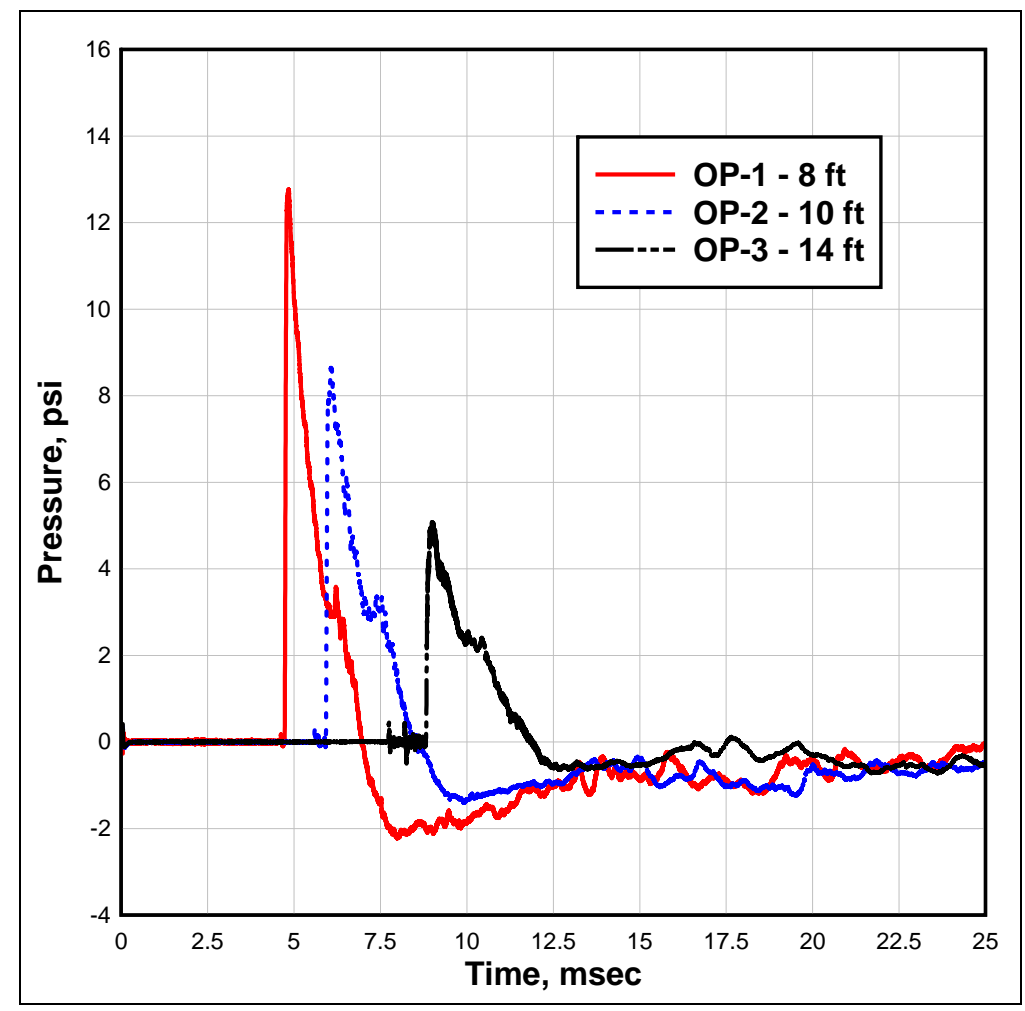

Figure 4.57. Ground surface overpressure time-histories at ranges of 8,10 , and $14 \mathrm{ft}$ from experiment BM-C-05.

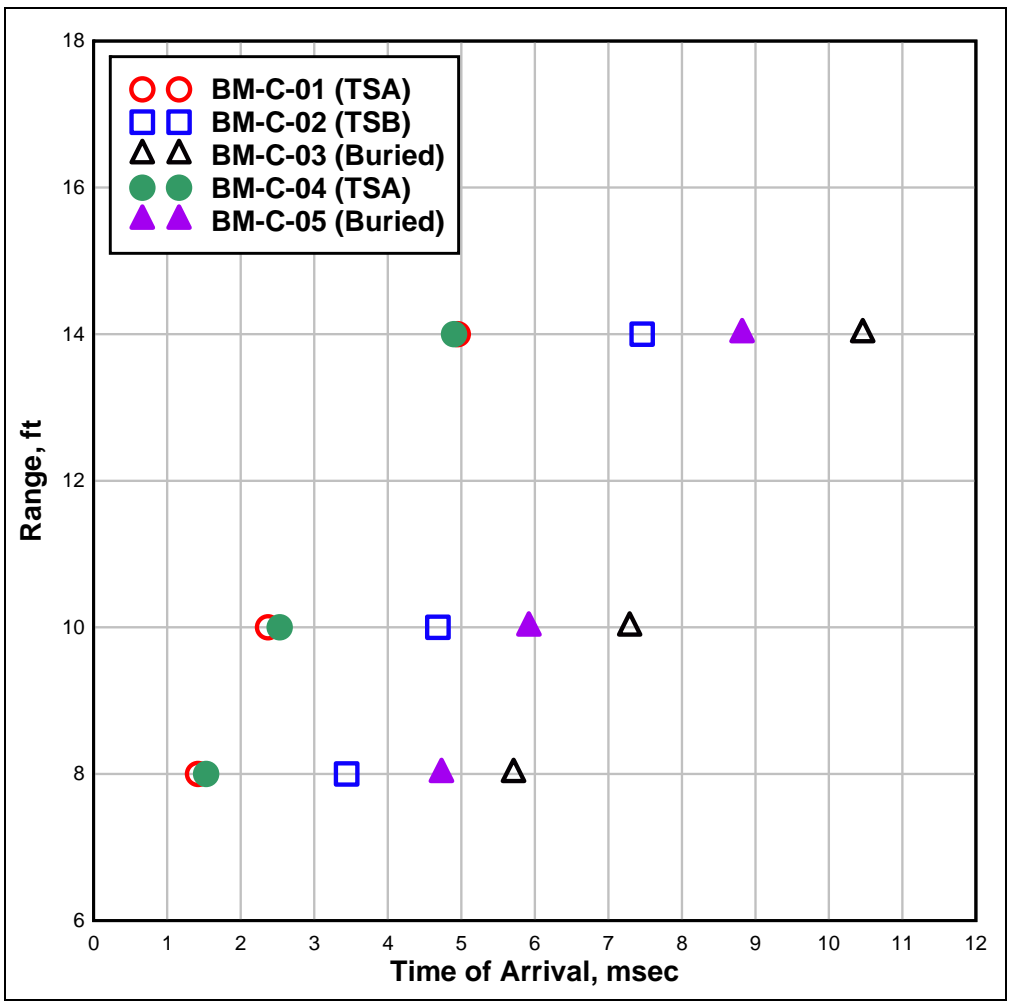

Figure 4.58. Ground surface overpressure times of arrival versus range for experiments BM-C-01 through BM-C-05. 


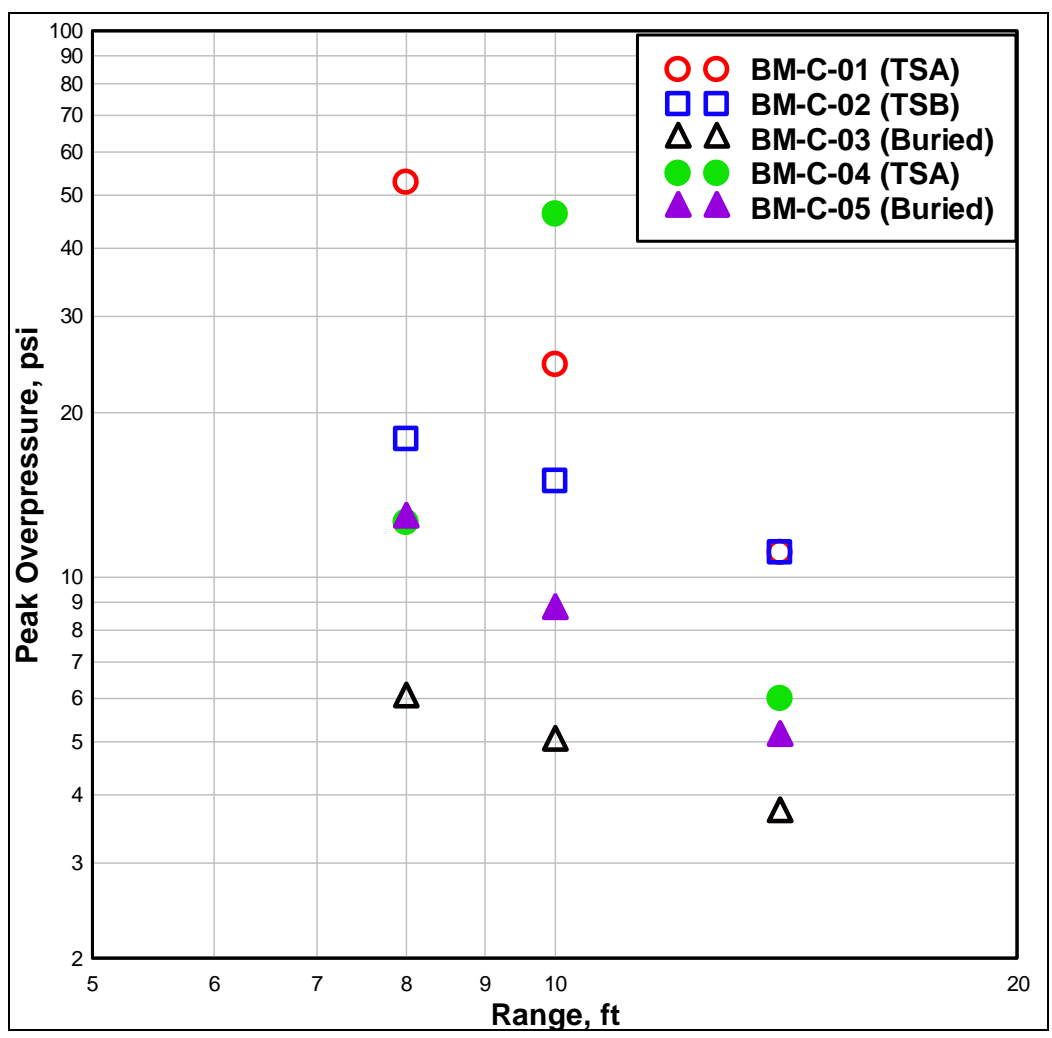

Figure 4.59. Ground surface peak overpressure versus range for experiment BM-C-01 through BM-C-05.

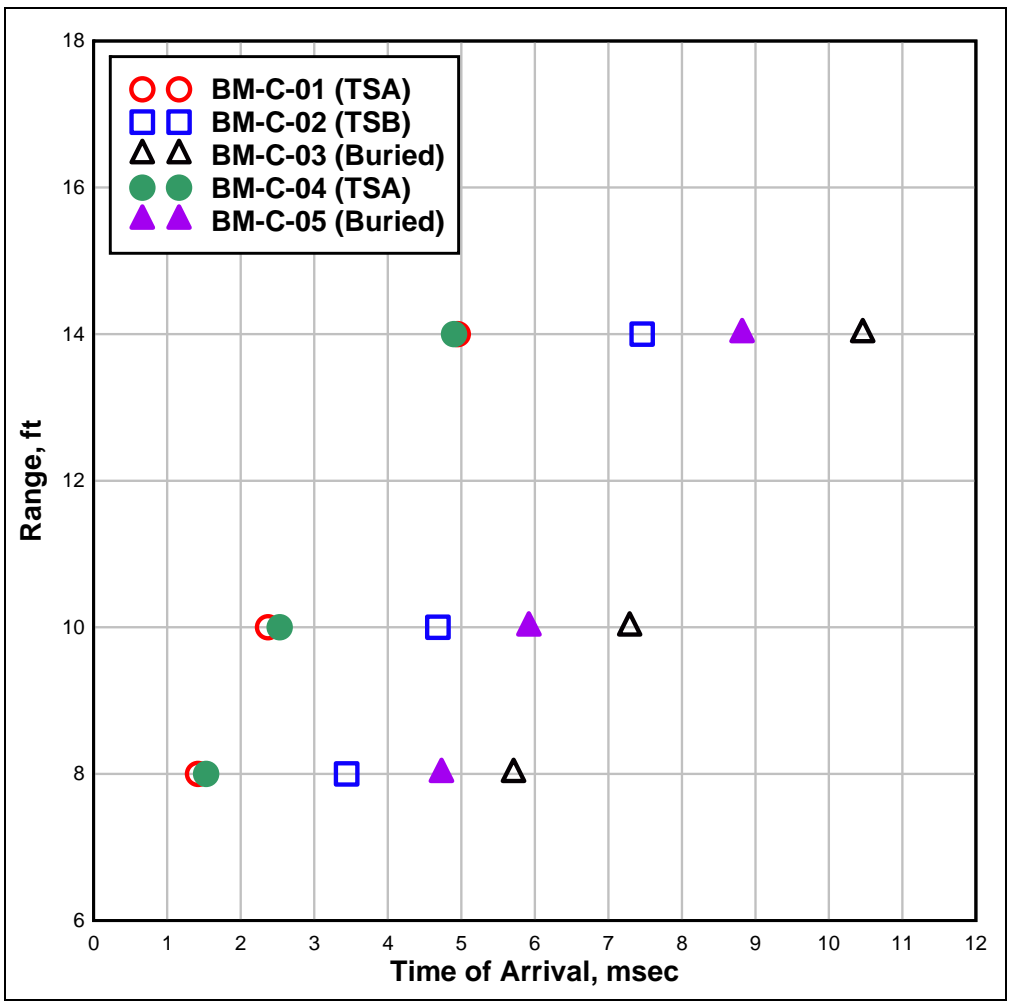

Figure 4.60. Ground surface peak overpressure times of arrival versus range for experiments $\mathrm{BM}-\mathrm{C}-01$ through $\mathrm{BM}-\mathrm{C}-05$. 
This latter variation may be the result of reflections off the IMD impact plates in BM-C-04. The times of arrival of the shocks and the times of arrival of the peaks followed the expected trend with the arrival time increasing with range from the GZ. The experiments with the charge buried 4 in., BM-C-03 and 05, had a significant increase in the arrival times and a significant decrease in peak pressures at the same ranges when compared with the experiments with the charge resting on the surface.

\section{Aboveground side-on overpressure}

Clay experiments BM-C-01, BM-C-02, and BM-C-03 were conducted with a series of five side-on overpressure gages above the testbed surface. For all three experiments, the standoff distance between the top of the charge and a horizontal plane through the side-on overpressures gages was held constant at $20 \mathrm{in}$. The gages were located in line so that one gage was directly above the charge, two had a horizontal offset of $18 \mathrm{in}$., and two had a horizontal offset of $36 \mathrm{in}$. A summary of the aboveground side-on overpressure data for the clay soil experiments is in Table 4.10. The table includes the experiment number, the gage number, horizontal range or distance from GZ (vertical distance held constant at 20 in.), range from the GZ, shock time of arrival, peak overpressure, time of peak pressure, rise time, and peak overpressure impulse. The stress time-histories obtained from the side-on overpressure gages in BM-C-01, BM-C-02, and BM-C-03 are presented in Figures 4.61-4.69. The two redundant gages at 18 and 36 in. are shown on the same plots. The shock times of arrival versus range and the peak side-on overpressure stresses versus range for the three experiments are presented in Figures 4.70 and 4.71, respectively.

As expected, the center gage, SOP3, directly over the charge and the closest to the charge, recorded the highest peak overpressures compared to the values from gages offset 18 and $36 \mathrm{in}$. For a given experiment, the gages at 18-in. offset also recorded higher peak pressures when compared to the peaks from gages at 36-in. offset. Comparisons of the data from redundant gages at the 18- and 36-in. offsets agreed reasonably well. The greatest variation in the peak pressure occurred in experiment BM-C-02 at the 18in. offset. When the results of the various experiments are compared, the charge buried 4 in., BM-C-03, had a significant reduction in the peak overpressure (Figure 4.71) and a significant increase in the shock arrival times (Figure 4.70) compared with the experiments with the charge resting on the surface, TSA, and tangent below, TSB, at the same ranges. 
Table 4.10. Side-on overpressure summary for clay soil experiments.

\begin{tabular}{|l|l|l|l|l|l|l|l|l|}
\hline $\begin{array}{l}\text { Experiment } \\
\text { Number }\end{array}$ & $\begin{array}{l}\text { Gage } \\
\text { Number }\end{array}$ & $\begin{array}{l}\text { Horizontal } \\
\text { Range } \\
\text { from GZ, }\end{array}$ & $\begin{array}{l}\text { Range } \\
\text { from GZ, } \\
\text { in. }\end{array}$ & $\begin{array}{l}\text { Shock } \\
\text { Time of } \\
\text { Arrival, } \\
\text { msec }\end{array}$ & $\begin{array}{l}\text { Peak } \\
\text { Pressure, } \\
\text { psi }\end{array}$ & $\begin{array}{l}\text { Time of } \\
\text { Peak } \\
\text { Pressure, } \\
\text { msec }\end{array}$ & $\begin{array}{l}\text { Rise Time, } \\
\text { msec }\end{array}$ & $\begin{array}{l}\text { Peak } \\
\text { Impulse, } \\
\text { psi-sec }\end{array}$ \\
\hline BM-C-01 & SOP-1 & 36 & 41.75 & 0.51 & 92.2 & 0.59 & 0.08 & 0.034 \\
\hline BM-C-01 & SOP-2 & 18 & 27.77 & 0.30 & 202.1 & 0.40 & 0.10 & 0.035 \\
\hline BM-C-01 & SOP-3 & 0 & 21.15 & 0.13 & 917.0 & 0.16 & 0.03 & 0.081 \\
\hline BM-C-01 & SOP-4 & 18 & 27.77 & 0.21 & 209.0 & 0.25 & 0.04 & 0.026 \\
\hline BM-C-01 & SOP-5 & 36 & 41.75 & 0.45 & 104.6 & 0.58 & 0.13 & 0.036 \\
\hline BM-C-02 & SOP-1 & 36 & 41.74 & 0.73 & 60.4 & 0.82 & 0.09 & 0.016 \\
\hline BM-C-02 & SOP-2 & 18 & 27.77 & 0.27 & 140.9 & 0.32 & 0.05 & 0.023 \\
\hline BM-C-02 & SOP-3 & 0 & 21.15 & 0.12 & 1072.6 & 0.15 & 0.03 & 0.125 \\
\hline BM-C-02 & SOP-4 & 18 & 27.77 & 0.20 & 227.5 & 0.25 & 0.05 & 0.027 \\
\hline BM-C-02 & SOP-5 & 36 & 41.75 & 0.60 & 50.3 & 0.75 & 0.16 & 0.016 \\
\hline BM-C-03 & SOP-1 & 36 & 41.74 & 1.82 & 15.3 & 1.89 & 0.07 & 0.007 \\
\hline BM-C-03 & SOP-2 & 18 & 27.77 & 0.88 & 35.3 & 1.05 & 0.17 & 0.008 \\
\hline BM-C-03 & SOP-3 & 0 & 21.15 & 0.39 & 275.3 & 0.72 & 0.33 & 0.146 \\
\hline BM-C-03 & SOP-4 & 18 & 27.77 & 0.75 & 24.1 & 0.88 & 0.13 & 0.014 \\
\hline BM-C-03 & SOP-5 & 36 & 41.75 & 1.72 & 13.8 & 1.99 & 0.27 & 0.008 \\
\hline
\end{tabular}

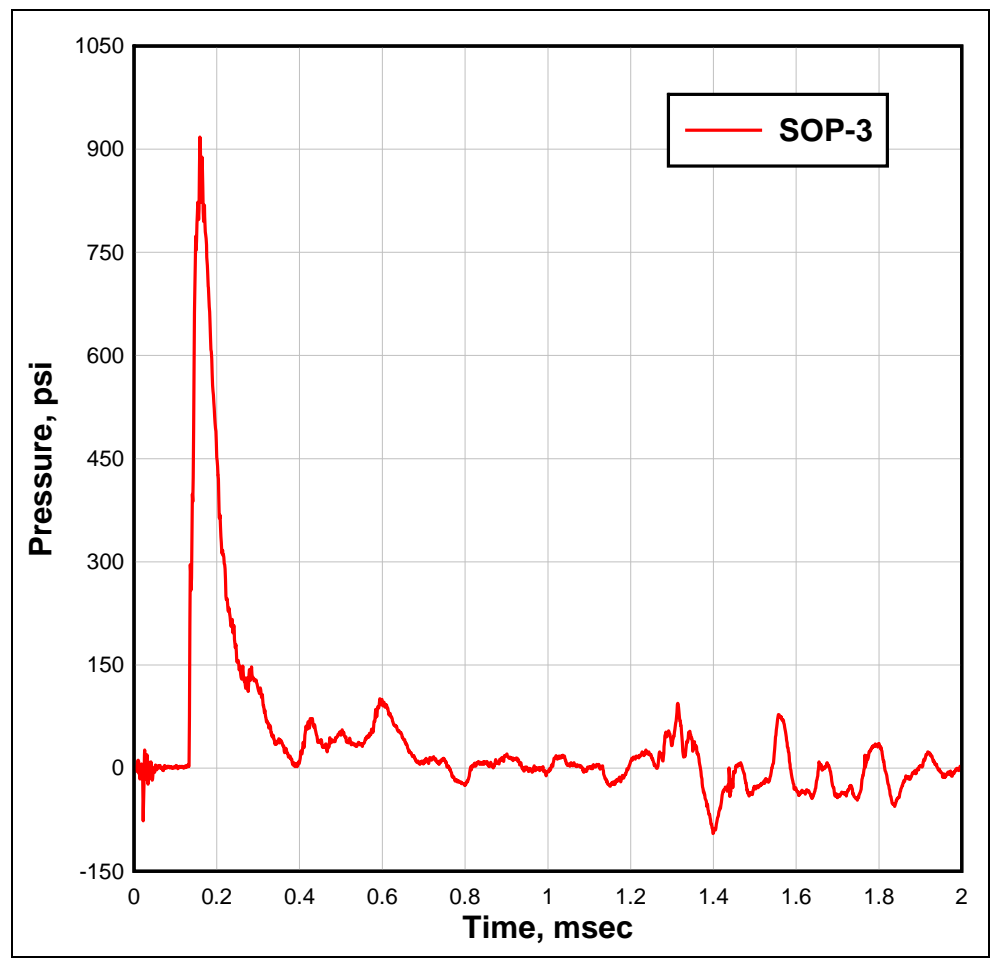

Figure 4.61. Side-on overpressure time-history directly above the charge GZ in experiment BM-C-01 


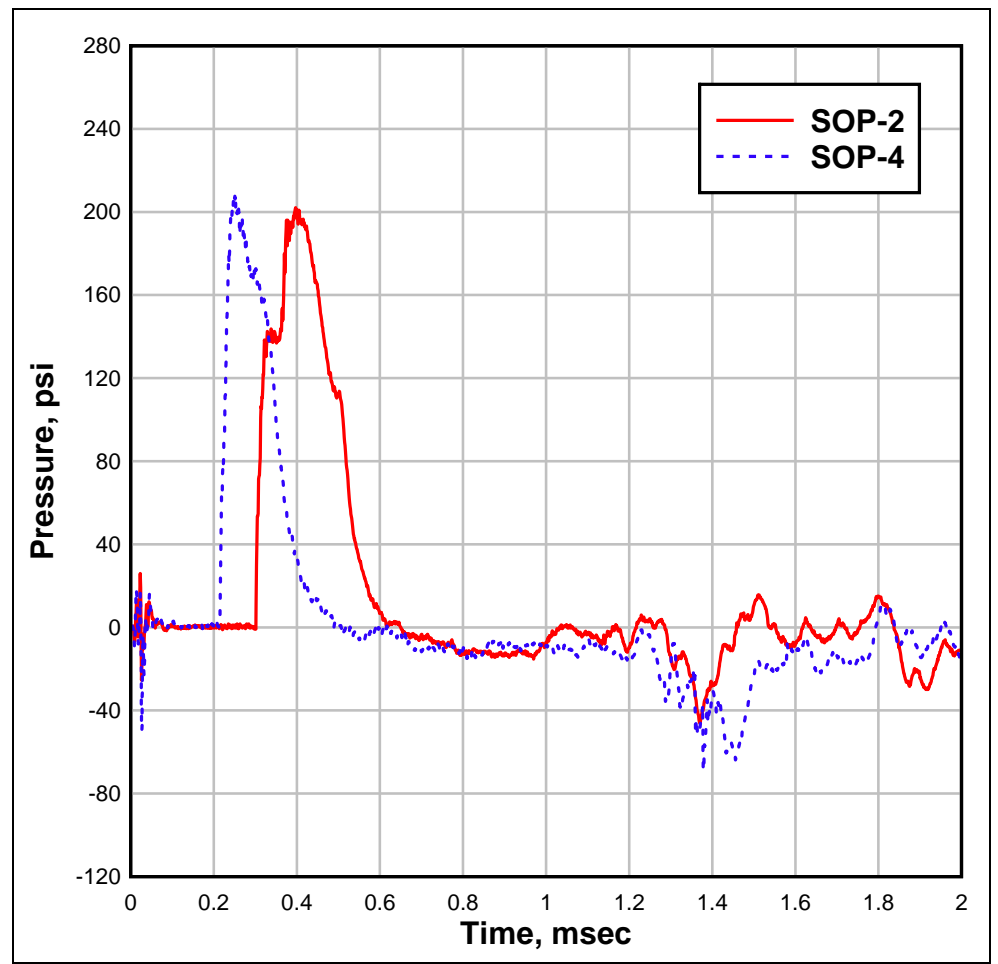

Figure 4.62. Side-on overpressure time-histories at a horizontal range of $18 \mathrm{in}$. from $\mathrm{GZ}$ in experiment BM-C-01.

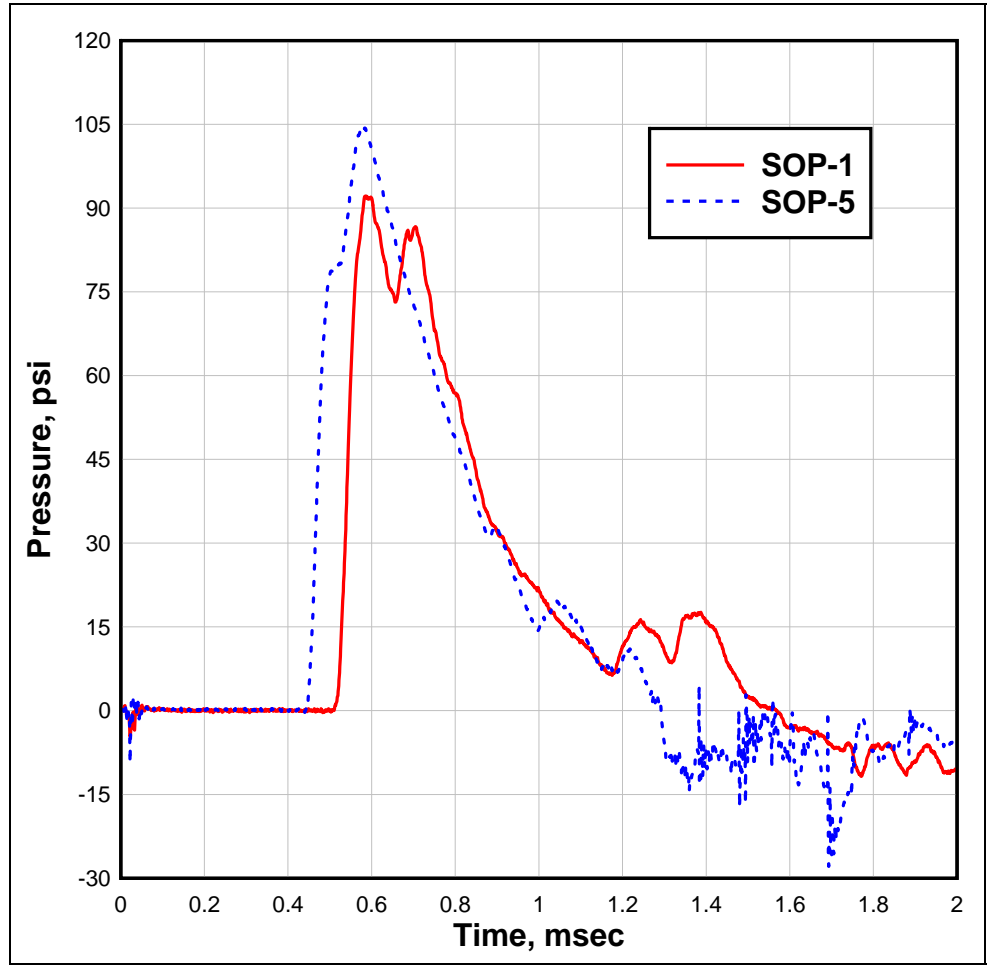

Figure 4.63. Side-on overpressure time-histories at a horizontal range of 36 in. from GZ in experiment BM-C-01. 


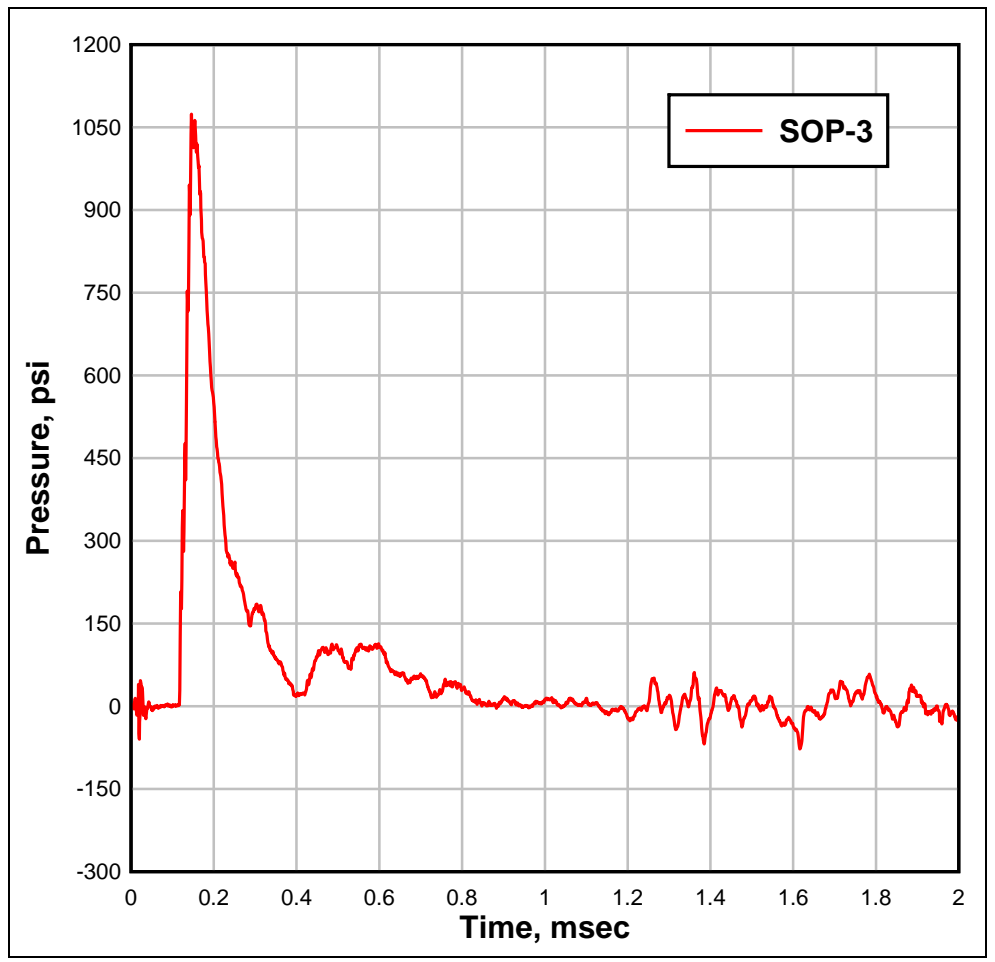

Figure 4.64. Side-on overpressure time-history directly above the charge GZ in experiment BM-C-02.

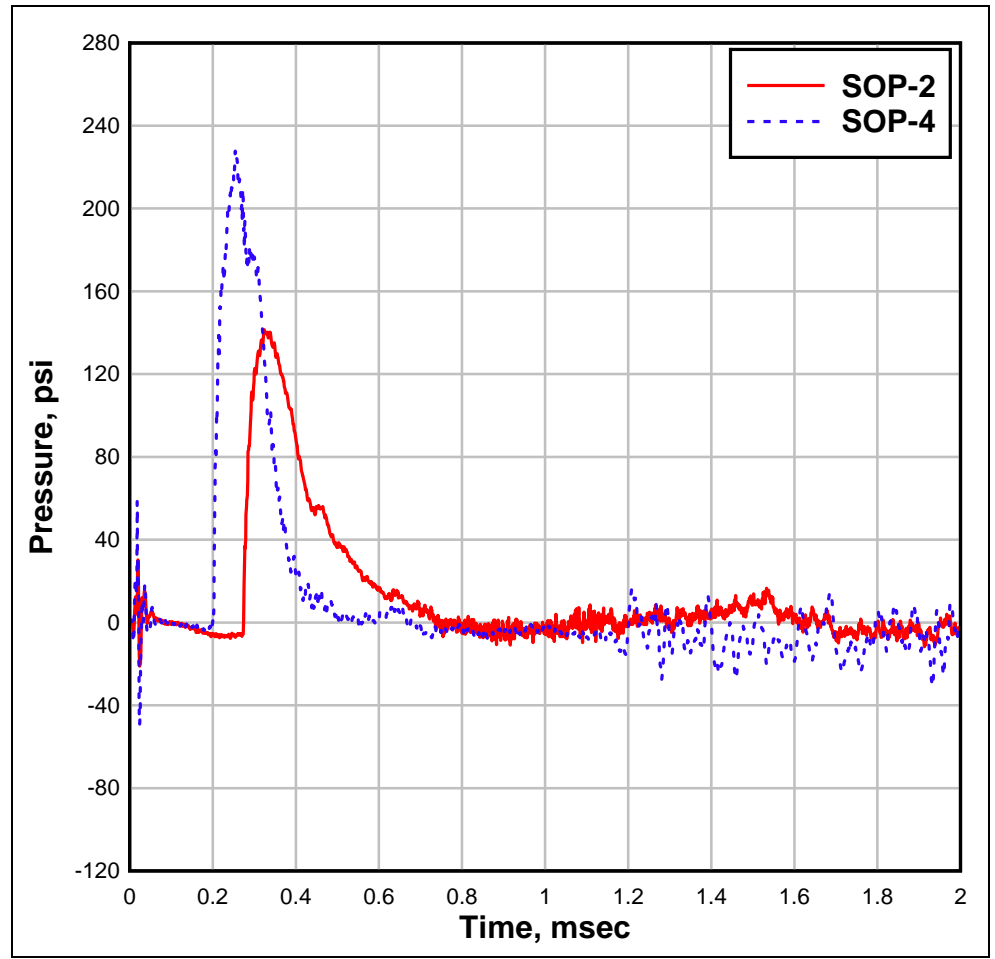

Figure 4.65. Side-on overpressure time-histories at a horizontal range of $18 \mathrm{in.} \mathrm{from} \mathrm{GZ} \mathrm{in} \mathrm{experiment} \mathrm{BM-C-02.}$ 


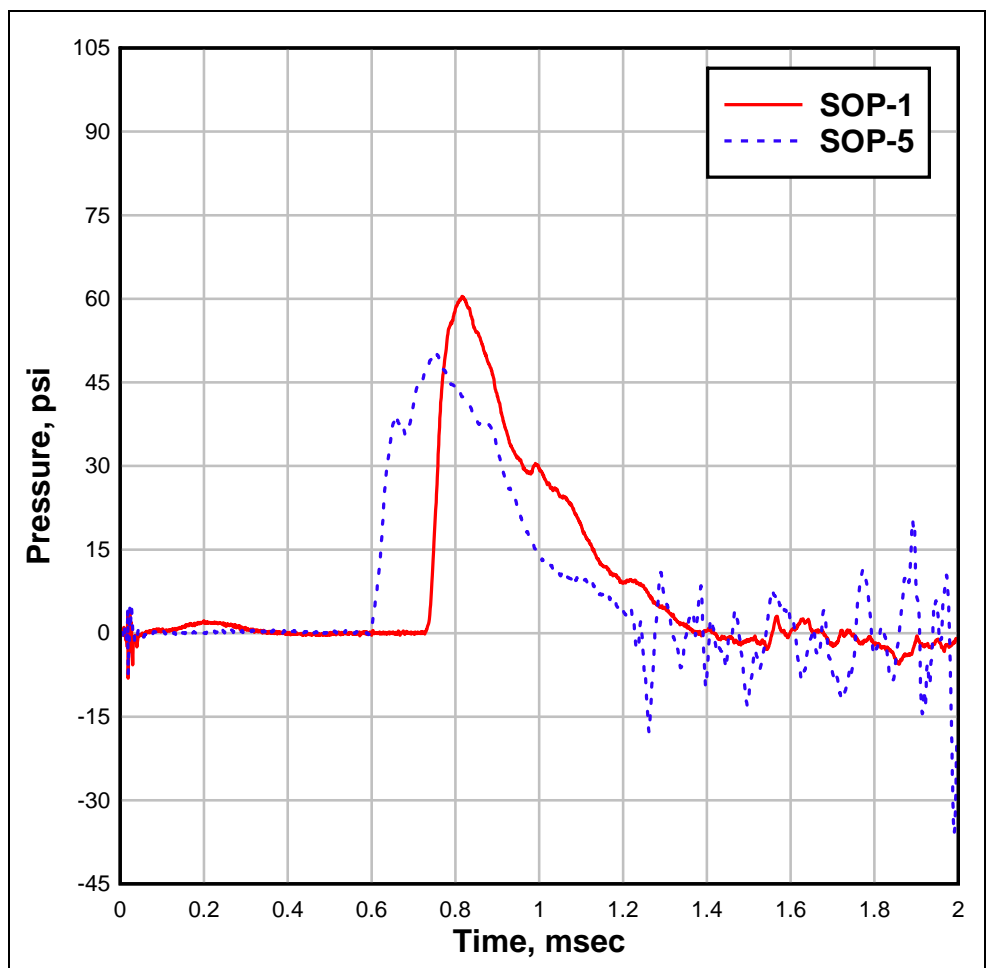

Figure 4.66. Side-on overpressure time-histories at a horizontal range of 36 in. from $\mathrm{GZ}$ in experiment BM-C-02.

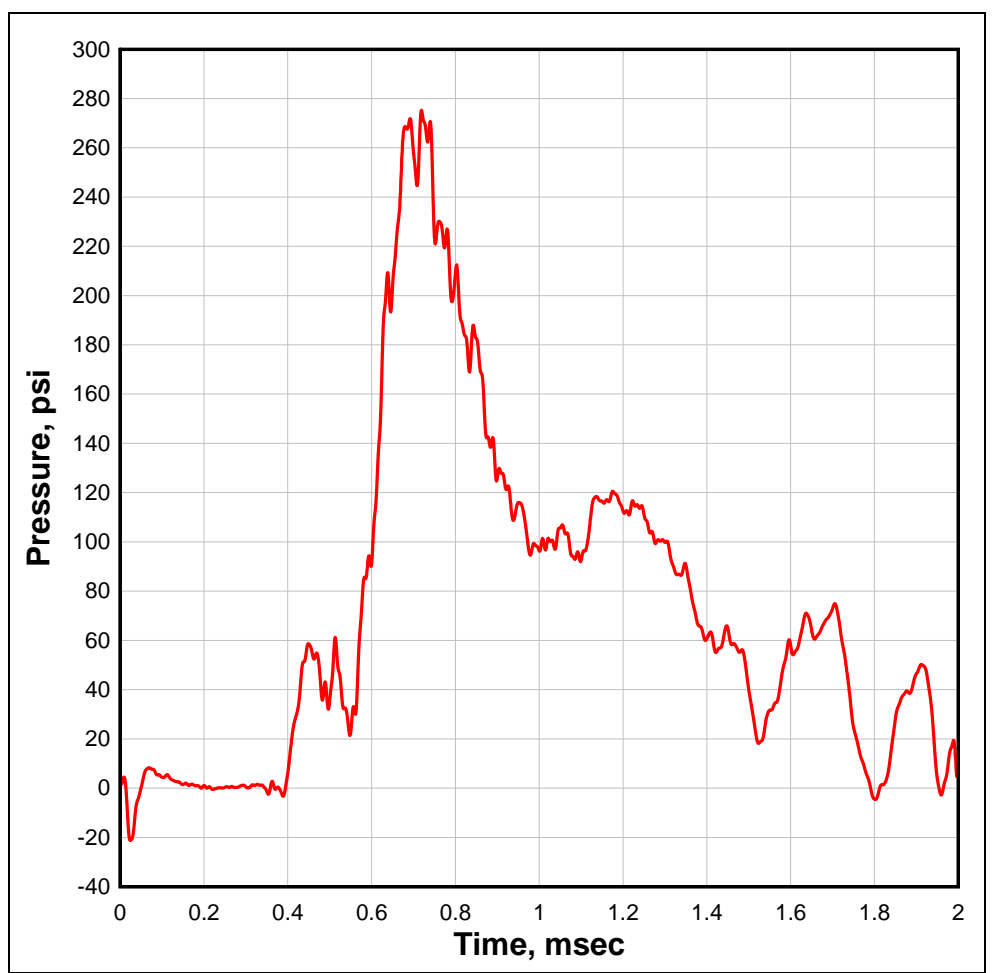

Figure 4.67. Side-on overpressure time-history directly above the charge GZ in experiment BM-C-03. 


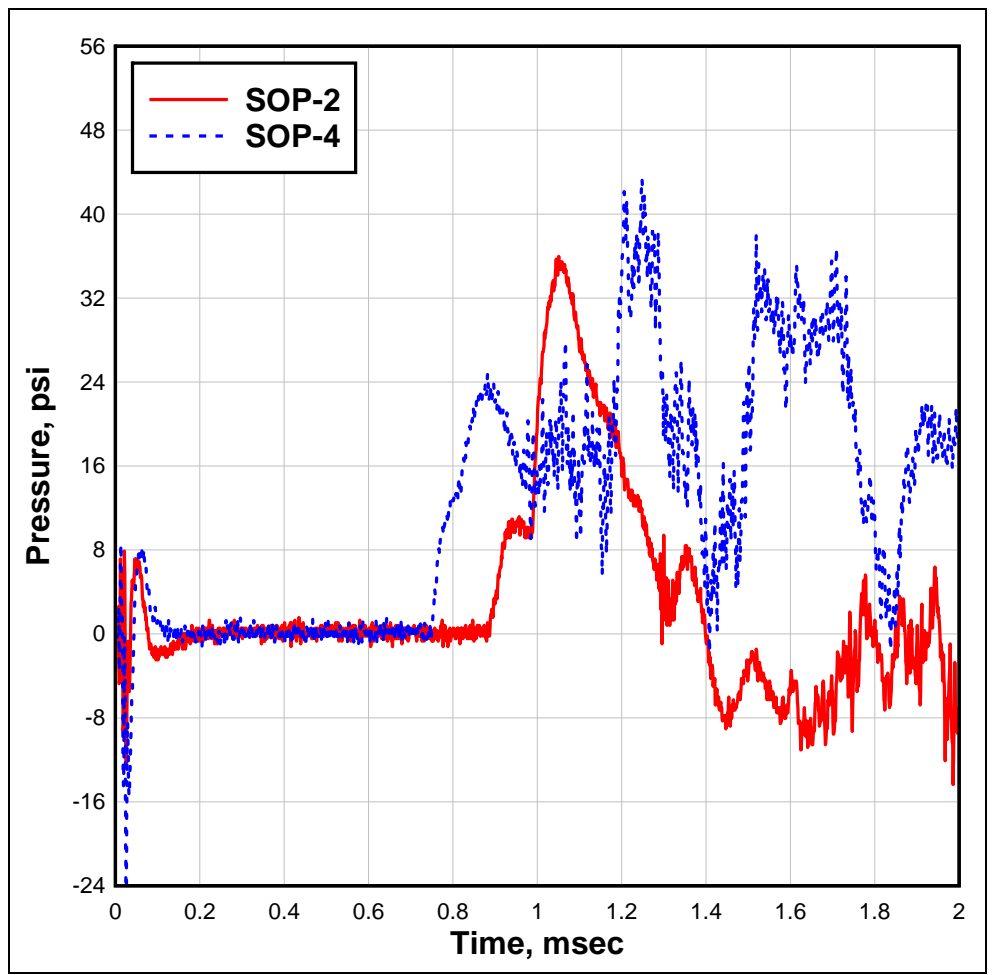

Figure 4.68. Side-on overpressure time-histories at a horizontal range of 18 in. from GZ in experiment BM-C-03.

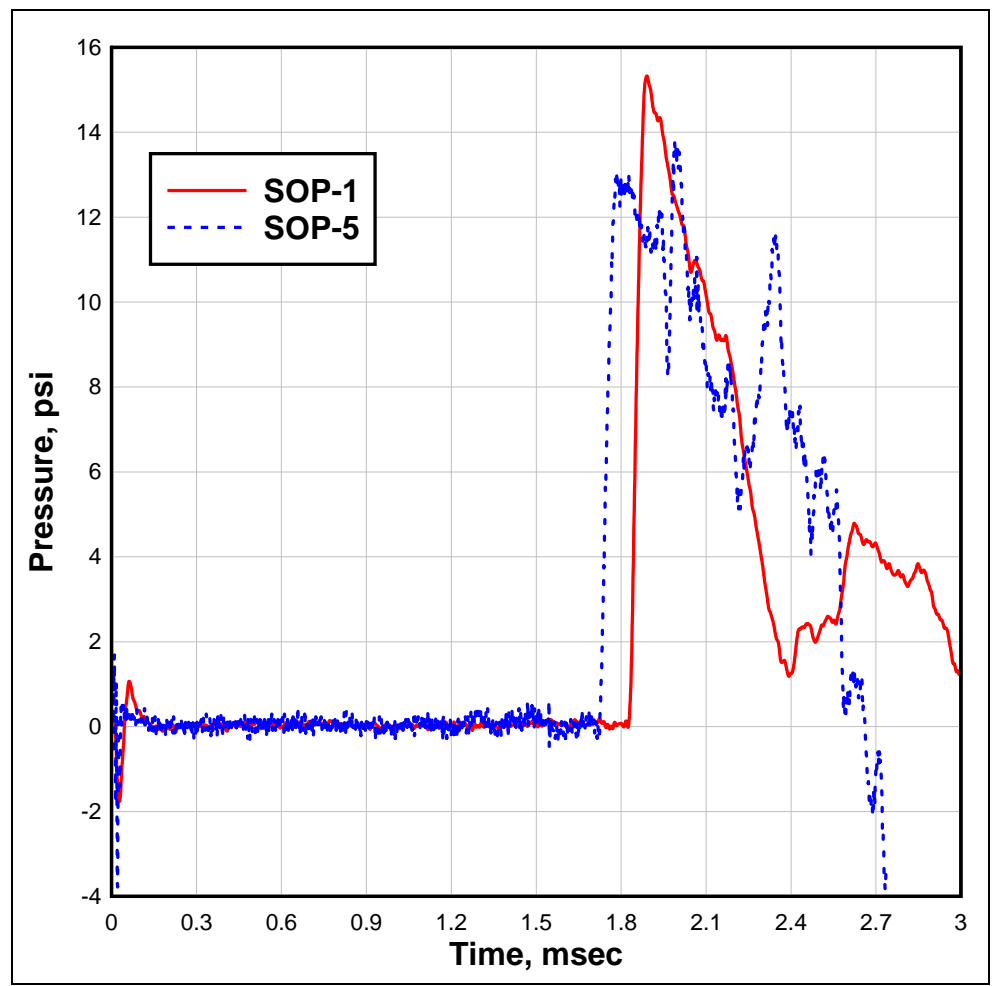

Figure 4.69. Side-on overpressure time-histories at a horizontal range of 36 in. from GZ in experiment BM-C-03. 


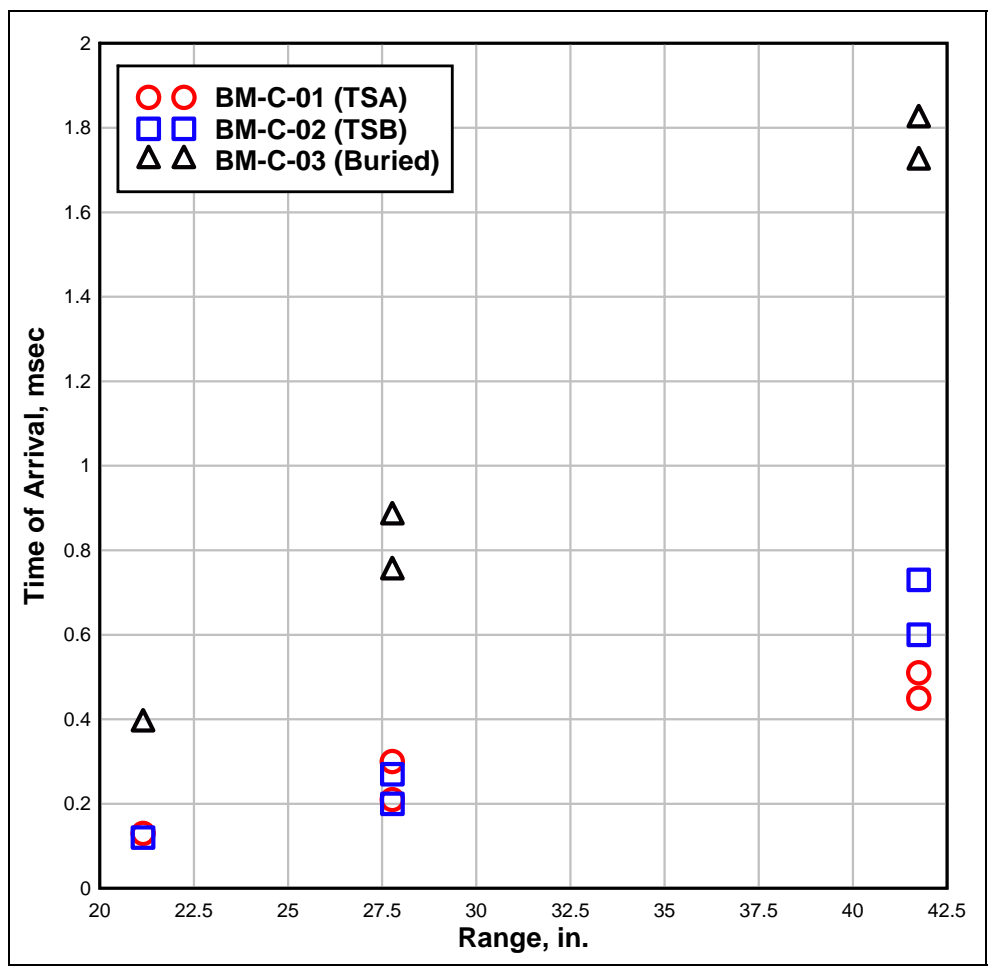

Figure 4.70. Shock times of arrival versus range from side-on overpressure gages in experiments BM-C-01 through BM-C-03.

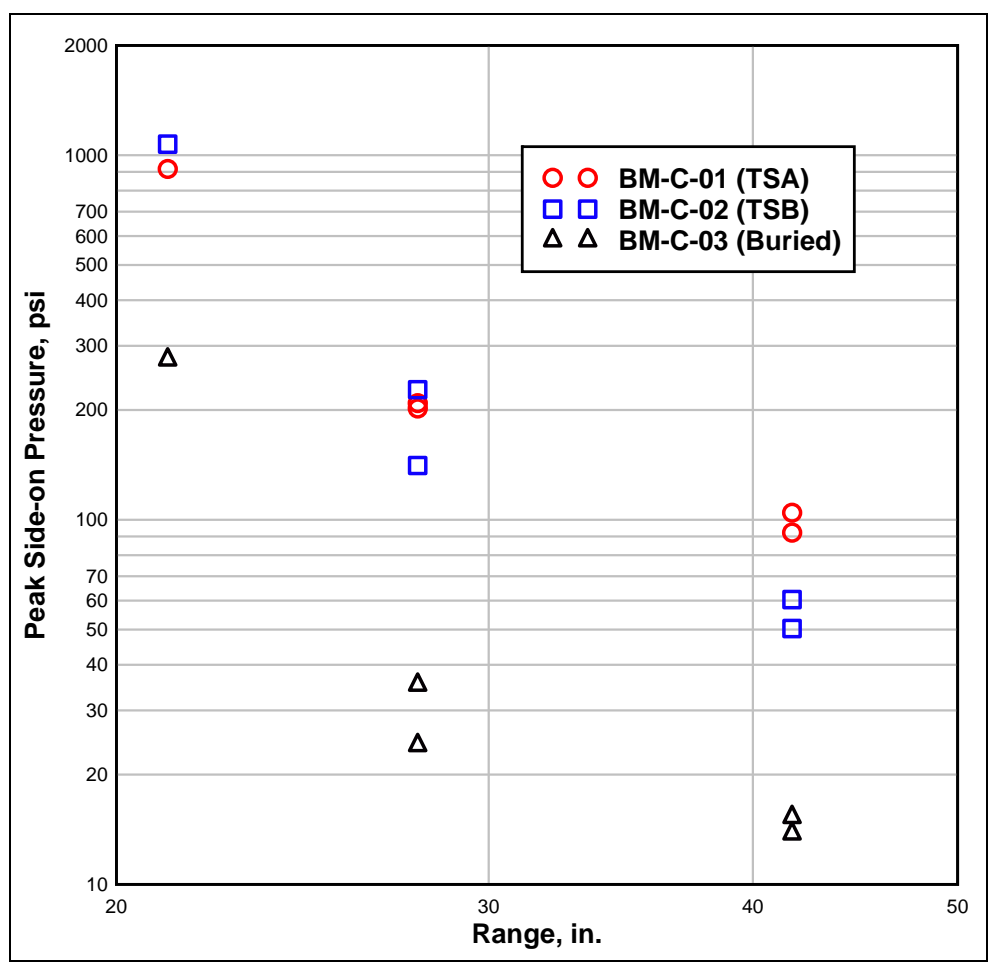

Figure 4.71. Peak side-on overpressure versus range in experiment BM-C-01 through BM-C-03. 
When the results of the TSA and TSB tests are compared, the peak pressures directly above the charge and at the 18-in. offset are approximately equal. The TSA peak pressures are about twice as high at the 36-in. offset as those for the TSB case.

\section{Impulse measurement device}

\section{Piston impulse}

Two of the clay experiments, BM-C-04 and BM-C-05, were conducted using the IMD to measure the total impulse imparted to the impact plate of the piston assembly. For both experiments, the standoff distance between the top of the charge and the face of the IMD impact plate was held constant at $20 \mathrm{in}$. The total mass of the IMD piston assembly for both experiments was approximately 5,500 lb with an impact plate surface area of $7.069 \mathrm{ft}^{2}$ (3- $\mathrm{ft}$ diameter). During the experiments, the motion of the IMD piston assembly was captured using three independent methods, i.e., an accelerometer located on the IMD piston-plate assembly, a displacement measurement gage (yo-yo gage) located on the top of the support structure, and high-speed video. In some cases, one or two of the measurements were unsuccessful, and the third measurement was used as the source for the measured displacement and velocity. In most cases, the high-speed video was the best source for data on IMD motion. Due to the high initial acceleration of the IMD piston assembly, the yo-yo gage was not dependable in capturing useful data, and, in some cases, the gage broke. Use of the accelerometer was partially successful, but it did experience some high-frequency noise and data shifts that made it difficult to select peak displacements and initial velocities from the records.

A summary of the IMD measured data obtained for the clay soil experiments is in Table 4.11. The table includes the peak displacements determined from the three measurement systems and the initial velocity captured both in the high-speed video and from integration of the acceleration record. The average displacement shown in the summary table is the average of the displacement measured by various methods where data were available. Due to the high-frequency noise and data shifts in the acceleration records, the peak displacement and initial velocity for the IMD piston assembly were not captured by the accelerometer in BMC-04. Also, due to an unknown spike at early time in the accelerometer in BM-C-05, the initial velocity was the only data captured in the record, and it was suspect. Therefore, the initial velocity captured from the high-speed 
Table 4.11. Summary of the IMD measured data.

\begin{tabular}{|c|c|c|c|c|c|c|c|}
\hline \multirow[b]{2}{*}{$\begin{array}{l}\text { Experiment } \\
\text { Number }\end{array}$} & \multicolumn{3}{|c|}{ Peak Displacement, in. } & \multirow[b]{2}{*}{$\begin{array}{l}\text { Average } \\
\text { Displacement, } \\
\text { in. }\end{array}$} & \multicolumn{2}{|c|}{ Initial Velocity, fps } & \multirow{2}{*}{$\begin{array}{l}\text { Calculated Peak } \\
\text { Displacement } \\
\text { Using Video Initia } \\
\text { Velocity, in. }\end{array}$} \\
\hline & $\begin{array}{l}\text { Yo-Yo/ } \\
\text { Scratch } \\
\text { Gage }\end{array}$ & $\begin{array}{l}\text { High- } \\
\text { Speed } \\
\text { Video }\end{array}$ & $\begin{array}{l}\text { Acceleration } \\
\text { Record }\end{array}$ & & $\begin{array}{l}\text { High- } \\
\text { Speed } \\
\text { Video }\end{array}$ & $\begin{array}{l}\text { Acceleration } \\
\text { Record }\end{array}$ & \\
\hline BM-C-04 & 2.95 & 1.98 & - & 2.47 & 3.75 & - & 2.63 \\
\hline BM-C-05 & $25+$ & $25+$ & - & $25+$ & 15.00 & 16 & 40 \\
\hline
\end{tabular}

video was the primary value used in the impulse calculations. As a method to compare the different measurement values, the peak displacement is also calculated using the initial velocity captured from the high-speed video. The calculations are explained in detail in Chapter 2 . The peak displacements calculated from the measured initial velocity values compared reasonably well with the average measured peak displacement values. The yo-yo gage captured a peak velocity for BM-C-04, but initial velocities of the IMD assembly appeared to exceed the ability of the gage. No useful data were obtained by the yo-yo gage for BM-C- 05 . For experiment BM-C-05, the IMD piston assembly exceeded the maximum stroke length of the system. The initial velocity was captured during the experiment, but the peak displacement was unavailable. Only minimum damage occurred in the IMD piston assembly when the system exceeded its capability for travel. The IMD piston assembly has a series of rubber catcher pads at the support structure to reduce damage to the system in case the maximum stroke of the system is exceeded.

Using the initial velocity obtained for the high-speed video, the total impulse imparted to the IMD piston assembly was calculated (Table 4.12). The calculated impulse is the total impulse and is directly related to the surface area of the impact plate. The mass of the IMD piston assembly used to calculate the impulse was 5,600 lb, which accounts for the weight of the system and the approximate dynamic drag in the system due to friction. The method used to calculate the total impulse is explained in detail in Chapter 2. As seen in Table 4.12, the total impulse imparted to the IMD increased by a factor of 4 when the charge position changed from sitting on the surface to buried 4 in. below the surface even though the charge standoff distance was the same for both experiments. 
Table 4.12. Total impulse imparted to the IMD.

\begin{tabular}{|l|l|l|l|l|}
\hline $\begin{array}{l}\text { Experiment } \\
\text { Number }\end{array}$ & Charge Position & $\begin{array}{l}\text { Initial Velocity, }{ }^{1} \\
\text { fps }\end{array}$ & $\begin{array}{l}\text { Average Total } \\
\text { Displacement, } \\
\text { in. }\end{array}$ & $\begin{array}{l}\text { Peak Impulse, } \\
\text { Ibf-sec }\end{array}$ \\
\hline BM-C-04 & Sitting on Surface & 3.75 & 2.47 & 650 \\
\hline BM-C-05 & Buried & 15.0 & $25+3$ & 2610 \\
\hline
\end{tabular}

1 Initial velocity obtained from the high speed video.

2 Peak impulse calculated using the initial velocity of the system. Impulse directly related to target mass and surface area.

3 Total displacement exceeded IMD maximum travel length; system bottomed out at $25 \mathrm{in}$.

Impact plate pressure measurements

The three flush-mounted pressure transducers mounted on the bottom plate of the piston assembly, gages RP1, RP2, and RP3, were an attempt to measure the reflected pressure on the surface of the impact plate. Due to the extremely harsh environment from the soil, airblast, and detonation products at this close proximity to the charge, the pressure data obtained were somewhat limited. The three gages included one PCB gage and two Kulite gages. The gages were equal distance from the charge and were at a 2.5-in.-radius off the center of the IMD impact plate. Two different Kulite gage cover plates were utilized during the test in an attempt to reduce or filter the loading by soil particles and/ or detonation products. No useful data were collected from the PCB gage. PCB gages are typically more sensitive to accelerations and were also exposed directly to the airblast and soil particles while the Kulite gages used a debris filter.

The pressure time-histories obtained from Kulite gages RP2 and RP3 for experiments BM-C-04 and BM-C-05 are presented in Figures 4.72 and 4.73, respectively. Pressure gage RP-3 in experiment BM-C-04 was damaged during the experiment and recorded only the time of arrival of the pressure. No useful data were recorded in pressure gage RP- 2 in experiment BM-C-05.

The times of arrival for the pressure data recorded by the two Kulite gages in experiment BM-C-04 compared very well with each other. The pressure data recorded by the Kulite gage in experiment BM-C-05 is questionable due to the nontypical rise and fall in the pressure time-history and the extremely high peak value. Experiment BM-C-05 had the charge fully buried in the soil and produced a much more complex loading condition. 


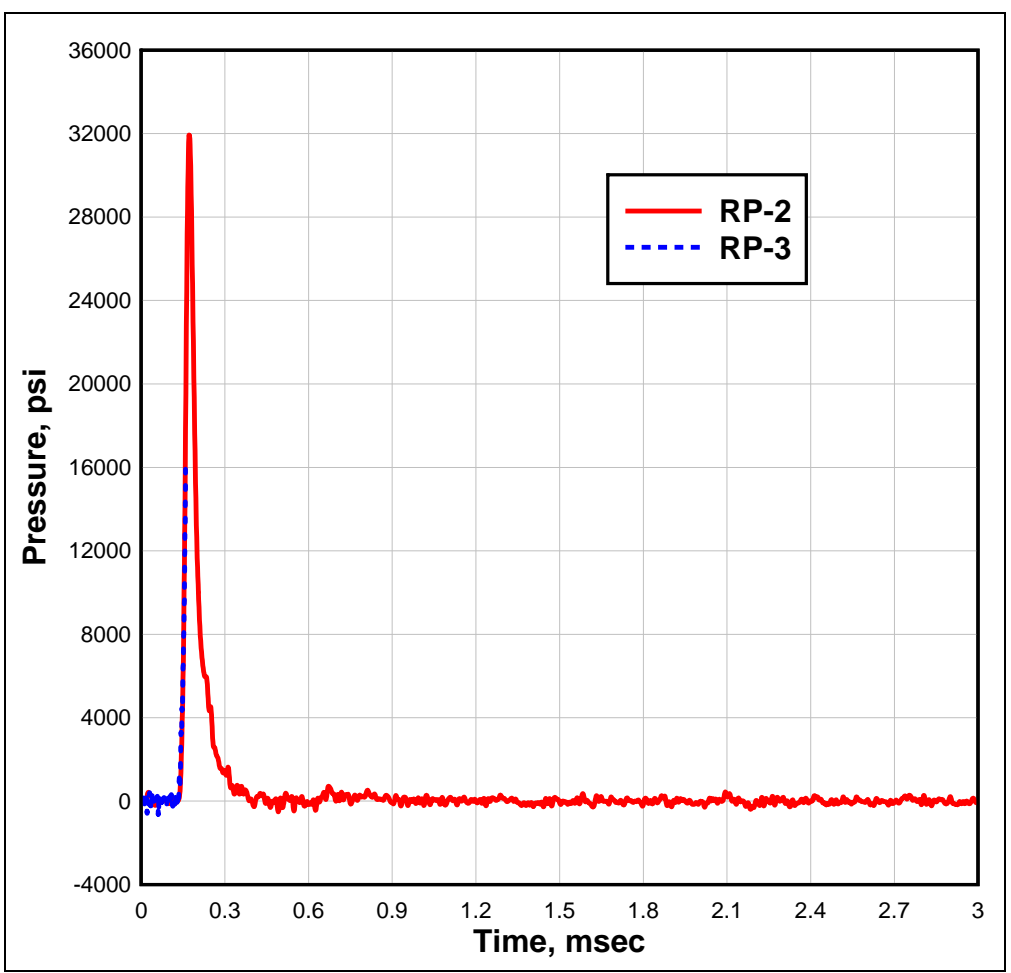

Figure 4.72. Impact-plate pressure time-histories RP2 and RP3 for experiment BM-C-04.

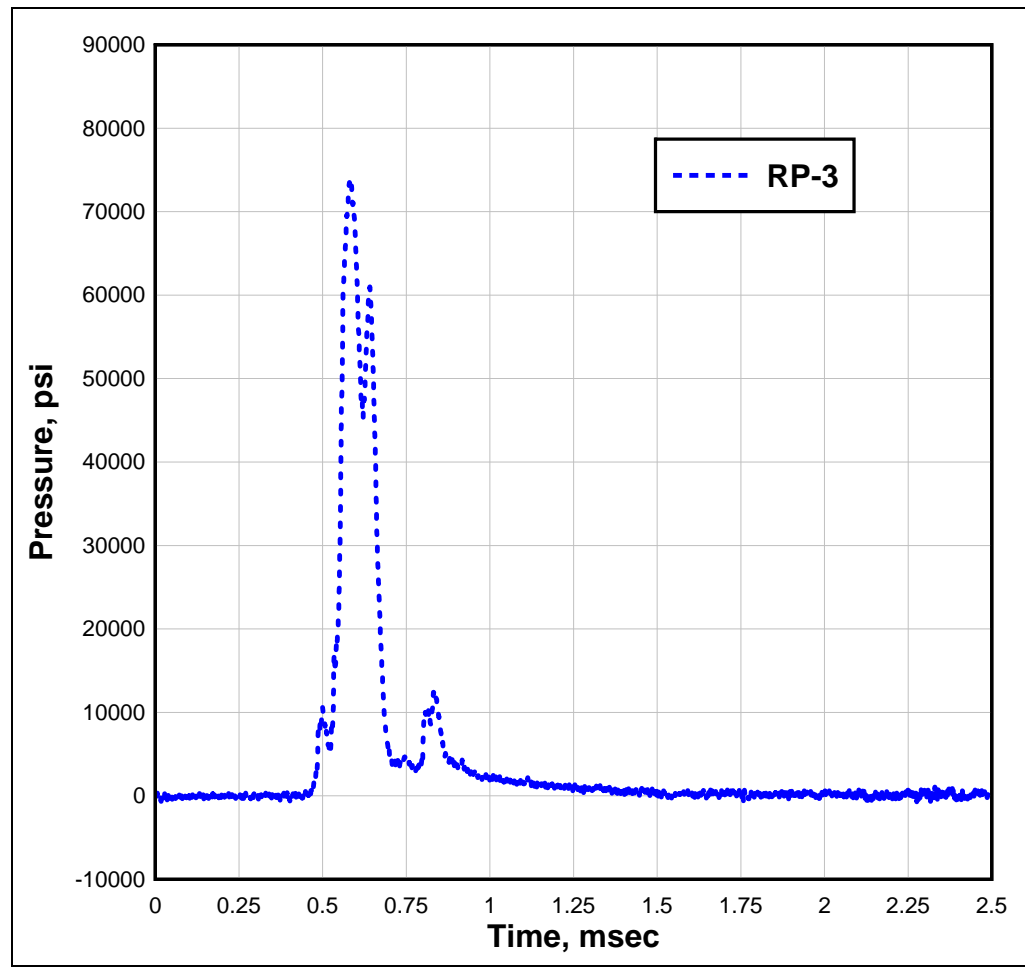

Figure 4.73. Impact-plate pressure time-history RP3 for experiment BM-C-05. 
The atypical pressure time-history recorded in gage RP-3 for BM-C-05 could have been the result of the soil ejecta hitting the gage covers/ filters and disrupting the pressure transmitted to the actual gage. If the times of arrival and peak pressures from experiments BM-C-04 and -05 are compared, gage RP-3 in experiment BM-I-05 recorded a much longer time of arrival and a significant increase in peak pressure.

IMD acceleration

Accelerometer SAV1 was mounted on the IMD piston assembly, and accelerometer SAV2 was mounted on the IMD support structure. The accelerometer on the piston assembly was an attempt to measure the motion, i.e., velocity and displacement, of the piston assembly. The accelerometer mounted on the support structure was an attempt to capture the global motion of the support frame. For both locations, the acceleration timehistories were integrated to capture velocity and displacement at the gage location. The accelerometers experienced a significant high-frequency ringing during the experiments. In some cases, this noise overwhelmed the data, and/ or a significant data shift occurred in the record, which made it difficult to extract useful information. Several attempts were made to modify the gage mounts to help isolate this high-frequency noise, but limited improvements were seen in the data.

The integrated velocity and double-integrated displacement time-histories from the accelerometers in experiments BM-C-04 and BM-C-05 are presented in Figures 4.74- 4.76. No useful data were captured by the accelerometer on the IMD piston assembly in experiment BM-C-04. The accelerometers on the IMD piston assembly in experiment BM-C-05 recorded a significant data shift and a loss of useful data at approximately $1.2 \mathrm{msec}$. The record shown in Figure 4.75 was corrected for the data shift and "filtered" for the high-frequency noise. Because of the high-frequency noise and the data shift in the record, the results are subject to question. The accelerometer on the support structure recorded the oscillation of the support structure at the center produced by the blast load. The maximum displacement of the support structure obtained in experiment BM-C-04 (Figure 4.74) was less than $1 / 8$ in. The maximum displacement recorded in experiment BM-C-05 (Figure 4.76) was less than 1/ 8 in. up to the point the piston assembly struck the support structure. When the piston impacted the support structure, a displacement of approximately 5/16 in. occurred in the structure at a time of $180 \mathrm{msec}$. 


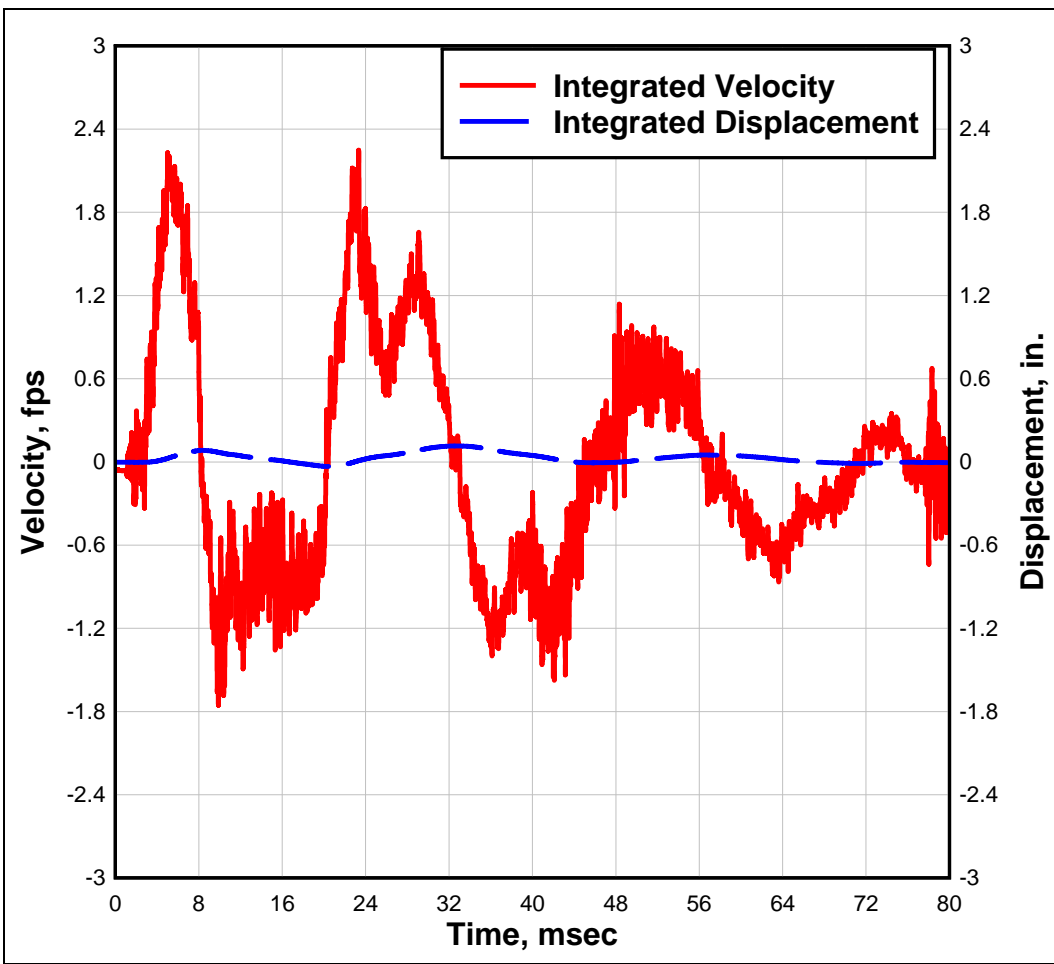

Figure 4.74. Velocity and displacement time-histories from integrated accelerometer SAV2 data in experiment BM-C-04.

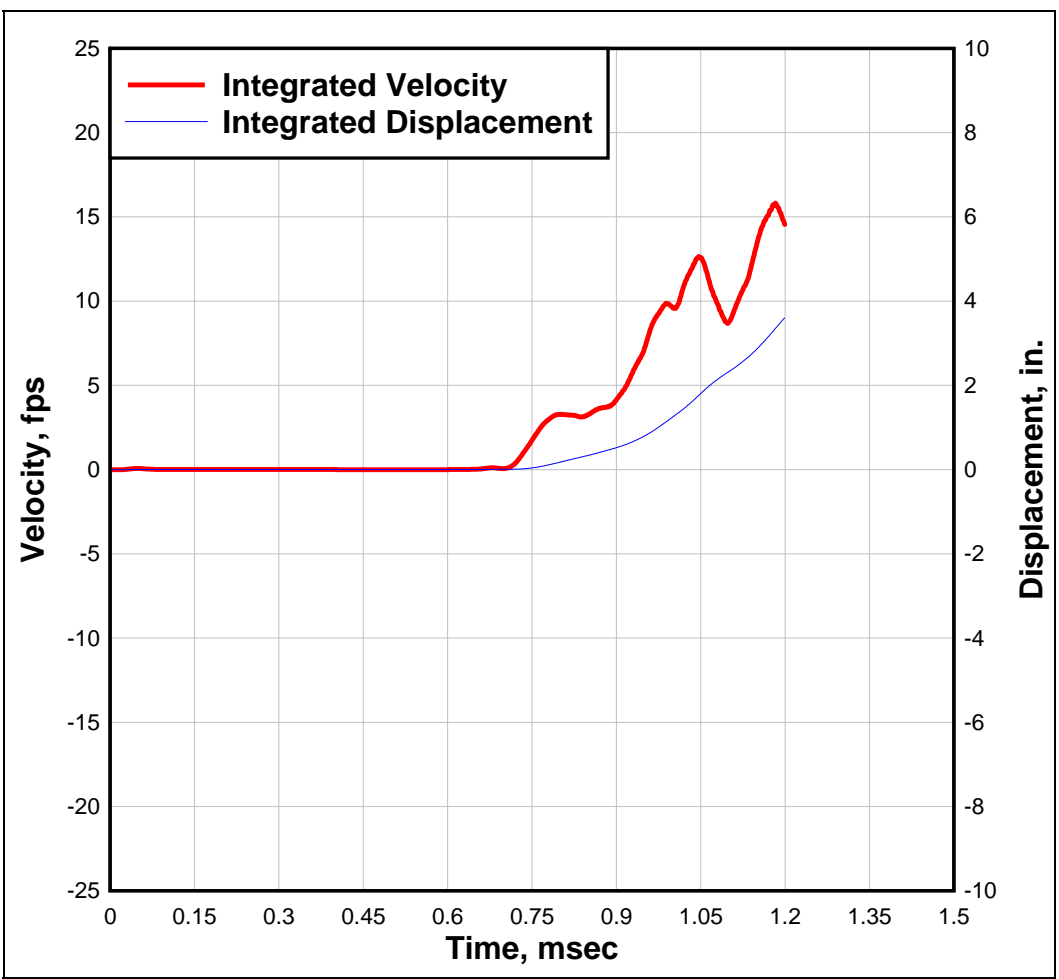

Figure 4.75. Velocity and displacement time-histories from integrated accelerometer SAV1 data in experiment BM-C-05. 


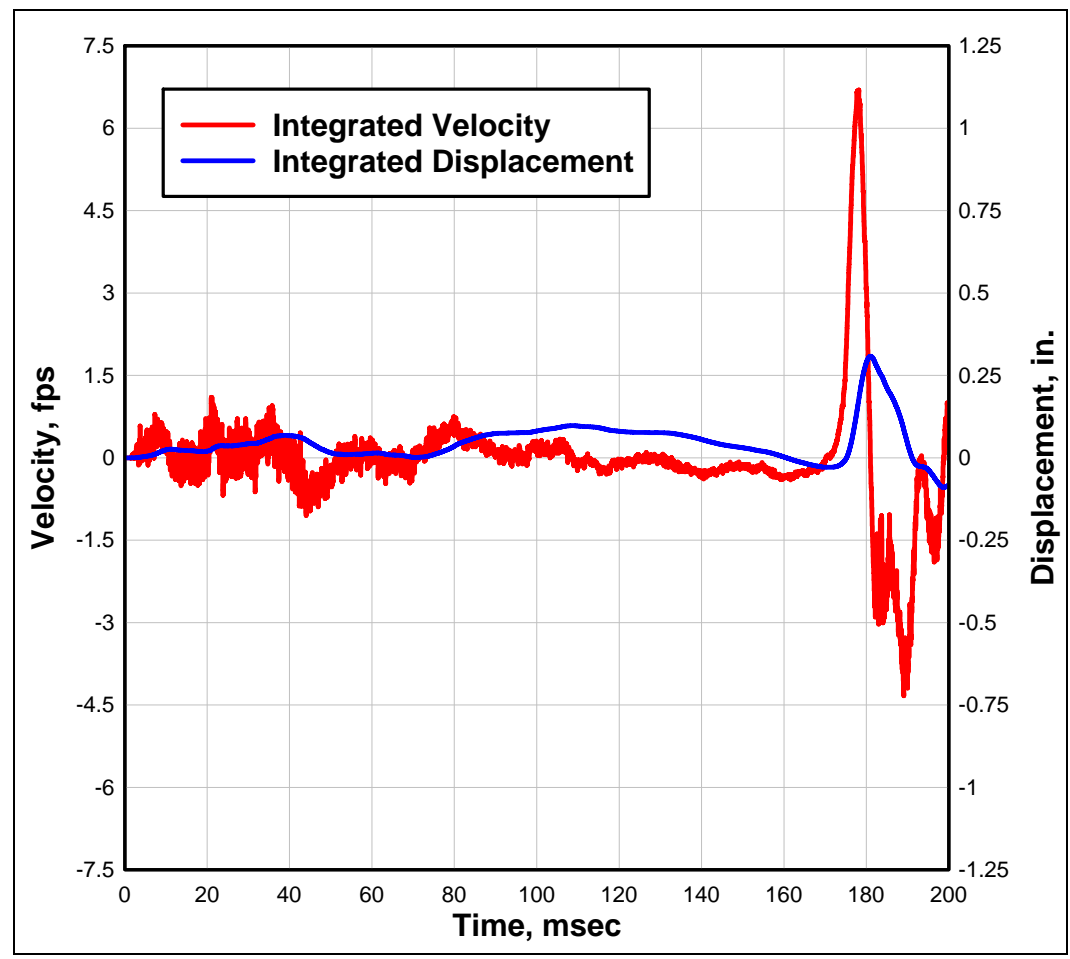

Figure 4.76. Velocity and displacement time-histories from integrated accelerometer SAV2 data in experiment for BM-C-05.

\section{Sand soil}

\section{Backfill quality control measurements}

The backfill was placed in lifts approximately 6 to 8 in. thick as described in Chapter 3. Quality control measurements for the as-placed soil were made in each lift. These measurements included the wet density obtained with a nuclear moisture-density gage and microwave and oven-dried water contents. The average values for all measurements of wet density, ovendried water content, and calculated dry density in each testbed are presented in Table 4.13. For all the sand soil experiments, the designated value of wet density was $109.8 \mathrm{lb} / \mathrm{ft}^{3}$, and the designated value of water content was $4.0 \%$. The calculated dry density was $105.6 \mathrm{lb} / \mathrm{ft}^{3}$, and the calculated air voids content was $29.8 \%$ based on a specific gravity of 2.67 . The soil classified as a poorly graded sand (SP) according to the Unified Soil Classification System as discussed in Chapter 3. 
Table 4.13. Summary of sand soil test series.

\begin{tabular}{|l|l|l|l|l|l|l|}
\hline $\begin{array}{l}\text { Experiment } \\
\text { Number }\end{array}$ & $\begin{array}{l}\text { Charge } \\
\text { Position }\end{array}$ & $\begin{array}{l}\text { Avg Wet } \\
\text { Density, } \\
{\mathrm{lb} / \mathrm{ft}^{3}}^{3}\end{array}$ & $\begin{array}{l}\text { Avg Dry } \\
\text { Density, } \\
\mathrm{lb} / \mathrm{ft}^{3}\end{array}$ & $\begin{array}{l}\text { Avg Water } \\
\text { Content, \% }\end{array}$ & $\begin{array}{l}\text { Crater } \\
\text { Diameter, ft }\end{array}$ & $\begin{array}{l}\text { Crater } \\
\text { Depth, ft }\end{array}$ \\
\hline BM-S-01 & TSA & 110.1 & 106.0 & 3.9 & 4.46 & 0.76 \\
\hline BM-S-02 & TSB & 110.4 & 106.2 & 4.0 & 5.42 & 0.90 \\
\hline BM-S-03 & Buried & 109.8 & 105.5 & 4.1 & 6.94 & 1.35 \\
\hline BM-S-04 & TSA & 109.5 & 105.5 & 3.8 & 4.46 & 0.79 \\
\hline BM-S-05 & Buried & 108.7 & 105.0 & 3.4 & 7.59 & 1.28 \\
\hline
\end{tabular}

\section{Crater surveys}

For each of the five experiments conducted with the sand soil, pretest and posttest cross sections were obtained along the primary axes (see Figure 3.9) through GZ. From these surveys, the resulting crater diameter and crater depth were calculated. A summary of these data for the sand soil testbeds is also provided in Table 4.13, which includes the experiment number, charge position, average soil composition properties, and approximate soil crater diameter and depth. Figures 4.77-4.81 present the pretest and posttest cross sections for each of the sand experiments along with a photograph of each posttest testbed crater.

\section{Ground shock stress and particle velocity}

The sand soil test series contained ground shock instrumentation in the two experiments with the charge buried 4 in. below the ground surface, i.e., experiments BM-S-03 and BM-S-05. The center of each gage was at the same depth as the center of the explosive charge. The as-placed gage locations and a summary of the measured soil stress and particle velocity data at each gage location in the backfill for experiments BM-S-03 and BM-S- 05 are given in Table 4.14, which includes the experiment number, gage number, range (radial distance) from GZ, time of shock arrival, peak velocity, and peak stress. Selection of the peak amplitude values and the times of arrival of peak amplitudes can be difficult in an environment where reflections are occurring rapidly from a number of sources, and gages are undergoing large motions. As always, the values shown in Table 4.14 are subject to different interpretations. In some cases, two peaks were recorded in the time-history records for both the radial stress and radial particle velocity. When a second peak was clearly present, it was included in the summary table. Possible causes for the second peaks 


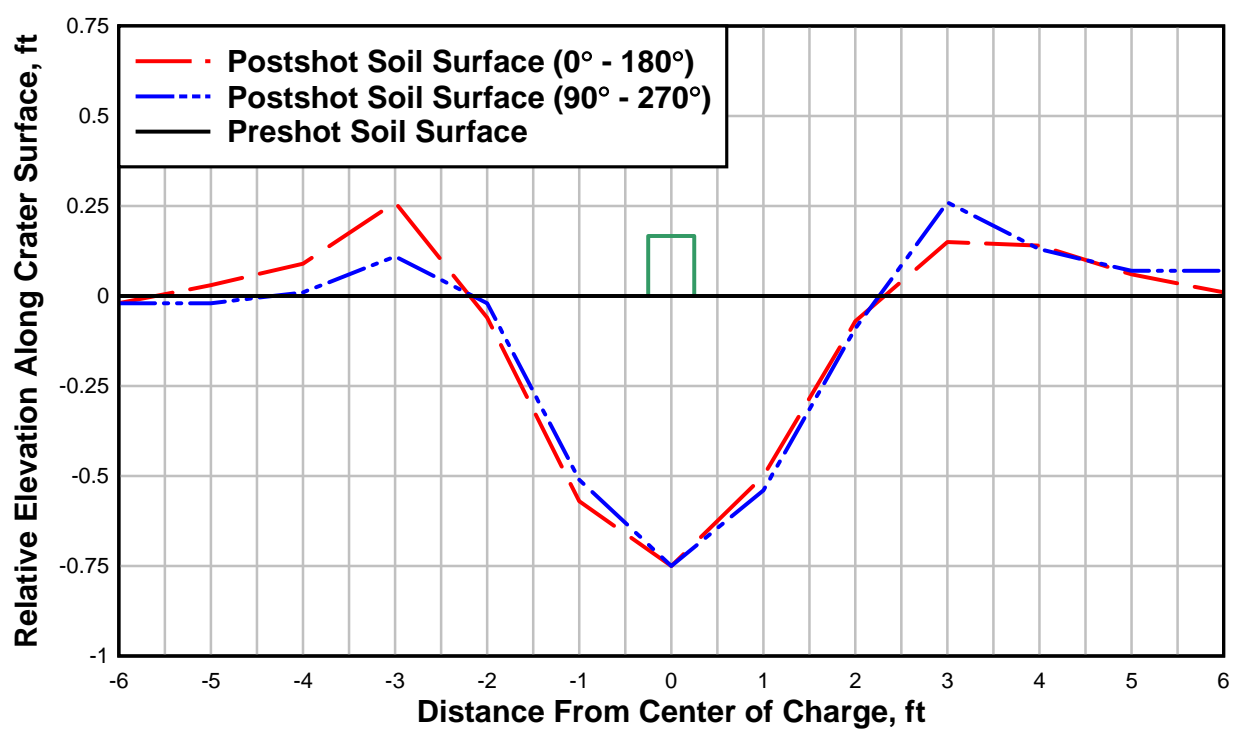

a. Measured posttest crater cross sections in BM-S-01.

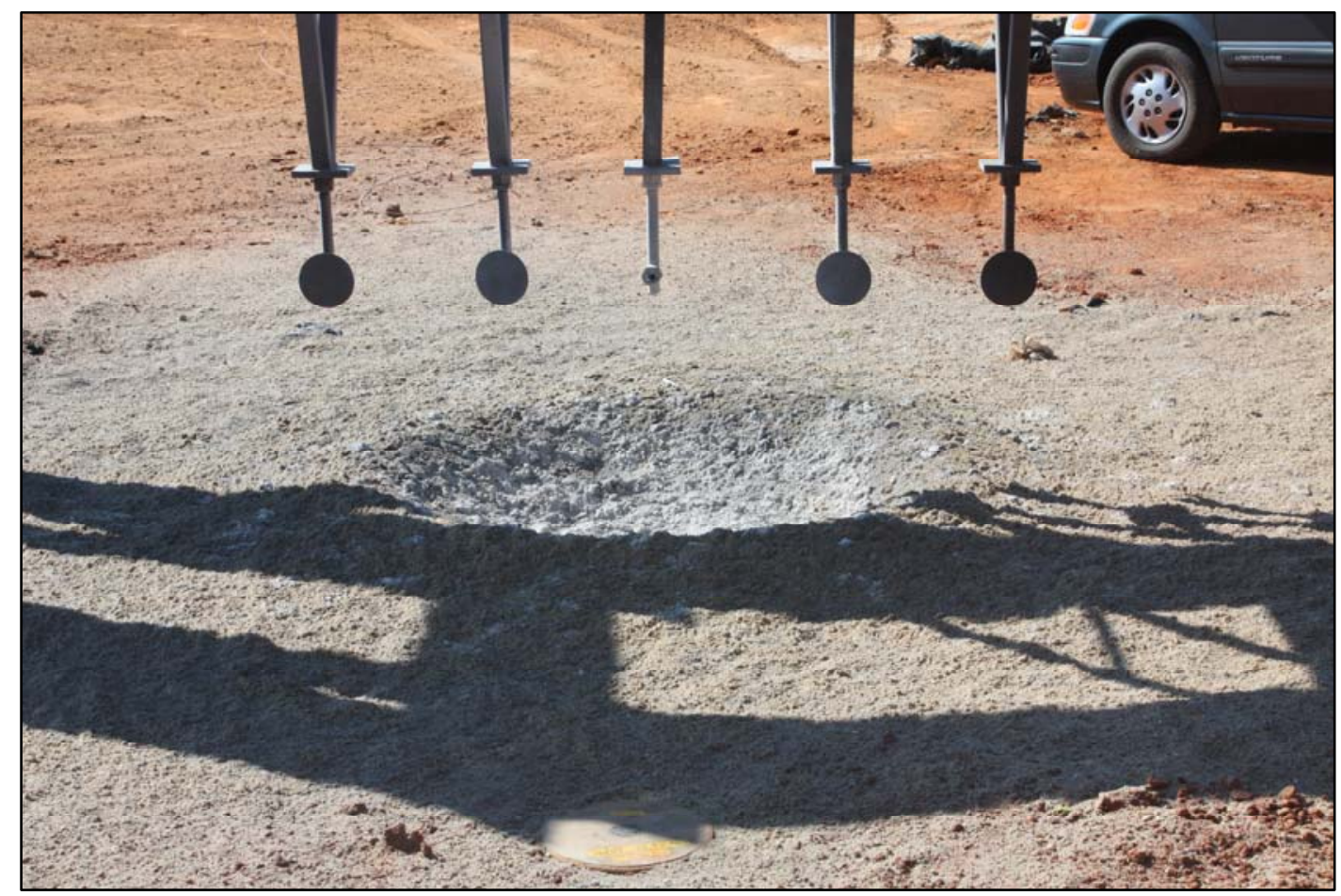

b. Photograph of posttest crater in BM-S-01.

Figure 4.77. Photograph and cross-section surveys of testbed crater in BM-S-01. 


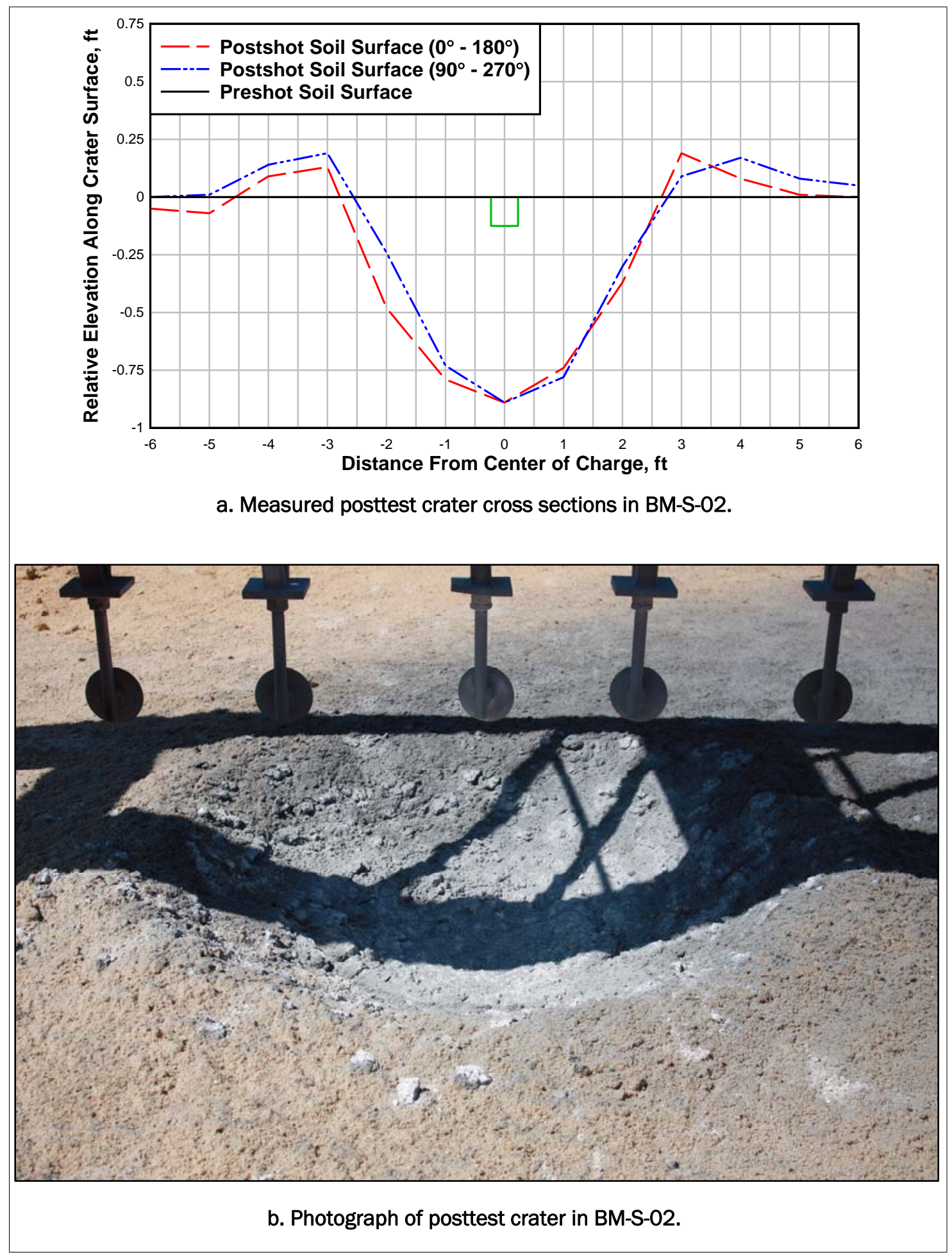

Figure 4.78. Photograph and cross-section surveys of testbed crater in BM-S-02. 


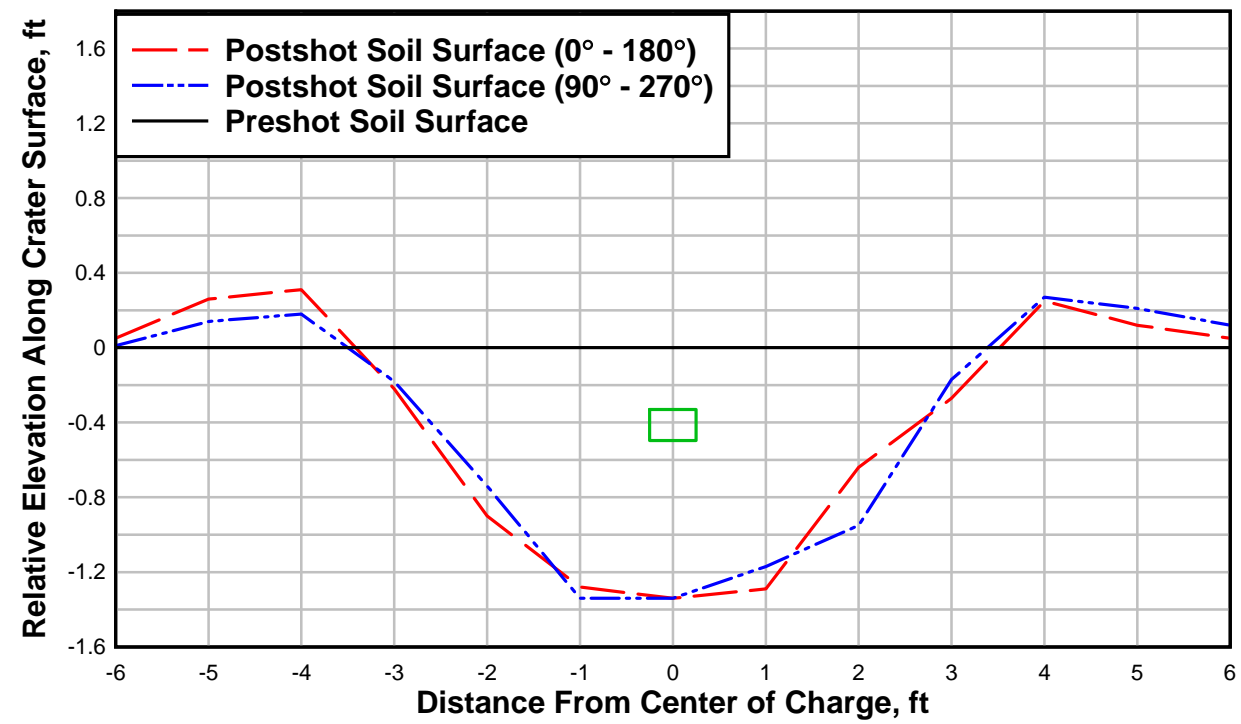

a. Measured posttest crater cross sections in BM-S-03.

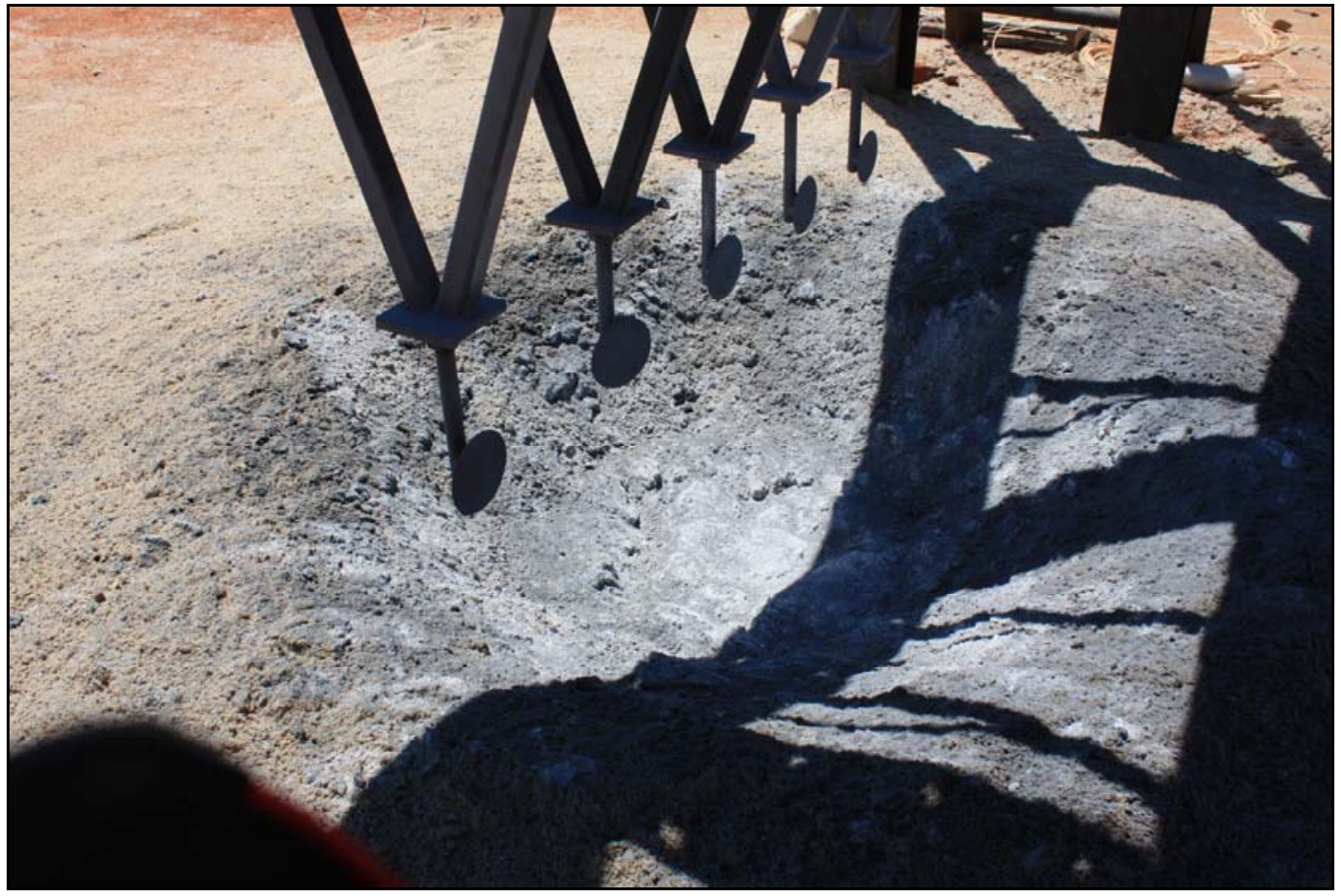

b. Photograph of posttest crater in BM-S-03..

Figure 4.79. Photograph and cross-section surveys of testbed crater in BM-S-03. 


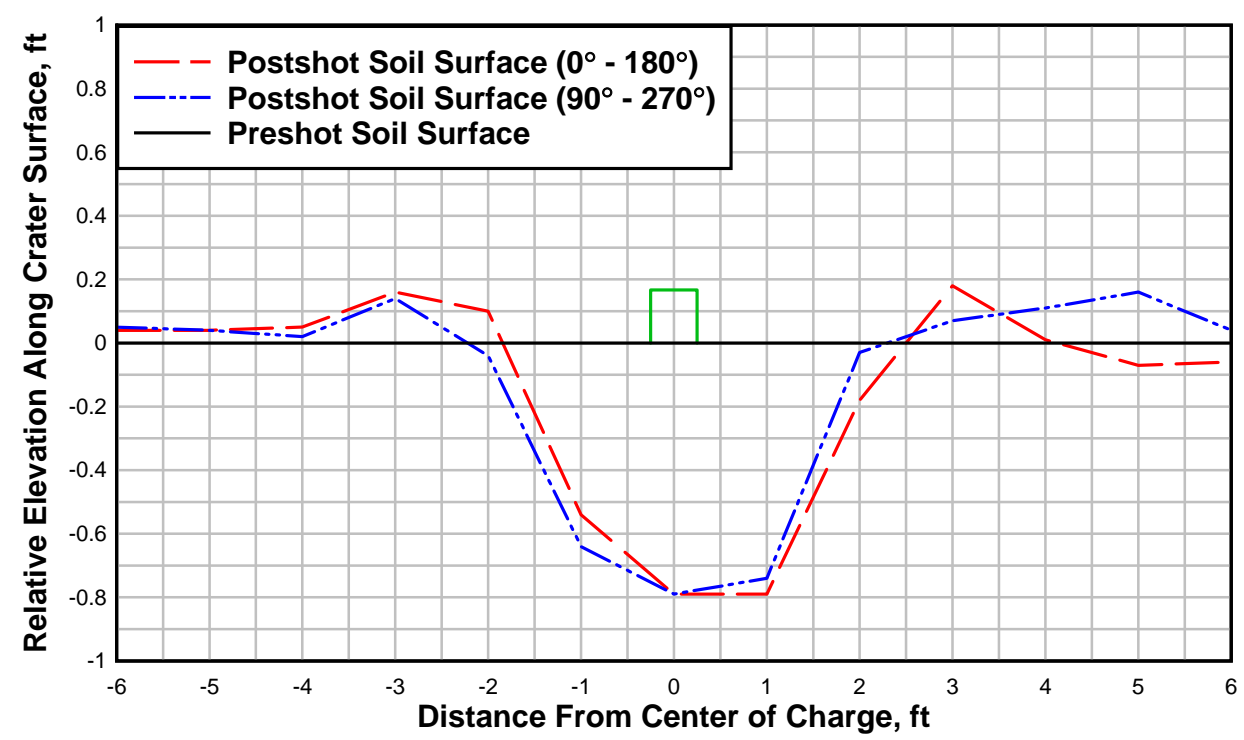

a. Measured posttest crater cross sections in BM-S-04.

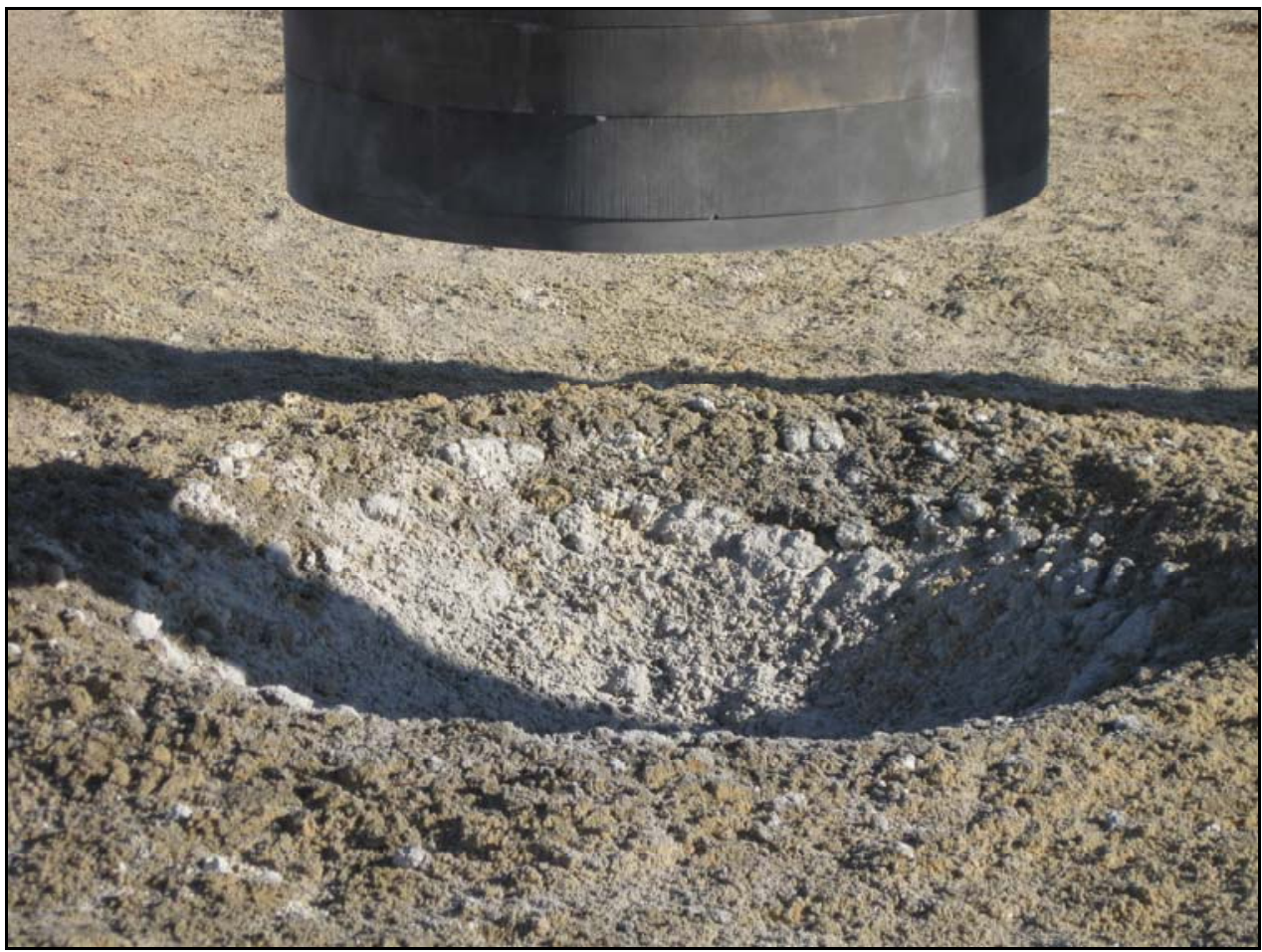

b. Photograph of posttest crater in BM-S-04.

Figure 4.80. Photograph and cross-section surveys of testbed crater in BM-S-04. 


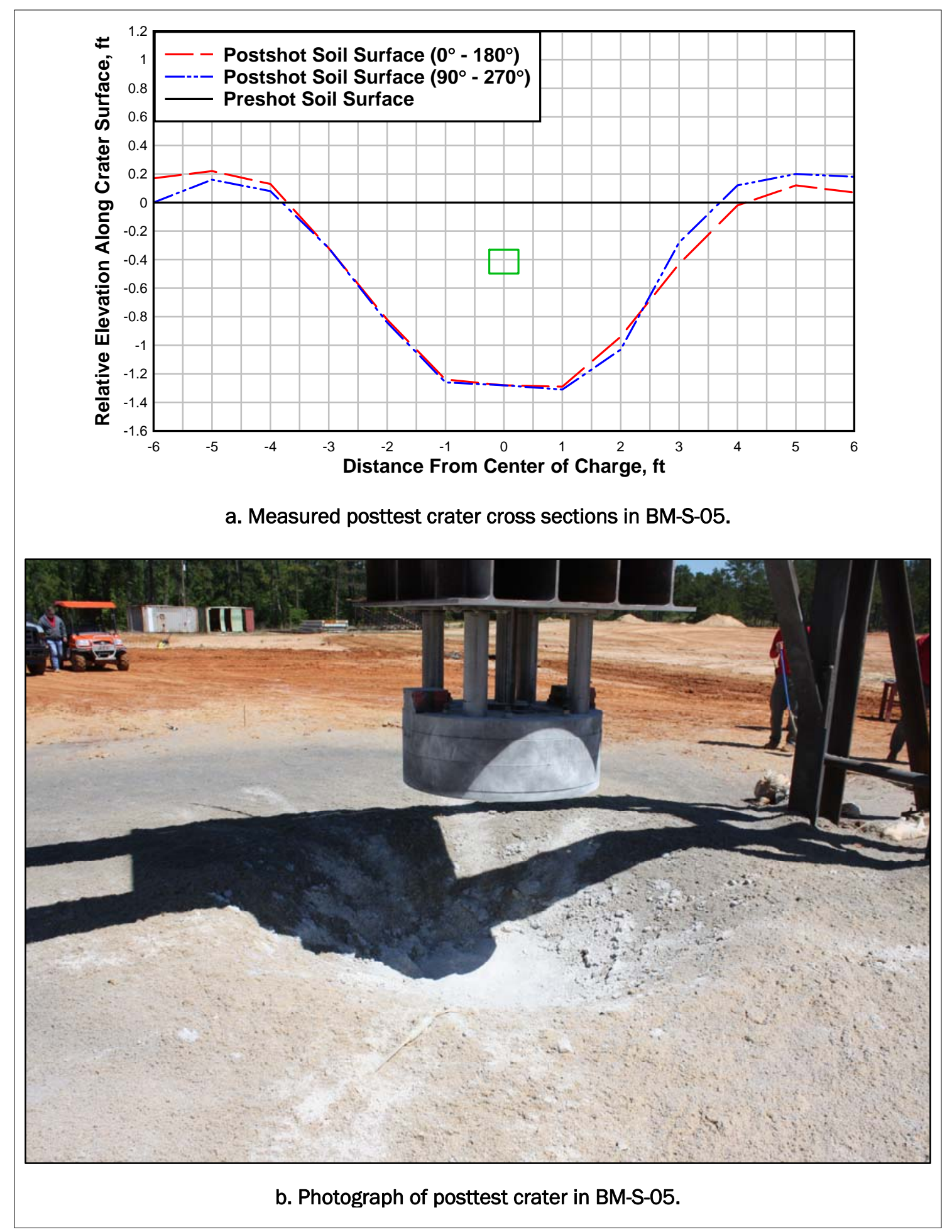

Figure 4.81. Photograph and cross-section surveys of testbed crater in BM-S-05. 
Table 4.14. Ground shock instrumentation summary for clay soil experiments.

\begin{tabular}{|l|l|l|l|l|l|l|l|}
\hline $\begin{array}{l}\text { Experiment } \\
\text { Number }\end{array}$ & $\begin{array}{l}\text { Gage } \\
\text { Number }\end{array}$ & $\begin{array}{l}\text { Radius } \\
\text { from GZ, ft }\end{array}$ & $\begin{array}{l}\text { Time of } \\
\text { Arrival, } \\
\text { msec }\end{array}$ & $\begin{array}{l}\text { Peak } \\
\text { Velocity, } \\
\text { fps }\end{array}$ & $\begin{array}{l}\text { Second Peak } \\
\text { Velocity, fps }\end{array}$ & $\begin{array}{l}\text { Peak } \\
\text { Stress, } \\
\text { psi }\end{array}$ & $\begin{array}{l}\text { Second } \\
\text { Peak Stress, } \\
\text { psi }\end{array}$ \\
\hline BM-S-03 & AR1 & 3 & 1.81 & 5.8 & 6.3 & -- & - \\
\hline BM-S-03 & AR2 & 4 & 2.50 & 3.1 & 3.5 & -- & -- \\
\hline BM-S-03 & AR3 & 5 & 3.30 & 1.6 & -- & -- & -- \\
\hline BM-S-03 & SR1 & 3 & -- & -- & -- & -- & -- \\
\hline BM-S-03 & SR2 & 4 & 2.28 & -- & - & 70 & 81 \\
\hline BM-S-03 & SR3 & 5 & 3.01 & -- & -- & 33 & - \\
\hline BM-S-05 & AR1 & 3 & 1.46 & 6.3 & -- & -- & - \\
\hline BM-S-05 & AR2 & 4 & 2.18 & 4.5 & 6.4 & -- & - \\
\hline BM-S-05 & AR3 & 5 & - & - & - & -- & - \\
\hline BM-S-05 & SR1 & 3 & - & - & -- & -- & - \\
\hline BM-S-05 & SR2 & 4 & 2.46 & - & - & 106 & 109 \\
\hline BM-S-05 & SR3 & 5 & 3.14 & - & - & 40 & 38 \\
\hline
\end{tabular}

include reflected waves from the testbed surface, aboveground pressures traveling along the ground surface, and reflections off the IMD device. No useful data were recorded by the soil stress gage at the 3-ft range, SR-1, in both experiments. Also, no useful data were recorded for the soil accelerometer gage at the 5-ft range, AR-3, in experiment BM-S- 05 .

\section{Soil stress measurements}

The radial stress time-histories obtained in the sand backfill in tests BM-S- 03 and BM-S- 05 at nominal ranges of 4 and $5 \mathrm{ft}$ are presented in Figures 4.82 and 4.83 , respectively, to a time of $20 \mathrm{msec}$. No useful stress time-history data were recorded at the 3 - $\mathrm{ft}$ range in both experiments. The resulting peak stresses and times of arrival follow the expected trend with the closest range data recording the largest peak stress and earliest time of arrival. The times of arrival and first peak stresses recorded in BM-S-03 and BM-S-05 agreed reasonably well at the 4- and 5-ft range. The peak stress was slightly higher in the BM-S-05 at both the 4- and 5-ft range. The peak stresses versus ranges for tests BM-S-03 and BM-S-05 are presented in Figure 4.84. 


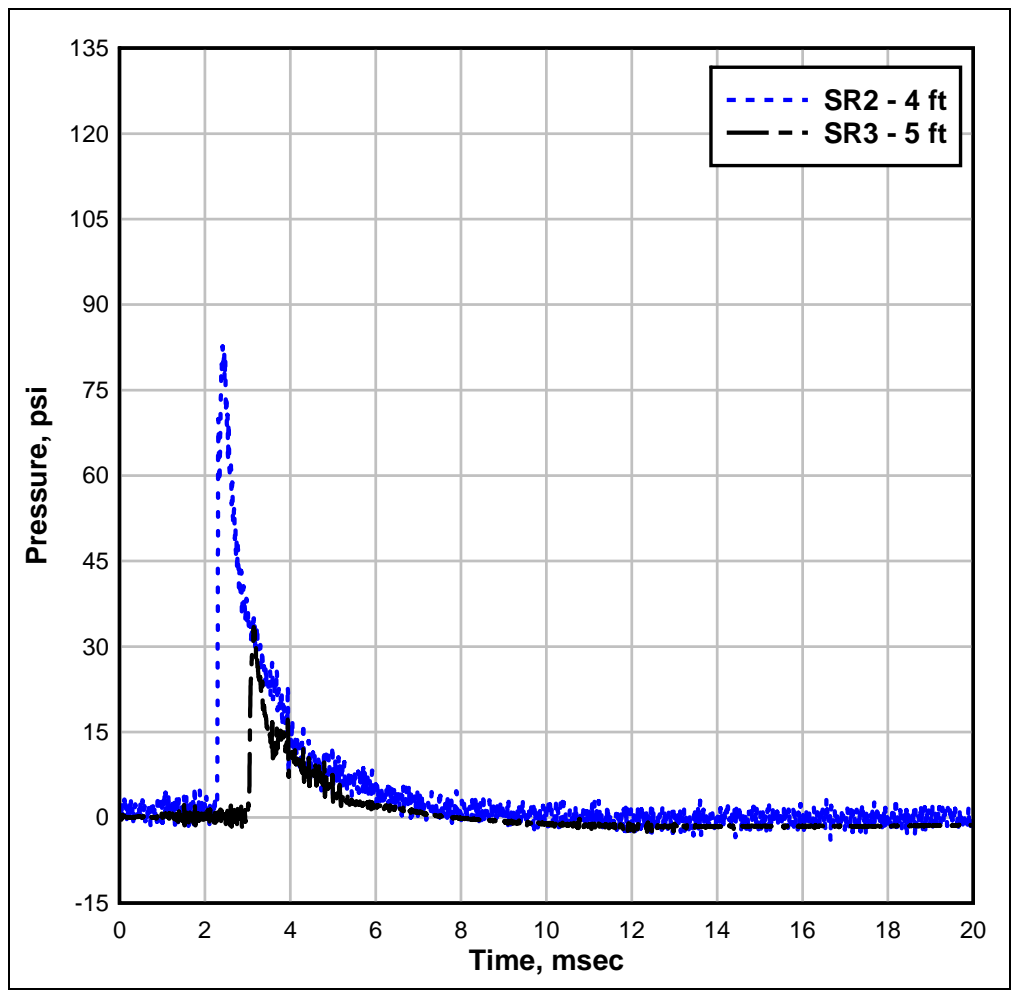

Figure 4.82. Radial stress time-histories measured in the experiment BM-S-03 backfill.

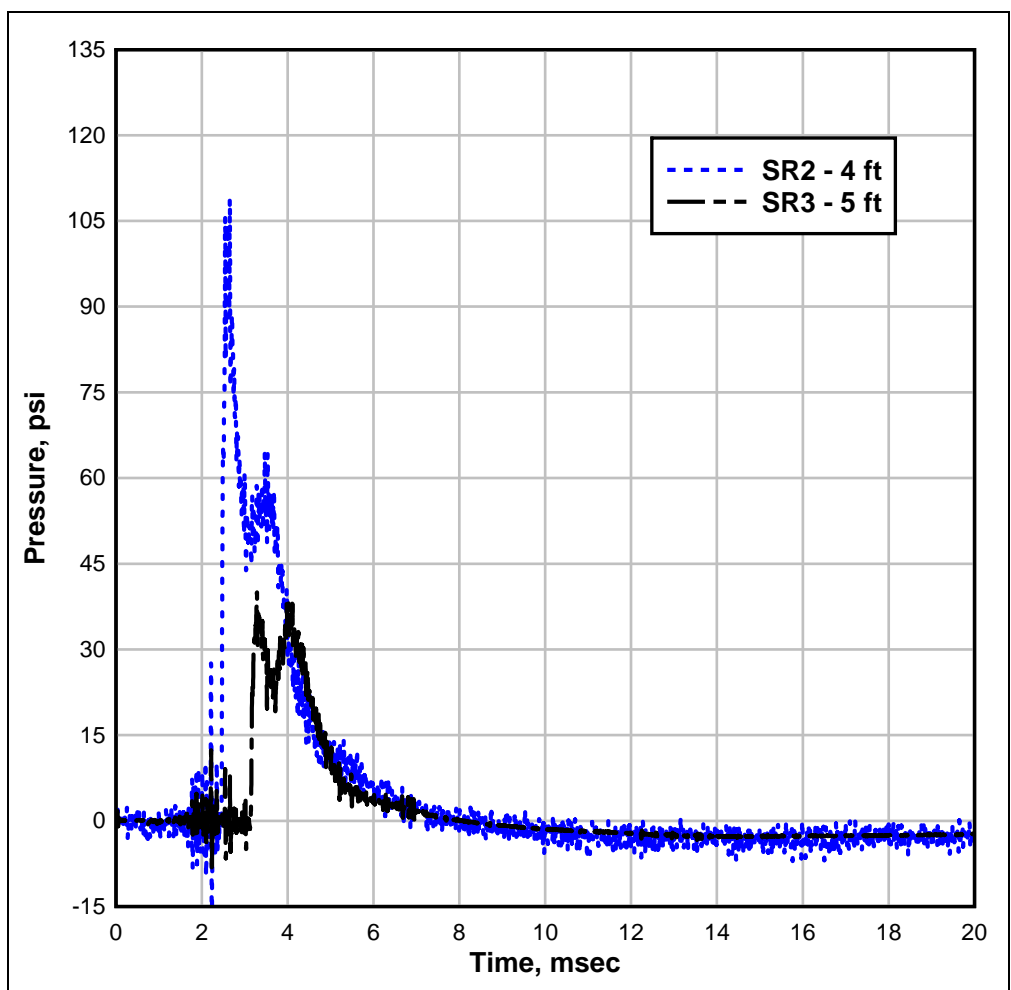

Figure 4.83. Radial stress time-histories measured in the experiment BM-S-05 backfill. 


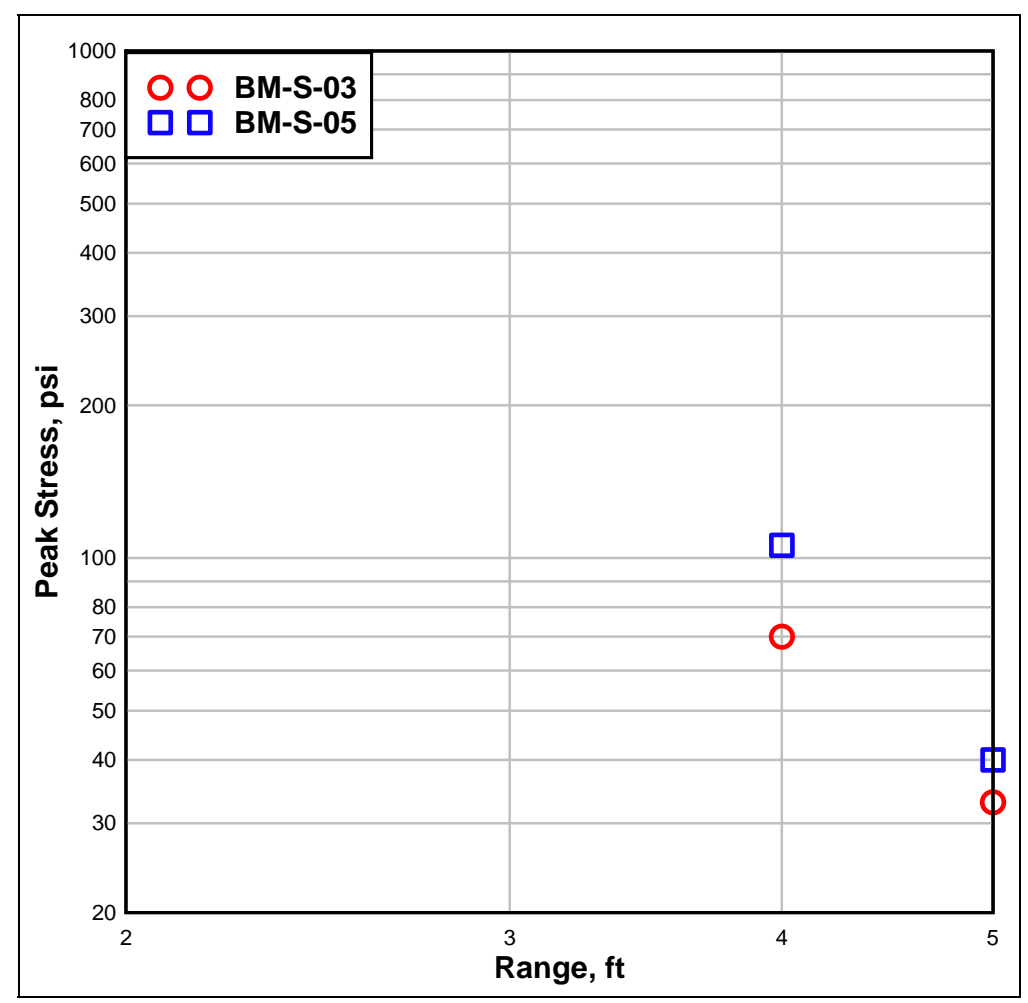

Figure 4.84. Peak stress versus range in the experiment BM-S-03 and BM-S-05 backfill.

\section{Soil motions}

The radial particle velocity time-histories obtained in sand backfill experiments BM-S-03 and BM-S-05 at nominal ranges of 3, 4, and $5 \mathrm{ft}$ are in Figures 4.85 and 4.86 , respectively. The responses were obtained by integrating the accelerometer data to obtain particle velocity. No useful data were recorded from the soil accelerometer gage at 5-ft range, AR-3, for experiment BM-S-05. The resulting peak velocity and times of arrival follow the expected trend, with the gages at the 3 - $\mathrm{ft}$ range recording the largest peak velocities and earliest times of arrival and the gages at the 5- $\mathrm{ft}$ range recording the latest times of arrival. A significant negative velocity occurred in the initial velocity time-histories recorded in BM-S- 05 at both $3 \mathrm{ft}$ and $4 \mathrm{ft}$ from the charge, and to a lesser degree in BM-S-03 at $5 \mathrm{ft}$ from the charge. This could possibly be caused by the airblast reflecting off the IMD impact plate. The first positive peak particle velocities versus range for experiments BM-S-03 and BM-S-05 are presented in Figure 4.87. In both experiments, two peak velocities were recorded at three gage locations. The reason for the second peaks is not clear, but they could be caused by a reflected wave from the ground surface or the IMD impact plate. 


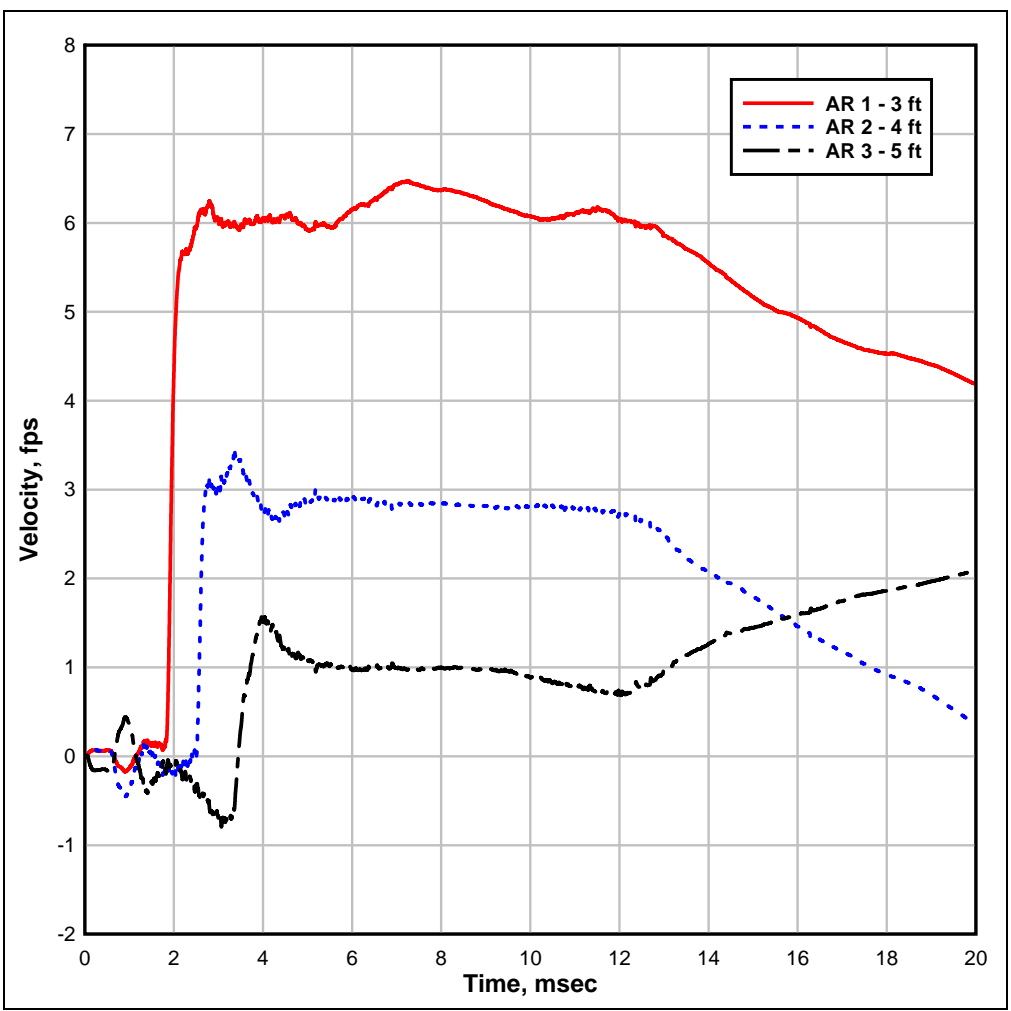

Figure 4.85. Radial particle velocity time-histories measured in the experiment BM-S-03 backfill.

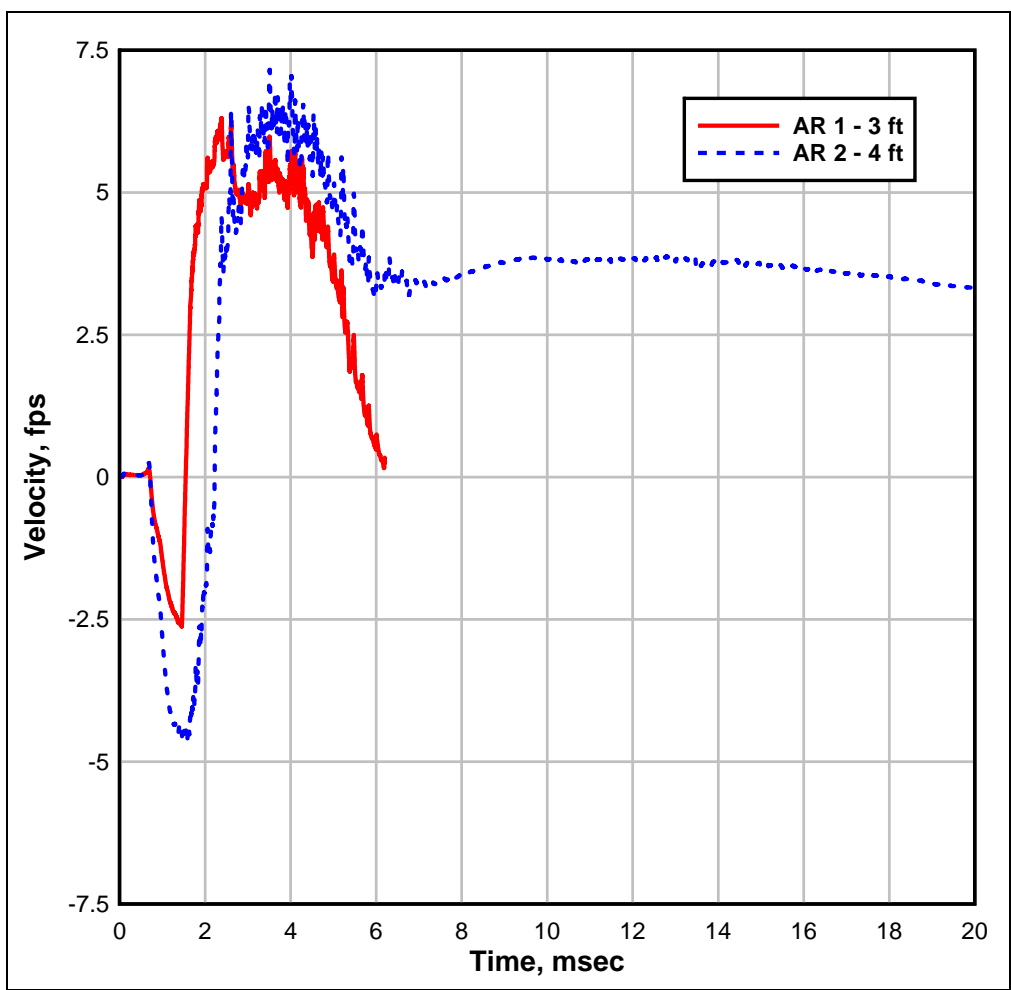

Figure 4.86. Radial particle velocity time-histories measured in the experiment BM-S-05 backfill. 


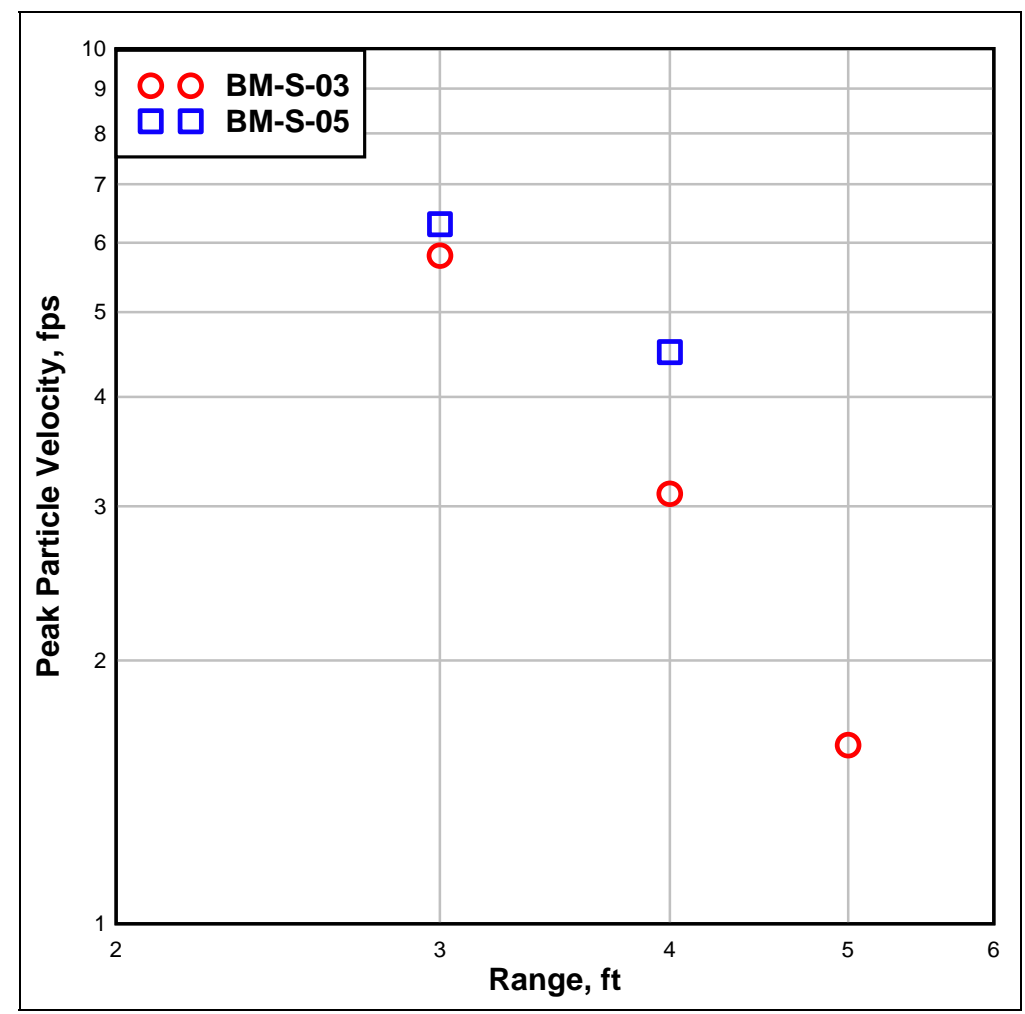

Figure 4.87. Peak particle velocity versus range in the experiment BM-S-03 and BM-S-05 backfills.

\section{Backfill ground shock arrival times}

The initial times of arrival for the ground shock measurements in the sand backfills are plotted versus range from the CG of the charge in Figure 4.88. The times of arrival follow the expected trend with an increase in time of arrival with an increase in range from the charge. The times of arrival of the stresses and particle velocities recorded in BM-S-03 and BM-S-05 agreed very well at the 3-ft, 4-ft, and 5-ft ranges where data were available. In some records, a clear arrival time was not present in the records due to frequency noise in the acceleration record or an unexplained gradual early rise prior to the sharp rise to peak. Therefore, some engineering judgment was required, and the values selected are subject to different interpretations. 


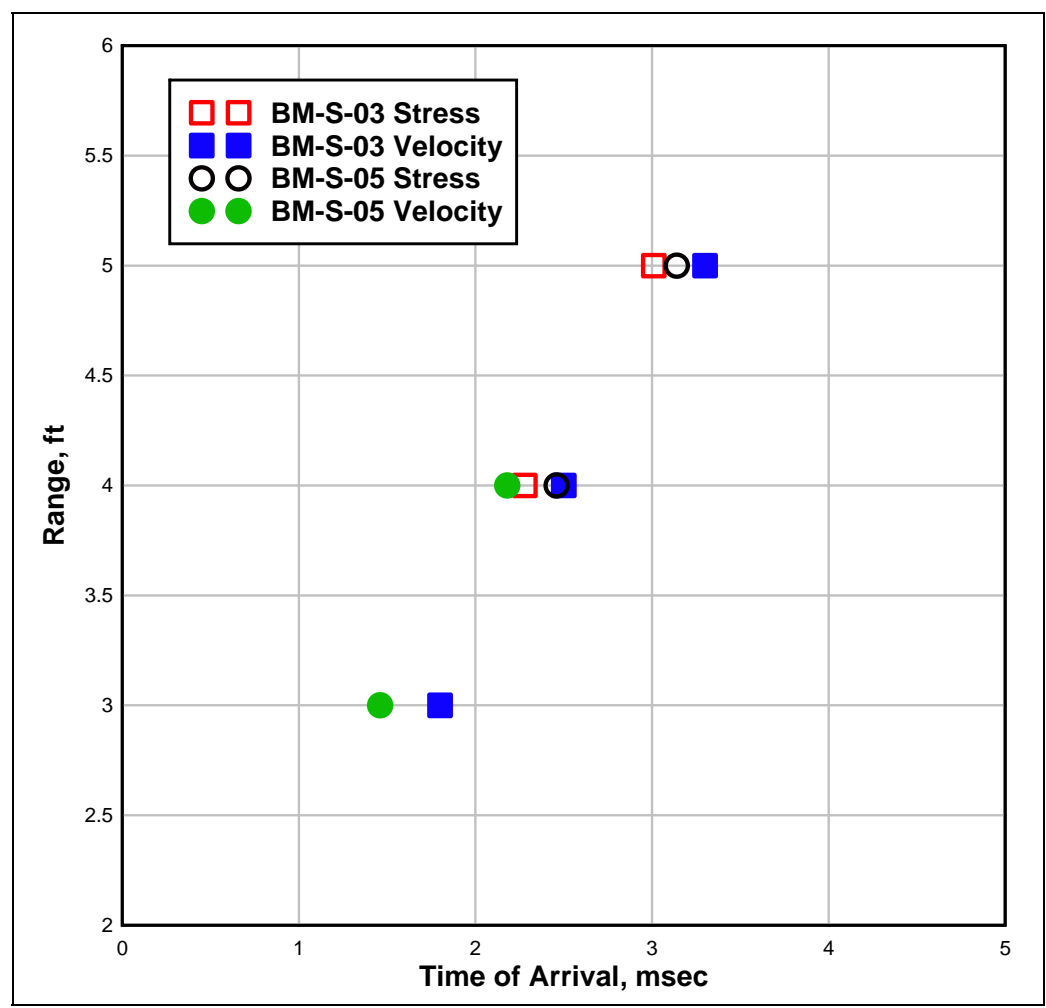

Figure 4.88. Initial ground shock times of arrival versus range from the CG of the charge in the experiment BM-S-03 and BM-S-05 backfills.

\section{Ground surface overpressure}

Three ground surface overpressure gages were installed in all five sand soil experiments. The gages were located at a range of $8 \mathrm{ft}(\mathrm{OP} 1), 10 \mathrm{ft}$ (OP2), and $14 \mathrm{ft}$ (OP3) from ground zero (GZ). A summary of the measured data from each gage is in Table 4.15. The table includes the experiment number, gage number, range from GZ, time of shock arrival, peak overpressure, time of peak overpressure pressure, time to peak (rise time), and peak overpressure impulse. The overpressure time-histories obtained at nominal ranges of 8,10 , and $14 \mathrm{ft}$ in experiments BM-S-01 through BM-S-05 are presented in Figures 4.89-4.93, respectively. The times of arrival of the overpressure versus range, the peak overpressure versus range, and the times of arrival of the peaks versus range are presented in Figures 4.94-4.96, respectively. 
Table 4.15. Ground surface overpressure summary for sand soil experiments.

\begin{tabular}{|l|l|l|l|l|l|l|l|}
\hline $\begin{array}{l}\text { Experiment } \\
\text { Number }\end{array}$ & $\begin{array}{l}\text { Gage } \\
\text { Number }\end{array}$ & $\begin{array}{l}\text { Range } \\
\text { from GZ, ft }\end{array}$ & $\begin{array}{l}\text { Shock } \\
\text { Time of } \\
\text { Arrival, } \\
\text { msec }\end{array}$ & $\begin{array}{l}\text { Peak } \\
\text { Pressure, } \\
\text { psi }\end{array}$ & $\begin{array}{l}\text { Time of } \\
\text { Peak } \\
\text { Pressure, } \\
\text { msec }\end{array}$ & $\begin{array}{l}\text { Rise Time, } \\
\text { msec }\end{array}$ & $\begin{array}{l}\text { Peak } \\
\text { Impulse, } \\
\text { psi-sec }\end{array}$ \\
\hline BM-S-01 & OP - 1 & 8 & 1.81 & 40.9 & 1.91 & 0.10 & 0.023 \\
\hline BM-S-01 & OP - 2 & 10 & 2.85 & 23.2 & 2.99 & 0.14 & 0.021 \\
\hline BM-S-01 & OP - 3 & 14 & 5.52 & 10.6 & 5.63 & 0.11 & 0.018 \\
\hline BM-S-02 & OP - 1 & 8 & 3.49 & 21.0 & 3.59 & 0.10 & 0.019 \\
\hline BM-S-02 & OP - 2 & 10 & 4.72 & 15.8 & 4.86 & 0.15 & 0.019 \\
\hline BM-S-02 & OP - 3 & 14 & 7.51 & 10.1 & 7.68 & 0.17 & 0.016 \\
\hline BM-S-03 & OP - 1 & 8 & 5.12 & 8.4 & 5.20 & 0.09 & 0.007 \\
\hline BM-S-03 & OP - 2 & 10 & 6.53 & 7.2 & 6.65 & 0.12 & 0.007 \\
\hline BM-S-03 & OP - 3 & 14 & 9.52 & 5.2 & 9.61 & 0.10 & 0.006 \\
\hline BM-S-04 & OP - 1 & 8 & 1.75 & 62.1 & 1.87 & 0.12 & 0.030 \\
\hline BM-S-04 & OP - 2 & 10 & 2.65 & 31.6 & 2.77 & 0.12 & 0.024 \\
\hline BM-S-04 & OP - 3 & 14 & 5.03 & 16.0 & 5.17 & 0.14 & 0.017 \\
\hline BM-S-05 & OP - 1 & 8 & 4.87 & 13.6 & 4.97 & 0.10 & 0.013 \\
\hline BM-S-05 & OP - 2 & 10 & 6.29 & 9.0 & 6.41 & 0.12 & 0.010 \\
\hline BM-S-05 & OP - 3 & 14 & 9.29 & 5.2 & 9.40 & 0.11 & 0.007 \\
\hline
\end{tabular}

In all five experiments, the results followed the expected trend with the peak overpressure decreasing with range. When the results of BM-S-01 are compared with the results of BM-S-04, both with the explosive charge sitting on the ground surface, the times of arrival compare well at all three ranges (Figure 4.94), but the peak overpressures were higher in BM-S-04 for all three ranges (Figure 4.95). This variation may be the result of reflections off the IMD impact plates in BM-S-04. The times of arrival of the shocks and the times of arrival of the peaks followed the expected trend with the arrival time increasing with range from the GZ. The experiments with the charge buried 4 in., BM-S-03 and 05, had a significant increase in the arrival times and a significant decrease in peak pressures at the same ranges when compared with those values from experiments with the charge resting on or tangent below the surface. 


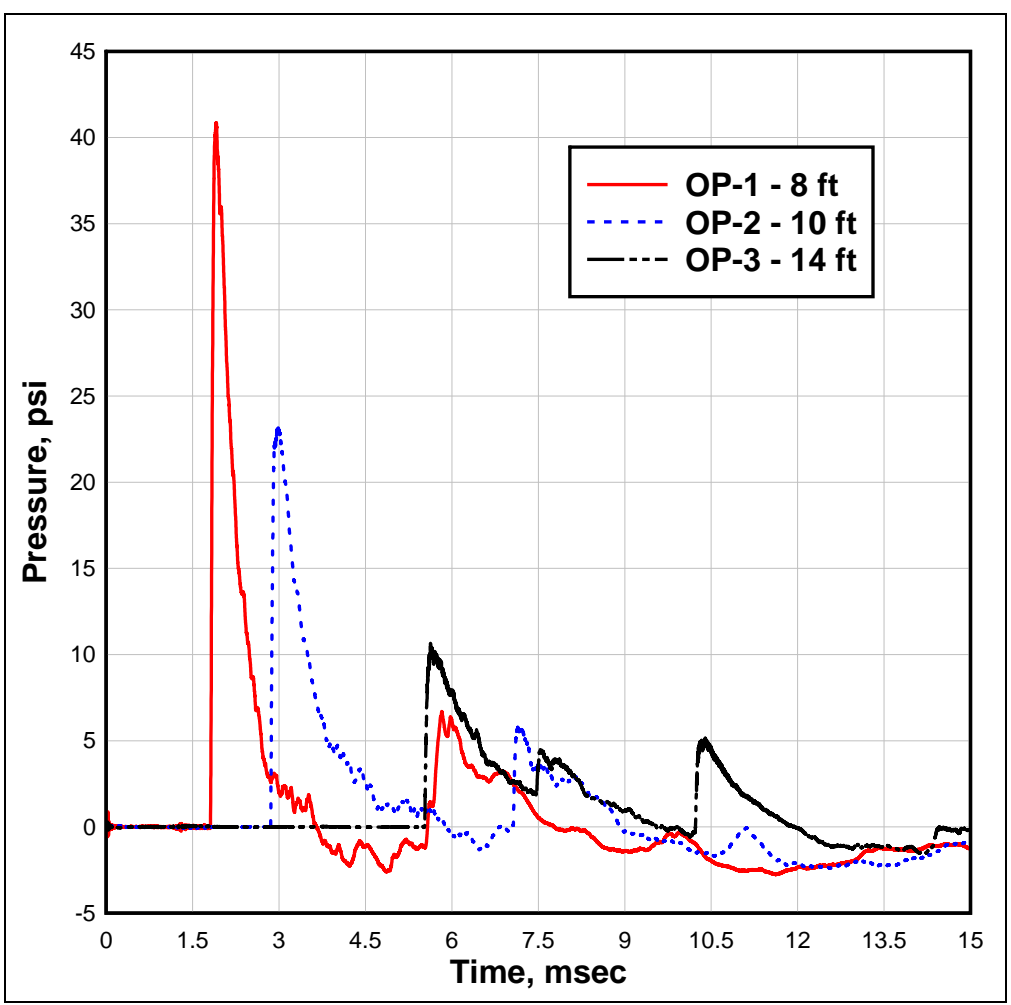

Figure 4.89. Ground surface overpressure time-histories at ranges of 8,10 , and $14 \mathrm{ft}$ in experiment BM-S-01.

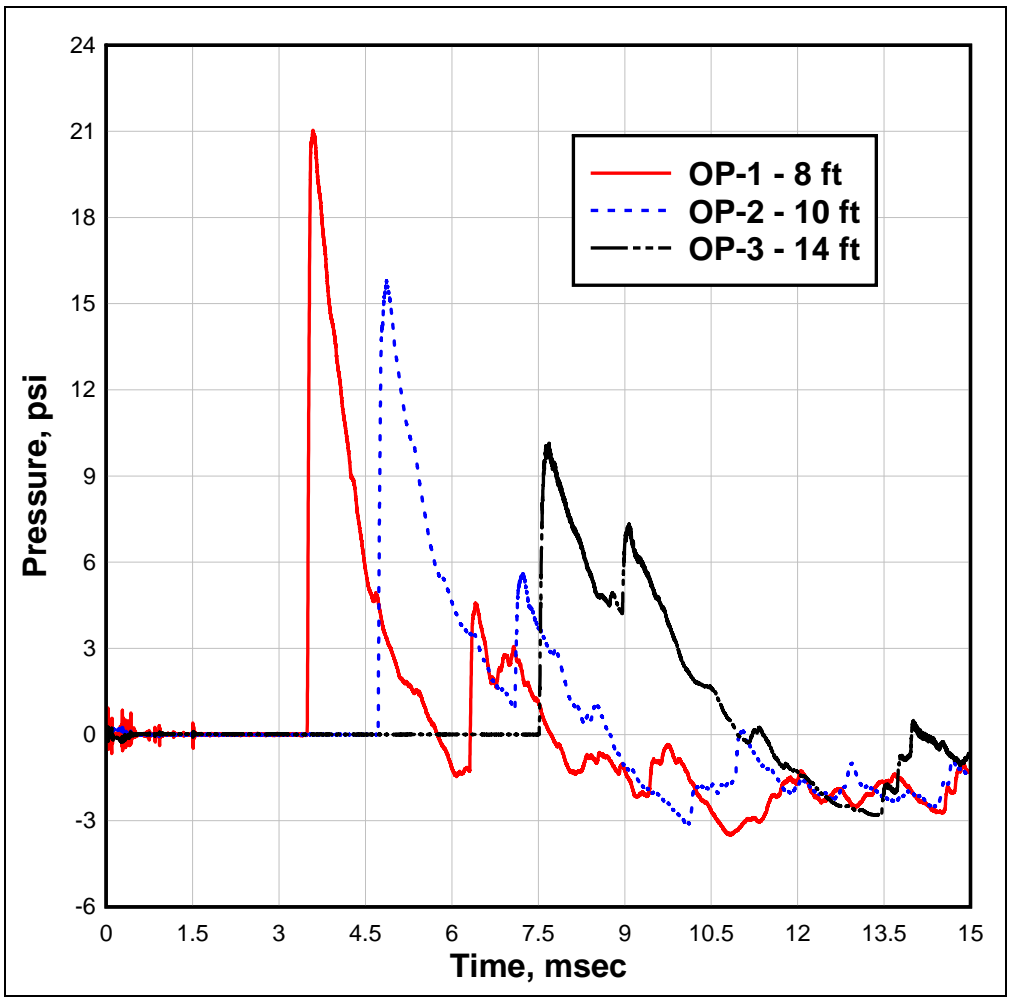

Figure 4.90. Ground surface overpressure time-histories at ranges of 8,10 , and $14 \mathrm{ft}$ in experiment BM-S-02. 


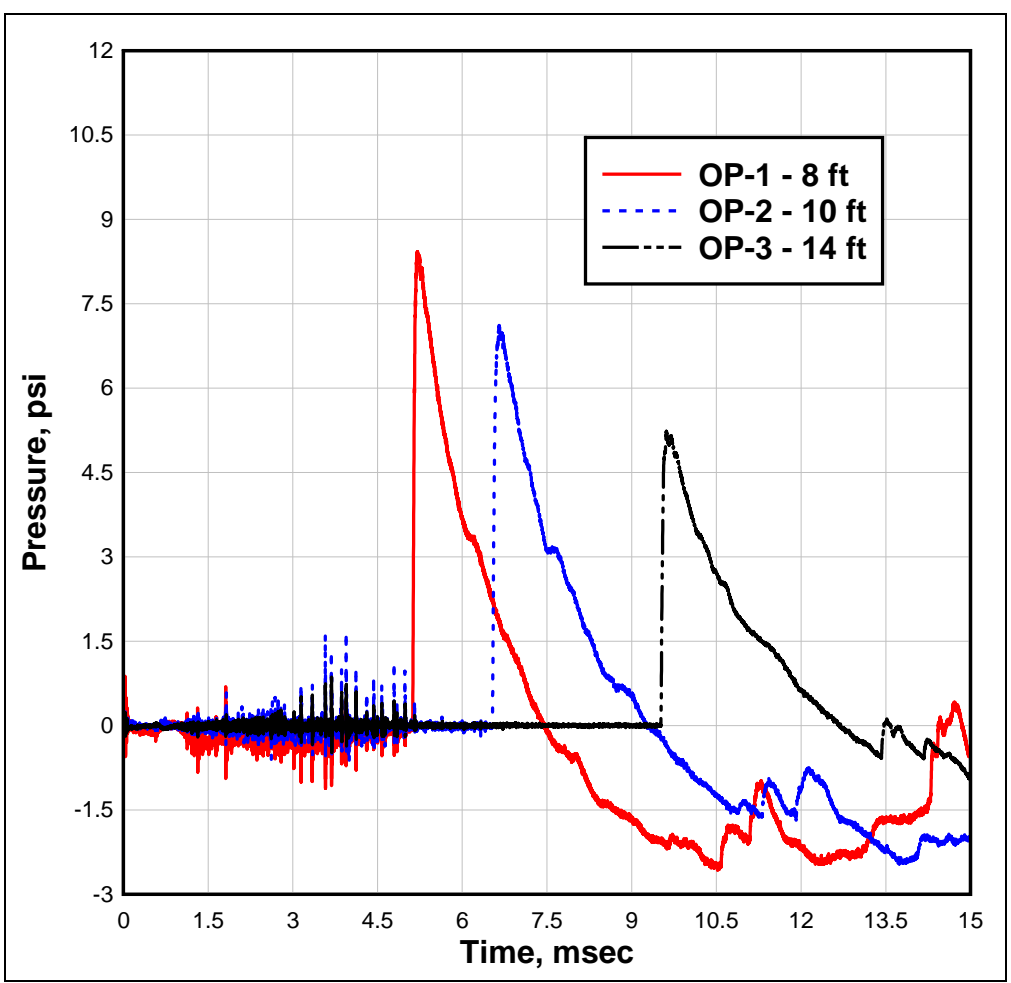

Figure 4.91. Ground surface overpressure time-histories at ranges of 8,10 , and $14 \mathrm{ft}$ in experiment BM-S-03.

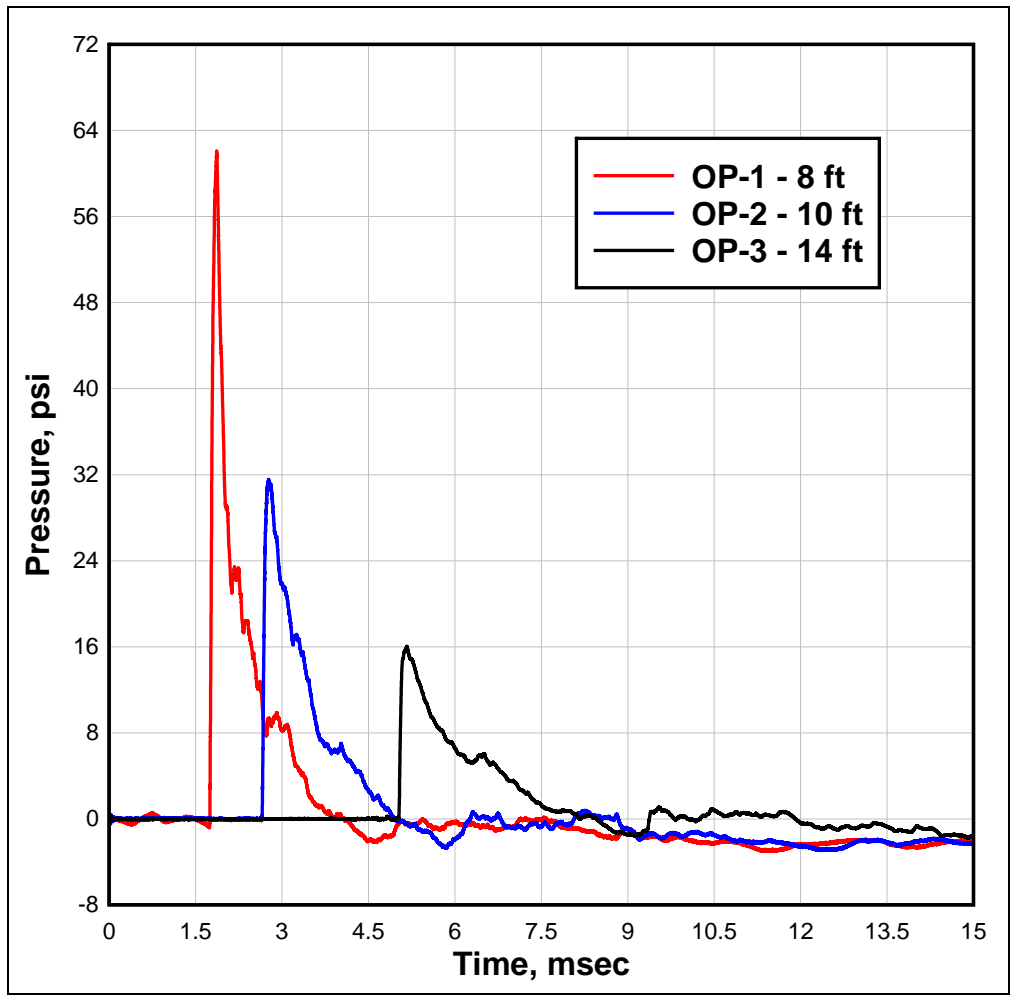

Figure 4.92. Ground surface overpressure time-histories at ranges of 8,10 , and $14 \mathrm{ft}$ in experiment BM-S-04. 


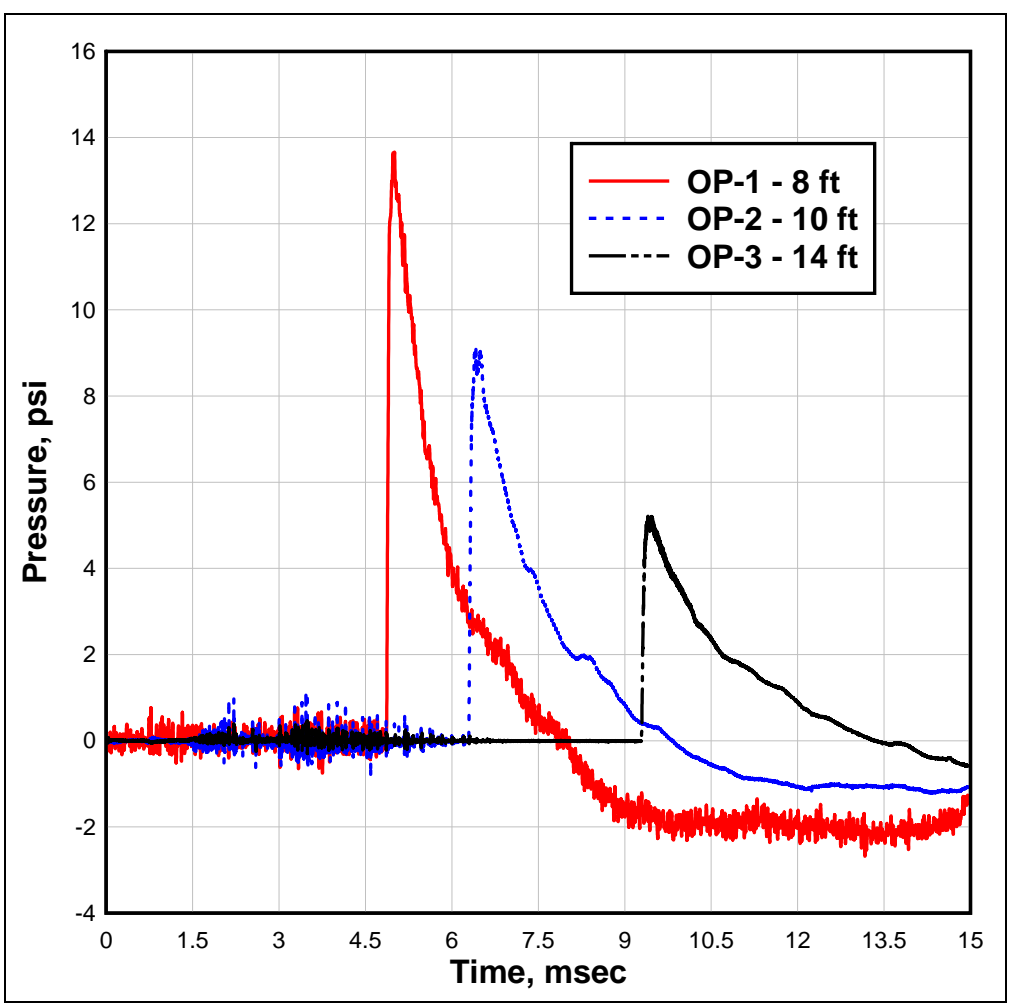

Figure 4.93. Ground surface overpressure time-histories at ranges of 8,10 , and $14 \mathrm{ft}$ in experiment BM-S-05.

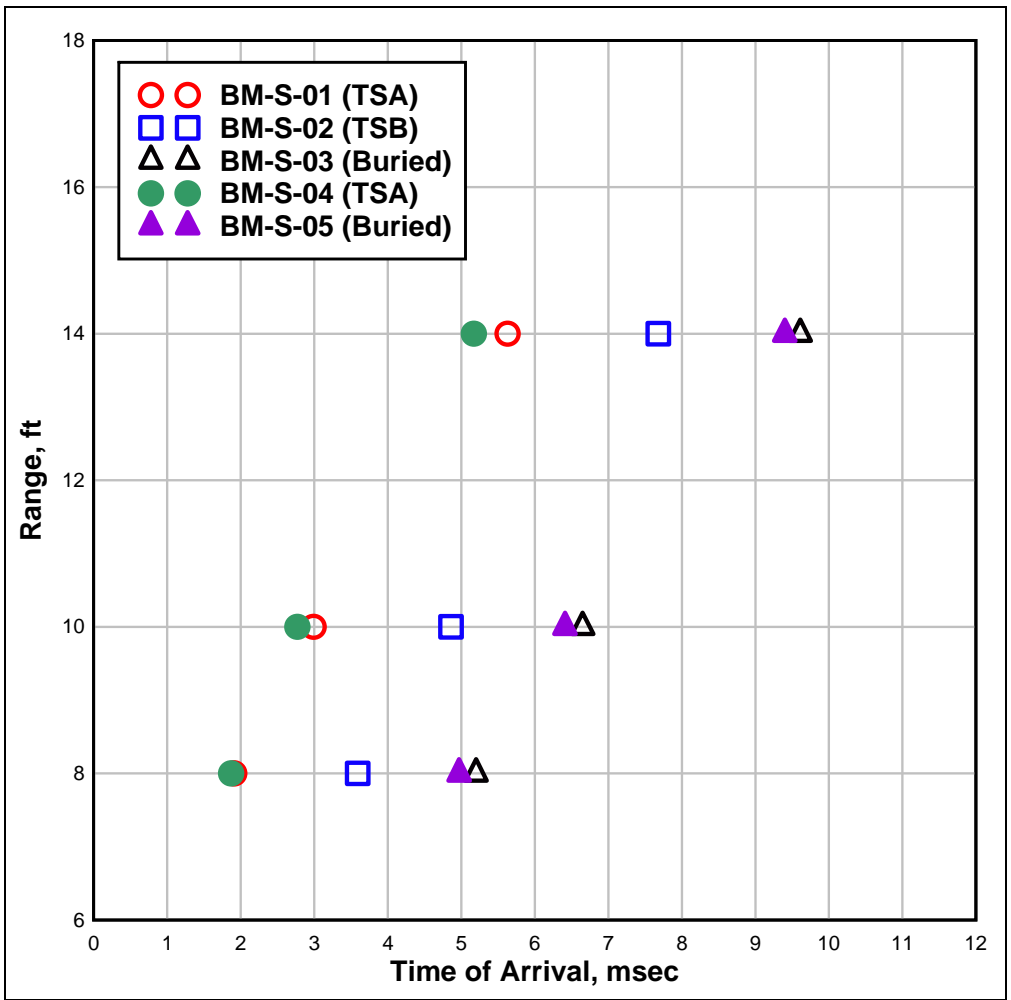

Figure 4.94. Ground surface overpressure times of arrival versus range for experiments BM-S-01 through BM-S-05. 


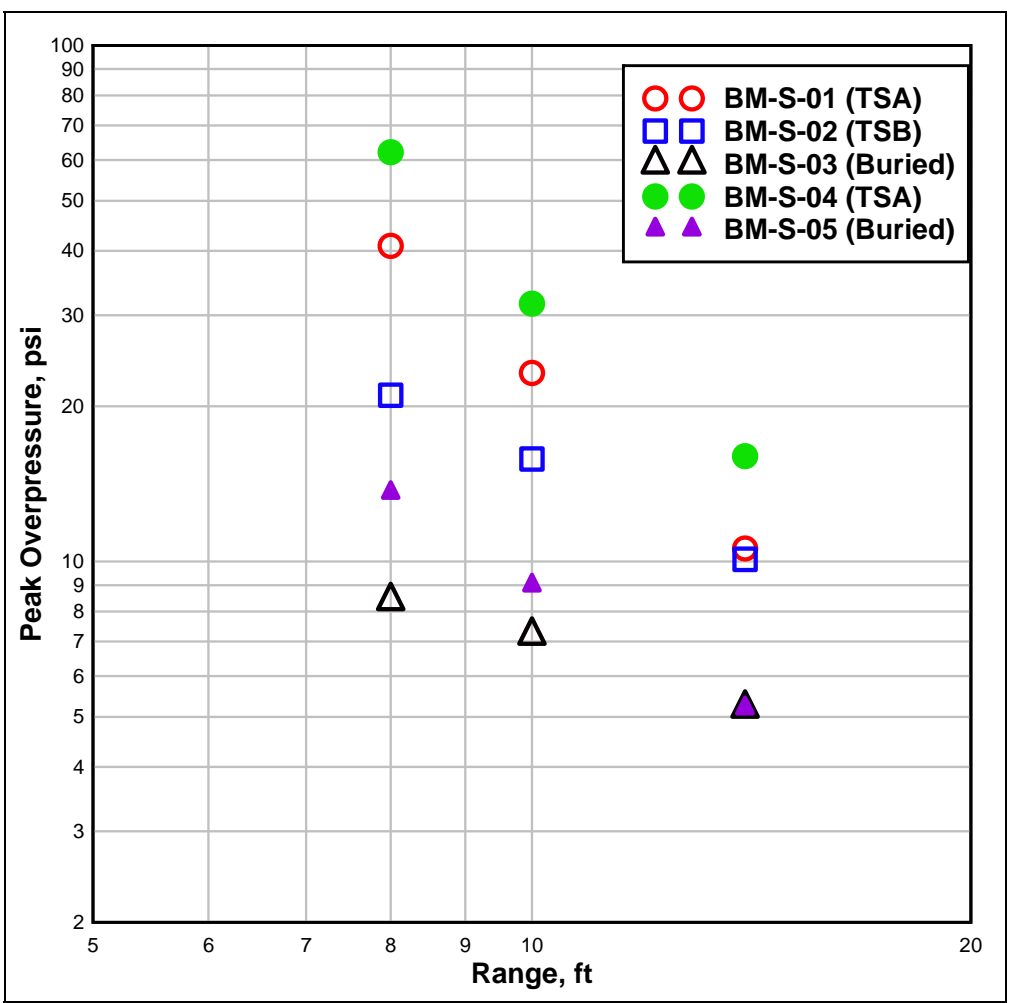

Figure 4.95. Ground surface peak overpressure versus range for experiments BM-S-01 through BM-S-05.

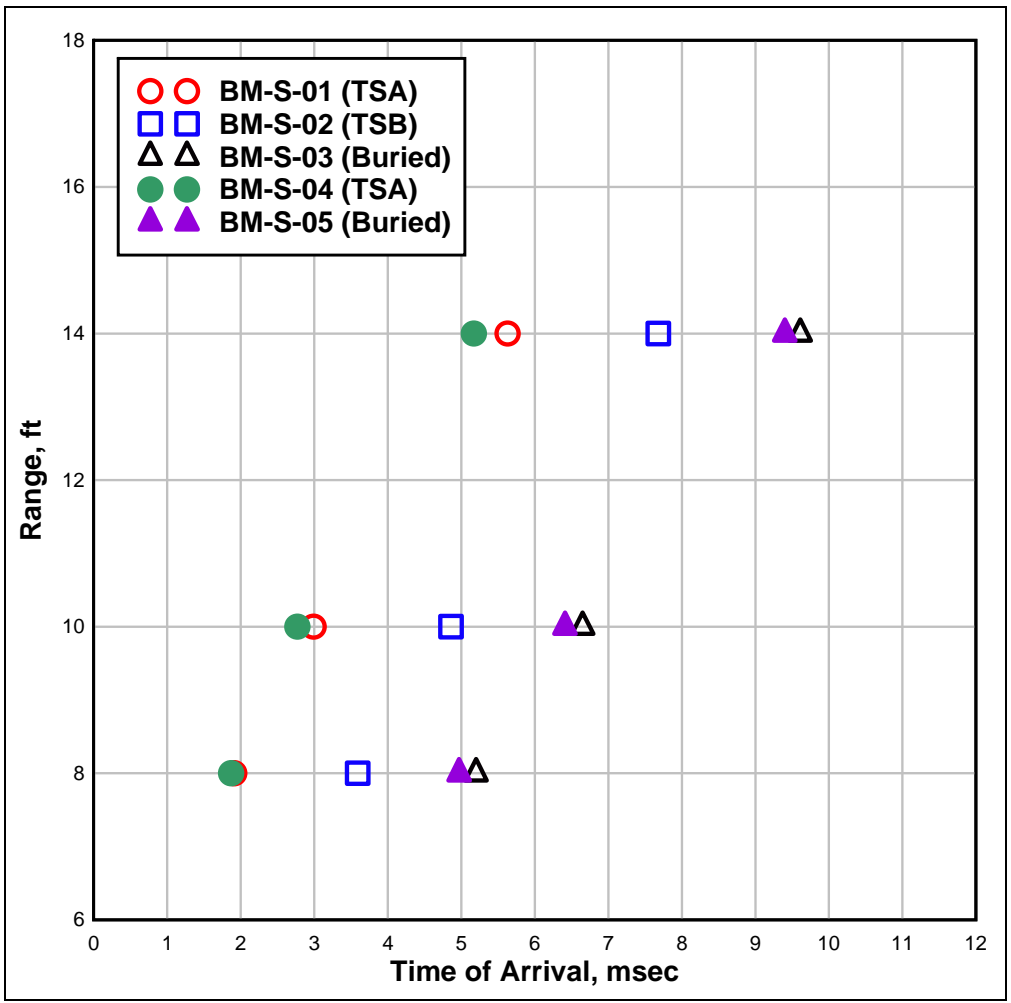

Figure 4.96. Ground surface peak overpressure times of arrival versus range for experiments BM-S-01 through BM-S-05. 


\section{Aboveground side-on overpressure}

Sand experiments BM-S-01, BM-S-02, and BM-S-03 were conducted with a series of five side-on overpressure gages above the testbed surface. For all three experiments, the standoff distance between the top of the charge and a horizontal plane through the side-on overpressures gages was held constant at $20 \mathrm{in}$. The gages were located in line so that one gage was directly above the charge, two had a horizontal offset of $18 \mathrm{in}$., and two had a horizontal offset of 36 in. A summary of the aboveground side-on overpressure data for the sand soil experiments is in Table 4.16, which includes the experiment number, gage number, horizontal range from GZ (vertical distance held constant at 20 in.), range from GZ, shock time of arrival, peak overpressure, time of peak pressure, rise time, and peak overpressure impulse. The stress time-histories obtained from the side-on overpressure gages in BM-S-01, BM-S-02, and BM-S-03 are presented in Figures 4.974.105. The data from the two redundant gages at $18 \mathrm{in.}$ and $36 \mathrm{in.}$ are shown on the same plots. The shock times of arrival versus range and the peak side-on overpressure stresses versus range from the three experiments are presented in Figures 4.106 and 4.107, respectively.

Table 4.16. Side-on overpressure summary for sand soil experiments.

\begin{tabular}{|l|l|l|l|l|l|l|l|l|}
\hline $\begin{array}{l}\text { Experiment } \\
\text { Number }\end{array}$ & $\begin{array}{l}\text { Gage } \\
\text { Number }\end{array}$ & $\begin{array}{l}\text { Horizontal } \\
\text { Range from } \\
\text { GZ, }\end{array}$ & $\begin{array}{l}\text { Range } \\
\text { from GZ, } \\
\text { in. }\end{array}$ & $\begin{array}{l}\text { Shock } \\
\text { Time of } \\
\text { Arrival, } \\
\text { msec }\end{array}$ & $\begin{array}{l}\text { Peak } \\
\text { Pressure, } \\
\text { psi }\end{array}$ & $\begin{array}{l}\text { Time of } \\
\text { Peak } \\
\text { Pressure, } \\
\text { msec }\end{array}$ & $\begin{array}{l}\text { Rise Time, } \\
\text { msec }\end{array}$ & $\begin{array}{l}\text { Peak } \\
\text { Impulse, } \\
\text { psi-sec }\end{array}$ \\
\hline BM-S-01 & SOP-1 & 36 & 41.75 & 0.52 & 81.6 & 0.61 & 0.09 & 0.033 \\
\hline BM-S-01 & SOP-2 & 18 & 27.77 & 0.32 & 180.5 & 0.38 & 0.06 & 0.040 \\
\hline BM-S-01 & SOP-3 & 0 & 21.15 & 0.12 & 1298.5 & 0.16 & 0.04 & 0.105 \\
\hline BM-S-01 & SOP-4 & 18 & 27.77 & 0.23 & 136.1 & 0.28 & 0.05 & 0.023 \\
\hline BM-S-01 & SOP-5 & 36 & 41.75 & 0.53 & 117.7 & 0.61 & 0.08 & 0.036 \\
\hline BM-S-02 & SOP-1 & 36 & 41.74 & 0.74 & 56.1 & 0.81 & 0.08 & 0.015 \\
\hline BM-S-02 & SOP-2 & 18 & 27.77 & 0.29 & 165.5 & 0.35 & 0.06 & 0.020 \\
\hline BM-S-02 & SOP-3 & 0 & 21.15 & 0.11 & 690.5 & 0.15 & 0.04 & 0.094 \\
\hline BM-S-02 & SOP-4 & 18 & 27.77 & 0.22 & 203.0 & 0.26 & 0.04 & 0.020 \\
\hline BM-S-02 & SOP-5 & 36 & 41.75 & 0.66 & 66.6 & 0.75 & 0.09 & 0.016 \\
\hline BM-S-03 & SOP-1 & 36 & 41.74 & 1.68 & 22.1 & 1.76 & 0.08 & 0.008 \\
\hline BM-S-03 & SOP-2 & 18 & 27.77 & 0.95 & 58.8 & 1.02 & 0.07 & 0.026 \\
\hline BM-S-03 & SOP-3 & 0 & 21.15 & 0.60 & 330.0 & 0.82 & 0.22 & 0.199 \\
\hline BM-S-03 & SOP-4 & 18 & 27.77 & 0.92 & 60.2 & 1.01 & 0.09 & 0.033 \\
\hline BM-S-03 & SOP-5 & 36 & 41.75 & 1.71 & 22.8 & 1.81 & 0.09 & 0.010 \\
\hline
\end{tabular}




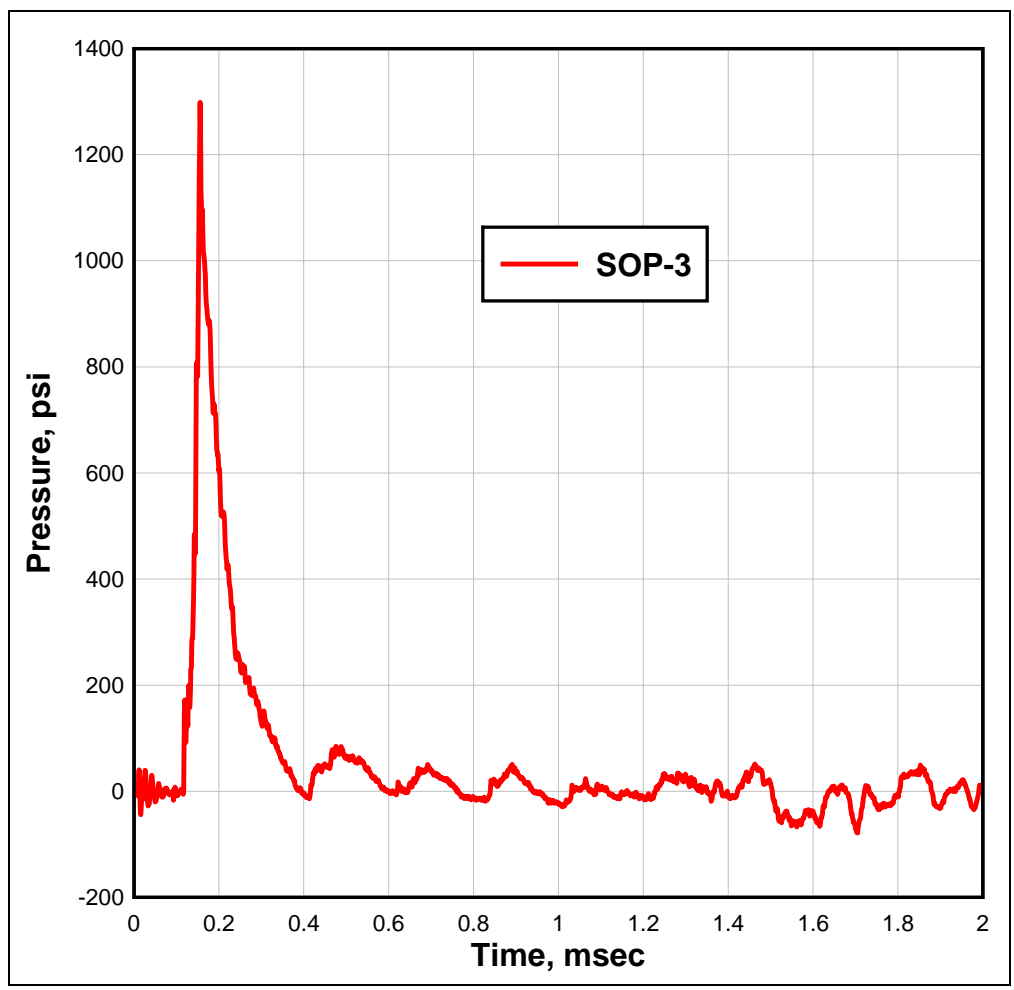

Figure 4.97. Side-on overpressure time-history directly above the charge $\mathrm{GZ}$ in experiment BM-S-01.

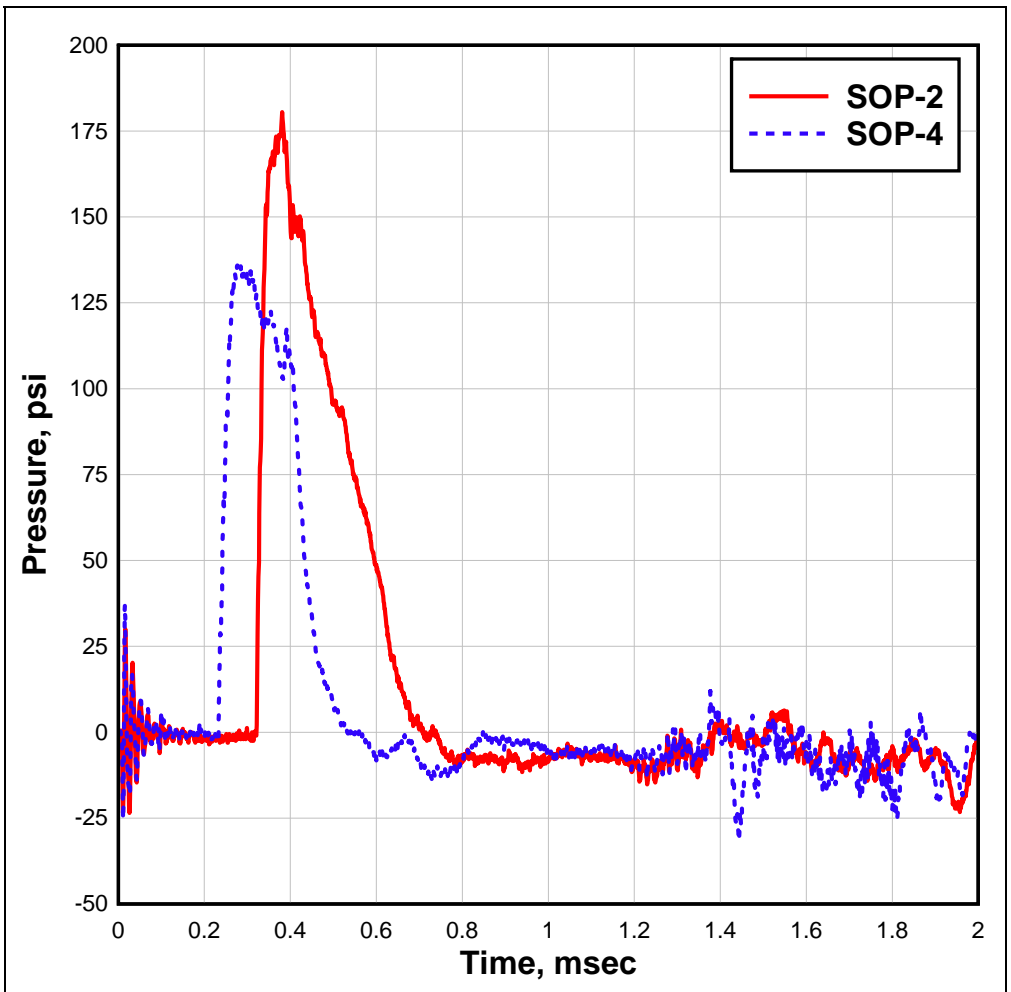

Figure 4.98. Side-on overpressure time-histories at a horizontal range of 18 in. from GZ in experiment BM-S-01. 


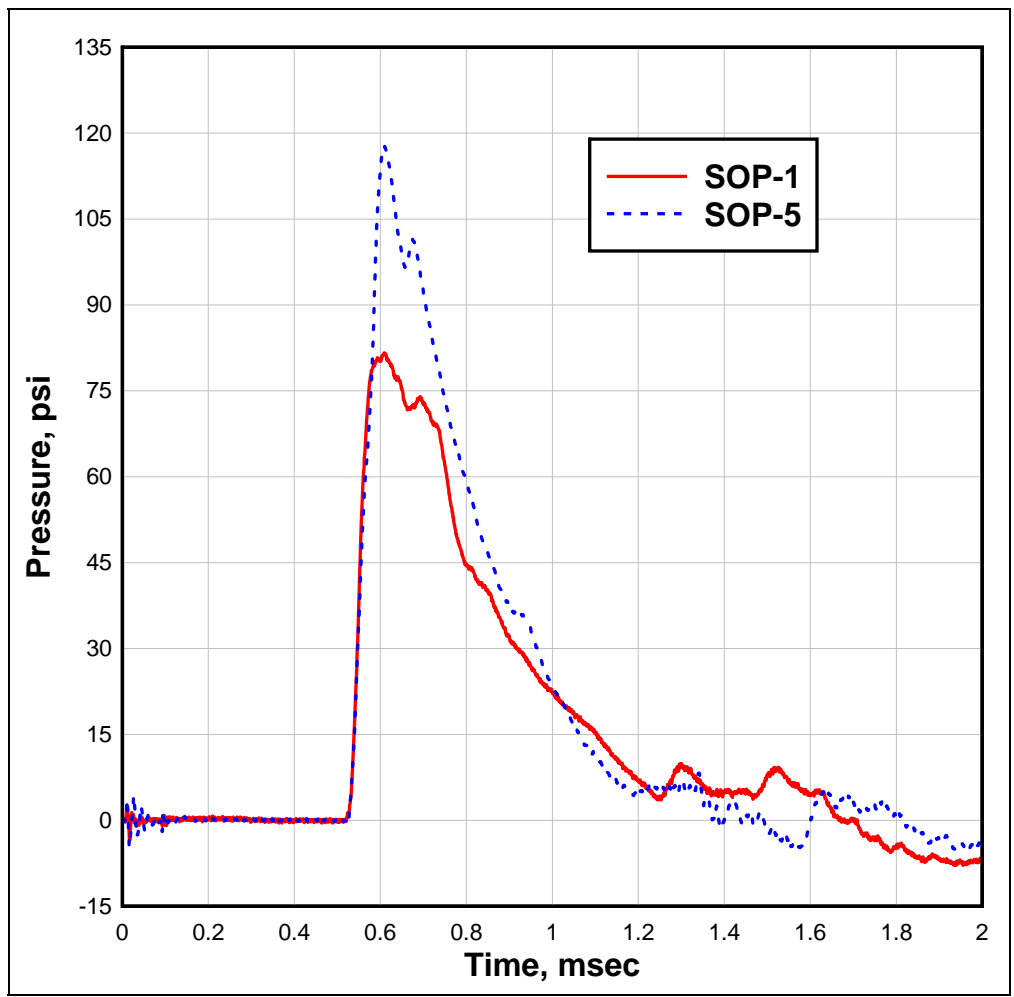

Figure 4.99. Side-on overpressure time-histories at a horizontal range of 36 in. from GZ in experiment BM-S-01.

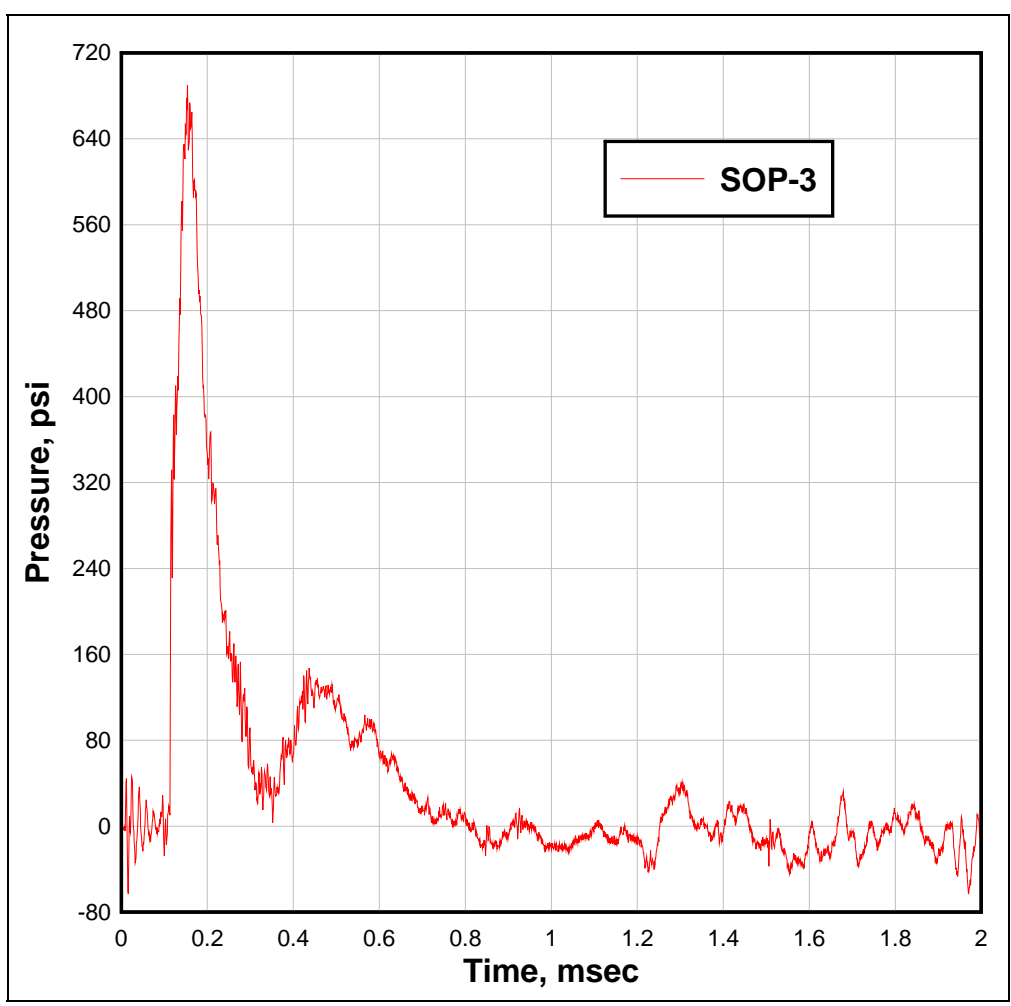

Figure 4.100. Side-on overpressure time-history directly above the charge GZ in experiment BM-S-02. 


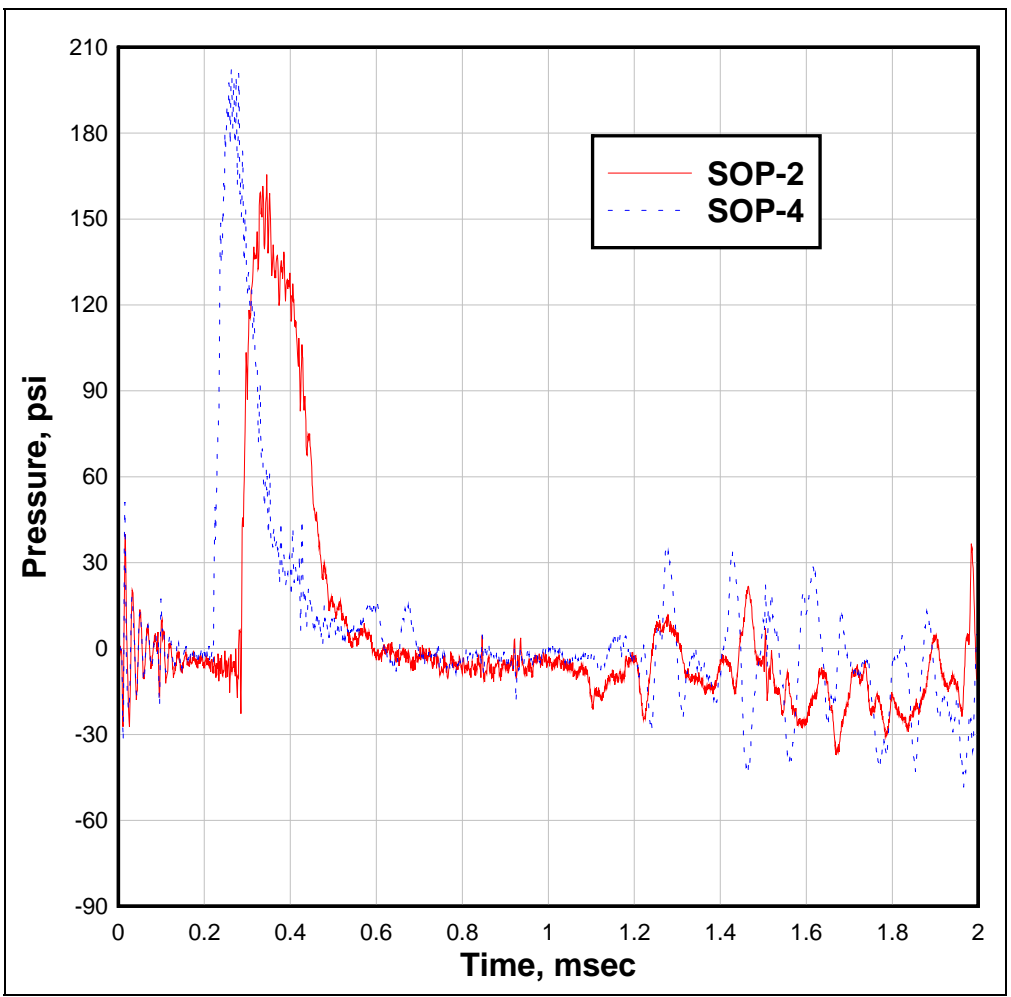

Figure 4.101. Side-on overpressure time-histories at a horizontal range of $18 \mathrm{in.} \mathrm{from} \mathrm{GZ} \mathrm{in} \mathrm{experiment} \mathrm{BM-S-02.}$

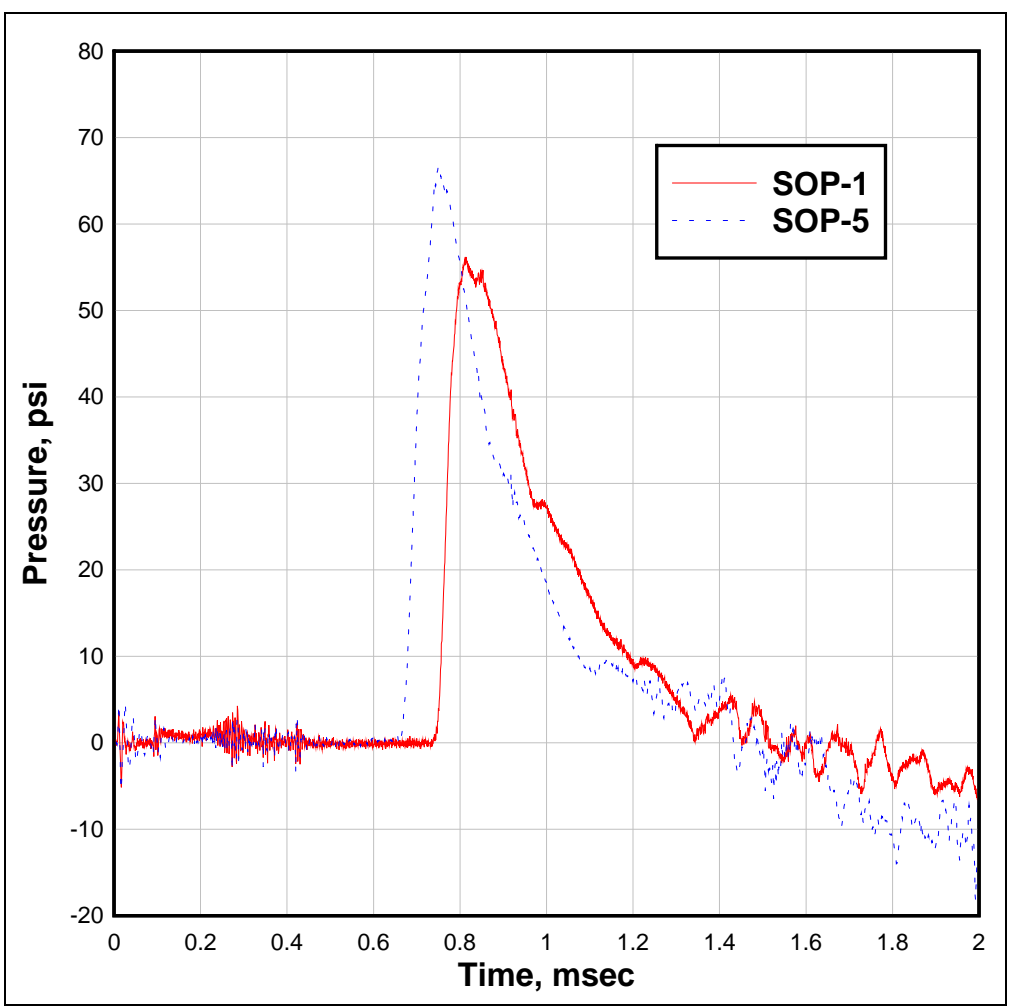

Figure 4.102. Side-on overpressure time-histories at a horizontal range of 36 in. from GZ in experiment BM-S-02. 


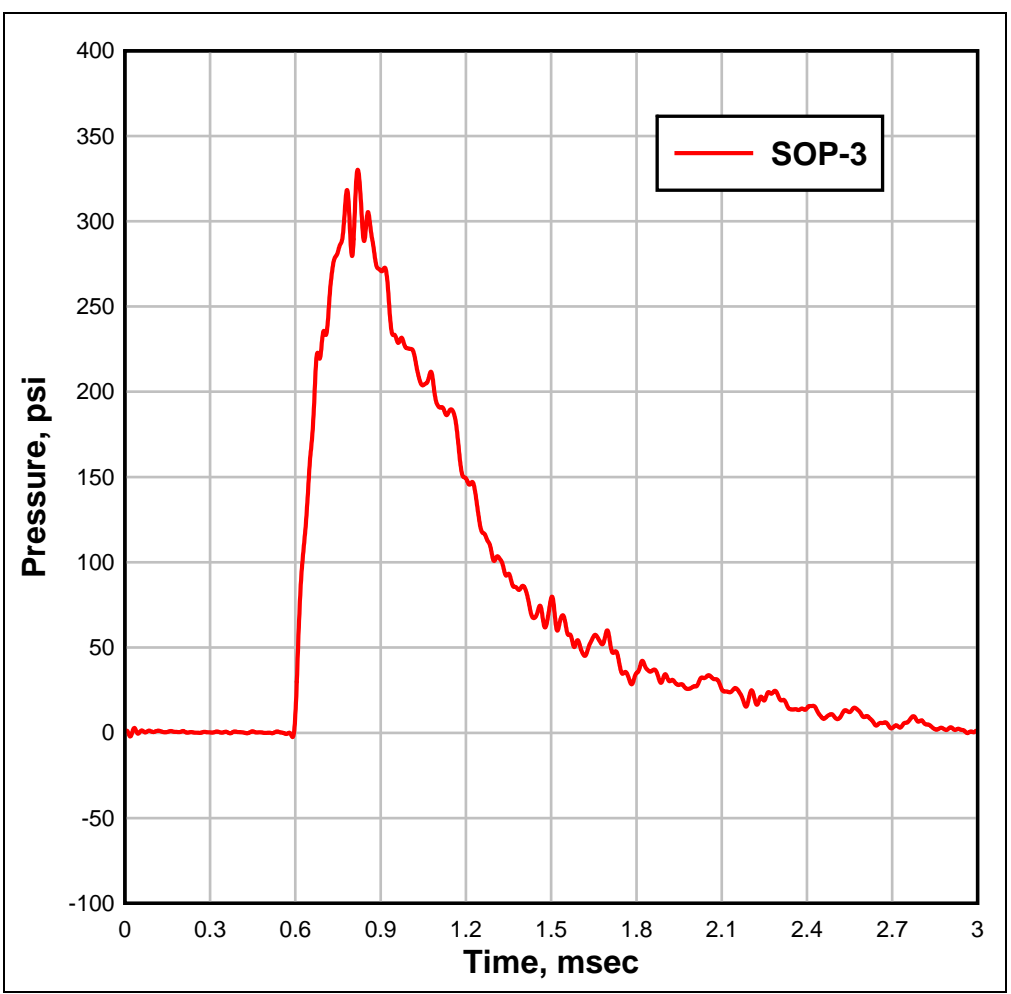

Figure 4.103. Side-on overpressure time-history directly above the charge GZ in experiment BM-S-03.

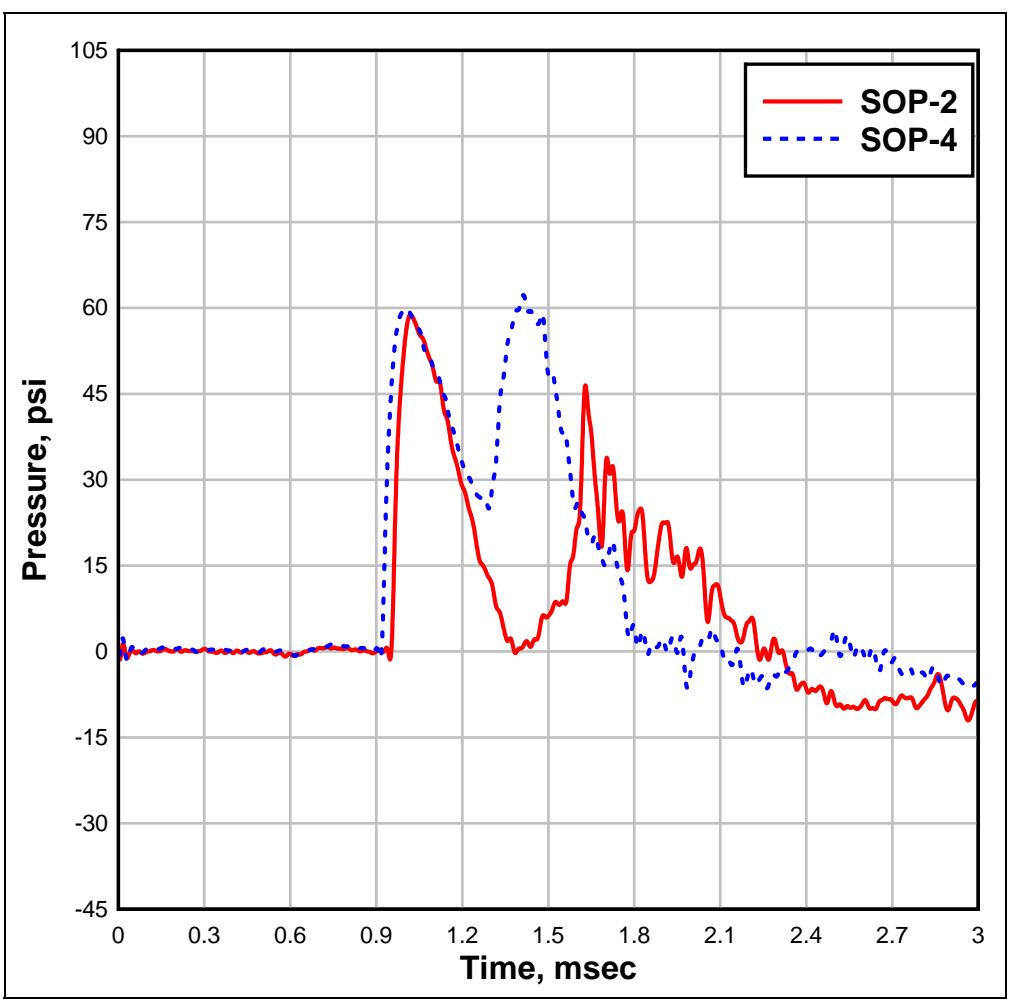

Figure 4.104. Side-on overpressure time-histories at a horizontal range of $18 \mathrm{in.} \mathrm{from} \mathrm{GZ} \mathrm{in} \mathrm{experiment} \mathrm{BM-S-03.}$ 


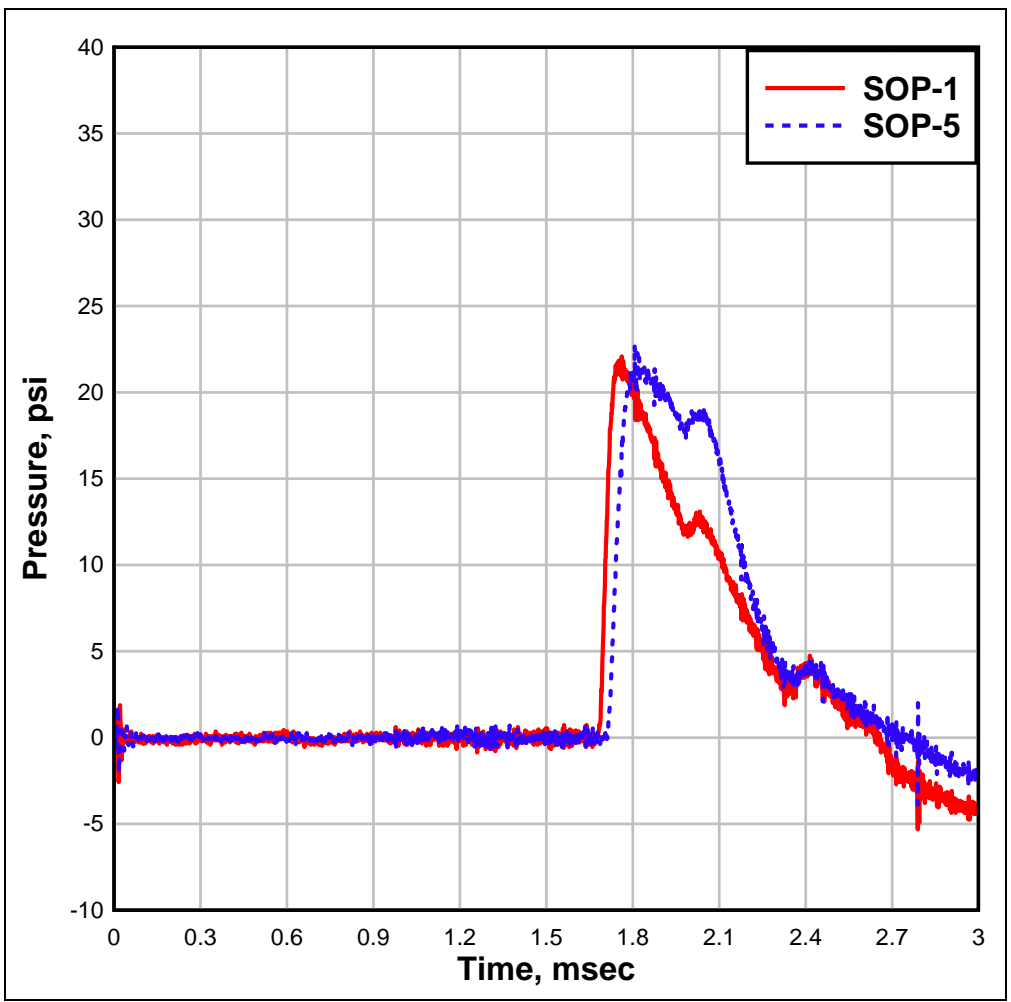

Figure 4.105. Side-on overpressure time-histories at a horizontal range of 36 in. from GZ in experiment BM-S-03.

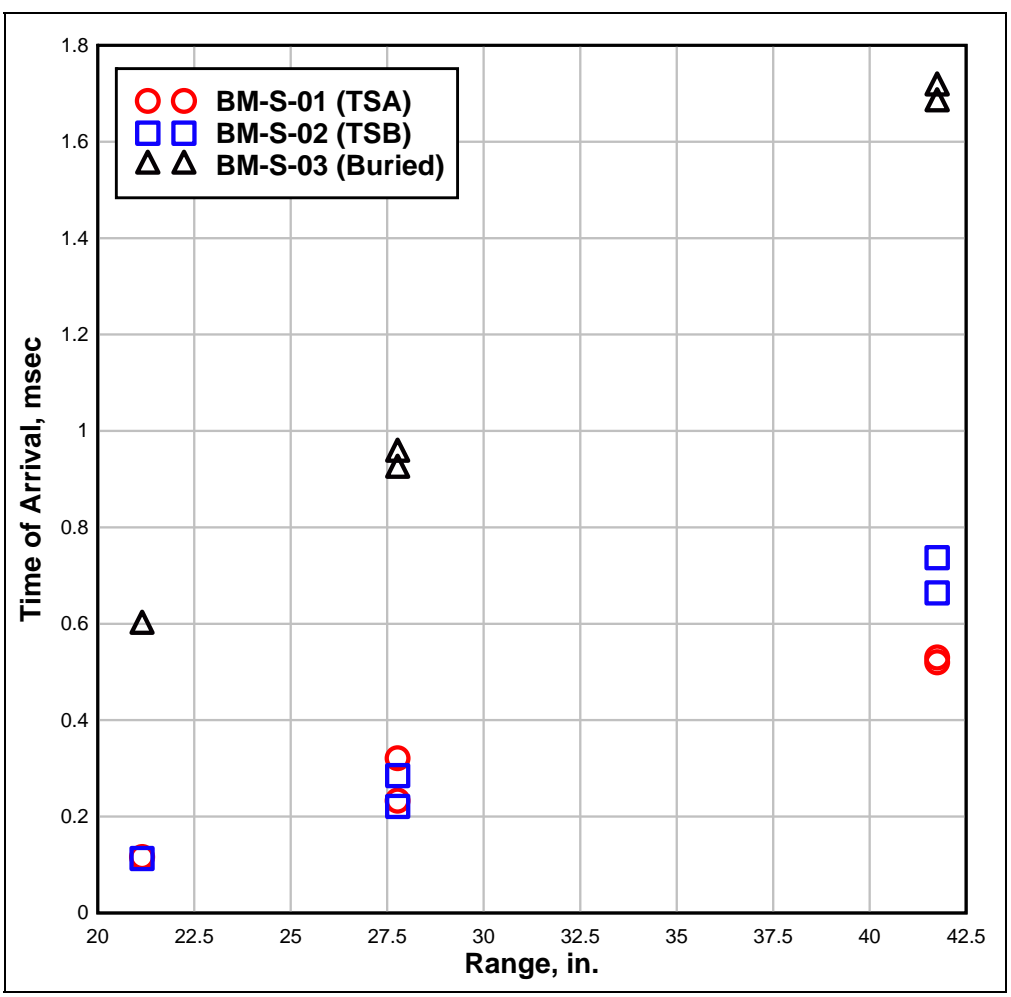

Figure 4.106. Shock time of arrival versus range from side-on overpressure gages in experiments BM-S-01 through BM-S-03. 


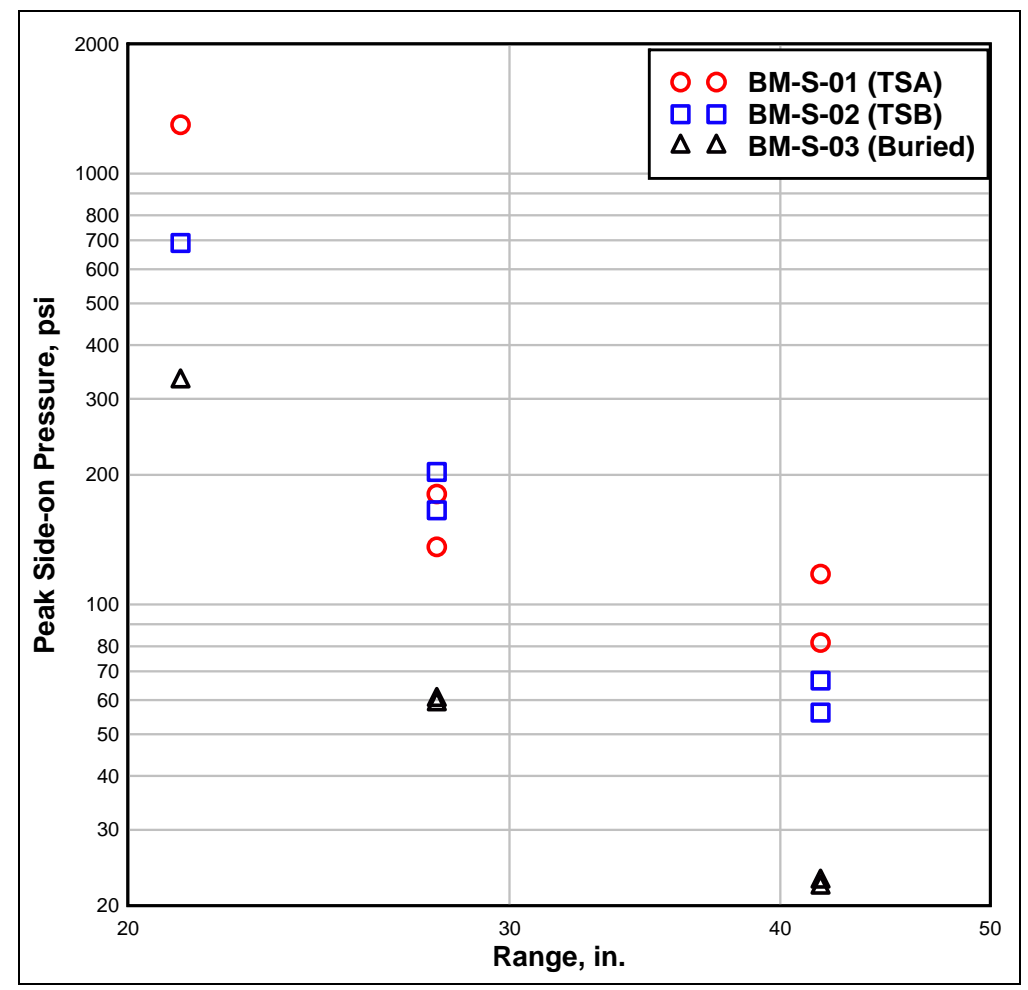

Figure 4.107. Peak side-on overpressures versus range in experiments BM-S-01 through BM-S-03.

As expected, the center gages, SOP3, directly over the charge and the closest to the charge, recorded the highest peak overpressures compared with the values from gages offset 18 and 36 in. For a given experiment, the gages at 18-in. offset also recorded higher peak pressures when compared with the peaks from gages at 36-in. offset. Comparisons of the data from redundant gages at 18- and 36-in. offset agreed reasonably well. The greatest variation in the peak pressure occurred in experiment BM-S-01 at the 18- and 36-in. offset. When the results of the various experiments are compared, the charge buried 4 in., BM-S-03, had a significant reduction in the peak overpressure (Figure 4.107) and a significant increase in the shock arrival times (Figure 4.106) compared with the experiments with the charge resting on the ground surface, TSA, and buried surface tangent, TSB, at the same ranges. When the results of the TSB and TSA tests are compared, the peak pressure directly above the charge is greater for the TSA case except at the 18-in. offset, where they are essentially the same. 


\section{Impulse measurement device}

Piston impulse

Two of the sand experiments, BM-S-04 and BM-S-05, were conducted using the IMD to measure the total impulse imparted to the impact plate of the piston assembly. For both experiments, the standoff distance between the top of the charge and the face of the IMD impact plate was held constant at 20 in. The total mass of the IMD piston assembly for both experiments was approximately 5,500 lb with an impact plate surface area of $7.069 \mathrm{ft}^{2}$ (3-ft diameter). During the experiments, the motion of the IMD piston assembly was captured using three independent methods, i.e., an accelerometer located on the IMD piston assembly, a displacement measurement gage (yo-yo gage) located on the top of the support structure, and high-speed video. In most cases, the high-speed video was the best source for data on IMD motion. Due to the high initial acceleration of the IMD piston assembly, the yo-yo gage was not dependable in capturing useful displacement time-history data, but peak displacement was available. Use of the accelerometer was partially successful, but it did experience some high-frequency noise and data shifts that made it difficult to select peak displacements and initial velocities from the records. Due to late-time debris and smoke, the peak displacement was obscured from view in the high-speed video.

A summary of the IMD measured data obtained for the sand soil experiments is in Table 4.17. The table includes the peak displacements determined from the two measurement systems and the initial velocity captured both in the high-speed video and from integration of the acceleration record. The average displacement shown in the summary table is the average of the displacements measured by the two methods. The initial velocity captured from the high-speed video was the primary value used in the impulse calculations. As a method to compare the different measurement values, the peak displacement is also calculated using the initial velocity captured from the high-speed video. The calculations are explained in detail in Chapter 2. The peak displacements calculated from the measured initial velocity values compare reasonably well with the average measured peak displacement values. The difference in calculated peak displacement and the average measured peak displacement was greatest in experiment BM-S- 05 or approximately $10 \%$ greater. 
Table 4.17. Summary of the IMD measured data.

\begin{tabular}{|c|c|c|c|c|c|c|c|}
\hline \multirow[b]{2}{*}{$\begin{array}{l}\text { Experiment } \\
\text { Number }\end{array}$} & \multicolumn{3}{|c|}{ Peak Displacement, in. } & \multirow[b]{2}{*}{$\begin{array}{l}\text { Average } \\
\text { Displacement, } \\
\text { in. }\end{array}$} & \multicolumn{2}{|c|}{ Initial Velocity, fps } & \multirow{2}{*}{$\begin{array}{l}\text { Calculated Peak } \\
\text { Displacement } \\
\text { Using Video Initial } \\
\text { Velocity, in. }\end{array}$} \\
\hline & $\begin{array}{l}\text { Yo-Yo/ } \\
\text { Scratch } \\
\text { Gage }\end{array}$ & $\begin{array}{l}\text { High- } \\
\text { Speed } \\
\text { Video }\end{array}$ & $\begin{array}{l}\text { Acceleration } \\
\text { Record }\end{array}$ & & $\begin{array}{l}\text { High- } \\
\text { Speed } \\
\text { Video }\end{array}$ & $\begin{array}{l}\text { Acceleration } \\
\text { Record }\end{array}$ & \\
\hline BM-S-04 & 2.75 & 2.29 & 2.18 & 2.4 & 3.6 & 3.4 & 2.4 \\
\hline BM-S-05 & 15.3 & - & 14.7 & 15.0 & 9.4 & 10.1 & 16.5 \\
\hline
\end{tabular}

Using the initial velocities obtained for the high-speed video, the total impulse imparted to the IMD piston assembly was calculated (Table 4.18). The calculated impulse is the total impulse and is directly related to the surface area for the impact plate. The mass of the IMD piston assembly used to calculate the impulse was 5,600 lb, which accounts for the weight of the system and the approximate dynamic drag in the system due to friction. The method used to calculate the total impulse is explained in detail in Chapter 2. As seen in Table 4.18, the total impulse imparted to the IMD increased by a factor of 2.6 when the charge position changed from sitting on the surface to buried $4 \mathrm{in}$. below the surface even though the charge standoff distance was the same for both experiments.

Table 4.18. Total impulse imparted to the IMD.

\begin{tabular}{|l|l|l|l|l|}
\hline $\begin{array}{l}\text { Experiment } \\
\text { Number }\end{array}$ & Charge Position & $\begin{array}{l}\text { Initial Velocity, }{ }^{1} \\
\text { fps }\end{array}$ & $\begin{array}{l}\text { Average Total } \\
\text { Displacement, } \\
\text { in. }\end{array}$ & $\begin{array}{l}\text { Peak Impulse, } \\
\text { Ib-sec }\end{array}$ \\
\hline BM-S-04 & Sitting on Surface & 3.56 & 2.4 & 619 \\
\hline BM-S-05 & Buried & 9.4 & 15.0 & 1635 \\
\hline
\end{tabular}

1 Initial velocity obtained from the high-speed video.

2 Peak impulse calculated using the initial velocity of the system. Impulse directly related to target mass and surface area.

Impact plate pressure measurements

The three flush-mounted pressure transducers mounted on the bottom plate of the piston assembly, gages RP1, RP2, and RP3, were an attempt to measure the reflected pressure on the surface of the impact plate. Due to the extremely harsh environment from the soil, airblast, and detonation products at this close proximity to the charge, the pressure data obtained were somewhat limited. The three gages included one PCB gage and two Kulite gages. The gages were equal distance from the charge at a 2.5-in. 
radius off the center of the IMD impact plate. Two different Kulite gage cover plates were utilized during the experiments in an attempt to reduce or filter the loading by soil particles and/ or detonation products. No useful data were collected from the PCB gage. PCB gages are typically more sensitive to accelerations and were also exposed directly to the airblast and soil particles while the Kulite gages used a debris filter.

The pressure time-histories obtained from Kulite gages RP2 and RP3 for experiments BM-S-04 and BM-S-05 are presented in Figures 4.108 and 4.109, respectively. The times of arrival for the pressure data recorded by the two Kulite gages in each experiment compared well with each other. The large variation in peak pressure measured in experiment BM-S-04 $(22,000$ to 36,000 psi) was observed in other experiments in which highpressure measurements were made in close proximity to the explosive charge. Pressure gage RP- 2 in experiment BM-S-05 appeared to miss the peak pressure but did record the time of arrival of the pressure. Experiment BM-S-05 had the charge fully buried in the soil and produced a much more complex loading environment. The pressure time-history recorded in the RP- 2 gage for BM-S- 05 was probably affected by the soil ejecta hitting the gage covers/ filters and disrupting the pressure transmitted to the actual gage. A comparison of times of arrival and peak pressures from the two experiments shows that BM-S-05 recorded a much later time of arrival and a slightly higher peak pressure.

\section{IMD accelerations}

Accelerometer SAV1 was mounted on the IMD piston assembly, and accelerometer SAV2 was mounted on the IMD support structure. The accelerometer on the piston assembly was an attempt to measure the motion, i.e., velocity and displacement, of the piston assembly. The accelerometer mounted on the support structure was an attempt to capture the global motion of the support frame. For both locations, the acceleration time-histories were integrated to capture velocity and displacement at the gage location. The accelerometers experienced significant high-frequency ringing during the experiments. In some cases, this noise overwhelmed the data, and/ or a significant data shift occurred in the record, which made it difficult to extract useful information. Several attempts were made to modify the gage mounts to help isolate this highfrequency noise, but limited improvements were seen in the data. 


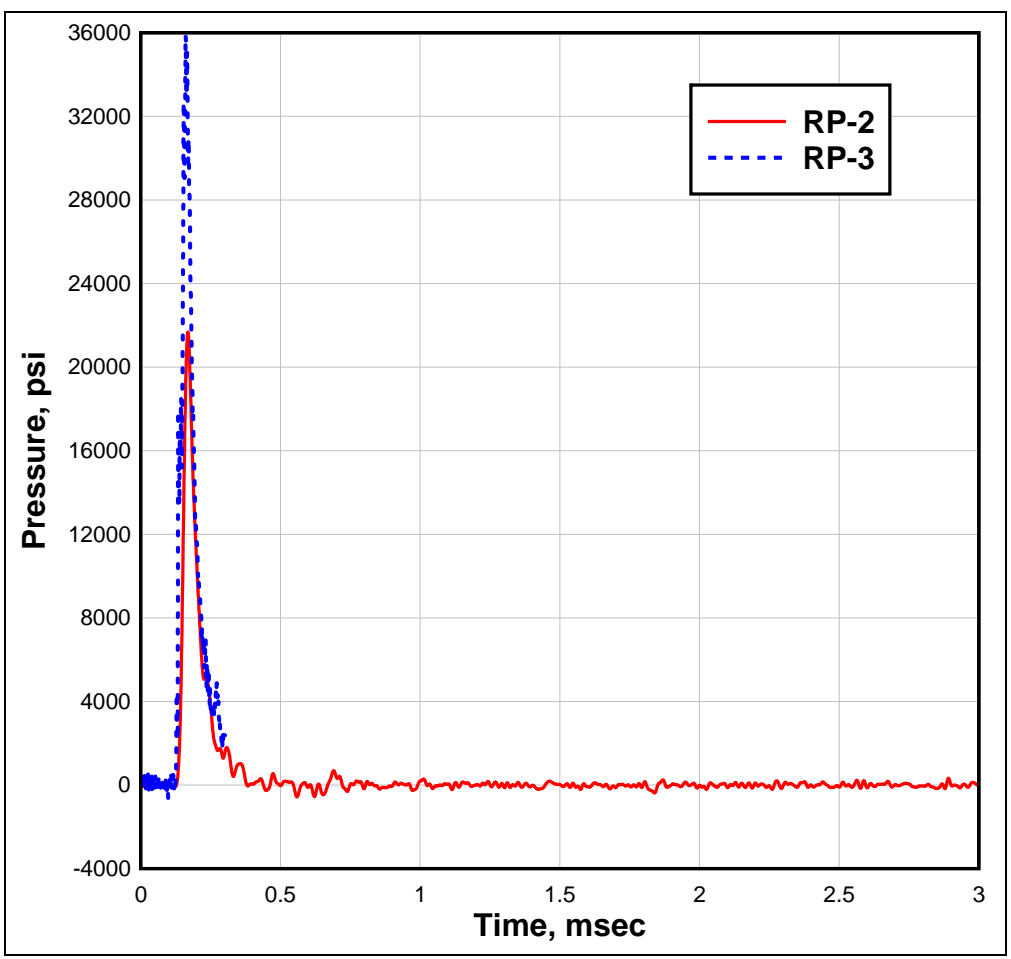

Figure 4.108. Impact-plate pressure time-histories RP2 and RP3 in experiment BM-S-04.

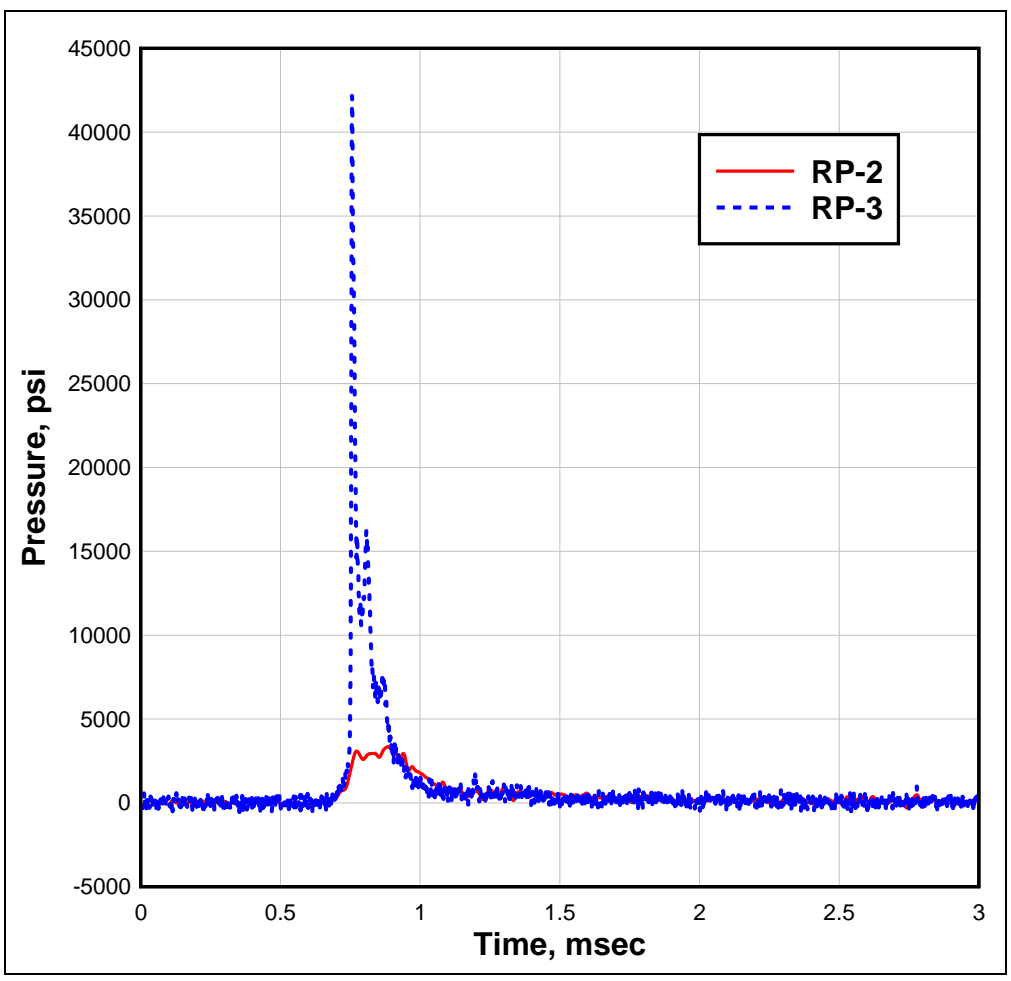

Figure 4.109. Impact-plate pressure time-histories RP2 and RP3 in experiment BM-S-05. 
The integrated velocity and double-integrated displacement time-histories from the accelerometers in experiments BM-S-04 and BM-S-05 are presented in Figures 4.110-4.113. The accelerometers on the IMD piston assembly in both experiments recorded a high-frequency noise at the beginning of the record, which made it difficult to select a peak velocity from the records. The records shown in Figures 4.110 and 4.112 were corrected for the data shift and "filtered" for the high-frequency noise. Because of the high-frequency noise and the data shift in the record, the results are subject to question. The accelerometer on the support structure recorded the oscillation of the support structure at the center produced by the blast load. The maximum displacement of the support structure obtained in both experiments (Figure 4.111 and 4.113) were less than 1/ 8 in. Based on the acceleration record from SAV2, the frequency motion of the structure from both experiments was estimated at approximately 15 to 20 msec.

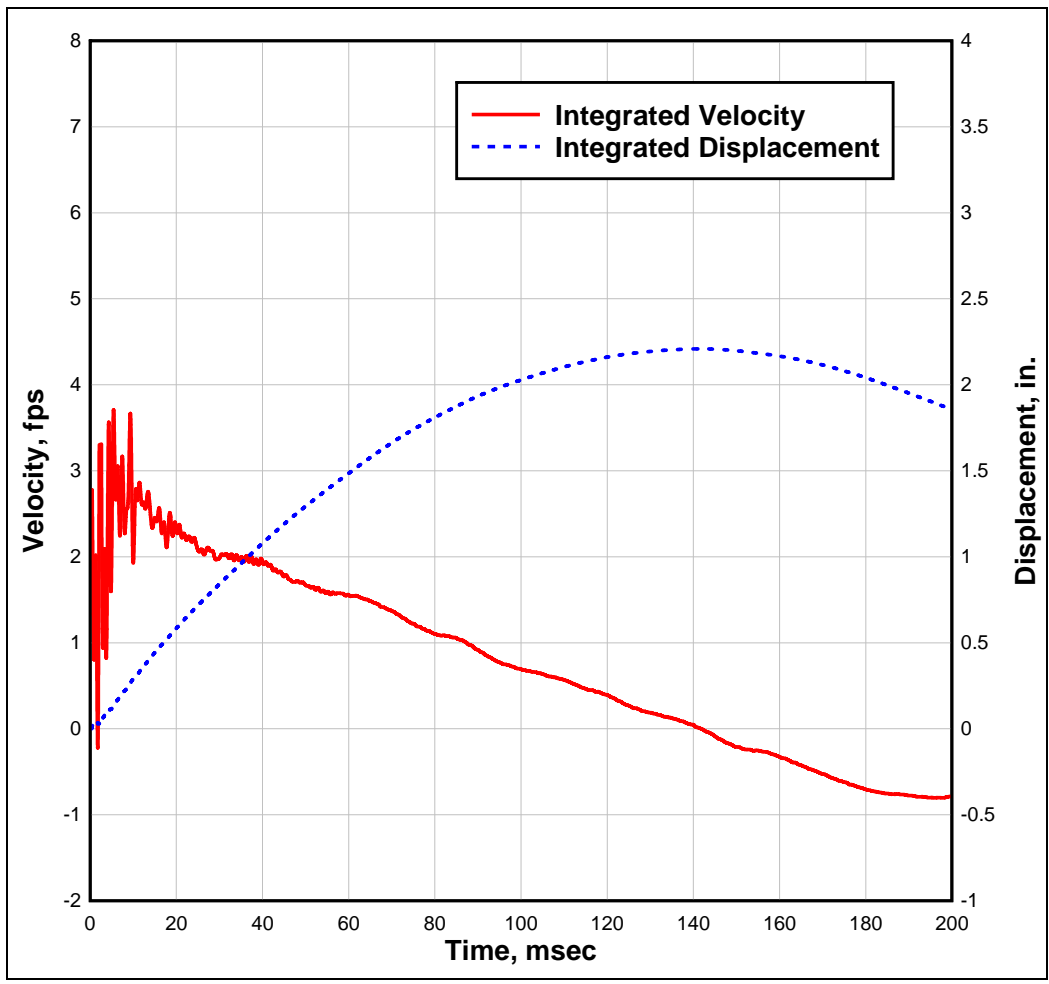

Figure 4.110. Velocity and displacement time-histories from integrated accelerometer SAV1 data in experiment BM-S-04. 


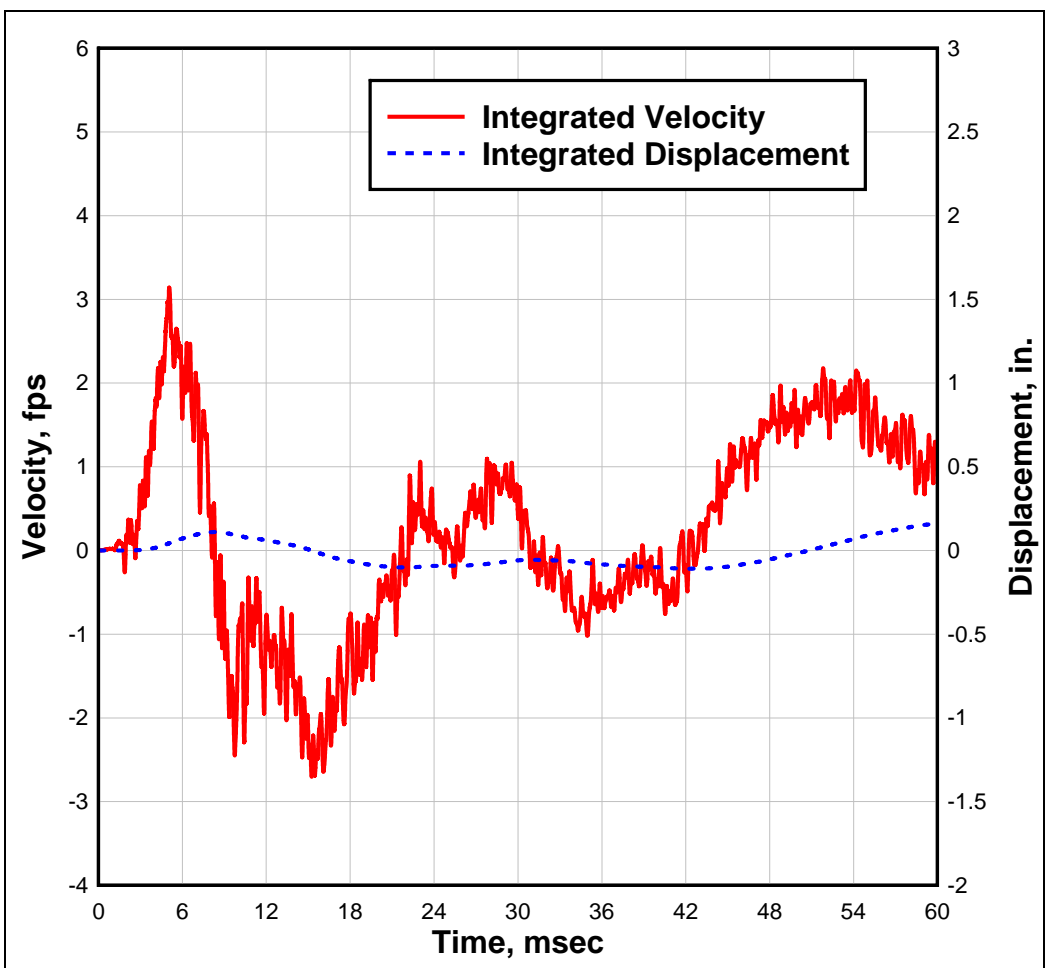

Figure 4.111. Velocity and displacement time-histories from integrated accelerometer SAV2 data in experiment BM-S-04.

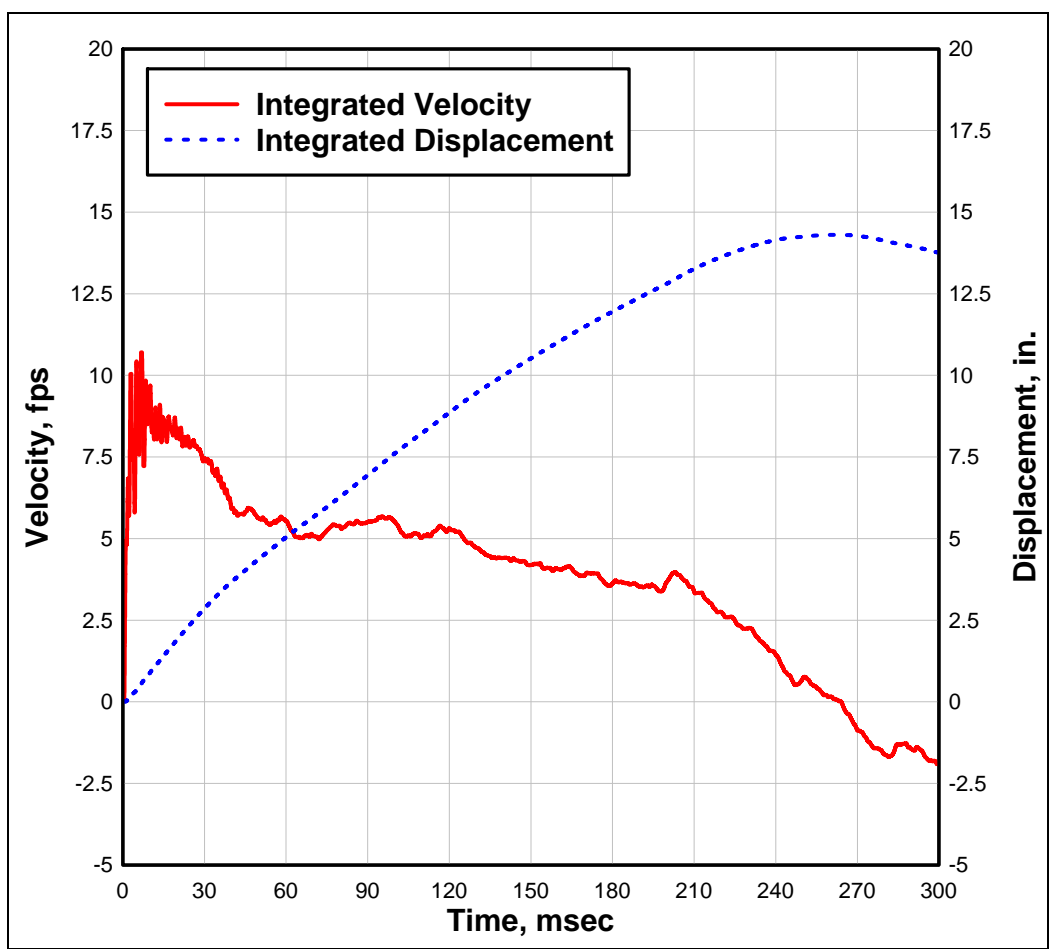

Figure 4.112. Velocity and displacement time-histories from integrated accelerometer SAV1 data in experiment BM-S-05. 


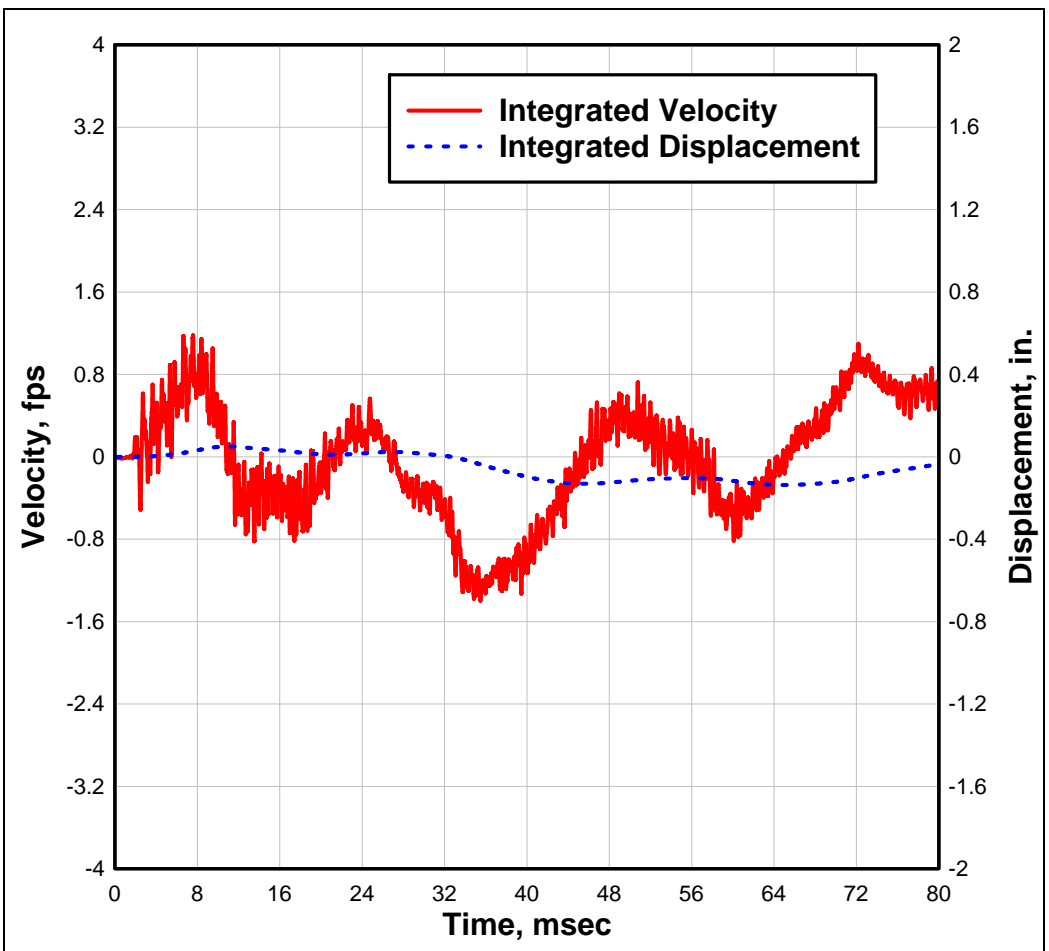

Figure 4.113. Velocity and displacement time-histories from integrated accelerometer SAV2 data in experiment for BM-S-05. 


\section{Comparisons of Experimental Data}

\section{Craters}

The first three experiments conducted for each backfill soil type had sideon overpressure gages located $20 \mathrm{in}$. above the explosive charges in the centers of the testbeds. These gages provided little if any interference with the ejecta emanating from the explosive-induced craters. The remaining two experiments in each series had the IMD device with its 3-ft-diameter, 4-1/2-in.-thick steel plate located directly over the explosive charge. This plate did affect the trajectory of the out-flying ejecta, some of which probably fell back into the crater, which would affect posttest crater measurements. Hence, the crater comparisons shown here used only the results from the first three experiments from each experiment series.

Figure 5.1 compares the crater cross sections obtained from experiments BM-I-01, BM-C-01, and BM-S-01 from the intermediate soil, clay, and sand backfill testbeds, respectively, in which the explosive charge for each was placed tangent surface above the respective testbeds. The crater produced in the wet clay testbed was the deepest of the three craters and had steep sides. The crater produced in the dry sand testbed had the shallowest depth and much flatter side slopes. The intermediate soil produced a crater with steep sides but was not as deep as the wet clay craters.

The wet clay inherently has more cohesion than the other two soils, which accounts for the steep crater side walls. Also, the wet clay with its lowest air voids content and lowest maximum shear strength will propagate a higher lever of ground shock into its testbed than the other two materials, which accounts for its deeper crater depth. On the other hand, the dry sand had the highest air voids content and highest shear strength such that its crater was the shallowest. Its side walls were also the flattest with slopes approximately equal to the sand's angle of friction.

Figure 5.2 compares the crater cross sections obtained from experiments BM-I-02, BM-C-02, and BM-S-02 from the intermediate soil, clay, and sand backfill testbeds, respectively, in which the explosive charge for each was placed in the surface tangent below position. The same trends discussed above for the surface tangent above experiments are shown again here. 


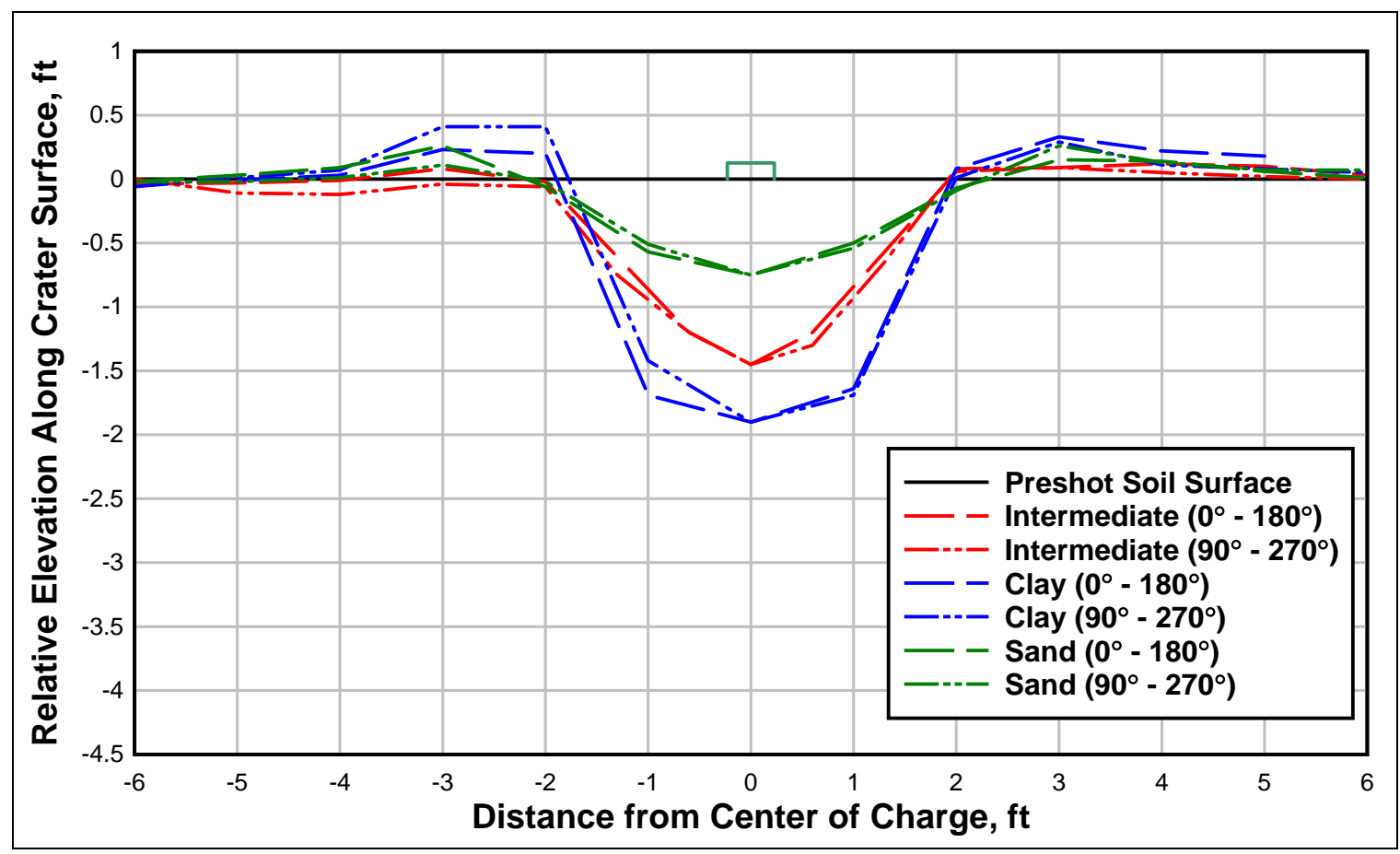

Figure 5.1. Crater profiles from three experiments with the charge placed tangent surface above.

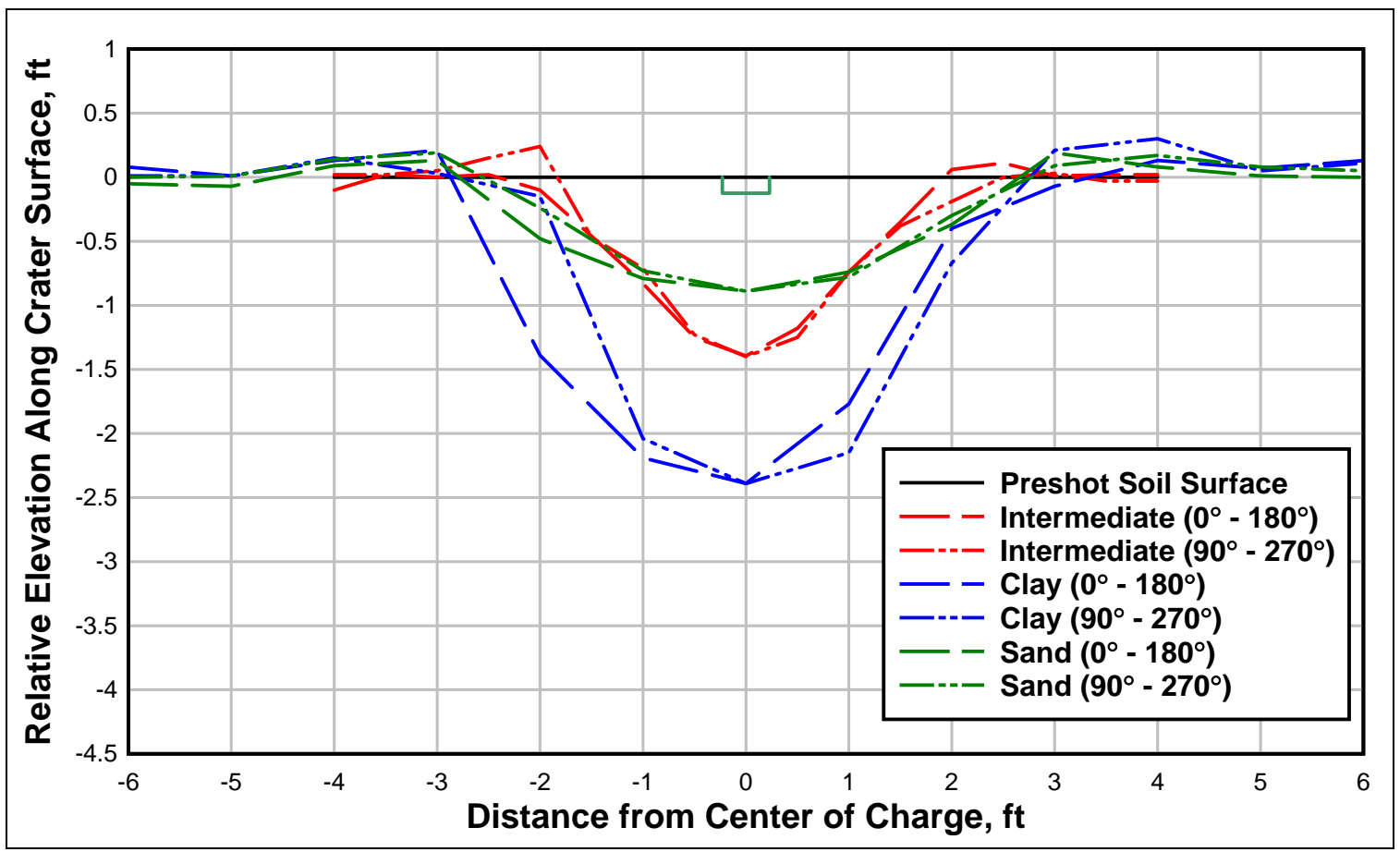

Figure 5.2. Crater profiles from three experiments with the charge placed tangent surface below. 
The primary differences in these craters are that the crater depths and surface diameters are larger for the charge in the surface tangent below explosive charge position. This is due to the increased coupling of the explosive energy into the testbed soils for the partially buried case.

Figure 5.3 compares the crater cross sections obtained from experiments BM-I-03, BM-C-03, and BM-S-03 from the intermediate soil, clay, and sand backfill testbeds, respectively, in which the explosive charge was buried $4 \mathrm{in}$. below the surface of the respective testbeds. Again, the same trends discussed above for the surface tangent experiments are shown in the figure and, again, the sizes of the craters are even greater for the fully buried explosive charge case due an even greater increase in coupling of the explosive energy.

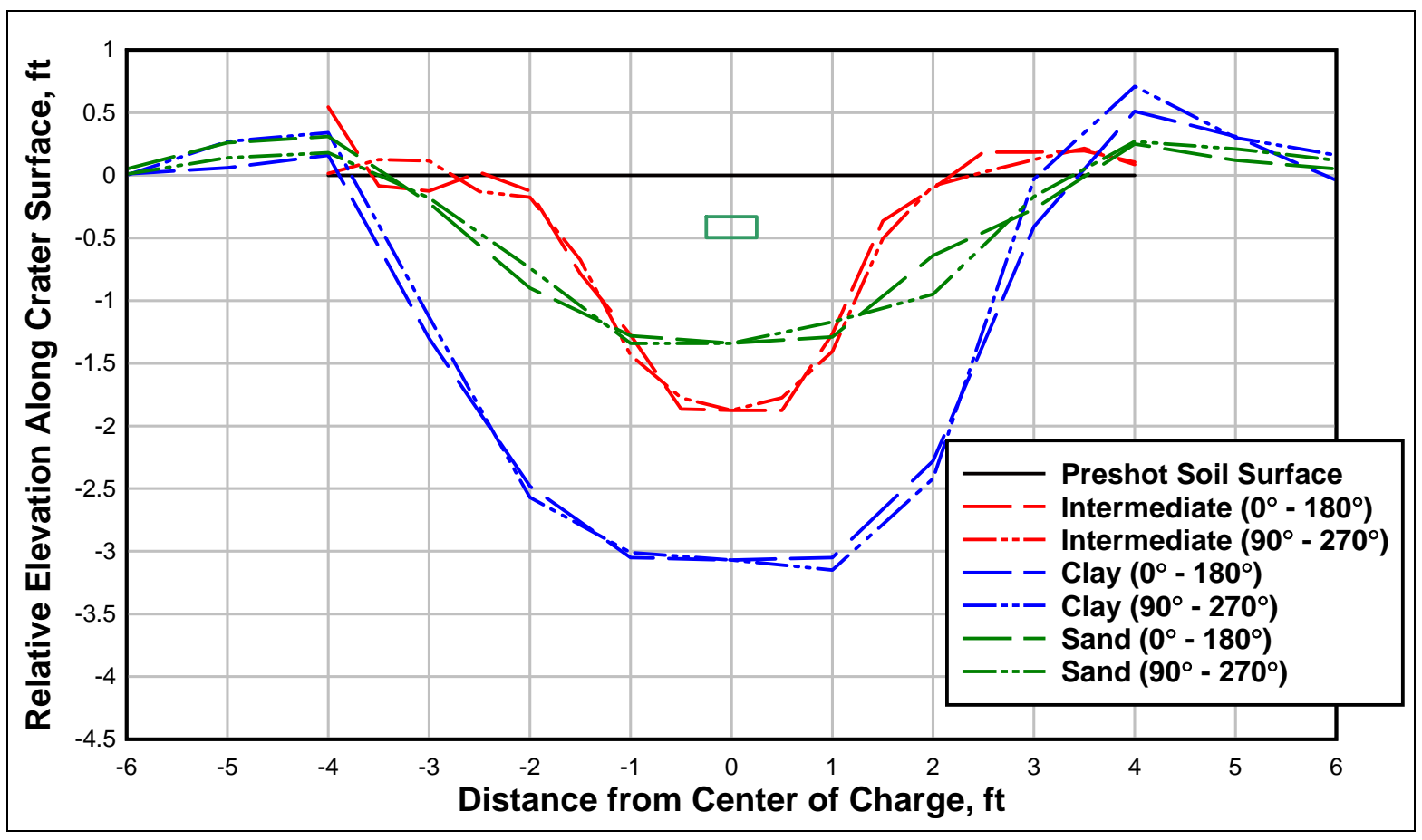

Figure 5.3. Crater profiles from three experiments with the charge buried 4 in.

\section{Ground shock}

ERDC personnel have fielded ground shock instrumentation in a wide variety of explosive environments for several decades. The center of the ground shock gages fielded in experiments BM-I-03 and -05, BM-C-03 and -05, and BM-S-03 and - 05 were placed at about the 5-in. depth, which is probably the shallowest depth in ERDC experience. Hence, the resulting ground shock data were affected by not only the ground shock emanating 
from the detonated buried charges but also from the airblast propagating outward and loading the ground surface at higher wave speeds than the ground shock propagation. For the BM-I-05, BM-C-05, BM-S-05 experiments in which the IMD system was in-place, reflections off the IMD impact plate also loaded the ground surface and in turn affected ground shock responses. As a result, the ground shock data presented in Chapter 4 reflected all of these influences.

The peak values of radial soil stress are plotted versus range from the center of the explosive charge in Figure 5.4. These peak stresses attenuate with range as expected but show no definitive effect of soil type. The peak values of particle velocity versus range are shown Figure 5.5. Again, peak values attenuate with range, and it appears that the values measured in the wet clay are generally higher than those measured in the intermediate silty sand at each range and both of the sets of measurements are generally higher than those for the dry sand. Experience has shown that measured peak particle velocities are generally more consistent and depict less data scatter than do peak soil stresses.

Ground shock times of initial arrival versus range for both soil stress and particle velocity are shown in Figure 5.6. It appears that the ground shock generally arrived earliest at each range in the intermediate silty soil backfill, the slowest in the clay backfill, and at times in between those in the dry sand backfill.

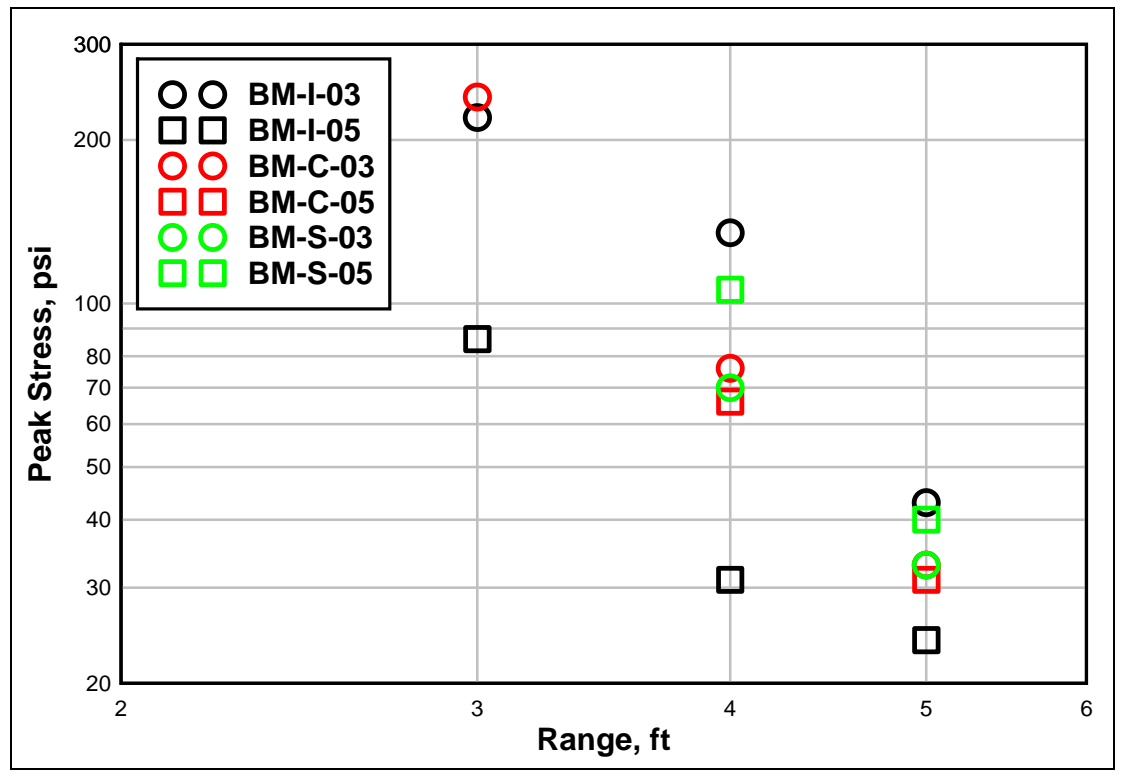

Figure 5.4. Peak soil stress versus range from the $C G$ of the buried charge. 


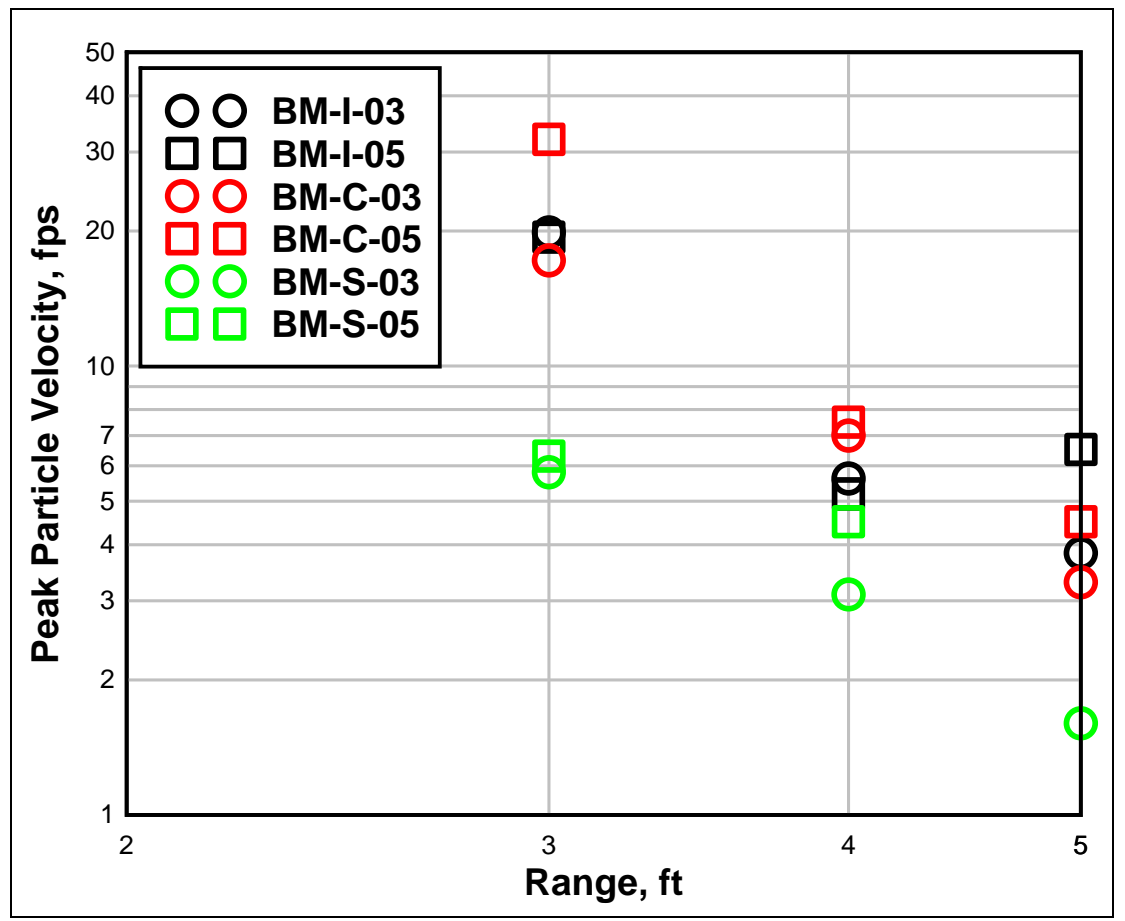

Figure 5.5. Peak particle velocity versus range from the CG of the buried charge.

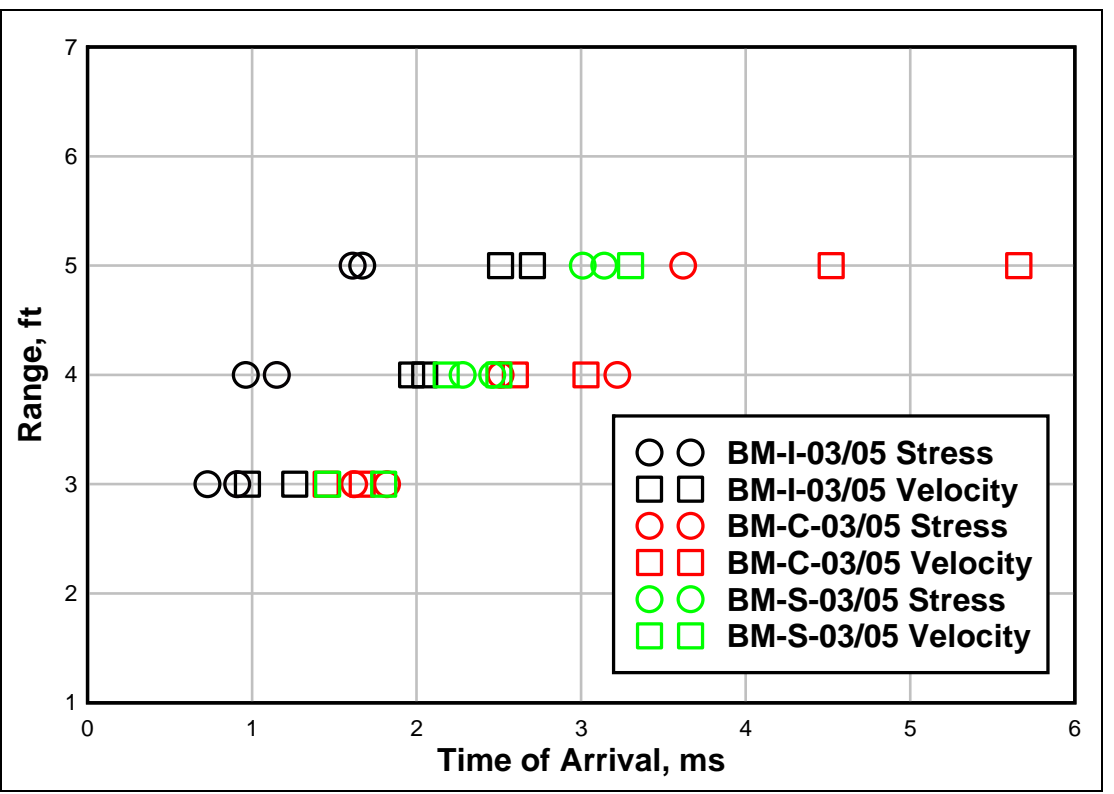

Figure 5.6. Initial ground shock times of arrival versus range from the CG of the buried charge. 


\section{Ground surface overpressure}

Time of arrival data versus range from the ground surface overpressure gages are shown in Figures 5.7- 5.9 for charge placements of tangent surface above, tangent surface below, and buried $4 \mathrm{in}$. below the ground surface, respectively. The arrival-time data in Figures 5.7 and 5.8 are well grouped and increase with range as expected. The arrival-time data in Figure 5.9 are less well grouped but also increase with range. The data in each figure show no effect of testbed soil type, even for the buried charge case. As the charge placement changes from tangent surface above to tangent surface below to fully buried, the arrival times increase at each range, which is expected, because the airblast loading must first go through some of the soil testbed in the tangent surface below and buried experiments before propagating outward on the ground surface. The airblast propagation velocity for these relatively close ranges is much higher than the shock propagation velocities through the backfill soils.

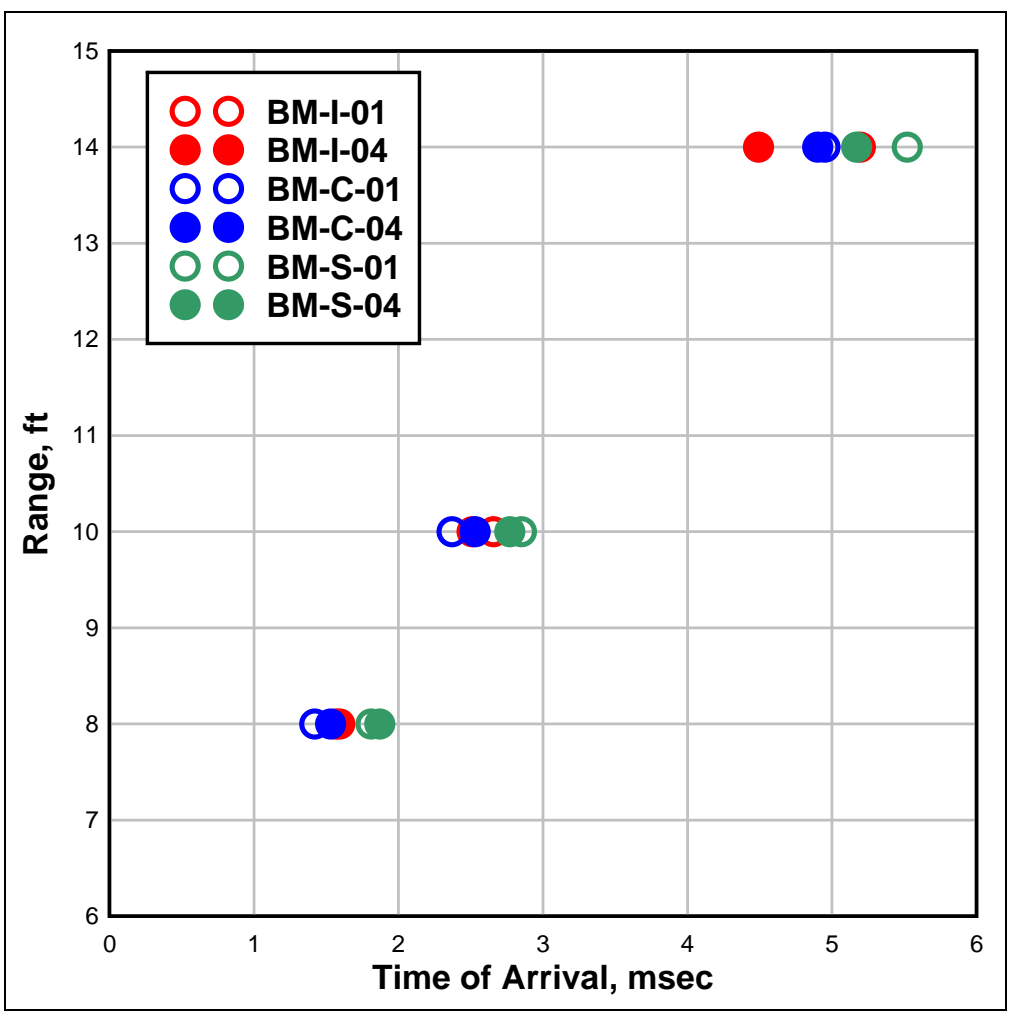

Figure 5.7. Ground surface overpressure times of arrival for charge placed tangent surface above. 


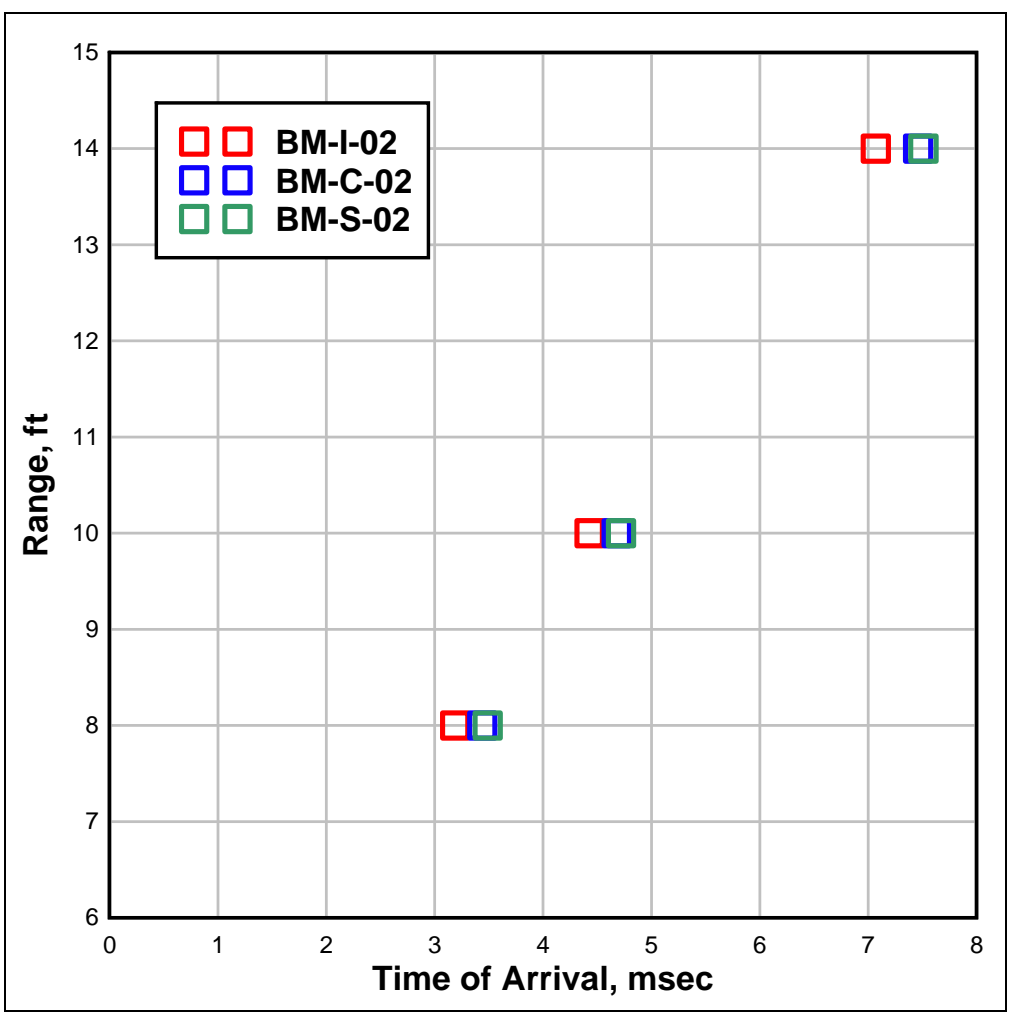

Figure 5.8. Ground surface overpressure times of arrival for charge placed tangent surface below.

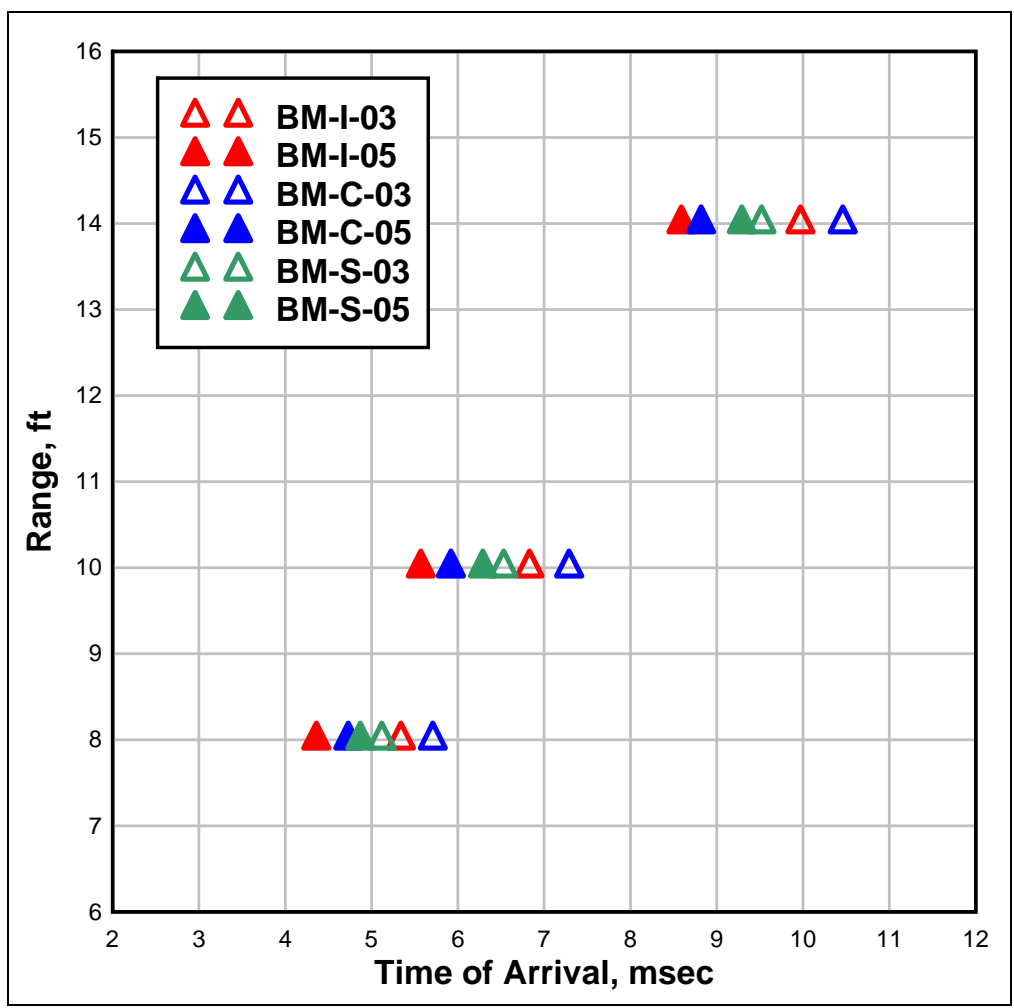

Figure 5.9. Ground surface overpressure times of arrival for charge buried 20 in. 
Peak surface overpressure versus range data are shown in Figures 5.10-5.12 again for charge placements of tangent surface above, tangent surface below, and buried 4 in. below the ground surface, respectively. As was noted in Chapter 4, the peak surface overpressure data from experiment BM-C-04 at the 8-ft range (Figure 5.10) were somewhat erratic and questionable. The remaining data in Figure 5.10 for the charge placed tangent surface above have a reasonable scatter in magnitude and decrease in magnitude with range as expected. The peak surface overpressure data in Figure 5.11 for the case of the charge placed tangent surface below are well grouped and also decrease in magnitude with range. The peak surface overpressure value at the 10-ft range from experiment BM-I-05 (Figure 5.12) appears too high in magnitude compared to the trends of the other data for this charge placement case and is also considered questionable. Otherwise, the data for the buried charge case exhibit reasonable scatter and a general trend of decreasing magnitude with increasing range. Excluding the questionable data, peak surface overpressure decreases in magnitude at each range as the charge location changes from tangent above to tangent below to fully buried.

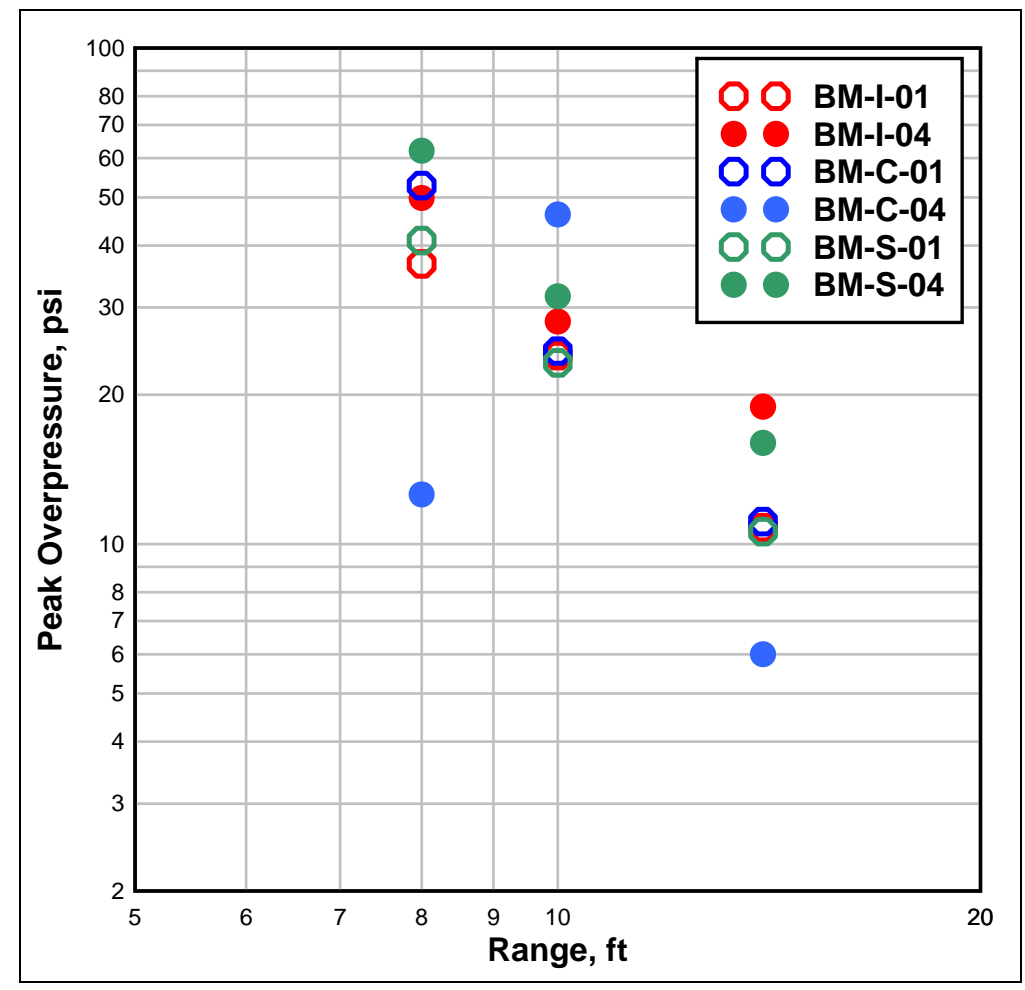

Figure 5.10. Peak ground surface overpressure for the charge placed tangent surface above. 


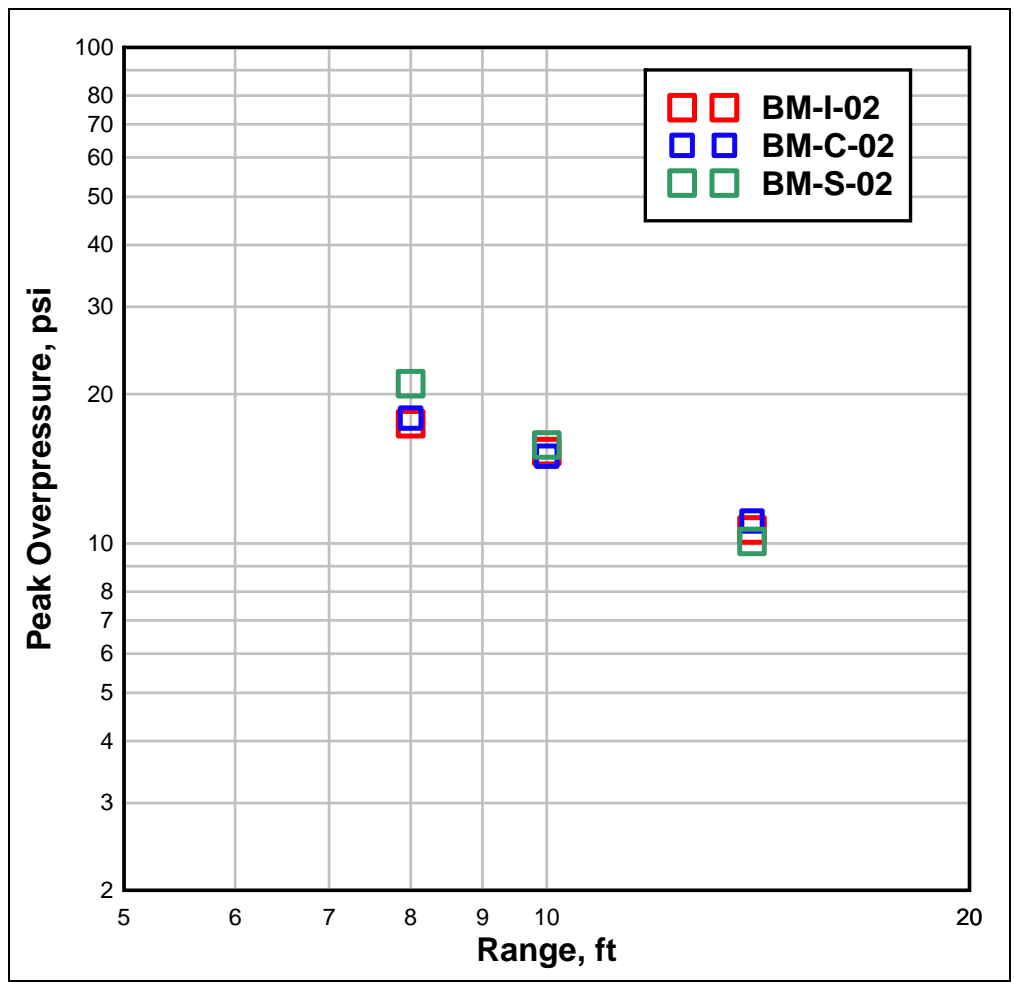

Figure 5.11. Peak ground surface overpressure for the charge placed tangent surface below.

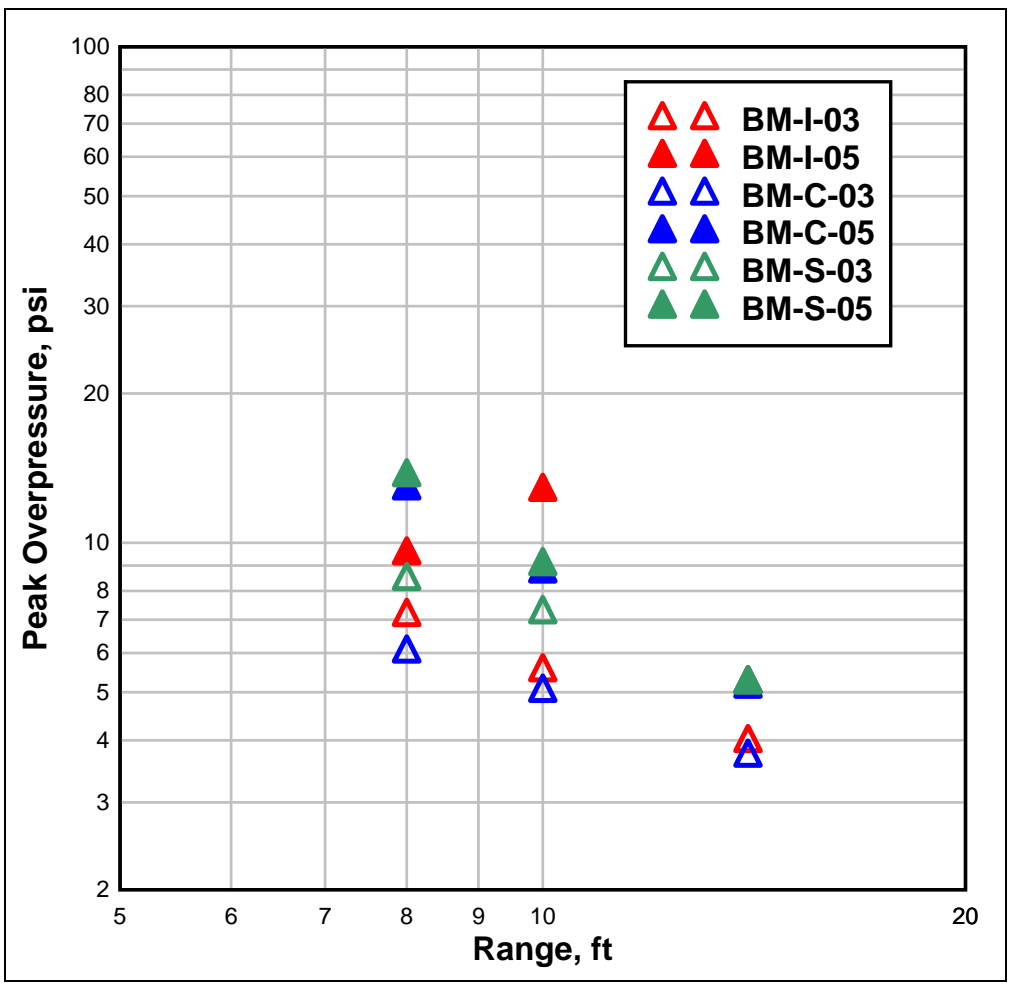

Figure 5.12. Peak ground surface overpressure for the charge buried 4 in. 


\section{Aboveground side-on overpressure}

Peak values for side-on overpressure versus range are shown in Figures 5.13- 5.15 for charge placements of tangent surface above, tangent surface below, and buried 4 in. below the ground surface, respectively. Peak values attenuate with range as expected. For the tangent surface above experiments (Figure 5.13), the peak side-on overpressure was highest in the intermediate silty sand experiments at all ranges. The same trend occurred in the tangent surface below experiments (Figure 5.14) except, as mentioned in Chapter 4, for the gage at about the 21-in. range in the silty sand experiment that was damaged and provided no useful data. For the buried charge experiments (Figure 5.15), the peak side-on overpressure at the 21-in. range was again highest in the intermediate silty sand experiment. At the 28- and 42-in. ranges (Figure 5.15), the peak values for the sand were the highest for the buried soil experiments. Otherwise, the peak data at most ranges do not show a clear effect of backfill soil type.

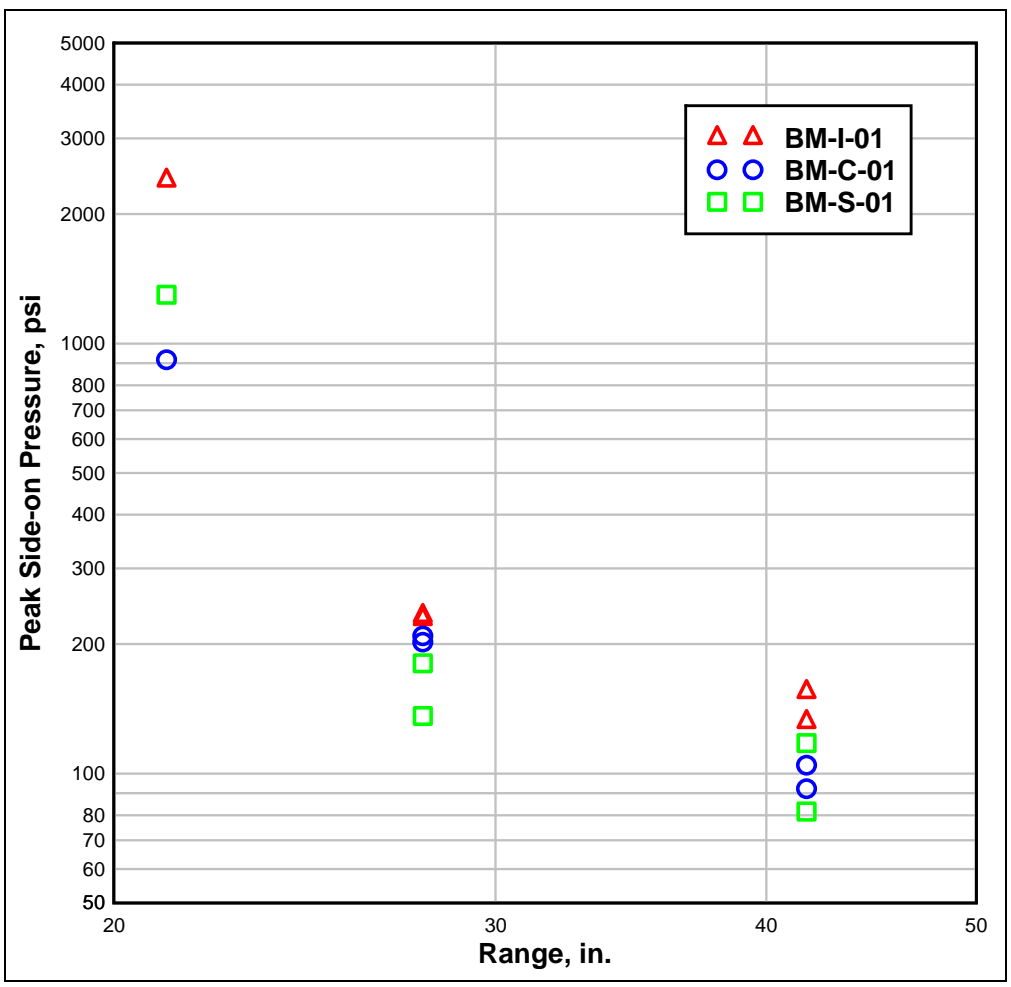

Figure 5.13. Peak side-on overpressure for the charge placed tangent surface above. 


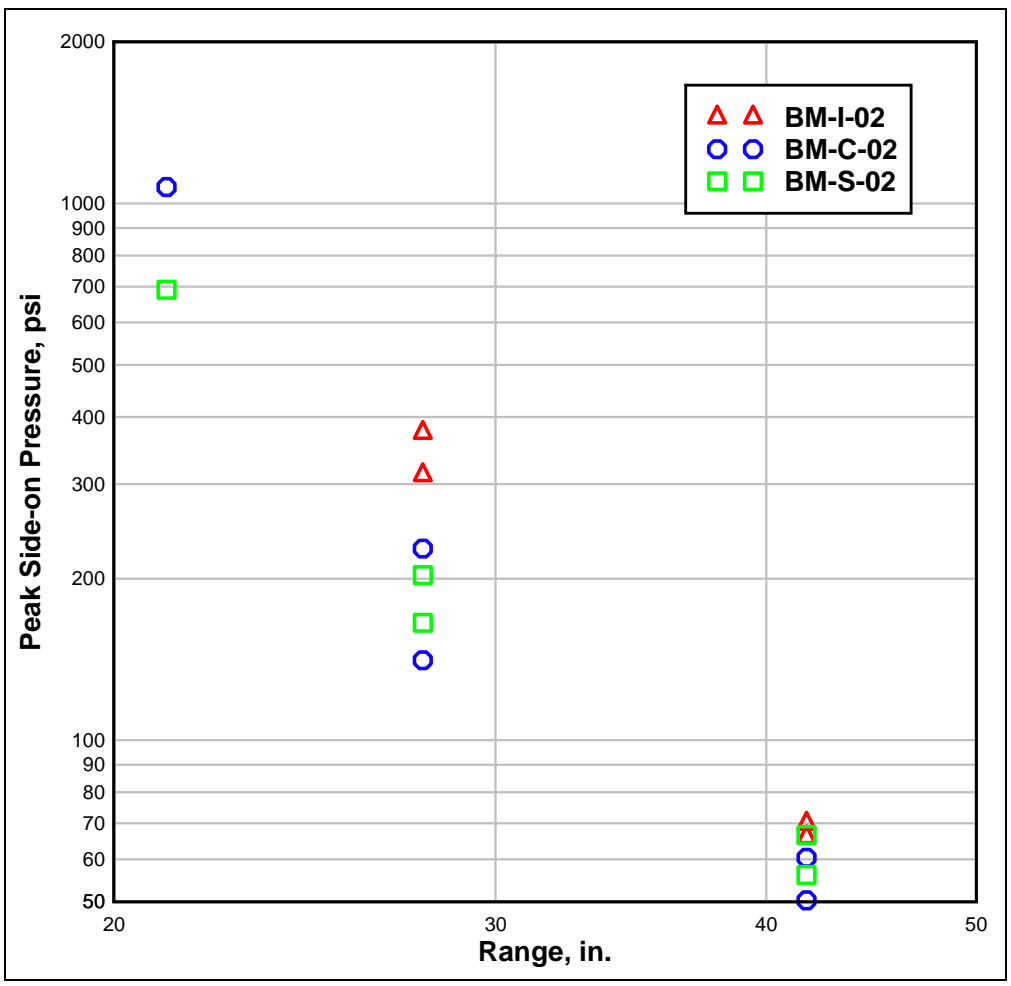

Figure 5.14. Peak side-on overpressure for the charge placed tangent surface below.

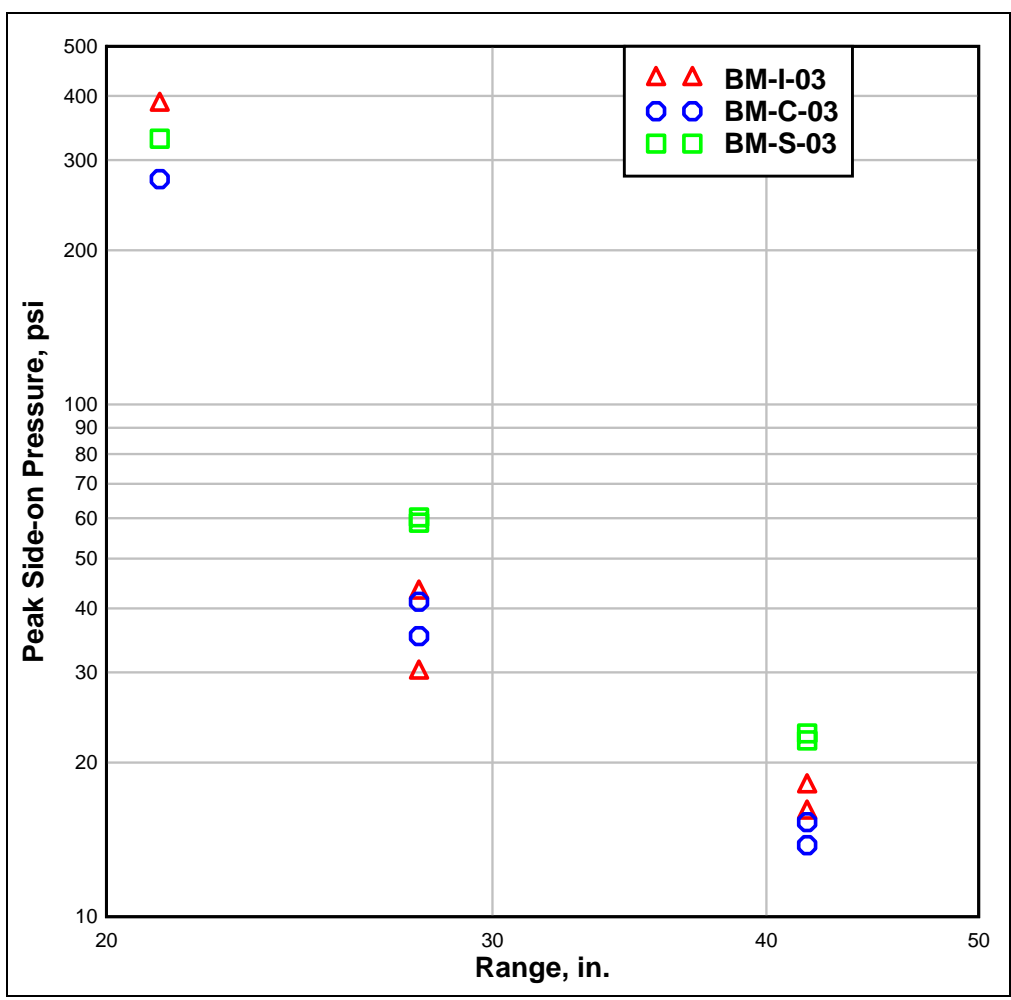

Figure 5.15. Peak side-on overpressure for the charge buried 4 in. 
The primary purpose of the side-on overpressure measurements was to obtain pressure time-histories from which airblast impulse could be calculated. Figure 5.16 shows the peak side-on overpressure impulse data versus range for the case of the explosive charge placed tangent surface above the testbed. At the closest range, the peak impulse from experiment BM-S-01, the sand backfill testbed, produced the highest impulse followed by that from the experiment with the intermediate silty sand testbed and then the clay testbed. At the 28- and 42-in. ranges, all of the peak impulse values decrease significantly to about the same range of values.

Figure 5.17 shows the peak side-on overpressure impulse data for the case of the explosive charge placed tangent surface below the testbed. The peak values at the two closest ranges are similar to those shown in Figure 5.16 for the tangent surface above case. The data at the closest range in Figure 5.17 may be slightly higher than the comparable data in Figure 5.16, but additional experimental results would be required to confirm this. At the 42-in. range, the peak impulse data for the tangent surface below case are about half the values for the tangent surface above case. This potentially slight increase at the closest range and reduction in peaks at the outer ranges seem to indicate that a small amount of focusing occurred for the tangent surface below case compared with the case for tangent surface

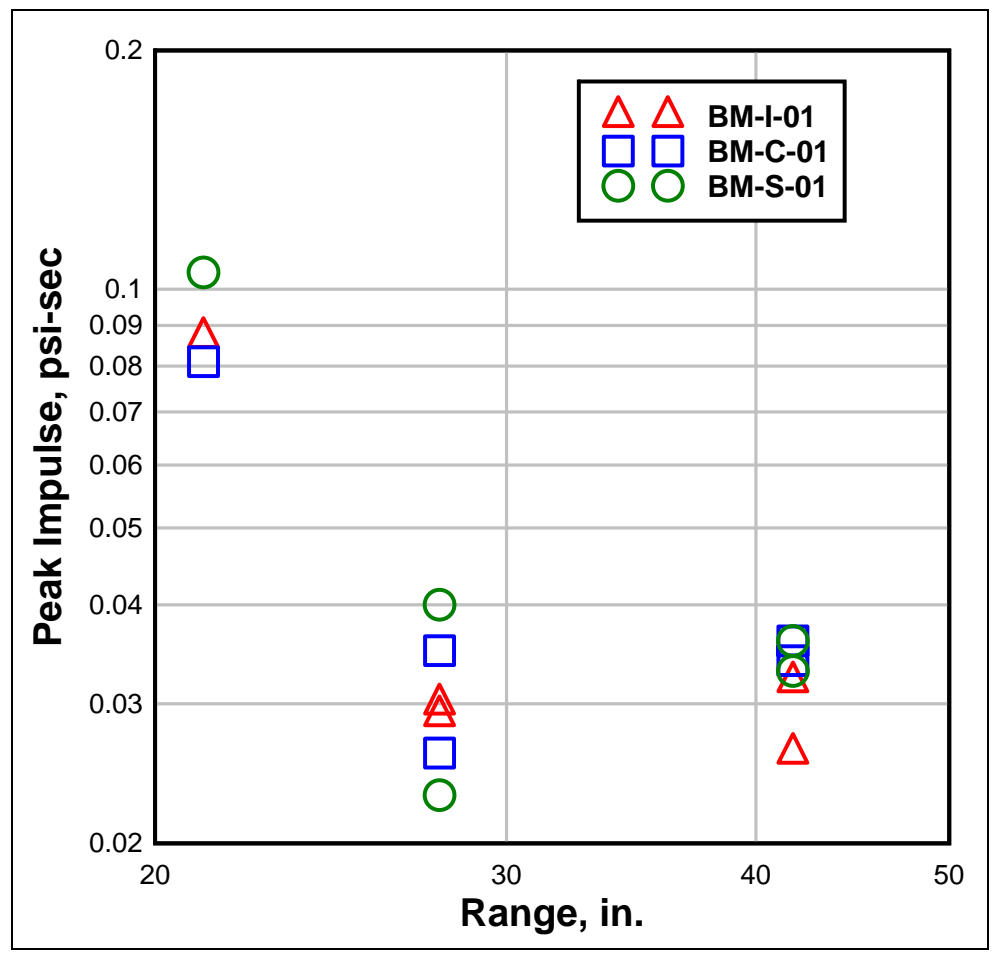

Figure 5.16. Peak side-on overpressure impulse for the charge placed tangent surface above. 


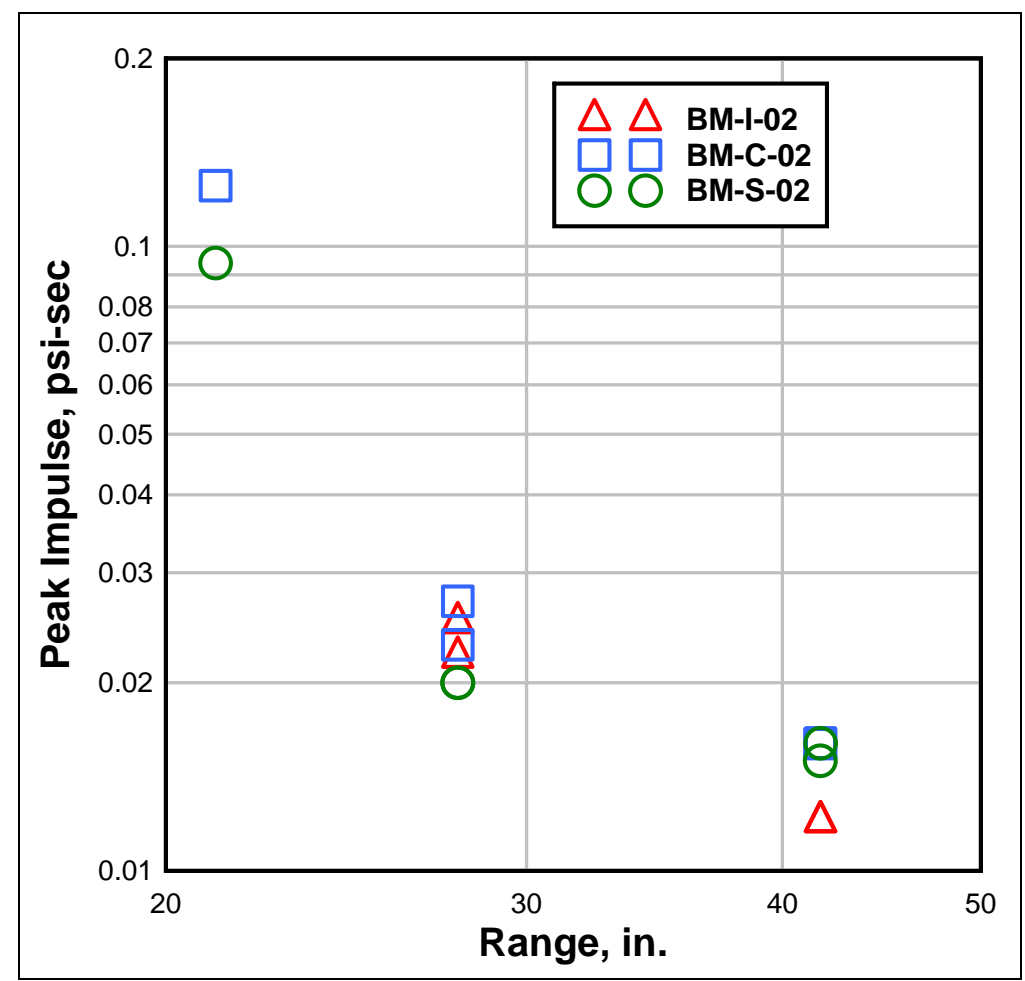

Figure 5.17. Peak side-on overpressure impulse for the charge placed tangent surface below.

above. This is consistent with the increased lateral confinement for the tangent surface below charge placement.

The peak side-on overpressure impulse data from the buried charge experiments are shown in Figure 5.18. The values of peak impulse at the 21-in. range (center of the testbeds) are about twice the values for the surface charge cases. At the 28-in. range, the peak impulse values for the intermediate soil and the clay are about a third of the comparable values for the tangent surface above case (Figure 5.16). Also at the about the 28-in. range from the explosive charge, the sand values for peak impulse are about three times those for the other two soil types. At the 42-in. range, the peak impulse values from the buried charge experiments are about half those from the tangent surface below experiments (Figure 5.17) and about a third or more of the peak impulses from the tangent surface above experiments (Figure 5.16). Again, this increased peak impulse directly above the charge (21-in. range) and the reduction in impulse at the 28- and 42-in. ranges appears to indicate a focusing effect above the charge. The variation in this focusing appears to be affected by soil type. The clay and intermediate soil responded in a similar manner at the 28-in. range (Figure 5.18) while the sand appeared to be less influenced. 


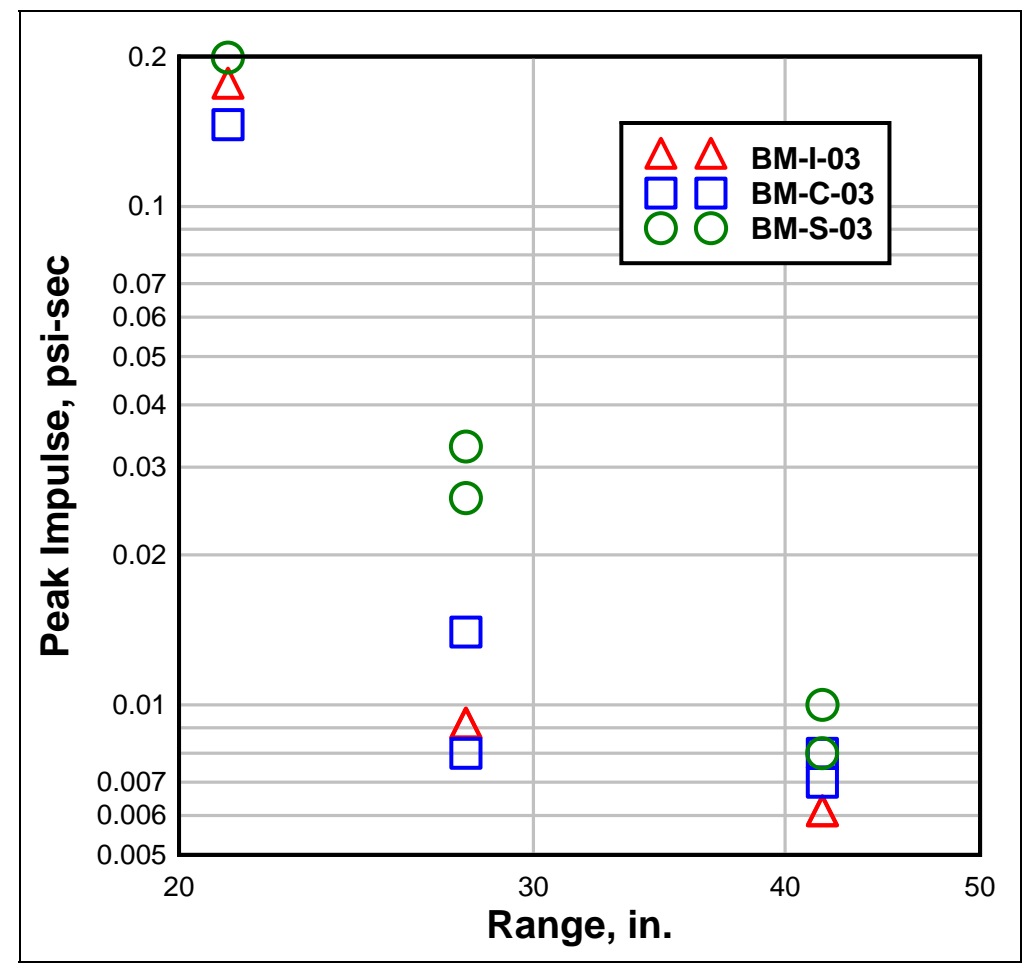

Figure 5.18. Peak side-on overpressure impulse for the charge buried 4 in.

\section{Total impulse from the IMD}

The calculated values of peak impulse imparted to the IMD presented in Tables 4.6, 4.12, and 4.18 are compared in Table 5.1. Peak impulse from the buried charges exceeded the peak impulse from the surface charge positions by factors ranging from 2.6 to 4 . For both explosive charge positions, peak impulse from the experiments in the clay testbeds was higher than those from experiments in the intermediate silty sand and sand testbeds. For the case of the tangent surface above charge position, peak impulse from the clay testbed experiments was $5 \%$ and $20 \%$ higher than the peak impulses imparted in the sand and silty sand testbeds, respectively. For the buried charge case, these differences were $60 \%$ and $40 \%$, respectively.

Table 5.1. Peak total impulse imparted to the IMD.

\begin{tabular}{|l|l|l|}
\hline \multirow{2}{*}{ Backfill Material } & \multicolumn{2}{|c|}{ Peak Impulse, psi-sec } \\
\cline { 2 - 3 } & Charge TSA & Charge Buried 4 in. \\
\hline Intermediate Silty Sand (SM) & 545 & 1880 \\
\hline Sandy Clay (CL) & 650 & 2610 \\
\hline Poorly Graded Sand (SP) & 619 & 1635 \\
\hline
\end{tabular}

1 Tangent surface above. 


\section{Summary and Conclusions}

A device for determining the aboveground impulse (impulse measuring device, IMD) due to the detonation of surface and buried explosives was designed, fabricated, calibrated, and deployed in a series of experiments for the purpose of quantifying the effects of three very different soil types on the impulse delivered to aboveground structures. The soil types included a 5.6\%-air-voids wet sandy clay, a 29.8\%-air-voids dry sand, and an intermediate material, i.e., 10.8\%-air-voids silty sand. The backfill materials were placed for each experiment so that variations in as-placed water content and dry density for each soil type were minimized based on results of field quality control test results. The 5-lb explosives were placed on the surfaces of the testbeds (tangent surface above), buried so that the top of the explosive was flush with the top of the testbeds (tangent surface below), and buried with the top of the explosive 4 in. below the testbed surface. The standoff distant between the top of the explosive charges and the face of the IMD impact plate was held constant at $20 \mathrm{in}$.

Testbed instrumentation for the experiments included gages that monitored airblast propagation across the top of the testbeds, soil stress and accelerometers to monitor ground shock, and side-on overpressure gages positioned at the same height above the testbeds as the height of the face of the impact plate of the IMD. Instrumentation for the IMD included a displacement gage to determine the maximum upward movement of the IMD piston assembly, accelerometers to monitor the movement of the IMD impact plate and the motion of the IMD support assembly, and highspeed video to capture the motion of the IMD piston assembly and crater ejecta.

The sizes of the soil craters increased as the depth of the explosive increased. The clay craters had the greatest depths and the steepest side slopes for all charge positions. The sand craters had the shallowest depths and flattest side slopes.

The ground shock data were influenced to varying degrees by the fastrunning propagation of the surface airblast and by reflections from the IMD impact plate and its support structure. The peak soil stress data did 
not exhibit discernible effects of backfill soil type, but the peak particle velocity data generally indicated higher values in the clay backfill, the lowest values in the dry sand backfill, and values in between for the intermediate silty sand backfill (i.e., the velocities increased with decreasing air voids and shear strength).

Ground surface overpressures attenuated with range, as expected, and showed a general trend of higher peak values at each range for the tangent surface above cases and lowest peak values for the buried charge cases.

Peak side-on overpressures directly over the explosive charges were highest for the intermediate silty sand experiments for the tangent surface above and buried charge positions. No data were obtained for the center gage in the silty sand experiment for the surface tangent below charge location. With range, the sand experiments exhibited higher peak side-on overpressures for the buried charge experiments. Otherwise, little effects of soil type could be seen in the side-on overpressure data.

Peak side-on overpressure impulse values at the 21-in. range (center of the testbeds) from the buried charge experiments were about twice the values obtained from the surface charge experiments. At the 28-in. range, the sand values for peak impulse for the buried charge case were about three times those for the other two soil types, which in turn were about a third of their comparable values for the surface charge cases. At the 42-in. range, peak impulse values from the buried charge experiments were about half those from the tangent surface below experiments and about a third or more of the peak impulses from the tangent surface above experiments. This increased peak impulse directly above the charge (21-in. range) and the reduction in impulse at the 28- and 42-in. ranges appears to indicate a focusing effect above the charge. The variation in this focusing appears to be affected by soil type in that the clay and intermediate soil responded in a similar manner at the 28-in. range in the buried charge case while the sand appeared to be less influenced. This apparent focusing of the overpressure impulse seems to be caused by lateral confinement of the explosive charge, which indicates that the sand material provided less lateral confinement than did the intermediate and clay soils. This phenomenon was well illustrated by comparisons of the craters for the three soil materials used in these experiments, in that the sand craters had the shallowest depths and flattest side slopes while craters for the other two materials were deeper and had steeper side slopes. 
Peak total impulse imparted to the IMD from the buried charges exceeded the peak total impulses from the tangent surface above charges by factors ranging from 2.8 to 4 . For both explosive charge positions, peak total impulse from the experiments in the clay testbeds was higher than values from experiments in the intermediate silty sand and sand testbeds. For the case of the tangent surface above charge position, peak total impulse from the clay testbed experiments was 5\% and 20\% higher than the peak total impulses imparted in the sand and silty sand testbeds, respectively. For the buried charge case, these differences were $50 \%$ and $40 \%$, respectively.

This initial series of IMD experiments was very successful in quantifying the airblast impulse and total impulse imparted to an aboveground structure. Effects of varying soil materials and charge depth of burial were observed. Additional experiments of this type need to be conducted so that improved quantification of the effects of these variables can be made, which in turn will significantly improve the analysis and design of aboveground structures subjected to surface and near-surface detonations. 


\section{References}

Akers, S. A., M. D. Adley, and J . D. Cargile. 1995. Comparison of constitutive models for geologic materials used in penetration and ground shock calculations. In Proceedings, 7th International Symposium on Interaction of Effects of Munitions with Structures. Mannheim, Germany.

American Institute of Steel Construction Inc. 1994. Load and resistance factor design. In Manual of steel construction; I, Structural members, specifications, and codes. Chicago, IL.

Baylot, J. T., and T. L. Bevins. 2007. Effect of responding and failing structural components on the airblast pressures and loads on and inside of the structure. Computers and Structures 85(11- 14):891- 910.

Bitting, R. L. 2001. Structural analysis of the vertical impulse measurement fixture. ARL-TR-2464. Adelphi, MD: Army Research Laboratory.

Endevco Corporation. 2005. Product data sheet, model 7270A. San J uan Capistrano, CA.

Gerlach, C. A., and G. R. J ohnson. 2009. Development of advanced computational approaches for explosive-soil-air-structure interactions, fragmentation, and shaped charges. ERDC/ GSL TN-09-1. Vicksburg MS: U.S. Army Engineer and Development Center.

Grujicic, M., B. Pandurangan, and B. A. Cheeseman. 2002. The effect of degrees of saturation of sand on detonation phenomena associated with shallow-buried and ground-laid mines. Shock and Vibration J ournal 13.

Hi-Techniques, Inc. 2004. Win600e/ meDAQ data acquisition systems. Madison, WI.

Intertechnology, Inc. 2007. Celesco model PT-101, cable extension position transducer. Ontario, Canada.

J oachim, C. E., G. W. McMahon, C. V. Lunderman, and S. B. Garner. 1999. Airblast effects research: small-scale experiments and calculations. Technical Report SL-99-5. Vicksburg MS: U.S. Army Engineer Waterways Experiment Station.

J ohnson, G. R., S. R. Beissel, C. A. Gerlach, R. A. Stryk, T. J. Holmquist, A. A. J ohnson, S. E. Ray, and J . J . Arata. 2006. User instructions for the 2006 version of the EPIC code. Minneapolis MN: Network Computing Services.

Kulite Semiconductor. 2007. Kulite miniature IS silicon diaphragm pressure transducers. Leonia, NJ : Kulite Semiconductor Products.

MoGlaun, J. M., S. L. Thompson, and M. G. Elrick. 1990. CTH: a three-dimensional shock physics code. International J ournal of Impact Engineering 10:351- 360. 
Namburu, R. R., B. J . Armstrong, and T. L. Bevins. 1998. Effects of water tamping on airblast and cratering from an aboveground cylindrical charge. AIAA 29th Plasmadynamics and Lasers Conference, Albuquerque, NM. Reston, VA: American Institute of Aeronautics and Astronautics.

PCB Piezotronics, Inc. 2008. Piezoelectric pressure sensor. New York.

Research Engineers International. 2005. STAAD.Pro. Yorba Linda, CA.

Snyman, I. M. and J. D. Reinecke. 2006. Measuring the impulse from an explosive charge. In Proceedings, 5th South African Ballistics Symposium, OTB, Western Cape, South Africa, 7.

U.S. Army Corps of Engineers. 1980. Laboratory soils testing. Engineer Manual 1110-2-1906. Washington, DC.

USACE Protective Design Center. 2002. Single-degree of freedom plastic analysis for windows (SPAn32). Omaha, NE.

. 2006. User's guide for the single-degree-of-freedom blast effects design spreadsheets (SBEDS). PDC-TR-06-02. Omaha, NE.

U.S. Army Engineer Waterways Experiment Station. 1960. The unified soil classification system. Technical Memorandum 3-357. Vicksburg MS.

Vision Research. 2009. Phantom v7.3 high speed digital imaging system. Wayne, NJ .

Wenzel, A. B. and E. D. Esparza. 1972. Measurement of pressure and impulse at close distance from explosive charges buried and in air. Fort Belvoir, VA: U.S. Army Mobility Equipment Research and Development Center.

Williams, E. M., J . E. Windham, J . Q. Ehrgott, J r., K. T. Danielson, and T. J . Gorsich. 2008. Effect of soil properties on an aboveground blast environment from buried bare charges. 20th Military Aspects of Blast and Shock (MABS) Conference. Oslo, Norway.

Zimmerman, H. D., M. H. Wagner, J . A. Carney, and Y. M. Ito. 1987. Effects of site geology on ground shock environments; Report 1, Constitutive models for materials I2, I3, and W1-W10. Technical Report SL-87-19. Vicksburg, MS: U.S. Army Engineer Waterways Experiment Station. 


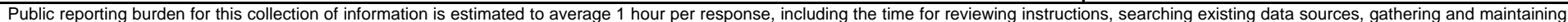

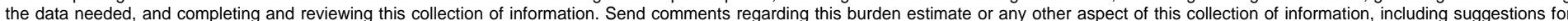

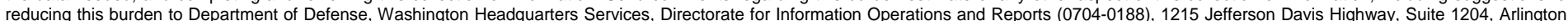

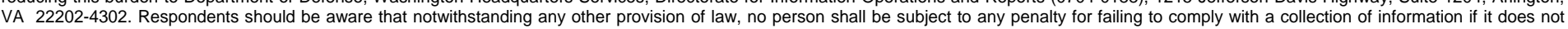
display a currently valid OMB control number. PLEASE DO NOT RETURN YOUR FORM TO THE ABOVE ADDRESS.

\begin{tabular}{l|c}
$\begin{array}{l}\text { 1. REPORT DATE (DD-MM- } Y Y Y Y) \\
\text { March } 2010\end{array}$ & $\begin{array}{c}\text { 2. REPORT TYPE } \\
\text { Final report }\end{array}$ \\
\hline
\end{tabular}

4. TITLE AND SUBTITLE

Tactical Wheeled Vehicle Survivability: Results of Experiments to Quantify

Aboveground Impulse

3. DATES COVERED (From - To)

5a. CONTRACT NUMBER

5b. GRANT NUMBER

5c. PROGRAM ELEMENT NUMBER

6. AUTHOR(S)

5d. PROJECT NUMBER

John Q. Ehrgott, Jr.

5e. TASK NUMBER

5f. WORK UNIT NUMBER

7. PERFORMING ORGANIZATION NAME(S) AND ADDRESS(ES)

8. PERFORMING ORGANIZATION REPORT NUMBER

U.S. Army Engineer Research and Development Center

Geotechnical and Structures Laboratory

ERDC/GSL TR-10-7

3909 Halls Ferry Road

Vicksburg, MS 39180-6199

9. SPONSORING I MONITORING AGENCY NAME(S) AND ADDRESS(ES)

10. SPONSOR/MONITOR'S ACRONYM(S)

U.S. Army Tank Automotive Research, Development and Engineering Center

Warren, MI 48397-5000;

Headquarters, U.S. Army Corps of Engineers

Washington, DC 20314-1000

TARDEC

11. SPONSOR/MONITOR'S REPORT NUMBER(S)

\section{DISTRIBUTION / AVAILABILITY STATEMENT}

Approved for public release; distribution is unlimited.

13. SUPPLEMENTARY NOTES

\section{ABSTRACT}

The U.S. Army Engineer Research and Development Center conducted a series of carefully controlled field experiments to quantify the aboveground environments created by the detonation of surface and near-surface bare-charge explosives in or on three very different soil backfills. The experiments provided blast pressure, soil stress, and impulse data for each soil type. To measure the aboveground impulse produced by the combined airblast and soil debris, an impulse measurement device was designed, fabricated, and calibrated for use in the field experiments. Results of these experiments are documented along with initial conclusions regarding the complex loadings that would be applied to an aboveground structure.

\section{SUBJECT TERMS}

Blast pressure

Dry sand backfill

16. SECURITY CLASSIFICATION OF:

\begin{tabular}{|l|l|}
\hline $\begin{array}{l}\text { a. REPORT } \\
\text { UNCLASSIFIED }\end{array}$ & $\begin{array}{l}\text { b. ABSTRACT } \\
\text { UNCLASSIFIED }\end{array}$ \\
\hline
\end{tabular}

Explosive experiments

Ground shock

Impulse measurement device

\begin{tabular}{|l|c|c|c|}
\multicolumn{2}{l|}{} & $\begin{array}{c}\text { 17. LIMITATION } \\
\text { OF ABSTRACT }\end{array}$ & $\begin{array}{l}\text { 18. NUMBER } \\
\text { OF PAGES }\end{array}$ \\
$\begin{array}{l}\text { c. THIS PAGE } \\
\text { UNCLASSIFIED }\end{array}$ & & 175 \\
\hline
\end{tabular}

Sandy clay backfill

Silty sand backfill 